Aus der Abteilung Neuroradiologie

(Prof. Dr. med. M. Knauth)

im Zentrum Radiologie

der Medizinischen Fakultät der Universität Göttingen

\title{
MR-tomographische Darstellung intracerebraler Blutungen mit und ohne Therapie
}

\author{
INAUGURAL-DISSERTATION \\ zur Erlangung des Doktorgrades \\ der Medizinischen Fakultät \\ der Georg-August-Universität zu Göttingen \\ vorgelegt von \\ Miriam Meddour \\ aus \\ Wolfen
}

Göttingen 2010 
Dekan:

I: Berichterstatter:

II: Berichterstatterlin:

II: Berichterstatter/in:

Tag der mündlichen Prüfung: 02.02.2011
Prof. Dr. med. C. Frömmel

Prof. Dr. med. M. Knauth

Prof. Dr. med. V. Rohde 


\section{Inhaltsverzeichnis}

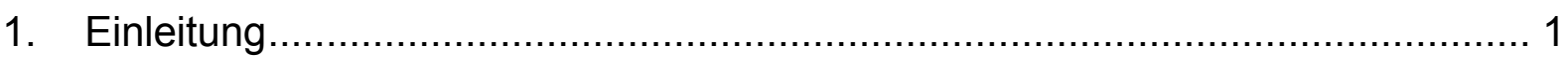

1.1 Grundsätze des Magnetresonanztomographen ………........................ 1

1.1.1 Geschichte der Magnetresonanztomographie ................................... 1

1.1.2 Neuroradiologische Diagnostik der Hirnblutung ................................. 1

1.1.3 Relevante Aspekte der MR-Physik in Kürze ….................................. 2

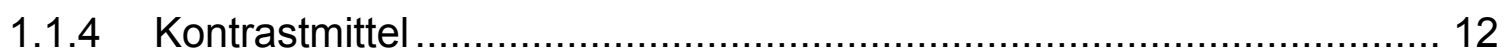

1.1.5 Bewegungskompensierende Techniken .......................................... 12

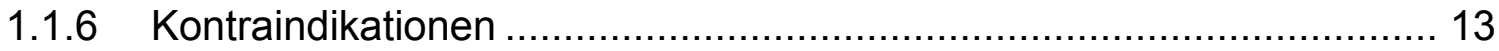

1.2 Ursache, Klinik und Therapie der intracerebralen Blutung ....................... 13

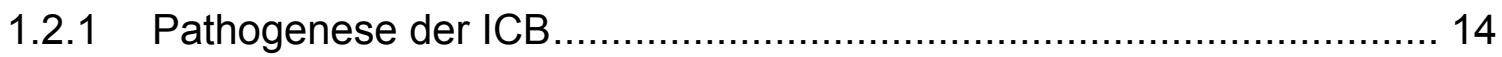

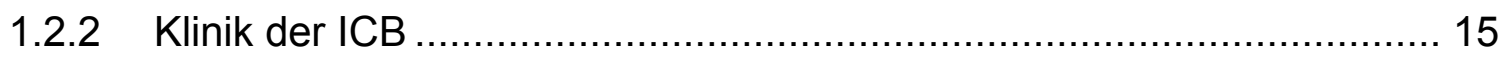

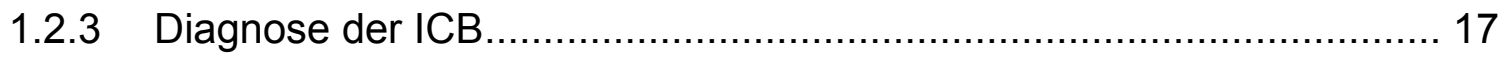

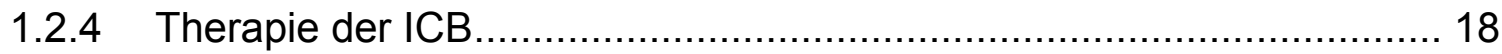

1.3 Hämoglobindarstellung und Hämatom ………..................................... 21

1.3.1 Struktur und Funktion des Hämoglobins und des Eisens.................... 21

1.3.2 Makroskopische Hämatomdarstellung ……....................................... 22

1.3.3 Wechselwirkungen zwischen Hämatom und MRT .............................. 24

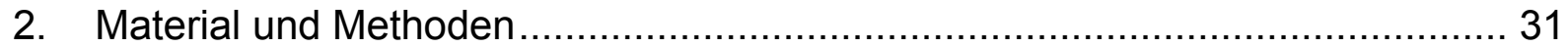

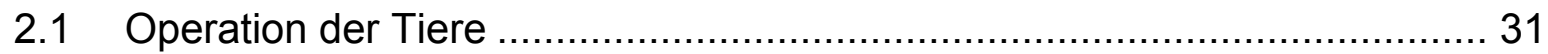

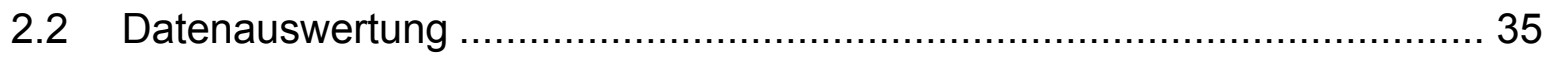

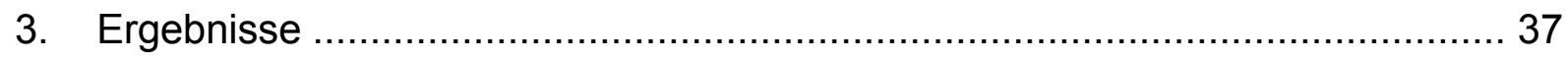

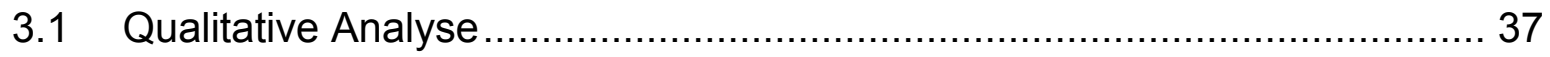

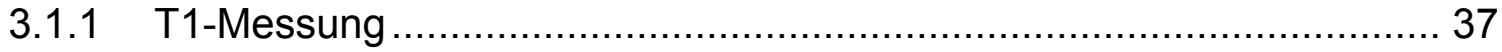

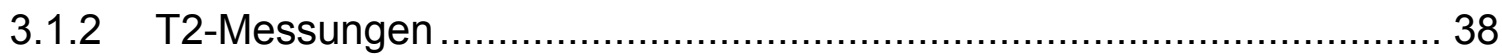




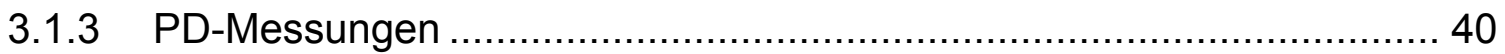

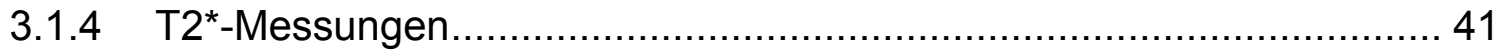

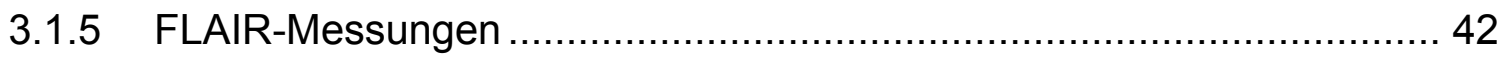

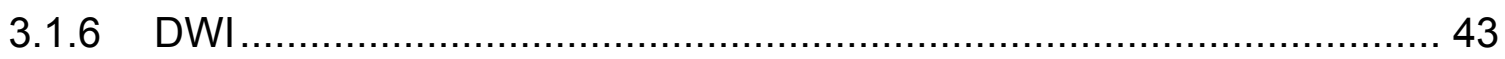

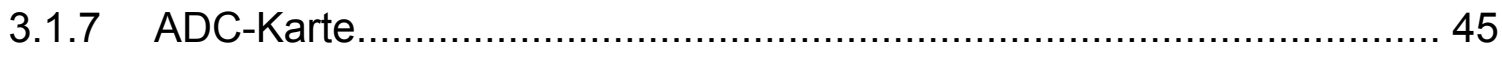

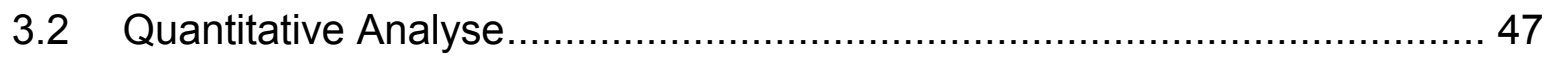

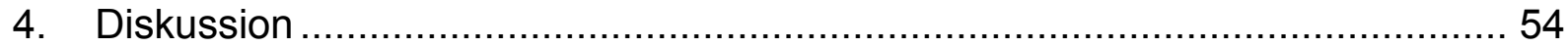

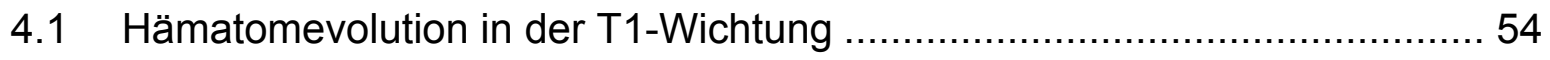

4.2 Hämatomevolution in der T2-Wichtung ………................................... 55

4.3 Hämatomevolution in der PD-Wichtung ............................................ 56

4.4 Hämatomevolution in der T2*-Wichtung ……..................................... 57

4.5 Hämatomevolution in der FLAIR-Wichtung …................................... 57

4.6. Hämatomevolution in der DWI und ADC-Karte....................................... 58

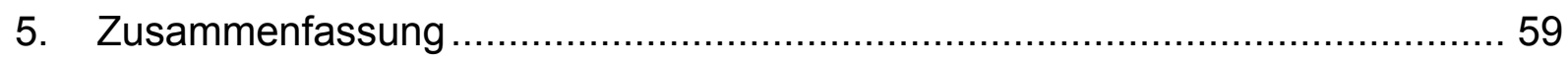

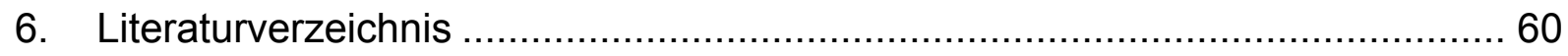

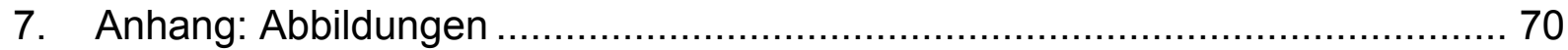




\section{Abkürzungen}

$\begin{array}{ll}\text { ADC } & \text { Apparent diffusion coefficient } \\ \text { B }_{0} & \text { äußeres magnetisches Feld } \\ \text { CT } & \text { der / die Computertomograph(ie) } \\ \text { DWI } & \text { Diffusion Weighted Imaging } \\ \text { EPI } & \text { Echo planar imaging } \\ \text { FLAIR } & \text { Fluid attenuated inversion recovery } \\ \text { GE } & \text { Gradientenecho } \\ \text { HF } & \text { Hochfrequenz } \\ \text { Hkt } & \text { Hämatokrit } \\ \text { ICB } & \text { intracerebrale Blutung } \\ \text { MHz } & \text { Megahertz } \\ \text { MRT } & \text { der / die Magnetresonanztomograph(ie) } \\ \text { NMDA } & \text { N-methyl-D-Aspartat } \\ \text { PAI } & \text { Plasminogenaktivator-Inhibitor } \\ \text { PDw } & \text { Protonendichtewichtung } \\ \text { rt-PA } & \text { rekombinanter Plasminogenaktivator } \\ \text { SE } & \text { Sime of inversion } \\ \text { SAR } & \text { Time to repeat } \\ \text { T } & \text { Tesla } \\ \text { TE } & \text { Time to echo } \\ \text { TI } & \text { Tifische Absorptionsrate } \\ \text { TR } & \text { Sino }\end{array}$




\section{Einleitung}

\subsection{Grundsätze des Magnetresonanztomographen}

\subsubsection{Geschichte der Magnetresonanztomographie}

Die Magnetresonanztomographie basiert auf der Tatsache, dass Atomkerne eine magnetisierende Eigenschaft besitzen. 1946 wurde von Bloch und Purcell die Möglichkeit entwickelt, magnetische Resonanz in Materialien zu induzieren, aufzufangen und zu quantifizieren (Bloch et al. 1946). 1952 erhielten sie dafür den Nobelpreis.

Lauterbur und Damadian wendeten Anfang der 70er Jahre diese Technologie an lebenden Organismen an; die daraus resultierenden Bilder wurden als Zeugmatographen bekannt (Seynaeve und Broos 1995). In den folgenden Jahren befasste sich Sir Peter Mansfield mit einer stetigen Verfeinerung der Bilderfassung und der Bilderzeugung. Dies führte zu einer genaueren Visualisierung anatomischer Details und folglich auch zu einer klinischen Anwendbarkeit des MRTs (Mansfield und Phays 1977; Garroway 1999). 2003 wurden Lauterbur und Mansfield schließlich für ihren Beitrag zur Ortsauflösung mittels Gradienten mit dem Nobelpreis in Medizin geehrt.

\subsubsection{Neuroradiologische Diagnostik der Hirnblutung}

Um eine Blutung, das Ausmaß der Gehirnverletzung sowie die Blutungsquelle zu erkennen und die möglicherweise reversiblen von den irreversiblen Schäden zu unterscheiden, gilt die CT gemeinhin als Goldstandard. Teilweise wird sie aber bereits von der MRT abgelöst. In der hyperakuten Phase, die einen Zeitraum von bis zu 24h nach Blutungsbeginn definiert, stellt man die Diagnose meist noch mittels CT (Wardlaw et al. 2004). Doch für diese Phase kann auch der MRT, mittels suszeptibilitätsgewichteter Sequenzen, auf die im Text noch genauer eingegangen wird, intracerebrale Blutungen (ICB) akkurat darstellen (Kidwell et al. 2004). Blutungen bis zu 3 Tage nach ihrem Beginn werden als akute Blutungen bezeichnet und können von erfahrenen Neuroradiologen mit einer Sensitivität von bis zu $100 \%$ 
am MRT diagnostiziert werden (Fiebach et al. 2004). Dies belegte Fiebach in der "Hemorrhage and Early MRI Evaluation"-Studie (HEME). In dieser Studie wurden 200 Patienten mit Verdacht auf hämorrhagischen Schlaganfall mittels MRT und CT evaluiert. Die Studie musste vorzeitig abgebrochen werden, da sich herausstellte, dass die MRT Blutungen detektierte, welche die CT nicht zeigte.

In Bezug auf chronische Hämatome, also Blutungen, die per definitionem nach über 30 Tagen noch nicht vollständig abgebaut sind, zeigte die Studie einen signifikant klaren Vorteil der MRT gegenüber der CT (Fiebach et al. 2004).

Doch neben logistischen Schwierigkeiten, wie z.B. die Patientenzugänglichkeit und die Überwachungsmöglichkeit von Vitalparametern, hat die MRT-Untersuchung noch einen Nachteil gegenüber der CT: die bisher vergleichsweise längere Untersuchungsdauer. Sogenannte ultrafast-MRTs zeigen zwar in der Theorie eine Verkürzung der Erfassungszeit von 20 min auf 5 min, jedoch sind diese Sequenzen in der Praxis noch nicht etabliert (U-King-Im et al. 2005 ).

\subsubsection{Relevante Aspekte der MR-Physik in Kürze}

\section{Allgemeine Erläuterung:}

Atomkerne haben, wie alle Elementarteilchen, die Eigenschaft sich um ihre eigene Achse zu drehen. Diese Eigenschaft wird als Spin bezeichnet. Jeder Kern induziert durch seinen Spin ein magnetisches Feld.

Die Kerne rotieren mit einer Frequenz, der sogenannten Präzessionsfrequenz. Die Kenntnis der Präzessionsfrequenz ist für die Energieübertragung essentiell. Denn um Energie auf Protonen übertragen zu können, wird ein HF-impuls derselben Frequenz benötigt.

Damit sich elektronische Wellen ohne Energieverlust ausbreiten können, und so ein konstantes Magnetfeld gewährleistet ist, verwendet man in MRT-Geräten supraleitende Magnete. Diese Magnete bestehen aus Spulen. Um ein maximal gleichmäßiges Magnetfeld aufzubauen, werden mindestens 4 Spulen benötigt. Drei davon sind sogenannte Gradientenspulen und werden zur Ortskodierung genutzt (Kumar et al. 1975). Sie entsprechen den Bildachsen x, y und z:

1. Gradient: Er wird direkt bei der initialen Anregung angelegt, um zu gewährleisten, dass mit Hilfe der Larmorgleichung (Details dazu später im 
Text) nur die Präzessionsfrequenzen der Protonen errechnet werden, die sich in der ausgewählten Schicht befinden.

2. Gradient: Er steht quer zu dem 1.Gradienten und bewirkt nach der Anregung der Schicht eine kontrollierte Dephasierung der Spins. So haben die Protonen der unterschiedlichen Zeilen jeweils einen anderen Spin und befinden sich damit in unterschiedlichen Phasenlagen.

3. Gradient: Er ändert die Präzessionsfrequenz der Spins.

Jetzt hat jede Bildzeile ihre eigene Phase und Frequenz. So kommt es zu einer Codierung der Signale in der Raumebene, die einem Voxel zugeordnet werden können.

Eine 4. Radiofrequenzspule wird dazu genutzt, die Echosignale aus dem Körper zu empfangen (Andrew 1985). Diese Information wird in einer Voxelmatrix, dem sogenannten k-Raum, abgespeichert. Die x-Achse dieser Matrix entspricht dabei der Präzessionsfrequenz, die y-Achse der Spinphase. Dieses Rohbild wird nun mittels der Fourier-Gleichung in das endgültige Bild umgewandelt (Twieg 1983).

Der Kern des k-Raums beinhaltet die Informationen über Form und Gewebskontrast. Die Peripherie des Raums beinhaltet Informationen über die räumliche Auflösung. Spezielle Erläuterung:

Atomkerne bestehen aus Protonen und Neutronen. Da beide Spins besitzen, neutralisieren sie sich gegenseitig. Daher eignen sich für die MRT nur Kerne mit ungerader Kernzahl. Denn diese heben sich nicht gegenseitig auf (Bloch et al. 1946). Die im Körper in hoher Zahl vorhandenen Wasserstoffprotonen bieten sich daher für die MR-Bildgebung besonders an. Wenn diese Kerne nun einem äußeren magnetischen Feld ausgesetzt sind $\left(B_{0}\right)$, interagieren die zwei magnetischen Felder miteinander, und die Kerne richten sich in dem Magnetfeld aus.

Um nun die Präzessionsfrequenz der Protonen berechnen zu können, die sich in der, für die Untersuchung relevanten Schicht befinden, wird die Larmorgleichung genutzt: $\omega_{0}=B_{0} Y$

Wobei $\omega_{0}$ die Präzessionsfrequenz ist, $\mathrm{B}_{0}$ die Kraft des äußeren magnetischen Feldes (gemessen in Tesla ( $\mathrm{T}$ ), SI-Einheit für die magnetische Induktion (B): 1T = 1V $x s \mathrm{~m}^{-2}$ ), und $\mathrm{y}$ die gyromagnetische Ratio (gemessen in Megahertz $(\mathrm{MHz})$ pro T). Dieses gyromagnetische Verhältnis ist für jedes Atom in einem bestimmten magnetischen Feld unterschiedlich (Bitar et al. 2006). Ein Wasserstoffatom beispielsweise präzipiert mit einer bekannten Frequenz von $42.57 \mathrm{MHz}$ pro $\mathrm{T}$, wobei 
ein Tesla dem 20.000-fachen des Erdmagnetfeldes entspricht. Das Erdmagnetfeld hat in unseren Breitengraden eine Magnetfeldstärke von ca. $5 \times 10^{-5} \mathrm{~T}$. Die in dieser Arbeit verwendete Feldstärke betrug $3 \mathrm{~T}$.

Legt man also ein konstantes äußeres Magnetfeld an, bzw. bringt man einen Körper in ein statisches Magnetfeld wie z.B. in ein MRT, so richten sich einige Spins entlang der magnetischen Achse von $\mathrm{B}_{0}$ aus, andere in antiparalleler Richtung (Bloch et al. 1946). Der kumulative Effekt all dieser magnetischen Momente der Kerne ergibt einen magnetischen Vektor: die Longitudinalmagnetisierung. Dieser Vektor verläuft im Patienten längs zu dem externen Feld und stellt somit die z-Richtung dar. Wird nun ein HF-impuls gesendet, so führt das zu einer Drehung dieses magnetischen Vektors in einem bestimmten Winkel. Denn der HF-impuls gibt an die Protonen Energie ab, die sich daraufhin antiparallel ausrichten, die Longitudinalmagnetisierung nimmt ab. Zusätzlich führt der Impuls zu einer Synchronisierung der Präzessionen. Dies bewirkt eine Magnetisierung in der Transversalebene. Der transversale Vektor induziert den elektrischen Strom. Dieser Strom wird als Signal zur Bilderstellung verwendet. Das so erhaltene MR-Signal wird daher von der Transversalmagnetisierung des Gewebes, also seiner Präzessionsfrequenz bestimmt (Damadian 1971).

Wird der HF-impuls nun ausgeschaltet, so richtet sich der Vektor wieder longitudinal, entlang der $\mathrm{B}_{0}$-Achse, aus. Die Längsmagnetisierung nimmt also wieder zu, die Quermagnetisierung nimmt ab.

Man misst nun die Geschwindigkeit, mit der das Magnetfeld wieder zu seinem ursprünglichen Gleichgewicht zurückfindet. Jedes Gewebe hat bei gegebener Feldstärke konstante Relaxationszeiten (Damadian 1971).

Die Zeitkonstante, die angibt, wie schnell die Erholung zu ihrem Ausgangswert stattfindet, wird T1-Relaxationszeit genannt.

Die Zeitkonstante, in der die Transversalmagnetisierung auf Grund von Interaktionen zwischen den Protonen abnimmt, ist die T2-Zeit.

Auch die T2*-Zeit kann so gemessen werden. Wobei diese zusätzlich von dem magnetischen Umfeld abhängt. Denn je mehr Magnetfeldinhomogenitäten, z.B. Metall in Zahnimplantaten oder Calcium in verkalkten Schädelkalotten, existieren, um so schneller nimmt die T2*-Relaxationszeit ab.

In Bezug auf Hämatomareale konnten Ripoll et al. in ihrer Arbeit mit 100\%iger Sensitivität die Entdeckung von Hämatomen erreichen (Ripoll et al. 2004). Sie 
beschreiben die starke Hypointensität selbst kleinster Blutungen, welche die

Diagnostik zwar sehr erleichtert, jedoch in manchen Fällen zu einer Überschätzung der Hämatomgröße führen kann und die tatsächliche Alterseinschätzung unmöglich macht (Ripoll et al. 2004).

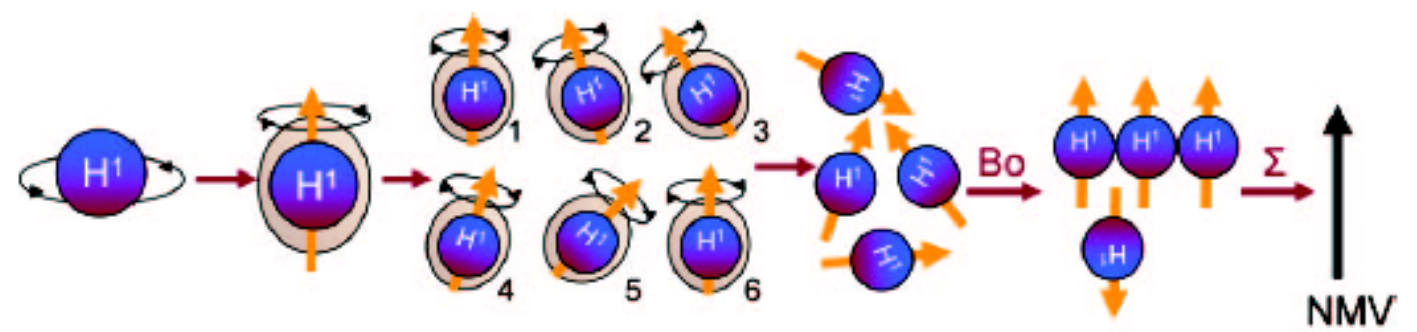

a.
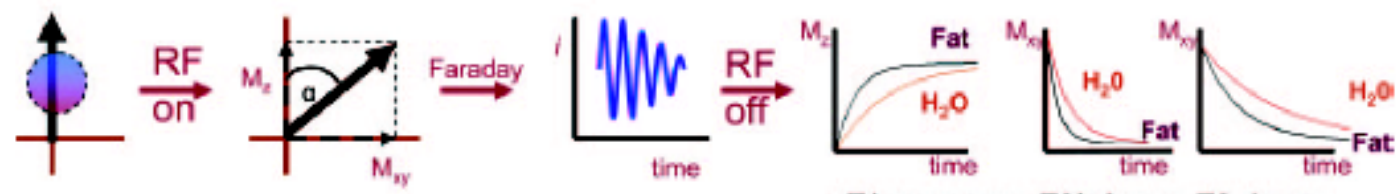

b

T1 recovery $\mathbf{T 2}^{\star}$ decay $\mathrm{T} 2$ decay

Abb.1 Physik eines MR-Signals

(a). Während ein 1H Kern rotiert, induziert er sein eigenes Magnetfeld (gelber Pfeil). Der 1H Kern dreht sich in verschiedenen Winkeln (1-6), aber sobald die Kerne einem äußeren magnetischen Feld ausgesetzt sind, reihen sie sich aneinander. Die Summe all dieser magnetischen Momente bildet den Magnetvektor.

(b) Wenn ein HF-Impuls appliziert wird, dreht sich der Vektor, welcher folgende Komponenten beinhaltet: longitudinale Magnetisierung (Mz) und transversale Magnetisierung (Mxy). Während die transversale Magnetisierung um die Spule präzediert, induziert sie eine Welle (i). Sobald der Hochfrequenzgenerator abgeschaltet wird, kommt es zur T1-Relaxation sowie zur T2- und T2*-Relaxation. (Bitar et al. 2006 S.514)
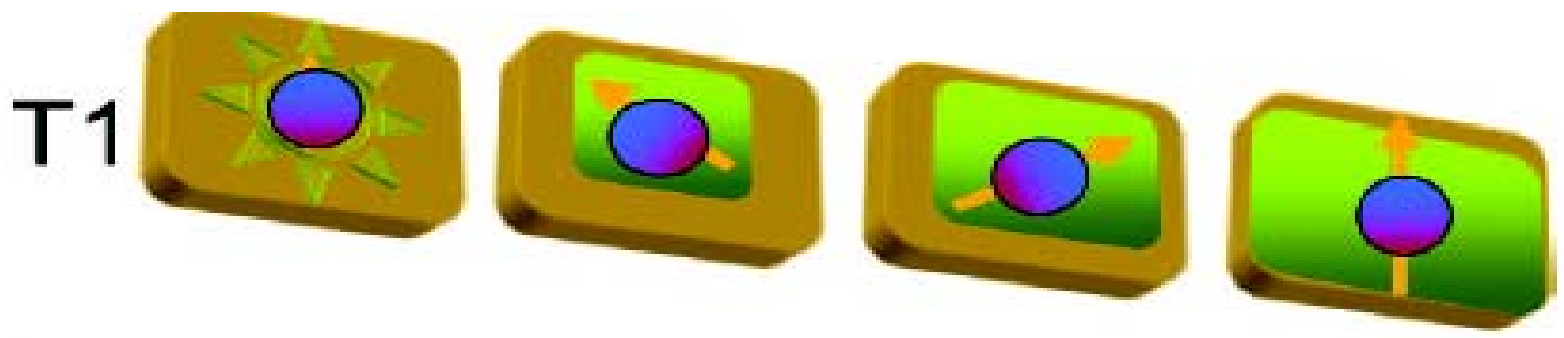

a.

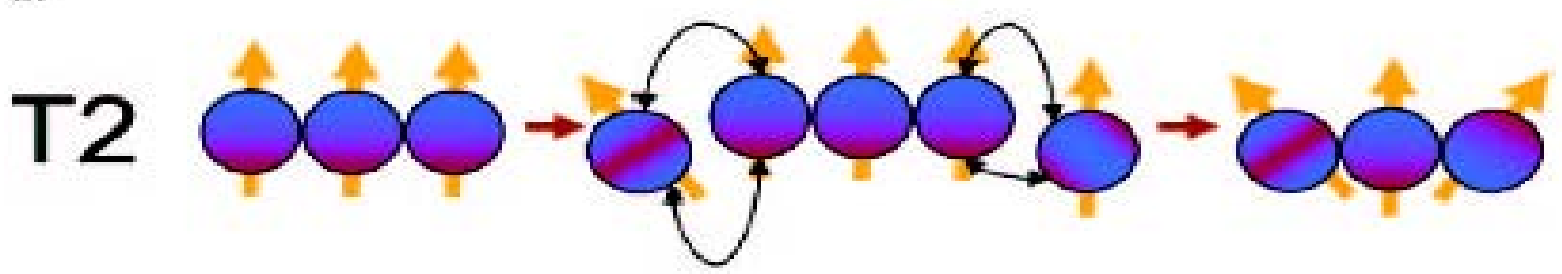

b.
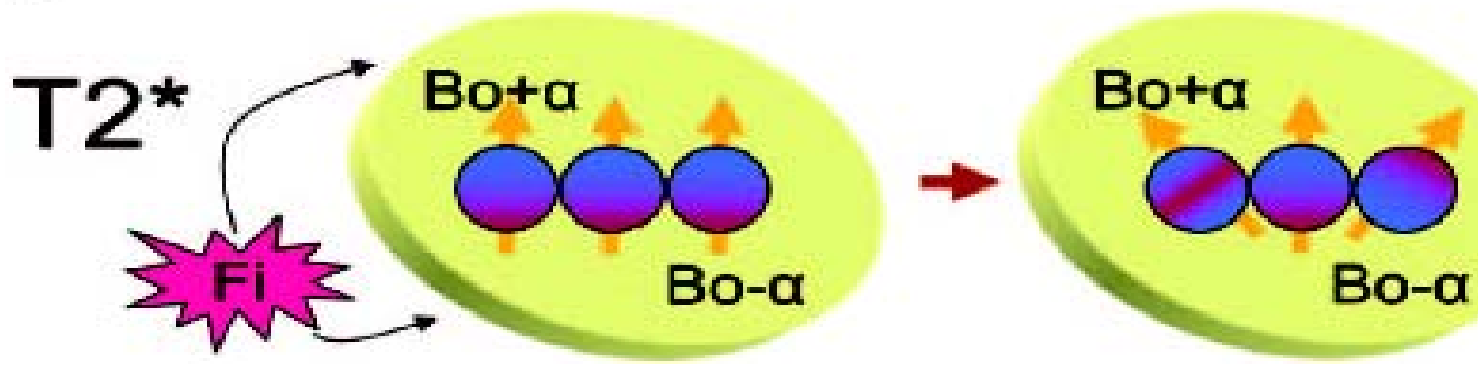
Abb. 2 T1-Relaxation setzt sich aus der longitudinalen Magnetisierung (gelb) zusammen, die Energie abgibt (grün). Die T2-Zeit setzt sich aus der transversalen Magnetisierung zusammen, die auf Grund von Interaktion abnimmt. Die T2*-Zeit bezieht sich ebenfalls auf die transversale Magnetisierung, die allerdings auf Grund von Magnetfeldinhomogenitätenabnimmt (Fi) (Bitar et al. 2006 S.515).

Dadurch, dass jedes Gewebe unterschiedliche magnetische Eigenschaften besitzt, kann man durch zwei Parameter auf die Kontrastdarstellung Einfluss nehmen:

Zum einen durch die Repetitionszeit (TR), zum anderen durch die Echozeit (TE).

Beide hängen von der Stärke von $\mathrm{B}_{0}$ ab.

- TR (in ms gemessen) ist die Zeit, zwischen 1. und 2. Radiofrequenzimpuls.

- TE (in ms gemessen) ist die Zeit zwischen dem Radiofrequenzimpuls und dem Zeitpunkt des höchst gemessenen Signals (siehe Abb.3) (Brown und Semelka 1999).

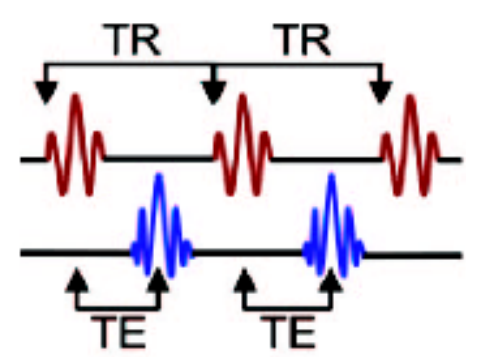

Abb. 3 (Bitar et al. 2006 S.516)

Stellt man eine kurze TR ein (zwischen 300 und 1000 ms) und eine kurze TE (weniger als $20 \mathrm{~ms}$ ), so hat sich die Longitudinalmagnetisierung der Gewebe zwischen den Impulsen noch nicht erholt und auch die Transversalmagnetisierung hat sich noch nicht ausgebildet. So können sich die unterschiedlichen T1-Werte der verschiedenen Gewebearten in ihrer Signalstärke bemerkbar machen. Folglich sind T1-gewichtete Bilder, neben der Stärke von $\mathrm{B}_{0}$, hauptsächlich von der TR abhängig (siehe Abb.4) (Bitar et al. 2006).

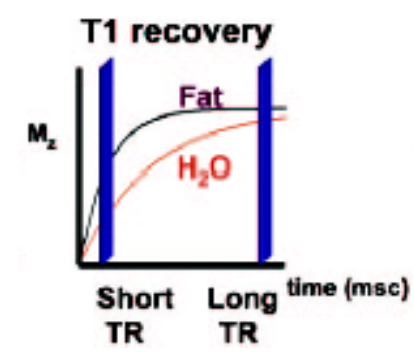

Abb. 4 (Bitar et al. 2006 S.516) 
Lange TE (länger als $80 \mathrm{~ms}$ ) sowie lange TR (zwischen 3000 und $6000 \mathrm{~ms}$ ) bewirken eine T2-Wichtung der Bilder. Denn bei langer TR haben die Unterschiede der T1Werte keine Relevanz mehr. Wird dazu eine lange TE eingestellt, so können sich die Unterschiede in der transversalen Relaxationszeit verdeutlichen. So erklärt es sich, dass die T2-Relaxationszeit neben der Stärke von $\mathrm{B}_{0}$ und dem Gewebetyp, von der TE abhängt (siehe Abb.5).

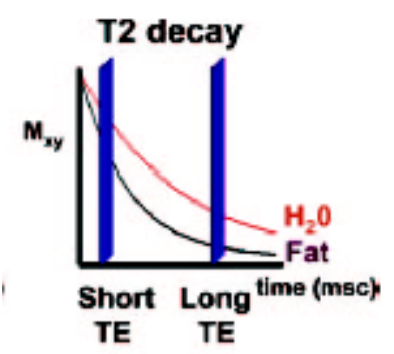

Abb. 5 (Bitar et al. 2006 S. 516)

Ist die TR aber lang und die TE kurz, so hat die T1-Zeit nur einen sehr geringen Einfluss auf die Darstellung und die TE hatte noch nicht genügend Zeit um einen T2Kontrast vollständig auszubilden. Das Bild ist also weder T1- noch T2-gewichtet. Daher ist der Kontrast im Bild hauptsächlich auf den Protonendichteunterschied zwischen zwei Geweben zurückzuführen.

Gewebearten mit vielen Protonen haben eine hohe Signalintensität: Die Präsenz von Proteinen und anderen Makromolekülen vermindert die Bewegung und folglich die Protonenrelaxation - Proteineffekt genannt (Brooks et al. 1989).

Bei geringerer Protonendichte ist die Darstellung dementsprechend hypointenser, die Blutungen erscheinen also dunkler (Bitar et al. 2006). Durch lokale Erhöhung der Proteinkonzentration dagegen, wie z.B. in einem Hämatomareal, kommt es zu einer stark verkürzten T2-Zeit, die sich folglich in der PDw als hyperintens darstellt (Yoon et al. 1988). Dieser Effekt kann durch eine akkurate Anpassung der Sequenzparameter an Feldstärke und Scannertyp noch verstärkt werden (Wiesman et al. 1999).

Es gibt viele verschiedene Sequenztechniken, die sich zur MR-Bildgebung eignen:

1) Die Spinecho (SE)-Technik: Bei dieser Technik wird solange ein HF-Impuls gesendet, bis der Magnetisierungsvektor des Gewebes im $90^{\circ}$-Winkel zu $\mathrm{B}_{0}$ steht. Während die Kerne die T1-, T2-, und T2*-Zeiten durchlaufen, dephasiert die transversale Magnetisierung langsam. Nun wird bei der Spinecho-Technik bereits zur Hälfte der TE ein $180^{\circ}$-Impuls appliziert. So 
werden die Präzessionen der Kerne wieder synchronisiert und ein Echo produziert (siehe Abb.6) (Hahn 1950).

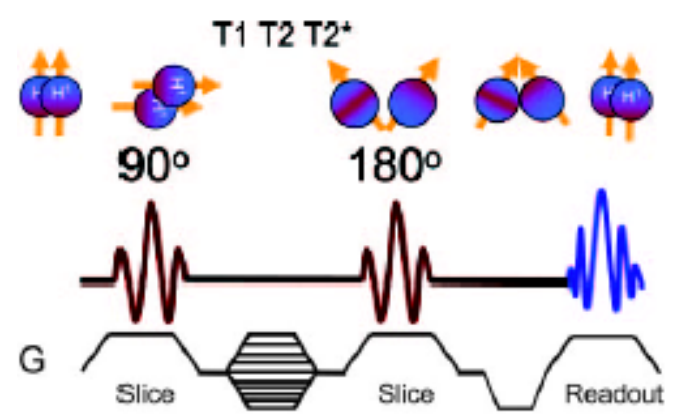

Abb. 6 (Bitar et al. 2006 S. 519)

a) Die fluid attenuated inversion recovery (FLAIR) Sequenz: Dies ist eine Sequenz, die hauptsächlich auf der SE-Sequenz basiert. Hier wird ein $180^{\circ}$ - Impuls gesendet, um den Magnetvektor um $180^{\circ}$ zu drehen. Wenn dieser HF-Impuls abgeschaltet wird, die Kerne sich also wieder in ihre ursprüngliche Position relaxieren, wird mit einem $90^{\circ}$-Impuls solange gewartet, bis die transversale Magnetisierung von Wasser vernachlässigbar klein ist. Dadurch gibt es nach der erneuten Synchronisierung der Kerne durch einen $180^{\circ}$-Impuls kein Echo ab und erscheint hypointens. Das Intervall zwischen diesen beiden Impulsen nennt man Inversionszeit (TI). (siehe Abb.7) (De Coene et al. 1992).

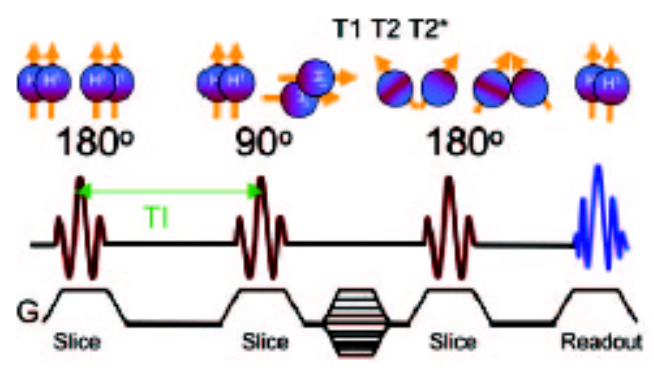

Abb. 7 (Bitar et al. 2006 S.523)

Diese Sequenz ist für Läsionen sinnvoll, die ansonsten kaum von Geweben, die hyperintense Flüssigkeiten enthalten, wie Sulci oder Ventrikel, zu unterscheiden wären (Bitar et al. 2006) und hat damit ihren Nutzen in einer Reihe von cerebralen Krankheiten bewiesen. Dazu gehört z.B. die Multiple Sklerose (Filippi et al. 1998).

In Bezug auf intracerebrale Blutungen wurde die FLAIR-Sequenz bisher wenig genutzt. Dies könnte unter anderem daran liegen, dass Ripoll et al. in ihrer 
Studie gezeigt haben, dass die FLAIR-Sequenz keine zusätzlichen, über die T2-gewichtete Bildgebung hinausgehende Information über die Blutung erbrachte. Das wird der Tatsache zugeschrieben, dass Wasser, welches die Schlüsselrolle in der FLAIR-Sequenz spielt, zu keiner Zeit Hauptkomponente des Hämatoms ist (Ripoll et al. 2004).
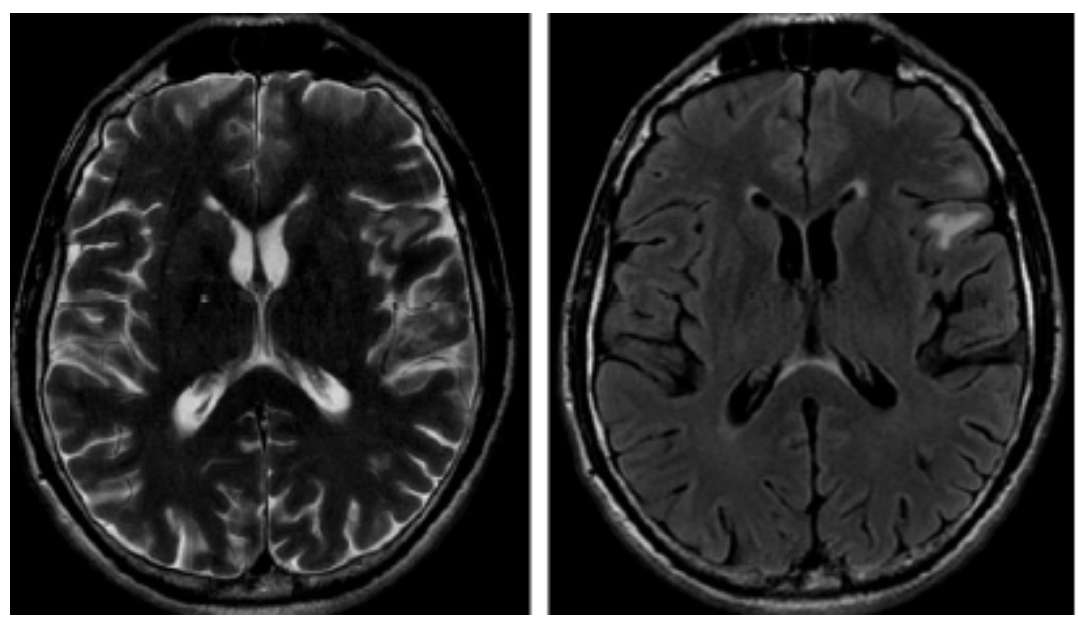

Abb. 13 Vergleich zwischen einer T2-gewichteten Spinechosequenz (links) und einem FLAIR-Bild (rechts) (Bitar et al. 2006 S.525).

2) Die Gradientenechosequenz (GE): Diese Sequenz entsteht, indem kurz nach dem ersten HF-Impuls ein zweites Magnetfeld angelegt wird. Dieses hat, durch ein Gefälle, große Inhomogenitäten. Dadurch werden die Protonen schneller dephasiert. Wird das Magnetfeldgefälle nun kurz darauf noch einmal, diesmal in umgekehrte Richtung geschaltet, so rephasieren die Protonenspins wieder. Dadurch geben sie ein Signal ab, dass schneller zustande gekommen ist, als bei jeder anderen Sequenz. Denn es konnte den zeitintensivsten Parameter, die TR, umgehen (Frahm et al. 1986). Folglich ist das Gradientenecho bei der Erfassung von schnellen Einzelsequenzen von Bedeutung und dient durch die Inhomogenität des Magnetfelds als Grundlage für T2*-gewichtete Bilder (Vogt et al. 2003). In der Folge sollen der Vollständigkeit halber noch Variationen der oben beschriebenen Sequenzen angesprochen werden.

a) Fast spin echo: Hier werden schnell hintereinander folgende $180^{\circ}$-Impulse abgegeben, die nur von einem $90^{\circ}$-Impuls gefolgt werden. So kann diese Sequenz die Zeit, die nötig ist, um ein Bild zu akquirieren, um den Faktor 
reduzieren, indem die $180^{\circ}$-Impulse abgegeben werden. Denn sie ersetzen die TR.

b) Das EPI (echo planar imaging): Hier läuft während einer einzigen TR die vollständige Datengewinnung aus dem k-Raum (Mansfield 1977). Dabei werden der Phasen-kodierende Gradient und der Frequenz-kodierende Gradient rasch an und ausgeschaltet. So wird der k-Raum schnell gefüllt. Obwohl man ansonsten immer mehr als nur eine TE benötigt, um ein komplettes MR-Bild zu messen, wird hier nach nur einem HF-impuls das gesamte Bild rekonstruiert. Die dazu benötigte Zeit misst nur zwischen 30 bis $40 \mathrm{~ms}$ (Cohen und Weisskoff 1991). Die EPI ist für magnetische Nebeneffekte anfälliger und sorgt so für größeren Gewebekontrast als solche mit konventioneller Gradientenecho-Sequenz (siehe Abb.8). Die EPI ist die Sequenz der Wahl für diffusionsgewichtete Bilder (diffusion weighted imaging, DWI).

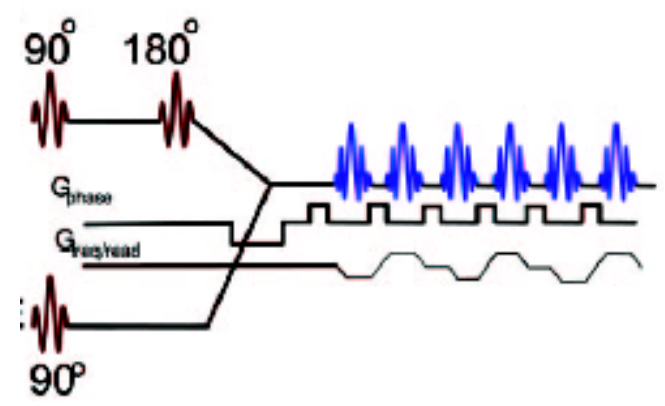

Abb. 8 (Bitar et al. 2006 S.530)

Nach dem Fickschen Gesetz ist Diffusion die Bewegung von Molekülen aufgrund eines Konzentrationsgradienten. In einem MR-Bild kann man jedoch nicht zwischen Diffusion aufgrund von Konzentrationsunterschieden, Druck, Temperatur oder Ionen unterscheiden. Deshalb wird nur der scheinbare Diffusionskoeffizient, der apparent diffusion coefficient (ADC), berechnet. Er ergibt sich aus der DWI mit heraus gerechnetem T2-Effekt. Die Signalintensität eines DWI-Bildes kann durch folgende Gleichung ausgedrückt werden:

$\mathrm{SI}=\mathrm{SI}_{0} \times \exp (-\mathrm{b} \times \mathrm{ADC})$ 
$\mathrm{SI}$ ist die Signalintesität, $\mathrm{SI}_{0}$ die Signalintensität auf T2-gewichteten Bildern und b der Diffusionssensitivitätsfaktor. Er setzt sich aus der gyromagnetischen Ratio, der Feldstärke des Gradienten und der Dauer des Impulses zusammen (Schaefer et al. 2000).

Im Gehirn ist die Diffusion nicht isotrop, sondern anisotrop. Das bedeutet, dass die Diffusion gerichtet abläuft. Um Fehlinterpretationen durch den T2-Durchscheineffekt zu vermeiden, erklärt sich die Notwendigkeit, immer sowohl die ADC-Karte wie auch das DW-Bild zu begutachten.

Diese Bilddarstellung ermöglicht es, zwischen schnell diffundierenden Protonen (ohne Diffusionsbarriere) und langsam diffundierenden Protonen zu unterscheiden (Stejskal und Tanner 1965). Um die Bewegung von Wassermolekülen, die nur in einer Richtung zu einer Zeit diffundieren, messen zu können, werden 2 gleich große, aber in unterschiedliche Richtung zeigende, Gradienten geschaltet. Nimmt man beispielsweise die x-Richtung, so wirken hier zwei gegensätzliche Gradienten. Wenn keine Bewegung zwischen den beiden Gradienten erfolgt, so dephasiert der erste Gradient den Spin, der zweite Gradient rephasiert inn wieder. Folglich wird eine hohe Signalintensität gesehen. Wenn es jedoch zwischen den beiden Gradienten eine Bewegung gibt (wie es bei freier Diffusion z.B. Wasser/Liquor der Fall ist), so werden die Protonen nicht von beiden Gradienten beeinflusst, sondern nur von jeweils einem. Folglich ist die Signalintensität niedriger (Bitar et al. 2006) (siehe Abb.9).

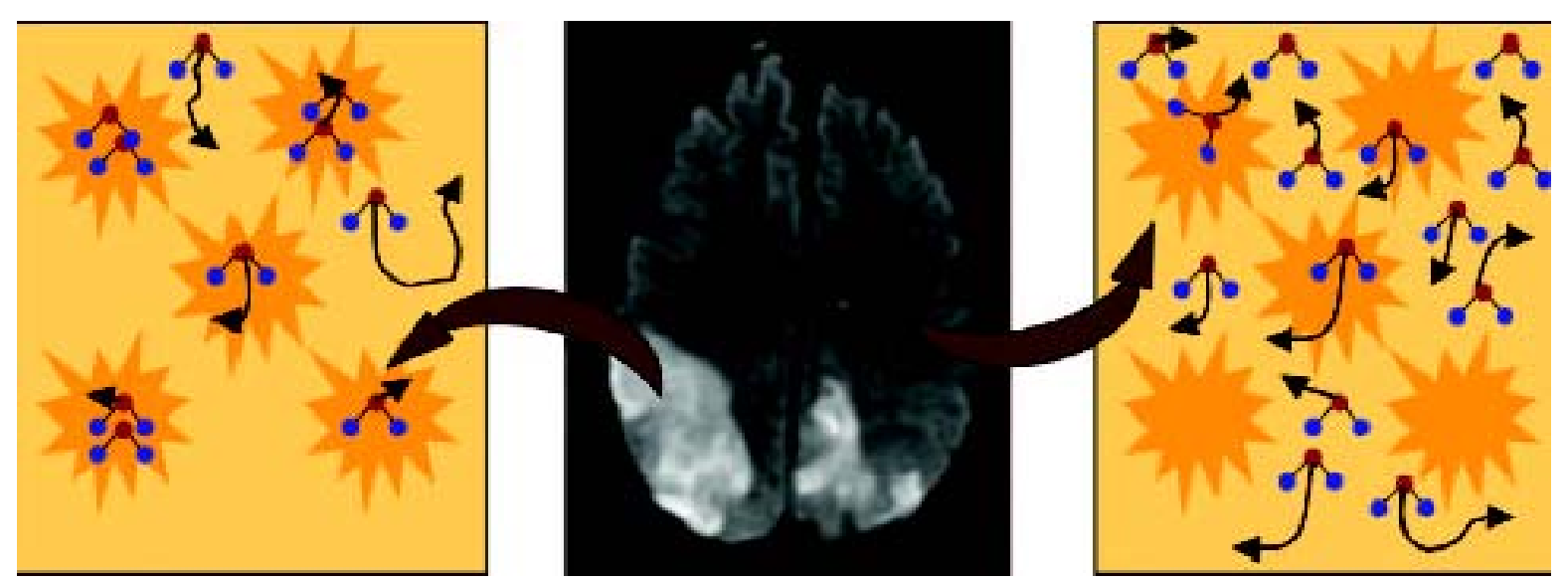

Abb. 9 Das linke Bild zeigt Gebiete mit eingeschränkter Diffusion, das rechte Bild Gebiete mit uneingeschränkter Diffusion (Bitar et al. 2006 S. 531). 


\subsubsection{Kontrastmittel}

Analog zu jodiertem Kontrastmittel bei der CT haben in der MRT intravenös applizierte paramagnetischen Substanzen, meistens Gadoliniumchelate, einen hohen Stellenwert für die Diagnostik (Okuda et al. 2000). Alle paramagnetischen Kontrastmittel haben gemeinsam, dass sie sowohl die T1- als auch die T2-Zeit verkürzen (White 2000).

Im Gegensatz zu dem jodreichen Kontrastmittel des CTs verursachen sie weniger Nebenwirkungen und seltener anaphylaktische Reaktion. Doch auch, wenn sie sicherer sind als jodidhaltiges Kontrastmittel, so sind Gadoliniumchelate dennoch nicht vollständig unbedenklich. Bei Patienten mit schwerer chronischer Nierenerkrankung zum Beispiel kann eine Kontrastmittelnephropathie auftreten (Ergun et al. 2006). Des Weiteren kann sowohl bei Dialysepatienten, wie auch bei Patienten mit hepatorenalem Syndrom oder nach Lebertransplantation, eine schwere bis tödliche verlaufende nephrotisch-systemische Fibrose auftreten (Kuo et al. 2007).

\subsubsection{Bewegungskompensierende Techniken}

Die relativ lange Zeit, die nötig ist, um alle zur Bildrekonstruktion nötigen Daten zu akquirieren, macht das MRT-Bild gegenüber Bewegungsartefakten empfindlich. Unvermeintliche Bewegungen sind beispielsweise der Blutfluss, der Herzschlag, die Atmung, der Schluckakt und die Peristaltik. Am empfindlichsten reagiert die Region entlang der Achse, in der das Echosignal aufgefangen wird. Hochentwickelte Verfahren machen es jedoch möglich, repetitive Bewegungsformen zu kompensieren. Mit Hilfe eines EKGs zum Beispiel können HF-impulse bewegungssynchron abgegeben werden und so Artefakte minimieren. Bei einem T1gewichteten Bild bedeutet das, dass die TR auf die Herzfrequenz abgestimmt ist. Da bei T2-gewichteten Bildern die TR länger ist, wird sie hier auf ein Vielfaches der Herzkontraktion eingestellt (Marcu et al. 2006). 


\subsubsection{Kontraindikationen}

Für ein MRT gibt es nur wenige Kontraindikationen. Es sind, bei Einhaltung der Sicherheitsgrenzen der spezifischen Absorptionsrate (SAR), keine biologisch relevanten negativen Effekte bekannt. Die meisten Kontraindikationen sind nur Vorsichtsmaßnahmen. Diese können in 4 Gruppen eingeteilt werden:

1) implantierte Schrittmacher und

2) Fremdkörper: Da magnetische Materialien und elektronische Geräte nicht nur eine potentielle Gefahr für den Patienten darstellen, sondern auch Artefakte verursachen, hat die American Society for Testing and Material folgende Terminologie herausgegeben (ASTM International 2005).

- MR sicher: Ein Gegenstand, der keine bekannte Bedrohung in jeglichem MR-Umfeld darstellt.

- MR eingeschränkt sicher: Ein Gegenstand, der bei bestimmten Gebrauchseinstellungen keine Gefahr im direkten MR-Umfeld darstellt.

- MR unsicher: Ein Gegenstand, der eine Gefahr in jedem MR-Umfeld darstellt.

3) instabile Patienten: Hier sollte der Nutzen einer MRT kritisch überdacht werden, da er in einer Notsituation nur schwer zugänglich ist und Wiederbelebungsmaßnahmen (z.B. Defibrilator) in einem MRT-Raum schwer durchführbar sind.

4) Schwangerschaft: Für Schwangere und den Fötus sind sowohl die MRT, als auch die Kontrastmittelauswirkungen unbekannt (Kanal et al. 2004; Marcu et al. 2006).

\subsection{Ursache, Klinik und Therapie der intracerebralen Blutung}

Bezüglich einer Gehirnblutung unterscheidet man 2 große Gruppen:

1) Die Subarachnoidalblutung ( $S A B)$, bei der sich das Blut im Subarachnoidalraum ausbreitet: nach der traumatischen SAB ist die häufigste Ursache einer SAB eine Blutung aus einer Gefäßaussackung einer intracraniellen Arterie - dem sogenannten Aneurysma. Eine weitere Ursache kann eine Blutung aus einer Gefäßmissbildung sein (Gorelick et al. 1986). 
2) Die intracerebrale Blutung (ICB), bei der Blut direkt in das Parenchym übertritt. Sie entsteht aus Arteriolen oder kleinen Arterien. Über Minuten oder Stunden breitet sie sich entlang der weißen Substanz aus (Caplan 1992). Im vorliegenden Text wird näher auf die ICB eingegangen.

\subsubsection{Pathogenese der ICB}

Unterteilt man die Blutungen nach ihrer Ätiologie, so werden traumatische Blutungen von spontanen ICBs unterschieden. Neben hohem Alter und stärkerem Alkoholkonsum (Ariesen et al. 2003; Sturgeon et al. 2007), zählt vor allem ein Hypertonus zu den Hauptrisikofaktoren einer ICB. Denn ein schlecht oder gar nicht behandelter, meist langjähriger-Hypertonus verdoppelt das Risiko für eine ICB (Thrift et al. 1998).

In bis zu 35\% der Fälle sind Hypertonie-bedingte ICBs, sogenannte „typische ICBs“, im Putamen lokalisiert, das Cerebellum kann in 16\%, der Thalamus in 15\% und die Pons kann in 5-12\% Ort der Blutung sein (Barnett et al. 1998).

Nach einer Studie von Garcia und Ho könnten kleine Gefäße, sogenannte Perforatoren, die in dem ungünstigen Winkel von $90^{\circ}$ von großen intracerebral liegenden Arterien abgehen, degenerative Prozesse begünstigen und so eine besondere Anfälligkeit für Druckbelastungen darstellen. Histologische Untersuchungen der Perforatoren zeigten durch Hyalinansammlungen entstandene Intimahyperplasien in den Gefäßwänden. Dies prädisponiert zu fokalen Nekrosen und folglich zu Gefäßwandbrüchen. Daraus entstehen oft klinisch inapparente Mikroblutungen, denen schließlich Massenblutungen folgen können (Garcia und Ho 1992).

Mittels T2-gewichteter MR-Aufnahmen, die kleinste Hämosiderinablagerungen erkennen lassen, konnten neuroradiologische Daten belegen, dass subklinische Blutungen bei Patienten, die eine spontane ICB erlitten haben, sehr häufig sind (Offenbacher et al. 1996). Cordonnier verglich T2-gewichtete Sequenzen von verschiedenen, bereits veröffentlichten Studien zwischen den Jahren 1988 und 2003 und zeigte eine Prävalenz dieser Mikroblutungen bei „gesunden“ Erwachsenen von $5 \%$. Bei $60 \%$ der Patienten, die später eine ICB erlitten, konnten vorbestehende Mikroblutungen detektiert werden (Cordonnier et al. 2007). 
Des weiteren wurde auf CT-Scans von Patienten mit hypertensiven Blutungen gesehen, dass kleine Blutungen in der Außenzone der Hauptblutung zu einer kontinuierlichen Ausdehnung führten. Dies wiederum resultiert in einer Umgebungsdruckerhöhung, welche die angrenzenden, bis dahin noch ungeschädigten Gefäße belastete und folglich neue Gefäßbrüche nach sich zog (Broderick et al. 1990; Brott et al. 1997). In den ersten 24 Stunden ist diese Blutungsausdehnung mit über 33\% Volumenexpansion am signifikantesten (Brott et al. 1997). Diese Expansion geht häufig mit bleibenden neurologischen Defiziten und erhöhter Sterblichkeit einher.

Auch wenn die genauen Abläufe der Blutungsvergrößerung noch nicht bekannt sind, scheinen hierbei, neben dem Zusammenbruch der Blut-Hirn-Schranke, Entzündungsprozesse eine Rolle zu spielen (Silva et al. 2005).

Des weiteren können in der Pathogenese einer ICB chronische Nierenerkrankungen eine Rolle spielen. Denn Nierenerkrankungen, mit konsekutiver Thrombozytendysfunktion, stellen einen Risikofaktor für hämorrhagische Insulte dar. (Bos et al. 2007). Obwohl dies die Schlussfolgerung nach sich ziehen sollte, dass die Einnahme von Thrombozytenaggregationshemmern zum Schutz vor koronaren Herzkrankheiten einen bedeutenden Risikofaktor darstellt, so wurde sowohl in kontrollierten Studien, wie auch in Fallkontrollstudien kein Inzidenzsteigerung im Vergleich mit der Normalbevölkerung bewiesen (Gorelick und Weismann 2005, Thrift et al. 1996).

\subsubsection{Klinik der ICB}

- Neurologlische Symptome, wie Bewusstseinseinschränkung oder Paresen, können innerhalb von Minuten oder auch erst innerhalb von Tagen auftreten und imponieren bei wachsender Ausdehnung klinisch wie ein stetig zunehmender Schlaganfall (Gorelick et al. 1986). Des Weiteren kann eine zunehmende Raumforderung des Hämatoms und eine Gehirn- oder Gefäßeinklemmung, die nicht selten zum Tod führt, die Folge sein (Xu et al. 1993).

- Durch die Blutungsausdehnung kann das Gehirnparenchym selbst eine mechanische Verletzung erleiden.

- Der intrakranielle Druck kann als Folge des Ödems, welches sich um die Blutung herum ausbildet, ansteigen. Dadurch kann es zum einen zu einem 
verminderten Blutfluss in der Blutungsumgebung und damit zur Ischämie kommen, zum anderen können zytotoxische Aminosäuren durch das angrenzende Gewebe exprimiert werden (Dearden 1998).

Lokalisationsbezogene Krankheitsbilder:

Neurologische Symptome variieren in Abhängigkeit des Blutungsortes.

- Putamen: Hemiplegie, Stupor und Koma.

- Kleinhirnblutungen: (meist im Nucleus dentatus): Ataxie, Erbrechen, Kopfschmerzen und Nackensteifigkeit. Bei größerer Ausdehnung können die Patienten zusätzlich Stupor als Folge zunehmender Stammhirneinklemmung entwickeln.

- Thalamus: (bis Capsula interna und/oder 3.Ventrikel): Hemiparese, Hemihypästhesie.

- Pons: Schnell einsetzendes tiefes Koma, totale Paralyse oder, wenn der Patient bei Bewusstsein sein sollte, Taubheit oder Dysarthrie.

- Epilepsie: In einer Studie zeigten Vespa et al., dass innerhalb von $72 \mathrm{~h}$ bei $29 \%$ aller Patienten mit einer ICB zusätzlich epileptische Anfälle auftreten. Diese Klinik wurde unabhängig von einer Mittellinienverschiebung oder anderen neurologischen Auffälligkeiten beobachtet (Vespa et al. 2003).

- Stupor und Koma: Dies wird als bedrohliches Zeichen gewertet .Nicht aber bei den Patienten die eine Thalamusblutung, durch die das retikuläre System ebenfalls angegriffen wurde, erlitten hatten. Denn im Gegensatz zu der Thalamusblutung, bei der nach Blutresorption eine Restitutio ad integrum erwartet werden kann, muss bei Patienten, die eine andere Blutungslokalisation haben, bei einer solchen Symptomatik von einem diffusen Gehirnschaden und damit von einer ausgeprägten Blutung ausgegangen werden.

- EKG-Veränderungen: Eine ST-Strecken Erniedrigung, U-Wellen, ein verlängertes QT-Intervall, flache oder spitze T-Wellen können bei manchen Patienten beobachtet werden. Durch Hypoperfusion des Hypothalamus kommt es zur zentralen Katecholaminfreisetzung. Dies kann wiederum zu subendokardialen Ischämien des linken Ventrikels führen. Die Katecholaminfreisetzung kann nicht nur die oben beschriebenen EKGVeränderungen hervorrufen, sondern auch eine Erhöhung der kardialen 
Enzyme und ventrikuläre Arrhythmien nach sich ziehen (Davis und Natelson 1993).

\section{Dauerhafte Schäden:}

Eine prospektive Studie zeigte, dass von 166 Patienten, die eine spontane ICB erlitten hatten, nur $12 \%$ nach 30 Tagen normal oder minimal beeinträchtigt waren (Daverat et al. 1991).

Es zeigte sich auch, dass, sobald die Blutung in den Ventrikel einbricht, die Wahrscheinlichkeit auf dauerhaft bestehende schwere Schäden signifikant erhöht wird und eine frühe Hämatomentlastung dann nicht zwingend zu einer Verbesserung führt (Hallevi et al. 2008).

\section{Mortalität:}

Ungefähr die Hälfte aller Patienten versterben innerhalb der ersten beiden Tage (Broderick et al. 1993; Franke et al. 1992).

Angaben bzgl. der 30-Tage-Mortalität bei Patienten mit ICB variieren zwischen 35und 52\% (Anderson et al. 1994; Broderick et al. 1993; Fogelholm et al. 2005 Flaherty et al. 2006). Als limitierende Hauptfaktoren sind initiales Blutungsvolumen und die initiale Bewusstseinslage zu nennen. Z.B.:

- Volumina von $60 \mathrm{~cm}^{3}$ oder größer, sowie ein Glasgow coma scale score von 8 oder weniger, zeigten eine 30-Tage-Mortalität von 91\% (Broderick et al. 1993).

- Volumina von nur $30 \mathrm{~cm}^{3}$, aber eine Glasgow coma scale von 9 oder mehr Punkten, zeigten eine 30-Tage-Mortalität von 19\% (Davis et al. 2006).

Die 10 Jahres-Überlebensrate betrug 18\% (Flaherty et al. 2006).

Aber auch das Hämatomwachstum ist ein bedeutender Prognosefaktor: eine Studie, die CT-Bilder auswertete, welche die ICB nach unmittelbarem Beginn sowie 24h später darstellten, zeigte, dass jedes weitere Blutungsvergrößerung um $10 \%$, zu einer 5\% größeren Wahrscheinlichkeit zu versterben führt (Davis et al. 2006). Die Chancen auf eine funktionelle Erholung nach ICB hängen, neben optimaler Therapie, von der Lokalisation der Blutung, der Größe, der die Blutung begleitenden Bewusstseinseinschränkung, dem Alter, sowie von der allgemeinen Gesundheit des Patienten ab (Broderick et al. 2007). 


\subsubsection{Diagnose der ICB}

ICBs müssen notfallmedizinisch versorgt werden, da rasch fortschreitende neurologische Verschlechterung, permanente Behinderung und Tod drohen (Broderick et al. 2007).

Es muss eine sofortige Diagnostik eingeleitet werden, um die pathophysiologischen Ursachen zu erkennen und schnellstmöglich zu behandeln. Denn analog zum Schlaganfall gilt auch hier: time is brain.

Ziel der bildgebenden Diagnostik muss es sein, einen ischämischen- von einem hämorrhagischen Schlaganfall zu unterscheiden. Und es sollten auch Zustände die einen Schlaganfall imitieren, ausgeschlossen werden.

Sowohl die CT als auch die MRT werden als Goldstandard in der Notfallsituation empfohlen (Kidwell und Wintermark 2008). Aufgrund besserer Verfügbarkeit und schnellerer Akquirierung der notwendigen Bilder, wird die native CT zur Zeit noch am meisten genutzt. Hyperakutes Blut erscheint in der CT hyperdens, akute Blutungen zeigen sich meist isodens und chronische Blutungen sind hypodens.

Auf die komplexe Darstellung von ICBs mittels dem MRT wird im Laufe dieses Textes noch ausführlich eingegangen.

\subsubsection{Therapie der ICB}

Die Therapie der ICB umfasst sowohl konservative als auch chirurgische Behandlungen.

a) Konservative Therapie:

Wegen einer intrakraniellen Druckerhöhung und möglichen Begleitsymptomen (s.o.), sollte, nach den Richtlinien der American Heart Association/American Stroke Association (AHA/ASA) zufolge, jeder Patient mit einer ICB auf der Intensivstation überwacht werden (Broderick et al. 2007). Um

- den intrakraniellen Druck besser kontrollieren zu können. Daher sollte der Patient mit einer $30^{\circ}$-Kopferhöhung gelagert werden. Aggressivere Methoden zur Drucksenkung sind die invasive Druckmessung (z.B. Codman-Sonde), der Gebrauch osmotischer Diuretika und Hyperventilation.

- den Blutdruck zu kontrollieren. Denn um eine Rezidivblutung zu verhindern ist ein gut eingestellter Blutdruck von essentieller Bedeutung, da er das Risiko einer ICB um 50\% senken kann (Chapman et al. 2004). 
- auftretende Krampfanfälle frühzeitig zu erkennen und adäquat behandeln zu können, z.B. mittels Benzodiazepinen und evtl. mit intravenöser Applikation von Phenytoin.

b) Operative Therapie:

Indikationen zur chirurgischen Behandlung einer ICB sollten insgesamt zurückhaltend gestellt werden. Eine retrospektive Studie an 75 Patienten, mit infratentorieller ICB, zeigte ein schlechteres Outcome nach operativer Behandlung als nach konservativer Therapie (Dolderer et al. 2004). Auch die chirurgische Evakuierung supratentorieller Blutungen ist umstritten (Minematsu 2003; Hankey 2003). Eine größere Studie zeigte, alle ICBs zusammennehmend, keinen signifikanten Vorteil für eine operative Hämatomevakuierung (International Surgical Trial in Intracerebral Haemorrhage ) (Mendelow et al. 2005).

Zusammenfassend muß jedoch eine offene Operation immer dann in Erwägung gezogen werden, wenn die intracranielle Druckerhöhung konservativ nicht beherrscht werden kann und das Leben des Patienten gefährdet.

c) Minimal invasive Therapie mittels Fibrinolyse:

Fortschritte im Bereich der stereotaktischen Aspiration von Hämatomen vermeiden große Anästhesien, lange Operationszeiten und vermindern den Blutverlust (Carviy et al. 2004). Folglich stellt sie zusammen mit dem Gebrauch von Fibrinolytika und nachfolgender Aspiration unter CT-Kontrolle eine weitere Möglichkeit der Behandlung dar (Rohde et al. 2002 b ). Dieser Therapieansatz wurde auch in vorliegender Arbeit benutzt. Aufgrund der zu erwartenden Auswirkung auf die Entwicklung des Hämatoms und dessen MR-tomographisches Erscheinungsbild wird im Folgenden auf die relevanten Gerinnungssubstrate eingegangen:

\section{Plasminsynthese:}

Plasmin ist eine Serinprotease, die in der Leber aus Plasminogen synthetisiert wird. Die physiologische Synthese der Plasminogenaktivatoren findet in den Endothelzellen des Gefäßsystems statt (Lijnen und Collen 1995).

Aufgrund seiner höheren spezifisichen Affinität zu dem Fibrin-Plasminogen-Komplex, spielt der lokale gewebsständige Plasminogenaktivator (t-PA) bei der Konvertierung die wichtigste Rolle (Matsu et al. 1981). Danach sind Streptokinase und Urokinase zu nennen (Wun 1988). 


\section{Allgemeine Wirkungsweise des Plasmins:}

Plasmin ist für die Fibrinolyse verantwortlich und wird hauptsächlich an den polymerisierten Fibrinmolekülen eines Thrombus wirksam. Es ist hier in der Lage die Helices des Fibrins spezifisch zu spalten und so das Blutgerinnsel aufzulösen. Die hierdurch entstandenen Fibrinbruchstücke inhibieren eine weitere Fibrinpolymerisierung und limitieren dadurch zusätzlich die Gerinnung.

Neben Fibrin, spaltet das Enzym Plasmin außerdem Prothrombin sowie die Faktoren V, VIII, IX. und XII. Dadurch wird die Gerinnungsfähigkeit des Blutes weiter heruntergesetzt.

Spezielle Wirkungsweise des Plasmins:

Wird nun t-PA aus den, nahe der Blutung gelegenen Endothelzellen ausgeschüttet, so bindet es sich, anstelle von den ansonsten unspezifischen proteolytischen Plasminogenspaltungen, an den Plasminogen-Fibrin-Komplex des Blutthrombus (Hoylaerts et al. 1982; Zamarron et al. 1984). Dieser Komplex erfährt daraufhin eine Konformationsänderung, die zu einer Steigerung der Plasminsynthese an der Thrombusoberfläche führt (Weitz et al. 1991). So minimiert sich das Hämatom stetig. Plasminaktivator-Inhibitor (PAI):

Bei PAI handelt es sich um ein Glykoprotein und Mitglied der Serinproteaseninhibitoren. Studien zeigten, dass das PAI-1 das Hauptregulatorprotein des fibrinolytischen Systems in vivo ist. Seine gerinnungshemmende Funktion selbst in Gegenwart von Heparin (Ehrlich et al. 1991) im klinischen Alltag zu einem nützlichen Agens.

PAI-1 hat im Blut zwei Hauptspeicherorte (Erickson et al. 1984): Nachdem es von den vaskulären Endothelzellen ausgeschüttet wird (Keeton et al. 1993), wird der größte Teil in den Thrombozyten gespeichert, ein weitaus kleinerer Anteil wird im Plasma gepoolt (Kruithof et al. 1984).

Damit die Halbwertszeit der an der Thrombusoberfläche kontinuierlich gebildeten tPAs verlängert wird, schützen es die frei zirkulierenden PAls vor einem Abbau (Collen 1980). Dadurch halten sie außerdem ihre Wirkung lokal begrenzt und verhindern so eine unerwünschte systemische Lyse (Hoylaerts et al. 1982; Bergman et al. 1983; Zamarron et al. 1984; Crabbe und Cloninger 1987). Im klinischen Alltag wird es auf Grund seiner hemmenden Wirkung auf den genetisch hergestellten, rekombinanten Plasminogen Aktivator (rt-PA) genutzt.

Rekombinanter Plasminogenaktivator (rt-PA): 
Das gentechnisch hergestellte Produkt, der rt-PA, unterscheidet sich von dem physiologischen Agens hinsichtlich seiner Pharmakodynamik nicht (Zamarron et al. 1984). Seine vorhandene hohe fibrinolytische Potenz sowie seine kurze Halbwertszeit führen zu einer praktischen Dosierung mit routinemäßigem intravenösen Gebrauch zur Rekanalisierung bei thrombosierten Gefäßen oder in der Therapie ischämischer Schlaganfälle (Friedman und Koroshetz 1995; Chiu et al. 1998). Es zeigte sich jedoch, dass er zwar das Hämatomwachstum signifikant verringert, doch auch, dass dadurch keine Lebensverlängerung resultiert (Mayer et al. 2008).

In der weissen Substanz wirkt rt-PA durch die Spaltung des NMDA-Rezeptors (Nicole et al. 2001; Matys und Strickland 2003) neurotoxisch (Lo et al. 2002; Thiex et al. 2004 b; Warren et al. 2003). Es kommt zu einer NMDA-induzierten intrazellulären Steigerung des Calciumspiegels, der wahrscheinlich einen weiteren Zelltod hervorruft (Nicole et al. 2001). Daher wurde in der vorliegenden Arbeit als Schutz PAI dazugegeben.

\subsection{Hämoglobindarstellung und Hämatom}

\subsubsection{Struktur und Funktion des Hämoglobins und des Eisens}

\section{Hämoglobin:}

Insgesamt ca. $3 \times 10^{8}$ Hämoglobinmoleküle nehmen $88 \%$ eines Erythrozyten ein, wobei das mean corpuscular haemogobin ( $\mathrm{MCH})$ ca. 30 pg beträgt. Das Hämoglobinmolekül setzt sich aus zwei Proteinkettenpaaren zusammen. Jede dieser Ketten besteht aus einem Molekül Porphyrin und einem Proteinanteil. Das Porphyrin besteht wiederum aus 4 Pyrrolringen, die über Methinbrücken miteinander verbunden sind. Die Stickstoffatome der Pyrrolringe binden 4 der 6 Koordinationsstellen des Eisens. Eine weitere Bindung wird mit dem Globinteil eingegangen und die 6. Bindungsstelle wird für die Sauerstoffbindung genutzt. Das bedeutet, dass jedes Hämoglobin, da es aus 4 Proteinketten besteht, auch 4 Sauerstoffmoleküle binden kann. Der Hämoglobinabbau findet unter physiologischen Bedingungen in Milz, Leber und Knochenmark statt. Während der Globinteil nach Abbau zu Aminosäuren für eine Neusynthese zu Verfügung steht, wird der 
Hämanteil zu Bilirubin abgebaut und mit der Galle ausgeschieden (Wintrobe et al. 1981).

Eisen: In der Nahrung liegt das Eisen in seiner dreiwertigen Form vor $\left(\mathrm{Fe}^{3+}\right.$, ferrischer Zustand). Im Körper wird es als reduzierte Form an Hämoglobin gebunden $\left(\mathrm{Fe}^{2+}\right.$, Ferro-form). Nimmt das Eisenion den Sauerstoff auf, so bleibt es zweiwertig (Perutz 1987).

Sobald die Erythrozyten das kapillare System verlassen, wird das Sauerstoffmolekül abgegeben und aus Oxyhämoglobin wird Deoxyhämoglobin. Auch hierbei bleibt das Eisen zweiwertig. Dadurch, dass Oxyhämoglobin keine freien Elektronen am Eisenmolekül hat, unterscheidet es sich vom deoxygenierten Zustand dadurch, dass das Hämmolekül 4 ungepaarte Elektronen vorweist. Außerdem liegt aufgrund spontaner Hämoglobinoxidierung im Körper ständig eine 1\%-ige Konzentration Methämoglobin $\left(\mathrm{Fe}^{3+}\right)$ vor. Dieses kann keinen Sauerstoff binden (Bradley 1992).

\subsubsection{Makroskopische Hämatomdarstellung}

In den ersten Stunden einer Blutung bildet sich ein Thrombus. Dessen innerer Kern beinhaltet intakte rote Blutkörperchen.

In den folgenden Wochen kann man eine Farbveränderung des äußeren Anteils des Hämatoms von rot zu braunschwarz bis orange beobachten. Dies wird den Makrophagen zugeschrieben, die durch die Verdauung der Erythrozyten am Randsaum des Hämatoms Hämosiderin produzieren. Die innen liegenden, intakten Erythrozyten werden nicht phagozytiert sondern zerfallen. Dadurch bildet sich eine Methämoglobinmasse, welche sich makroskopisch braun darstellt.

Nach Monaten bis Jahren zeigt sich nur noch ein orangefarbener Randsaum entlang des Hämatoms, der die hämosiderinbeladenen Makrophagen enthält und kennzeichnend für ein altes Hämatom ist (siehe Abb.10) (Grossmann 1988). 


\section{EVOLUTION OF HEMATOMAS}
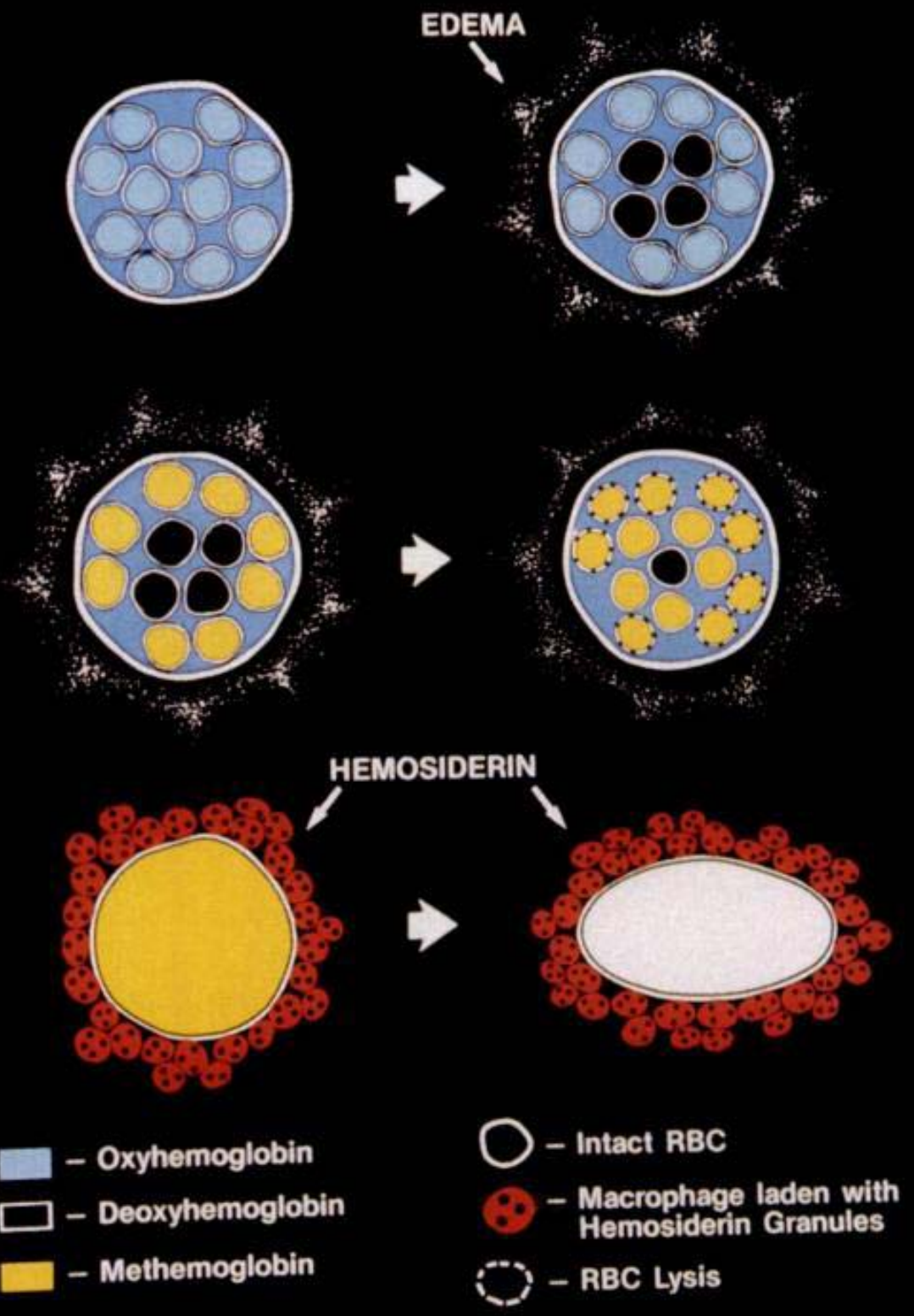

Abb. 10 Diagramm der biochemischen Evolution einer ICB. Es ist von links nach rechts und von oben nach unten zu lesen. Intrazelluläres Oxyhämoglobin (blau) wird zu intrazellulärem Deoxyhämoglobin oxidiert (schwarz).

Dieses wird dann zu intrazellulärem Methämoglobin (gelb) oxidiert. Schließlich wird das Methämoglobin als Folge der Erythrozytenlyse frei, woraus Hämosiderin (rot) wird. Über die Zeit wird das Methämoglobin resorbiert und es bleibt nur noch ein Randsaum, der aus Hämosiderin besteht übrig (Grossman et al.1988 S.442). 


\subsubsection{Wechselwirkungen zwischen Hämatom und MRT}

Die Darstellung eines Hämatoms hängt hauptsächlich von dessen Alter sowie von der ausgewählten MR-Sequenz ab (Bradley 1993).

1) Allgemeiner Teil:

Da sich das Hämoglobin im Körper durch die Sauerstoffaufnahme bzw. Abgabe in seiner Zusammensetzung und daher in seiner Signalgebung ändert, ist Blut eine der schwierigsten Substanzen die es mittels MRT darzustellen gilt.

Die magnetischen Eigenschaften des Hämoglobins wurden zuerst von Pauling und Coryell beschrieben (Pauling und Coryell 1936). Die Hämatomdarstellung hängt von gepaarten, bzw. ungepaarten Elektronen, also von einem eventuellen paramagnetischen Zustand des Moleküls ab (Wintrobe et al. 1981). Oxyhämoglobin ist diamagnetisch, besitzen also keine ungepaarten Elektronen. Dagegen ist Deoxyhämoglobin mit 4 ungepaarten Elektronen und Methämoglobin mit 5 ungepaarten Elektronen, paramagnetisch.

2) T1 und T2:

Für die Verkürzung der T1- und T2-Zeit spielen neben der Oxygenierung weitere Komponenten eine Rolle. Sie hängen mit den Protonen der Proteine zusammen (Daszkiewicz et al. 1965):

- "Effekt des gebundenen Wassers": Wassermoleküle binden sich in einer Lösung an Proteine. Blut stellt sich als eine Lösung verschiedener Proteine dar. Den Hauptanteil bildet das Hämoglobin. Doch es gibt auch noch Proteine, wie Fibrinogen und Lipoproteine, die zwar in viel niedrigerer Konzentration vorhanden sind, aber auch mit den Wasserprotonen interagieren und so das Relaxationsverhalten der Wasserprotonen beeinflussen (siehe Abb. 11) (Clark et al. 1990).

- Paramagnetische Effekte der Moleküle untereinander (Bradley 1992; Fullerton 1992): Vorkommen bei Deoxyhämoglobin und Methämoglobin. Obwohl beide Moleküle auf Grund ungepaarter Elektronen paramagnetisch sind, zeigt sich doch nur bei Methämoglobin eine relevante Hypointensität in der T1-Sequenz. Dies ist dadurch zu erklären, dass sich die Wasserprotonen dem Deoxyhämoglobin nur sehr schlecht nähern können, daher schlecht gebunden werden und folglich die T1-Zeit länger ist, als bei Methämoglobin (Singer und Crooks 1978). 
Die Erklärung für die T2-Relaxationszeit-Verkürzung ist ähnlich. Auch hier verursachen Wasser-Protein-Verbindungen durch größere Inhomogenitäten der lokalen Magnetfelder und damit schnelleren Dephasierung eine, im Vergleich zum Gehirnparenchym erheblich verkürzte TE. Dies bedeutet also, dass die physiologischen Veränderungen eines Hämatoms, die Deoxygenierung des Hämoglobins, die steigende Viskosität, die erhöhte Hämoglobinkonzentration und die Fibrinpolymerisation während der Thrombusbildung, den entscheidenden Einfluss auf die T2-Zeit ausüben (Hayman et al. 1989). Wenn nun verschiedene Relaxationsmechanismen einen Einfluss auf die T1- oder T2-Relaxationszeit haben, so stehen sie in folgendem Zusammenhang:

1/T2 observed=1/T2 $\mathrm{Hb}$ paramagnetisch+1/T2 Hb Protein+1/T2 Fibrinprotein+1/T2 Plasmaprotein (Daszkiewicz et al. 1965).

Es konnte gezeigt werden, dass von den genannten Komponenten das Deoxyhämoglobin den größten Einfluss auf die T2-Relaxationszeit hat. Die Fibrinpolymerisation hat den kleinsten Einfluss (Clark et al. 1990; Parizel et al. 2001).

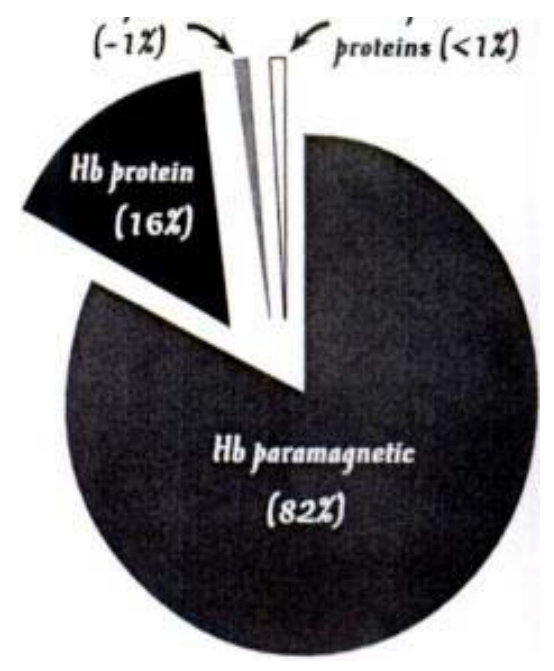

Abb. 11 Dieses Kreisdiagramm zeigt die proportionalen Anteile der Proteine eines deoxygenierten Thrombus an der Relaxationszeit. Das Hämoglobinprotein ist dafür hauptverantwortlich. Fibrin zeigt sich mit $1 \%$ als sehr kleiner Anteil genauso wie übrige Proteine mit einem Beitrag von unter 1\% (Clark et al. 1990 S.206).

Bezüglich der MR-Darstellung, lassen sich 5 Hämatomstadien auf den T1- und T2Wichtungen erkennen. Die für diese Studie zusätzlich verwendeten Sequenzen und die Darstellung der Hämatomstadien, werden im Text separat besprochen. 
1) Bei der hyperakuten Blutung besteht das Hämatom aus einer Mischung von Oxyhämobglobin und Deoxyhämoglobin. Es ist zu beachten, dass die meisten Blutungen typischerweise arteriellen Ursprungs sind und damit vorwiegend Oxyhämoglobin enthalten. Dies besitzt keine paramagnetischen

Eigenschaften, folglich kann es also schlecht dargestellt werden (Allkemper et al. 2004).

a) T1-Wichtung: Dieses Stadium zeigt sich isointens im Vergleich zum Gehirnparenchym, da hier der noch relativ hohe Anteil an Oxyhämoglobin eine relativ längere T1-Zeit bewirkt (Hayman et al. 1989).

b) T2-Wichtung: Diese Darstellung wird durch den noch überwiegend flüssigen Hämatomcharakter bestimmt. Die TE ist dadurch relativ lang, die Blutung erscheint leicht hyperintens.

2) In der akuten Phase besteht das Hämatom hauptsächlich aus Deoxyhämoglobin, das sich in noch intakten Erythrozyten befindet (Seidenwurm et al. 1989).

a) T1-Wichtung: Das Deoxyhämoglobin hat zwar paramagnetische Eigenschaften, jedoch bewirkt es keine T1-Vekürzung, da sich die Wassermoleküle dem Hämoglobin nicht genug nähern können - Blut erscheint im MRT leicht hypointens.

b) T2-Wichtung: Die T2-Hypointensität entsteht durch Dephasierung, die aus einer Diffusion der Wassermoleküle über die Erythrozytenmembran resultiert. Durch zunehmende Thrombosierung, die die Viskosität steigen lässt, steigt ebenfalls die T2-Hypointensität (Clark et al. 1990).

3) Im früh subakuten Hämatomstadium versagen die energieverbrauchenden, sauerstoffabhängigen Vorgänge. So kann die instabile Ferro-Form des Eisens nicht mehr erhalten werden (Bradley 1993). Das Eisen-lon wird zu seiner Ferri-Form oxidiert und liegt als intrazelluläres Methämoglobin vor.

a) T1-Wichtung: Das Methämoglobin zeigt sich hyperintens. Denn die Dipoldipol-Interaktionen der Protonen und Elektronen führen zu einer Relaxationszeitverkürzung. Außerdem verstärkt die gute Zugänglichkeit des Wassers an das Methämoglobin die Signalintensität.

b) T2-Wichtung: Hierauf nimmt die zunehmende Zelllyse mit dem noch nicht freigesetzten Methämoglobin Einfluss, und zeigt sich hier noch immer hypointens (Bradley 1993). 
4) Im spät-subakuten Stadium, liegt das Methämoglobin extrazellulär vor. Dies stellt sich sowohl in der T1- wie auch in der T2-Bildgebung hyperintens dar.

a) T1-Wichtung: Hierfür gilt, dass die Wassermoleküle, ebenso wie bei der frühen Subakutblutung, frei über die Erythrozytenmembran diffundieren können.

b) T2-Wichtung: Durch die zunehmende Lyse der Erythrozyten, mit der daraus resultierenden Protonendichtesteigerung, verkürzt sich die T2Relaxationszeit (Hackney et al. 1987). Daraus folgt, dass die T2-Wichtung für die Unterscheidung zwischen früher (lange T2) und später (kurze T2) Subakutblutung unerlässlich ist.

5) Im chronischen Stadium wird der Hämatomrand vom phagozytierten Hämosiderin und Ferritin bestimmt. Im Zentrum befindet sich das noch nicht vollständig lysierte Methämoglobin in Form sogenannter Hemichrome.

a) T1-Wichtung: Die Hemichrome erscheinen überwiegend isointens. Die Hämosiderin- und Ferritinanteile sind leicht hypointens (Bradley 1993).

b) T2-Wichtung: Hier stellt sich das noch nicht vollstängid lysierte Methämoglobin leicht hyperintens dar. Der Hämatomrand ist dagegen stark hypoinens (Thulborn et al. 1990).

Sobald das Methämoglobin völlig lysiert ist, ist auf beiden Wichtungen nur noch ein dunkler Hämosiderinstreifen als Zeichen einer stattgefunden Blutung zu sehen (siehe Tab.1).

\begin{tabular}{|c|c|c|c|c|c|}
\hline \multirow[b]{2}{*}{ ICH Stage } & \multirow[b]{2}{*}{ Lesion Age } & \multirow{2}{*}{$\begin{array}{l}\text { Affected Brain } \\
\text { Compartment }\end{array}$} & \multirow{2}{*}{$\begin{array}{l}\text { Involved Magnetic } \\
\text { Susceptible Substance }\end{array}$} & \multicolumn{2}{|c|}{$S I^{*}$} \\
\hline & & & & T1-weighted MR & T2-weighted MR \\
\hline Hyperacute & $<24 \mathrm{~h}$ & Intracellular & Oxyhemoglobin & Isointense & Slightly hyperintense \\
\hline $\begin{array}{l}\text { Acute } \\
\text { Subacute }\end{array}$ & $1-3 d$ & Intracellular & Deoxyhemoglobin & Slightly hypointense & Hypointense \\
\hline Early & $>3 d$ & Intracellular & Methemoglobin & Very hyperintense & Hypointense \\
\hline Late & $>7 d$ & Extracellular & Methemoglobin & Very hyperintense & Very hyperintense \\
\hline Chronic & $>30 d$ & & & & \\
\hline Center & & Extracellular & Hemachromes & Isointense & Slightly hyperintense \\
\hline $\operatorname{Rim}$ & & Extracellular & Hemosiderin & Slightly hypointense & Very hypointense \\
\hline
\end{tabular}

Tab.1 (Allkemper et al. 2004 S.875)

Im Folgenden wird auf alle Sequenzen eingegangen, die in der vorliegenden Arbeit genutzt worden sind: 
1) DWI.

- Oxyhämoglobin zeigt sich bei 1,5 T hyperintens. Bei einer Feldstärke von 3,0 T ist es eher hypointens mit einem, im Vergleich zum normalen Gehirnparenchym, niedrigem ADC (Kang KB et al. 2001). Dies kann die relative Schwierigkeit für Wasserdiffusion über die Erythrozytenmembran widerspiegeln.

- Extrazelluläres Methämoglobin hat einen höheren ADC als normales Gehirngewebe. Dies bedeutet, dass die Mobilität von Wasser im Extrazellularraum erhöht ist. Sie verlängert die T2-Komponente, führt zu einem T2-Durchscheineffekt und resultiert in einer stärkeren Signalintensität.

- Blutungen, die noch Deoxyhämoglobin, intrazelluläres Methämoglobin oder schon Hämosiderin beinhalten, erzeugen ein hypointenses Bild. Da diese Blutprodukte eine niedrige Signalintensität auf T2-gewichteten Bildern haben, kann der ADC hier nicht akkurat berechnet werden (Atlas et al. 2000). Daraus folgt:

- Hyperakutes Stadium: Blut ist hyperintens

- Akute und früh subakute Phase: Das Hämatom stellt sich hypointens dar.

- Spät subakutes Stadium: Erythrozyten lösen sich auf und das bis dahin intrazelluläre Methämoglobin wird frei. Dies führt zu einer Aufhebung der Effekte, die durch die magnetische Inhomogenität entstanden sind (Bradley 1993). Diese Lyse beeinflusst auch die molekulare Diffusion und folglich den ADC-Wert. Während dieses Vorganges variiert das Hämatom ständig in seiner Zusammensetzung und spiegelt sich in dem inkonstanten ADCWert und der variablen Bilddarstellung, wieder.

- Chronisches Stadium: Hämosiderin und Ferritin lassen den ADC-Wert ansteigen. Doch durch den T2-Durchscheineffekt ist dies auf der DWI als Hypointensität zu sehen ist.

2) FLAIR-Wichtung:

- Hyperakutes, akutes und subakutes Stadium: Da es bei 3,0 T auf Grund der höheren Suszeptibilitätsempfindlichkeit zu stärkeren Signalverlusten und damit zu einer hypointenseren Darstellung der Hämatome kommt, erscheinen die Blutungen in der FLAIR-Wichtung hypointens. 
- Spät subakute Phase: Das Hämatom erscheint hyperintens, da das extrazellulär liegende Methämoglobin zu einer T2-Verlängerung führt.

- Chronische Phase: Das Hämatom wird auch hier, wie in der T2-Sequenz, auf Grund des Hämosiderins, hypointens dargestellt.

3) T2*-Wichtung:

- Hyperakutes, akutes und subakutes Stadium: Blutungen stellen sich in der T2*-Sequenz hauptsächlich hypointens dar. Sie haben jedoch zentrale Hyperintensitäten als Zeichen der noch oxygenierten Erythrozyten.

Die Hypointensität wird durch die schnelle, von der Peripherie fortschreitende, Deoxygenierung erklärt. Denn daraus resultieren große Unterschiede in der magnetischen Empfindlichkeit dieser Areale. Konsequenterweise könnte man nun, durch das zunehmende Hämatomalter, davon ausgehen, dass die Hypointensität immer mehr von der Peripherie zur Mitte fortschreitet.

- Chronisches Stadium: Es können sich selbst nach 4 Monaten noch Hyperintensitäten in der Hämatommitte zeigen. Also zu einer Zeit, in der sich die paramagnetisch wirkenden Hämoglobinprodukte dort schon längst darstellen sollten.

Die Ätiologie dieses Phänomens ist noch unbekannt (Linfante et al. 1999). Trotz allem dominiert im chronischen Stadium, auf Grund des paramagnetischen Hämosiderins, die hyperintense Darstellung (Ripoll et al. 2002). Dadurch wird das wahre Alter verschleiert und macht so die Hämatomeinschätzung unsicher. Daher nutzen einige Autoren das Ödem, welches die Blutung umgibt, zur Differenzierung zwischen akutem und chronischem Hämatom (Nighoghossian et al. 2002).

4) Protonendichtewichtung (PDw):

- Hämatomdarstellung im Verlauf: Die Signalintensität, die noch in der hyperakuten Phase eindrücklich zu sehen ist, schwächt sich mit zunehmendem Deoxyhämoglobingehalt ab. 


\section{Material und Methoden}

\subsection{Operation der Tiere}

Die vorliegenden Ergebnisse entstanden aus einer Kooperationsarbeit zwischen der neurochirurgischen und neuroradiologischen Abteilungen der Universitätsmedizin Göttingen sowie der klinischen Forschergruppe "MR-Forschung in der Neurologie und Psychiatrie". Gemäß der konsensuellen Studienplanung wurden die MRTUntersuchungen sowie Sequenzauswahl, -anpassung und -optimierung gemeinsam unter Federführung der Forschergruppe durchgeführt, wobei insbesondere auf Vermeidung unnötig langer Untersuchungszeiten geachtet wurde. Für den klinischtierexperimentellen Teil (Operation, anästhesiologische Versorgung und Überwachung) war das neurochirurgische Team unter Leitung von Prof. Veit Rohde verantwortlich, insbesondere Herr Gerrit Meier im Rahmen seiner Promotionsarbeit. Das Tierprotokoll für diese Studie, wurde beim dem Niedersächsischen Landesamt für Verbraucherschutz und Lebensmittelsicherheit gemäß $\S 8$ Absatz 1 des Tierschutzgesetze beantragt und genehmigt. Es handelte sich um 21 männliche Schweine, die zwischen 30 und $35 \mathrm{~kg}$ wogen. Sie wurden alle vom gleichen Zuchtbetrieb (Fa Zuchtgut Relliehausen) geliefert und in der zentralen tierexperimentellen Einrichtung der Universitätsklinik Göttingen untergebracht. Zu den in dieser Studie relevanten Tieren zählen 18 Schweine. Denn das erste Schwein diente im Pilotversuch der Festlegung des genauen MRT-Protokolls. Zwei weitere Tiere mussten auf Grund neurologischer Komplikationen gemäß den geltenden Tierschutzregeln eingeschläfert werden.

Damit ein venöser Zugang (Braunüle 18G, Fa Braun) in die Ohrvene gelegt werden konnte, wurden die Tiere an dem Tag der Operation durch 7-10 mg/kg Körpergewicht Azaperone (Stresnil, Fa Janssen $\mathrm{GmbH}$, Neuss) sediert. Über diesen Zugang wurde Ketamin, 1-2 mg/kg Körpergewicht (Ketamin 10\%, SANOFI-CEVA GmbH) und Propofol (Disoprivan 1\%, Fa AstraZeneca, Wedel) verabreicht. Danach konnte die endotracheale Intubation mit einem Tubus mit Innendurchmesser von 6,5 mm der Firma Portex Limited, England, durchgeführt werden.

Für eine kontrollierte Beatmung während der Operation sorgte ein Narkosegerät der Firma Dräger. Sie erfolgte durch Sauerstoffgabe mit einer Atemfrequenz von 10 Atemzügen pro Minute und einem Atemzugvolumen von $500 \mathrm{ml}$. Das Verhältnis von Inspirationsdauer zu Expirationsdauer betrug 1:2. Die Aufrechterhaltung der Narkose 
erfolgte durch Propofolinjektionen. Um das zur Blutungsinduktion benötigte Blut zu bekommen, wurde ein arterieller Zugang über die Femoralartrie gelegt.

Die Köpfe der Tiere wurden mit einem Band fixiert, bevor man unter sterilen Bedingungen eine kleine Inzision über der Sutura coronalis durchführte.

Nun erfolgte, mit einem 3,97 mm Bohrer, die Schädeltrepanation. Dies geschah mit Hilfe eines Codman Microsensor ICP-Monitors $0,7 \mathrm{~cm}$ rechts paramedian und 1,7 cm vor der Coronarnaht (siehe Abb. 14).

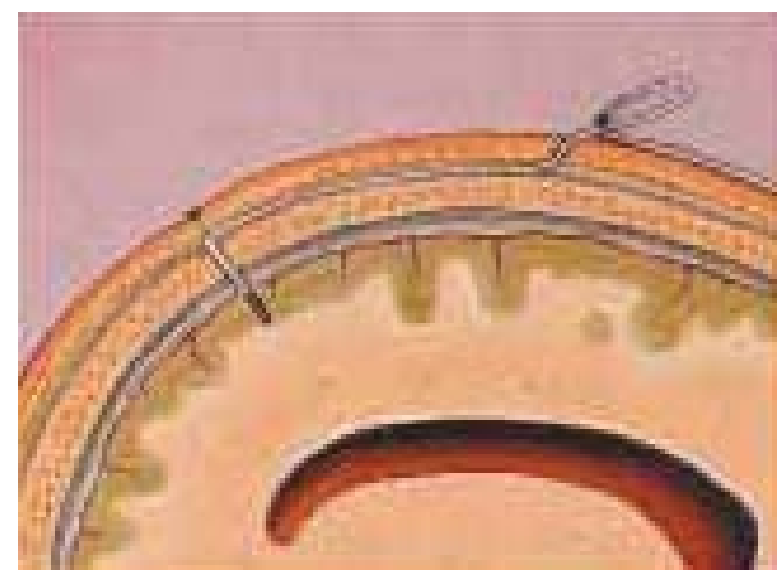

Abb.14 Codeman ICP-monitoring system (Quick set-up-guide S.7)

So wurde die Blutung im Frontallappen induziert. Dadurch bestand die geringste Gefahr für neurologische Defizite. Dort wurde die Spitze eines 6-French EMB80 Fogarty Ballonkatheters der Firma Edwards Lifesciences $1 \mathrm{~cm}$ tief in den rechten Frontallappen eingeführt und mehrmals für jeweils zwei Sekunden dilatiert. In die so vorgefertigte Höhle konnte nun ein 1,2 cm großer Katheter, der mit einem Rickham Reservoir (Fa Codman) in Verbindung stand, eingelegt werden (siehe Abb. 15). 


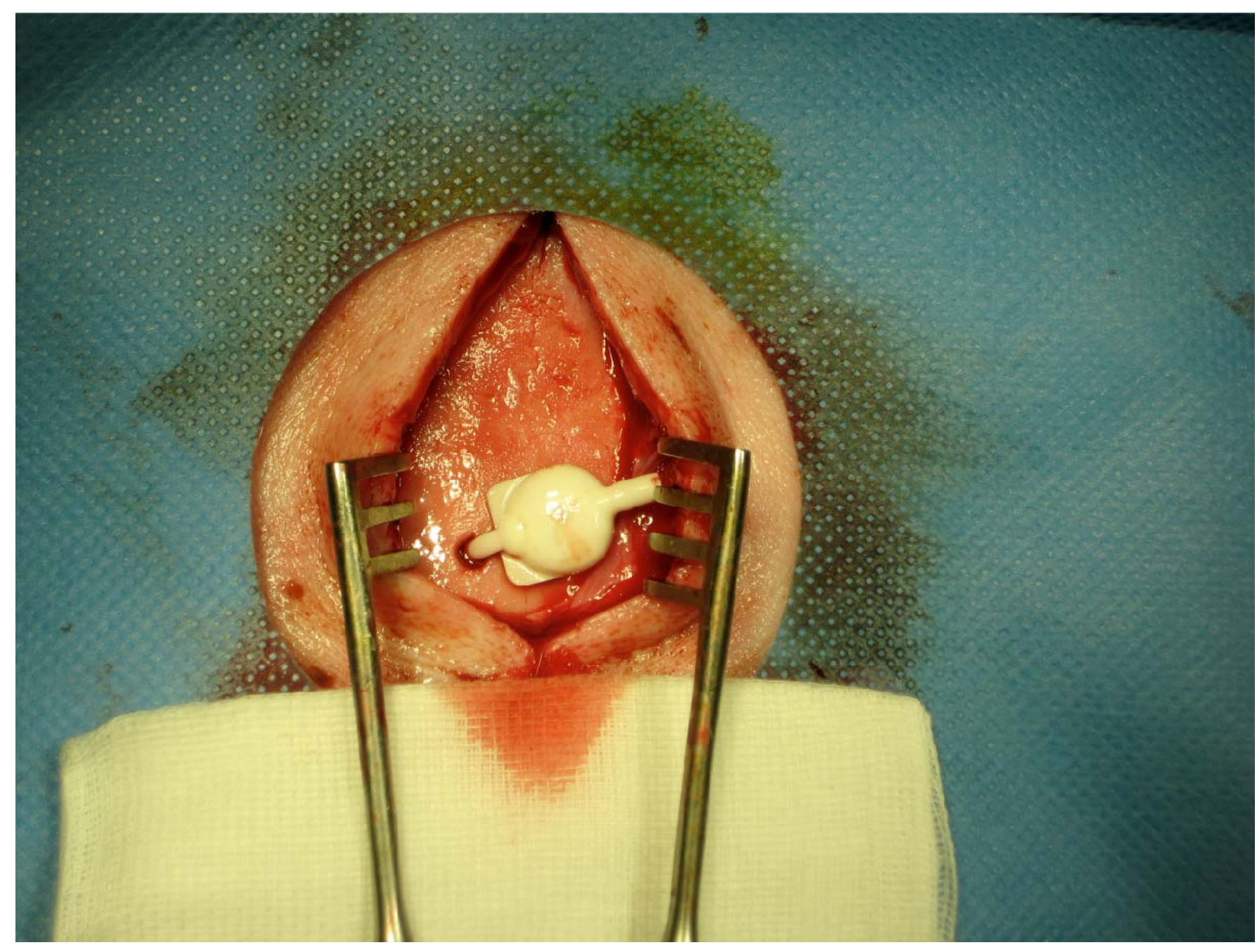

Abb.15 Rickham Kapsel in situ (Fotographie von Gerrit Maier)

In diesen Katheter mit Reservoir wurde langsam autologes arterielles Blut injiziert.

Dazu wurde die Doppelte-Injektionsmethode angewandt (Deinsberger et al. 1996):

Zuerst wurden ca. $2 \mathrm{ml}$ Blut appliziert und nach einer einminütigen Pause, in der die

Gerinnung gewährleistet werden sollte, gab man weitere $5 \mathrm{ml}$ Blut dazu.

So wurde ein eventueller Blutreflux über den Katheter in den Subduralraum

verhindert. Das applizierte Blutvolumen hing vom Anstieg des gemessenen

intracerebralen Drucks ab. Das so erschaffene Hämatom musste jedoch eine Mindestgröße von $1 \mathrm{ml}$ haben.

Die Schweine wurden, unter Propofolsedierung und manueller Beatmung mit Raumluft, in das MR-Gerät gelegt. 
Nach dieser Messung wurden die Tiere in 3 Gruppen eingeteilt. (Lyse, Lyse+PAI, Kontrollgruppe).

Als rekombinanter Gewebe Plasminogen-Aktivator wurde Alteplase (Actilyse $®$

Boehringer Ingelheim GmbH, Biberach/Deutschland) verwendet.

Die Dosierung wurde individuell anhand des, mittels der T2*-Sequenz berechneten

Blutungsvolumens, angepasst. Sie entsprach der Blutungsgröße in mm, multipliziert mit 0,1 mg Actilyse.

Als Nebenwirkungen sind bei Alteplase unter anderem Hypotension, Fieber, Übelkeit und Blutungen berichtet worden. Außerdem können cerebrale Ödeme, cerebrale Herniationen und Krampfanfälle auftreten (Alteplase, Medikamentenbeipackzettel). Da zwei der Schweine Komplikationen in Form von Krampfanfällen erlitten, mussten sie gemäß den Tierschutzregeln vorzeitig aus der Studie ausgeschlossen werden. Nach 15 Minuten Einwirkzeit wurde das Reservoir wieder punktiert um das lysierte Hämatom zu aspirieren - die sogenannte stereotaktische Fibrinolyse.

Bestandteile der stereotaktischen Instrumente sind eine helikale Schraube, die sich, da sie mit einem Motor verbunden ist, mit 200 Umdrehungen / min in den Blutthrombus hineindrehen kann. Des Weiteren gehört ein röhrenförmiger Absauger, der zugleich sowohl den Vakuumdruck an der Messsonde reguliert als auch die Schraube spült, zu dem Instrumentarium.

Da die schnelle Thrombosierung in der akuten Hämatomphase die stereotaktische Aspiration erschwert, wurde bisher in mehreren experimentellen Tier- (Rohde et al. 2002 b; Thiex et al. 2003; Thiex et al. 2004 a) und einer Patientenstudie (Rohde et al. 1995) der lytische Wirkstoff rt-PA hinzugefügt - ebenso wie in der vorliegenden Arbeit.

Das Procedere der 6 PAI-Tiere verlief bis zur Hämatomaspiration identisch. Doch anschließend wurde der Plasminogenaktivator-Inhibitor-1 der Firma Oxford Biomedical Research in Kochsalzlösung mit der Konzentration 1,1 mg/ml aufgelöst und in das Reservoir injiziert.

Bei allen Schweinen wurde der Katheter nach Injektion und Aspiration in loco belassen und die Wunde verschlossen.

Die Rickham Kapsel wurde bei den Schweinen in der präformierten Höhle belassen, die ICP-Sonde konnte jedoch entfernt und die Haut mittels Hautnaht und Sprühpflaster (Nobecutan-Spray, Fa Astra Chemicals $\mathrm{GmbH}$, Wedel) verschlossen werden. 
Nach der letzten von 3 MRT-Untersuchungen wurden die Schweine in den Operationssaal zurückgebracht und in eine Ketamin, Pentobarbital, Propofol und Isoflurane Narkose versetzt. Nach der veterinärmedizinischen Tötung der Tiere wurden noch weitere, über die vorliegende Arbeit hinausgehende neuropathologische Untersuchungen durchgeführt.

\subsection{Datenauswertung}

Die MRT-Bilder wurden bei allen Tieren während der ersten Stunde post operationem mit einem 3,0 T. Tomographen erzeugt (Magnetom Trio, Siemens Medical Solutions, Erlangen/Germany). Dabei wurde eine standard zirkulär polarisierte (CP) „bird-cage“-Kopfspule verwendet. Die normalerweise verwendete 8Kanal-Spule ist nach oben geschlossen und hätte dadurch eine adequate Lagerung sowie die Ausführung des Beatmungsschlauches nach oben erschwert oder unmöglich gemacht.

Es wurden nun folgende Sequenzen durchgeführt:

1. T1-gewichteter isotroper 3D-Datensatz (Schichten: 176 TR: 1950 ms, TE: 2,99 ms, Akquisitionen: 1 Schichtdicke: $1 \mathrm{~mm}$, FOV: 256, Flip-Winkel:9², IR: 1100 $\mathrm{ms})$

2. T2w-TSE (TR: 5500 ms, TE:96 ms, FOV: 256, TSE-Faktor: 21, Akquisitionen: 3, Schichtdicke: $4 \mathrm{~mm}$ )

3. PDw-TSE (Schichten: 24 TR: 5500 ms, TE: 16 ms, FOV: 256, TSE-Faktor: 21)

4. FLAIR-TSE (Schichten: 19, TR: $10430 \mathrm{~ms}$, TE:125 ms, TI:2500, FOV: 280, Akquisitionen:3, Schichtdicke: $4 \mathrm{~mm}$, TSE-Faktor: 27, Flip-Winkel: 60)

5. T2*-GE(Schichten: 24,TR:500 ms, TE:11 ms, FOV: 256, Flip-Winkel:15, Akquisition: 2, Schichtdicke: $4 \mathrm{~mm}$, Flip-Winkel: 10)

6. DWI-EPI (Schichten: 19, TR: 3100 ms, TE: 97 ms, FOV: 230, b-Werte: 0, 500, 1000, 1550, Akquisition:3, Schichtdicke: 4 mm, EPI-Faktor: 128)

Der ADC-Karte wurde, unter Berücksichtigung der Stejskal-Tanner-Gleichung (Stejskal et Tanner 1965), auf der herstellereignen Workstation (Leonardo®, Siemens Medical Solutions, Erlangen, Germany) unter Verwendung einer Standardsoftware erstellt (Syngo, Siemens Medical Solutions, Erlangen/Germany). Nach der jeweiligen Behandlung wiederhohlte man die 2.- und 3.-MRT-Untersuchung jeweils am 3. oder 4. Tag und am 10. oder 11. Tag post operationem. Außerdem wurden Hämatomsignalintensitäten dokumentiert. 
Zur Datenauswertung benutze man eine Leonardo®-Workstation (Siemens Erlangen/Deutschland, aktuelle Syngo-Software), wobei die Signalstärke, außer bei der ADC-Karte (hier in $\times 10^{-5} \mathrm{~mm}^{2} / \mathrm{s}$ ), in institutional units (IU) angegeben wurde: qualitativ wurde die Schicht mit der besten Detektierbarkeit des Hämatoms bestimmt und der interessierende Bereich, eine sog. „region of interest“ (ROI), im Hämatom festgelegt. In Bezug auf die DWI, wurde die ROI, welche in der T2*-Wichtung bereits festgelegt worden war, in die korrespondierende Schicht kopiert. Doch um optimale Ergebnisse, ohne Einfluss von Artefakten (dickere Schädelkalotte der Schweine als beim Menschen, an Menschen angepasste Sequenzparameter) zu bekommen, wurden die ROls in dieser Sequenz individuell der Blutung angepasst.

Das Ergebnis der ROI-Analyse wurde in digitalisierter Form in eine Datenbank übertragen und ein, für jede Sequenz individueller Vergleichswert wurde in der kontralateralen Hemisphäre festgelegt. So konnte die Blutung in der Auswertung als hyperintens, isointens oder hypointens beschrieben und bewertet werden.

Die statistische Analyse erfolgte anhand des students-t-test: Hierbei dient der Mittelwert als Parameter, mit dessen Hilfe ein Vergleich zwischen 2 Stichproben erfolgt. In der vorliegenden Arbeit wurde eine Signifikanz ab einem $p$-Wert von $<0,05$ festgelegt.

Zwar wird im Text auf die signifikanten Werte zwischen den Gruppen eingegangen, jedoch liegt der primäre Fokus der Arbeit auf der Analyse des Bildeindrucks der Hämatome. 
3. Ergebnisse

3.1 Qualitative Analyse

3.1.1 T1-Messung

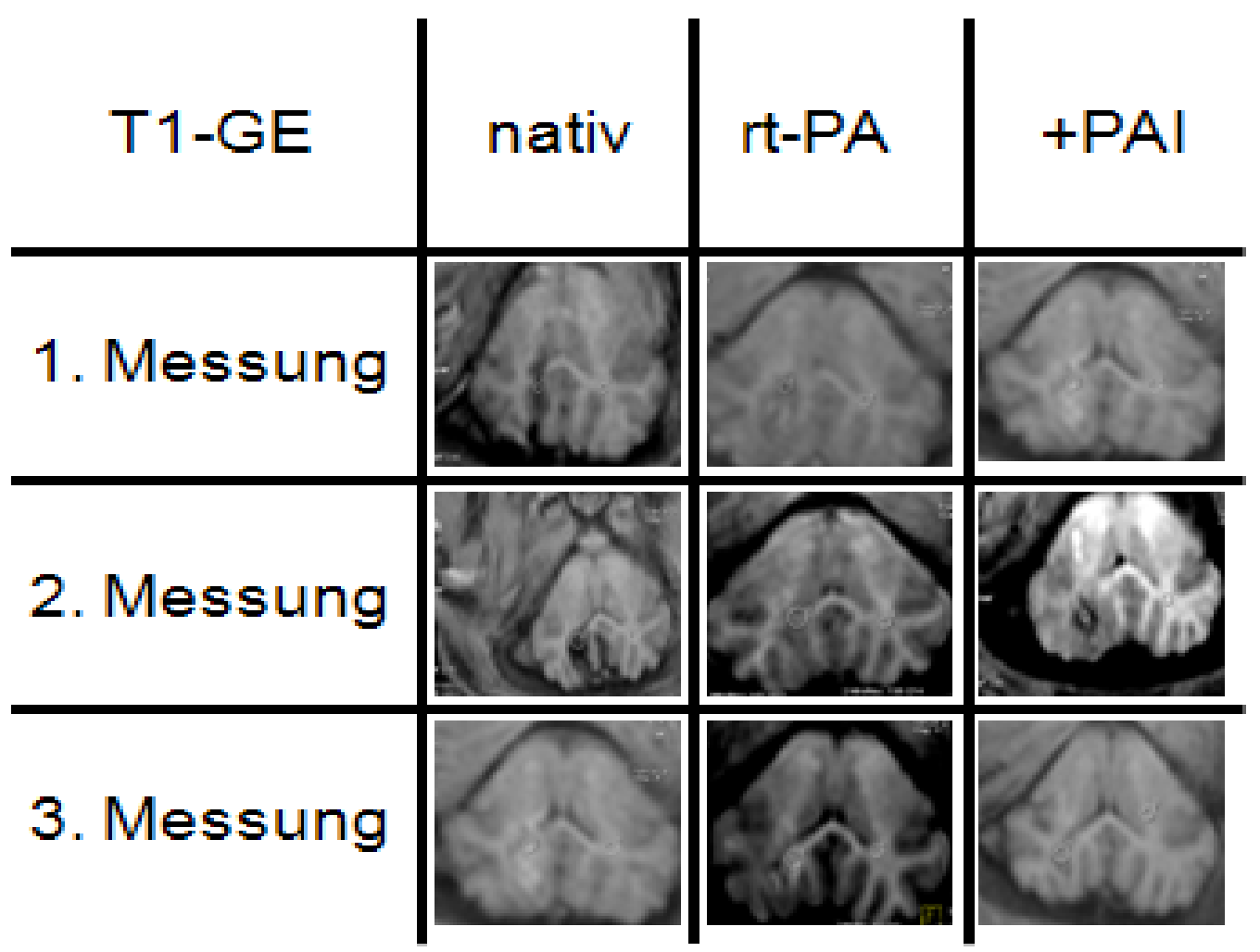

Abb.16

Kontrollgruppe:

Die Hämatome der therapielosen Blutungen, entwickelten sich im Verlauf aller Messungen, wie erwartet, zunehmend von hypointens zu hyperintens.

Lysierte Hämatome:

- 1. Messung: Jedes der lysierten Hämatomen war hypointens.

- 2. Messung: Eine Blutung erschien bereits hyperintens, alle anderen blieben hypointens.

- 3. Messung: Nun waren 2 dieser 5 hypointensen Hämatome zeitgerecht hyperintens. Die restlichen 3 Hämatome wurden zwar ebenfalls zunehmend hyperintenser, jedoch blieben sie, im Vergleich zur kontralateralen Seite, hypointens. 


\section{PAI-behandelte Hämatome:}

- 1. Messung: Alle Hämatome zeigten sich hypointens.

- 2. Messung: Ein Hämatom war hyperintens, die restlichen blieben auch hier hypointens.

- 3. Messung: Hier zeigte sich eine Blutung, zeitgerecht entwickelt, hyperintens. Die anderen 4 Hämatome blieben zwar insgesamt hypointens, zeigten aber zum einen zunehmend Inhomogenitäten aus Hyper- und Hypointensitäten, zum anderen entwickelte sich ein deutlich hyperintenser Randsaum um die Blutung herum.

\subsubsection{T2-Messungen}

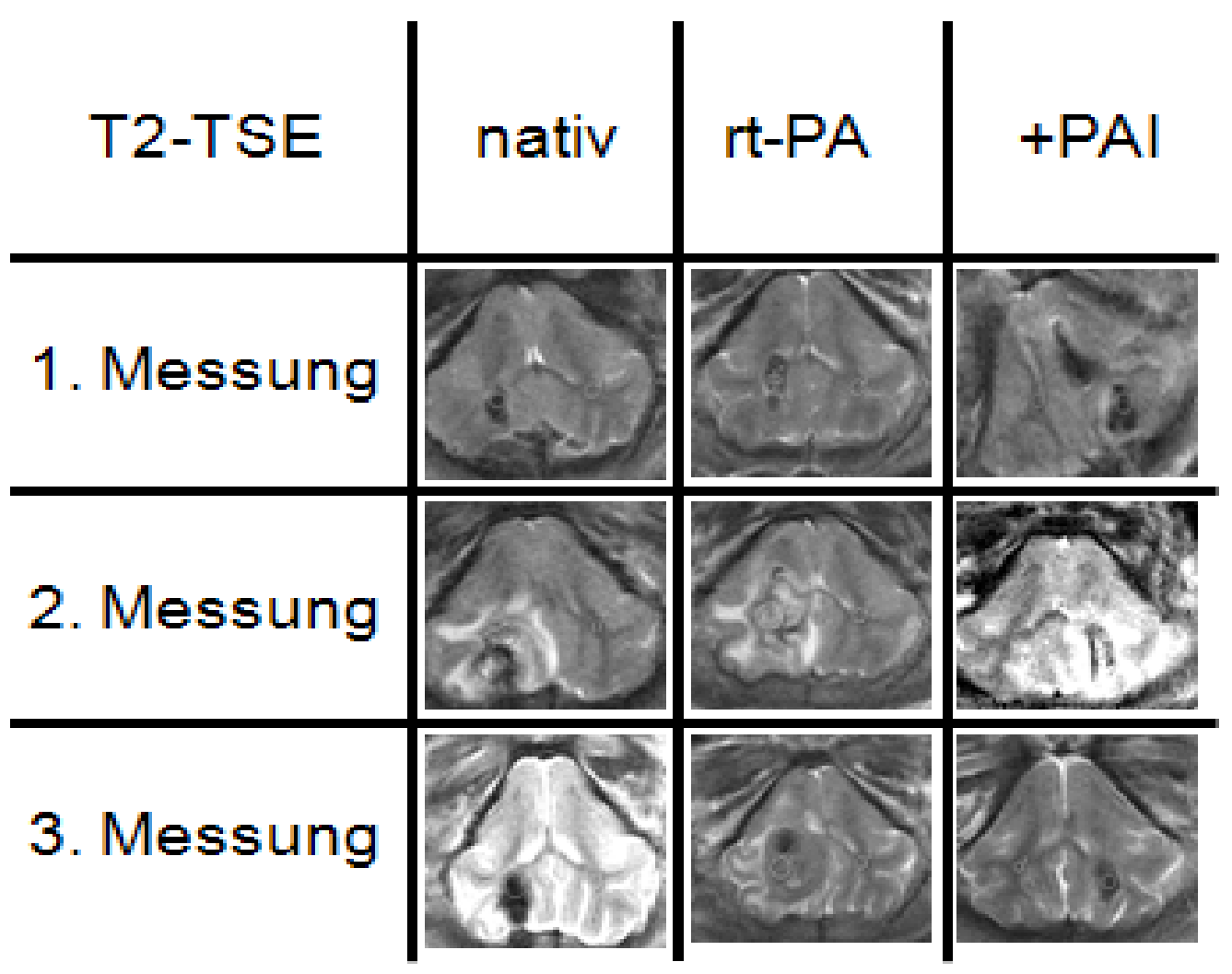

Abb.17

Kontrollgruppe:

- 1. Messung: 5 Hämatome waren hypointens. Eine Blutung blieb zu allen Messzeitpunkten hyperintens. 
- 2. Messung: Nun stellte sich noch eine weitere Blutung hyperintens dar. Die restlichen Blutungen blieben hypointens. In dieser Messung erschienen die Hämatome am größten und es war jeweils ein hyperintenser Randsaum um die Blutung zu sehen.

- 3. Messung: Die Blutung, die in der 2.Messung hyperintens geworden war, stellte sich jetzt wieder hypointens dar. Die übrigen Hämatome blieben unverändert. Jedoch war zu diesem Zeitpunkt die stärkste Signalintensität zu verzeichnen.

Lysierte Hämatome:

- 1. Messung: Alle Blutungen erschienen hypointens.

- 2. Messung: Vier Hämatome waren bereits hyperintens. Dies ist eigentlich erst zur spät subakuten Phase zu erwarten.

- 3. Messung: Von diesen 4 Hämatomen waren 3 wieder hypointens mit einem Doppelring aus Hypo - und Hyperintensität. Dies erwartet man in der T2-Wichtung während der frühen subakuten Phase eines Hämatoms. Die restlichen Hämatome dieser Gruppe waren nun alle, zeitgerecht, im spätsubakuten Stadium. Sie stellten sich also hyperintens mit hypointensem Randsaum dar.

\section{$\underline{\text { PAl-behandelte Hämatome: }}$}

- 1. Messung: Alle Hämatome waren hypointens.

- 2. Messung: Ein Hämatom zeigte sich in seinem zeitgerechten Abbaustadium. Die restlichen Hämatome schienen dem Abbau hinterher zu sein.

- 3. Messung: 3 der vorher hyperintensen Hämatome waren nun wieder hypointens. Ein weiteres Hämatome wurde hyperintens. Und das Hämatom mit dem Randsaum blieb über den gesamten Messzeitraum überwiegend hypointens. 


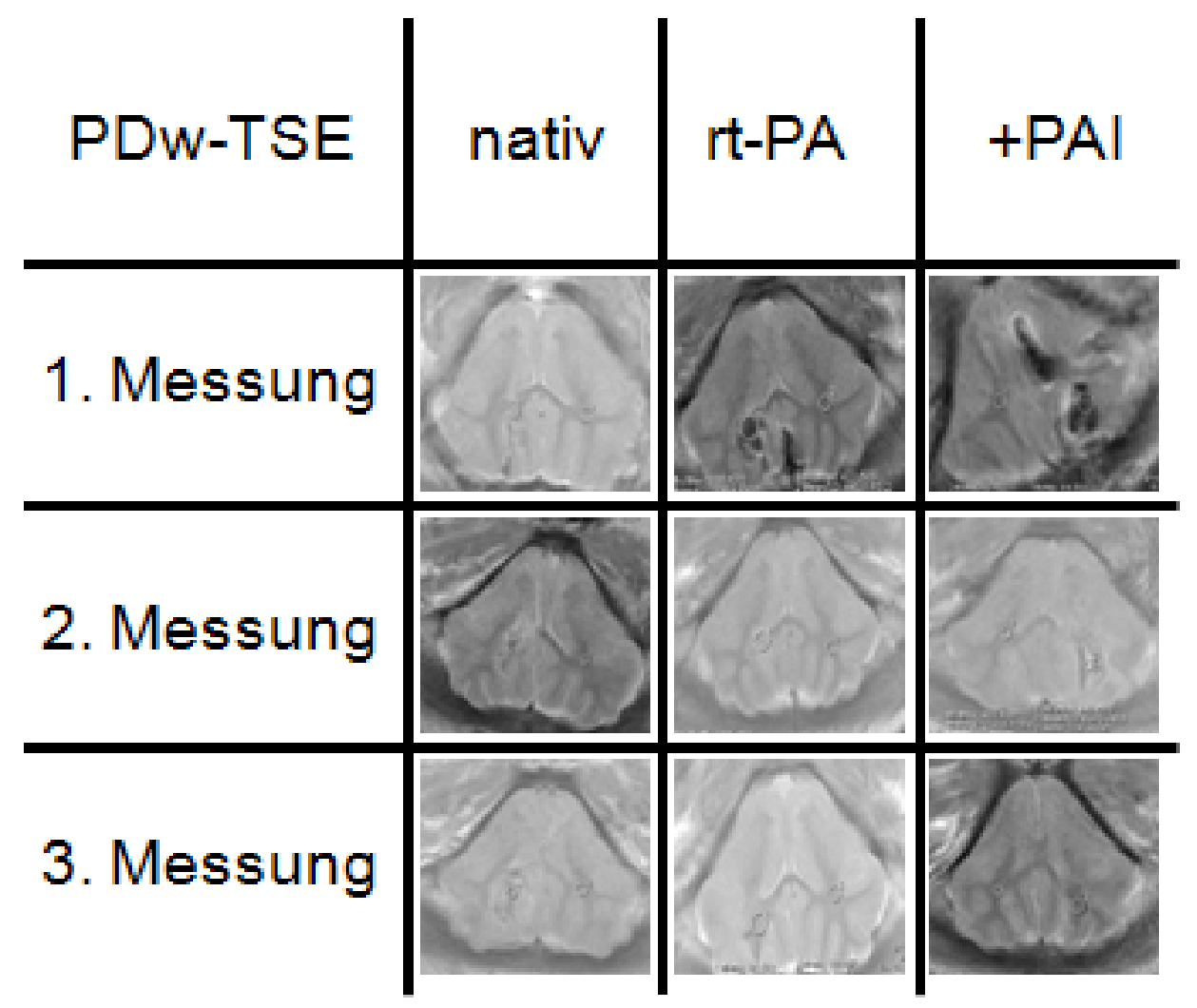

Abb.18

Kontrollgruppe:

- 1. Messung: Hier zeigten sich 5 von 6 Blutungen hypointens.

- 2. Messung: Zwei der vorher 5 hypointensen Blutungen stellten sich nun hyperintens dar.

- 3. Messung: Jetzt waren wieder alle Hämatome, die sich schon zu Messung 1 hypointens zeigten, hypointens. Eine Blutung wurde zwar kontinuierlich dunkler, blieb jedoch im Vergleich immer hyperintens.

\section{Lysegruppe:}

- 1. Messung: 5 Hämatome stellten sich hypointens dar. Eines blieb auch in dieser Behandlungsgruppe zu jedem Messzeitpunkt hyperintens.

- 2. Messung: Nun wurden 3 Hämatome als hyperintens eingestuft.

- 3. Messung: Alle Blutungen waren hyperintens.

PAl-behandelte Hämatome:

- 1. Messung: Auch hier waren 5 Hämatome hypointens und eines hyperintens.

- 2. Messung: Alle Hämatome stellten sich hyperintens dar. 
- 3. Messung: Nun waren 5 hypointens. Und eine Blutung blieb hyperintens.

\subsubsection{T2*-Messungen}

Abb.19

Kontrollgruppe:

- 1. Messung: Alle Blutungen zeigten sich hauptsächlich hypointens mit hyperintensen Einschlüssen und wiesen eine schwere Abgrenzbarkeit zum umgebenden Gewebe auf.

- 2. Messung: 5 von 6 Blutungen blieben hypointens mit hyperintensen Arealen. Ein Hämatom zeigte sich übewiegend hyperintens.

- 3. Messung: Alle Hämatome waren sowohl hypointens, als auch klarer abgrenzbar im Vergleich zur Vormessung.

Lysierte Hämatome:

- 1. Messung: Auch in dieser Behandlungsgruppe waren alle Blutungen zum größten Teil hypointens, besaßen aber hyperintense Einschlüsse.

- 2. Messung: 5 Hämatome waren hypointens. Hier waren jedoch, im Vergleich zur Kontrollgruppe, weniger hyperintense Einschlüsse vorhanden. Und auch hier ließ sich ein Hämatom finden, das sich überwiegend hyperintens darstellte.

- 3. Messung: Alle Hämatome waren hypointens.

PAl-behandelte Hämatome:

- 1. Messung: Hier waren wieder alle Blutungen zum größten Teil hypointens mit hyperintense Einschlüssen.

- 2. Messung: Ebenso wie die 2 vorherigen Gruppen, zeigten sich hier 5 Hämatome hypointens und ein Hämatom war hyperintens

- 3. Messung: Alle Blutungen waren hypointens. 
3.1.5 FLAIR-Messungen

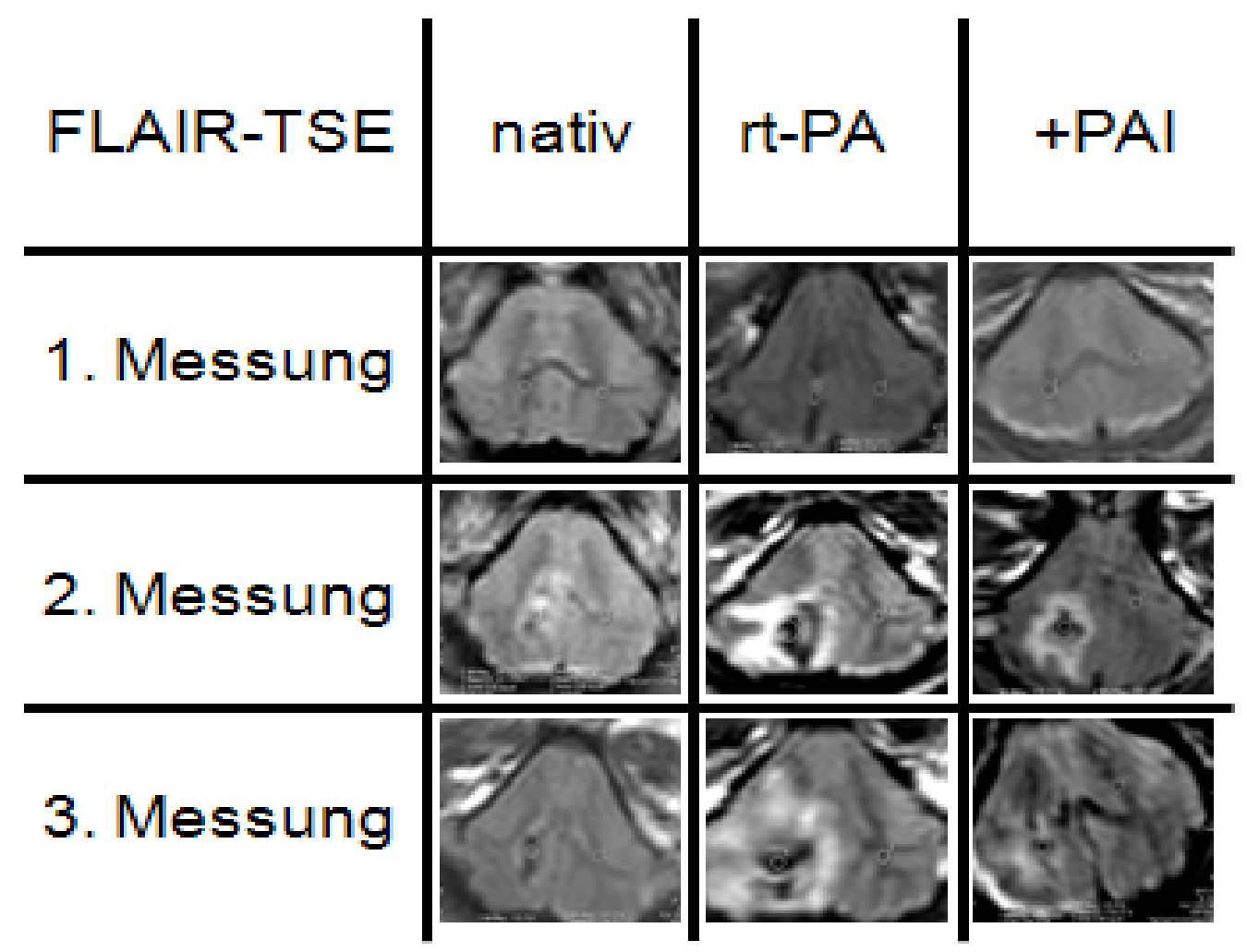


Kontrollgruppe:

- 1. Messung: Alle Hämatome stellten sich hypointens dar.

- 2. Messung: 5 von 6 Blutungen waren hypointens. Jedoch hatte jedes Hämatom einen starken hyperintensen Randsaum. Ein Hämatom war komplett hyperintens.

- 3. Messung: Jetzt zeigten alle Blutungen nur noch einen kleinen hypointensen Restkern, umgeben von einem hyperintensen Randsaum.

Lysierte Hämatome:

- 1.Messung: Alle Hämatome waren hypointens.

- 2. Messung: 2 Blutungen waren komplett hyperintens. Die restlichen 4 Hämatome hatten einen noch auffälligeren hyperintenseren Randsaum als die Kontrollgruppe.

- 3. Messung: Hier hatte der hyperintense Randsaum sowohl im Vergleich zur Vormessung, als auch im Vergleich zur Kontrollgruppe, an Intensität zugenommen. Ein hypointenser Blutungskern blieb aber auch hier.

PAl-behandelte Hämatome:

- 1. Messung: Alle Hämatome stellten sich hypointens dar.

- 2. Messung: Die Hämatome teilten sich in 3 hyperintense Blutungen und 3 hypointensen Blutungen auf. Jede hatte auch hier einen ausgeprägten hyperintensen Randsaum.

- 3. Messung: Alle Hämatome waren wieder hypointens. Der Rand war nicht mehr so betont hyperintens wie zur vorherigen Messung, aber trotzdem deutlicher sichtbar als der Rand der Kontrollgruppe.

\subsubsection{DWI}




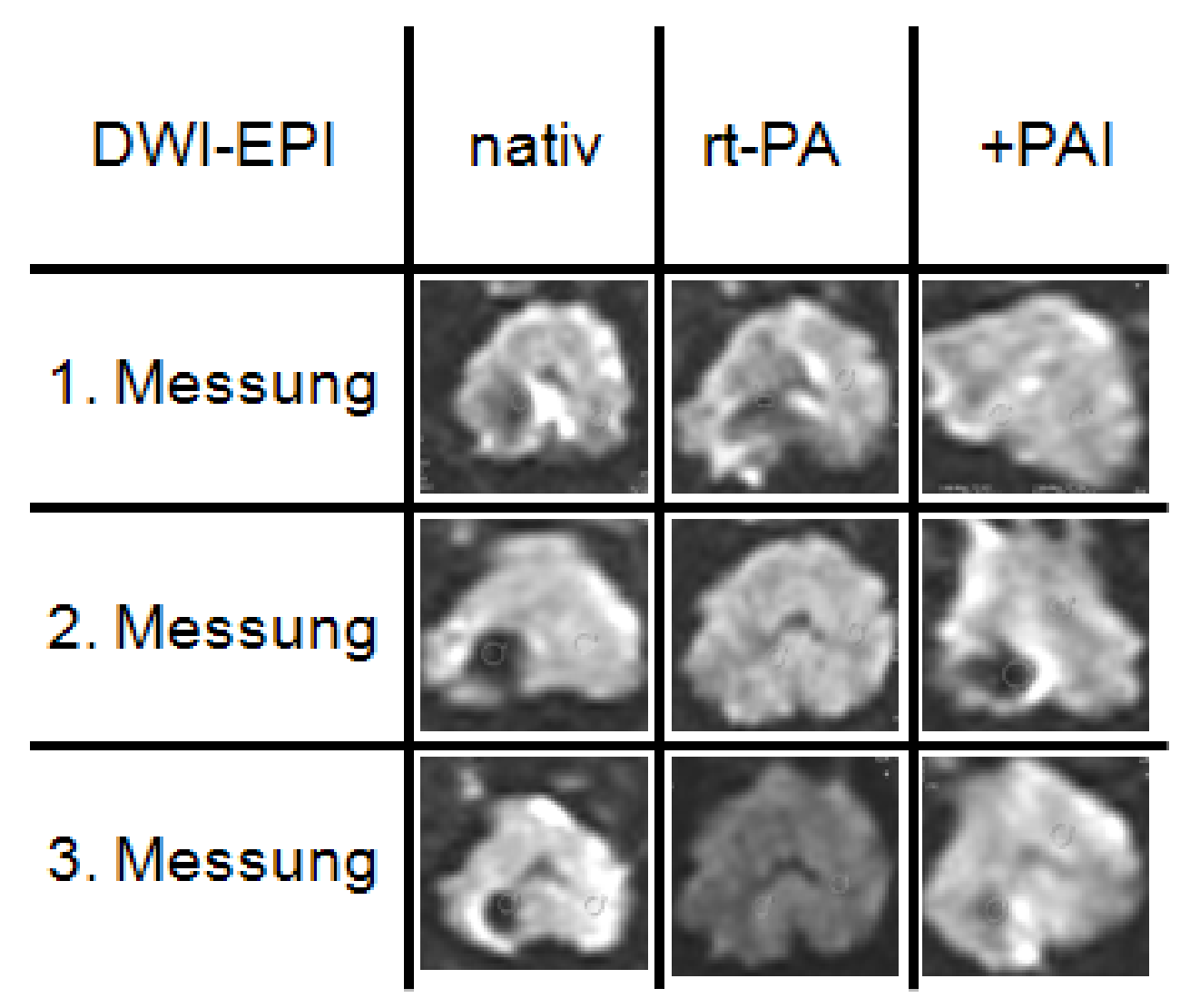

Abb. 21.

Kontrollgruppe:

- 1. Messung: Alle Hämatome zeigten sich hypointens .

- 2. Messung: Auch hier waren alle Hämatome hypointens.

- 3. Messung: Hier waren ebenfalls alle Blutungen hypointens.

Lysierte Hämatome:

- 1. Messung: Alle Blutungen waren hypointens.

- 2. Messung: Ein Hämatom stellte sich hyperintens dar und eines isointens. Die restlichen Blutungen waren in dieser Behandlungsgruppe ebenfalls hypointens.

- 3. Messung: Das Hämatom, welches in der 2. Messung isointens war, stellte sich zu dieser Messung hyperintens dar. Weitere 2 Hämatome wurden hyperintens. Und 2 Blutungen waren hypointens, wovon eins davon ein Hämatom war, welches sich in der 2. Messung hyperintens darstellte.

PAl-behandelte Hämatome:

- 1. Messung: Alle Blutungen waren hypointens. 
- 2. Messung: Die Hälfte der Blutungen war hyperintens, die andere Hälfte hypointens.

- 3. Messung: 2 der vorher hyperintensen waren nun hypointens. Und eins der hypointensen Hämatome wurde hyperintens. So dass hier insgesamt 2 hyperintense und 4 hypointense Blutungen detektiert wurden.

\subsubsection{ADC-Karte}




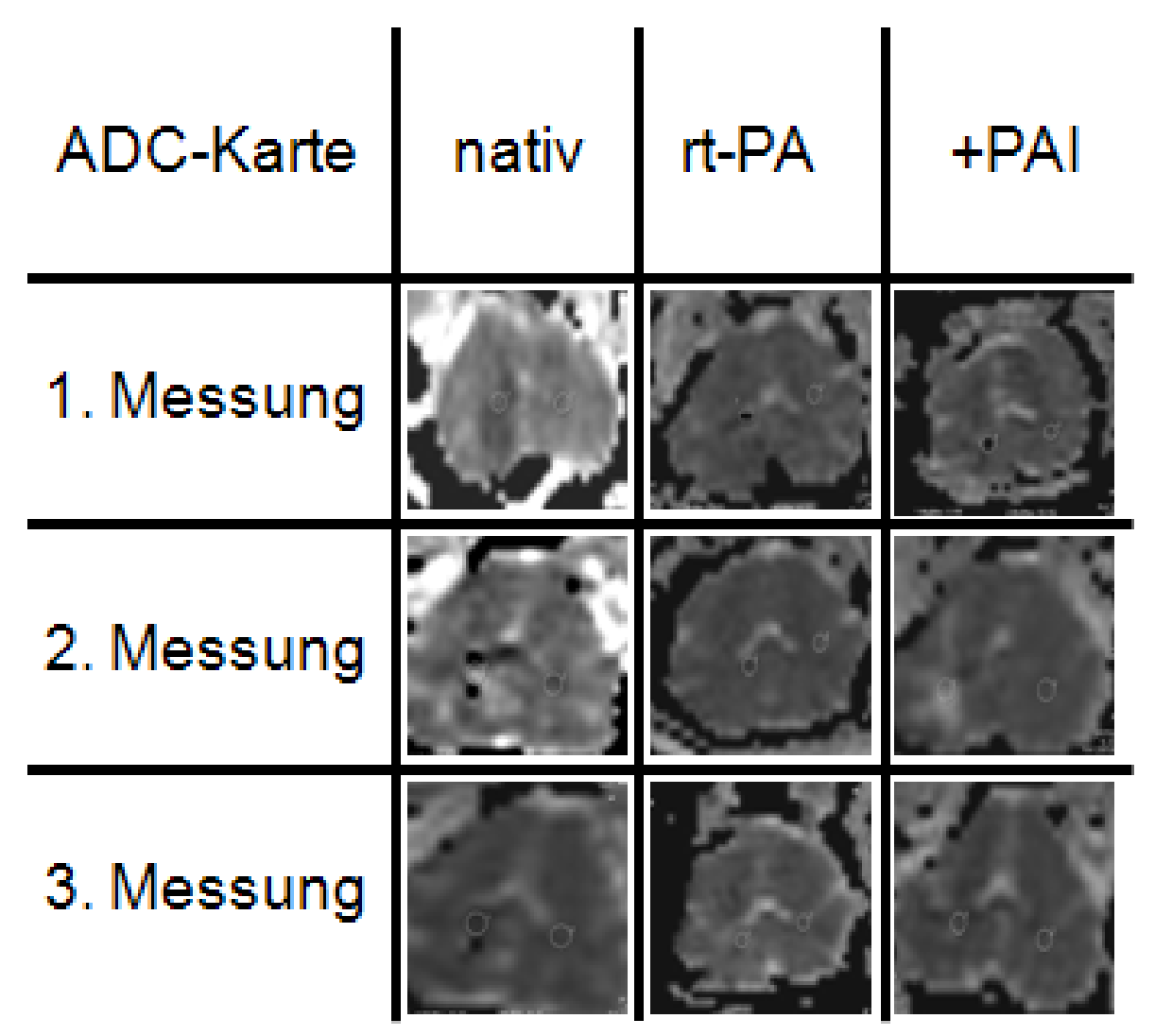

Abb. 22

Kontrollgruppe:

- 1.Messung: eingeschränkte Diffusion.

- 2. Messung: Hier stellte sich bei 4 Blutungen eine erleichterte Diffusion dar. Die beiden übrigen wiesen eine eingeschränkte Diffusivität auf.

- 3. Messung: Nun zeigten sich noch 2 Hämatome mit erleichterter Diffusion. Bei den restlichen war die Diffusion eingeschränkt.

Lysierte Hämatome:

- 1. Messung: Eingeschränkte Diffusivität bei allen Hämatomen.

- 2. Messung: Eine Blutung zeigte eine Diffusionserleichterung. Dies blieb auch bei der 3. Messung so.

- 3. Messung: Und zu diesem Zeitpunkt zeigten 4 weitere Hämatome eine Diffusionserleichterungen. Nur eine Blutung zeigte sich über alle Messungen hinweg eingeschränkt diffusionsfähig. 
- 1. Messung: 2 Hämatome zeigten eine erleichterte Diffusion. Diese blieb auch in allen Folgemessungen unverändert.

- 2. Messung: Nun waren es insgesamt 5 Hämatome mit erleichterter Diffusivität.

- 3. Messung: 2 der 5 Hämatome zeigten nun eine, mit ihrer Umgebung identische Diffusivität. Die 3 restlichen Hämatome blieben erleichtert diffusionsfähig.

\subsection{Quantitative Analyse}

\section{T1:}

In dem direkten Vergleich der Mittelwerte pro Sequenz erwiesen sich für die 1. Messung, ähnliche Ausgangswerte (Tab.2).

Kontrollgruppe: Die Werte stiegen insgesamt am deutlichsten an.

Lysegruppe: Die Werte dieser Blutungen nahmen am wenigsten an Signalintensität zu.

PAl-Gruppe: Die Ergebnisse erreichten in der 2. Messung den relativ höchsten Wert, wiesen aber zum 3. Messzeitpunkt ähnliche Werte wie die Kontrollgruppe auf.

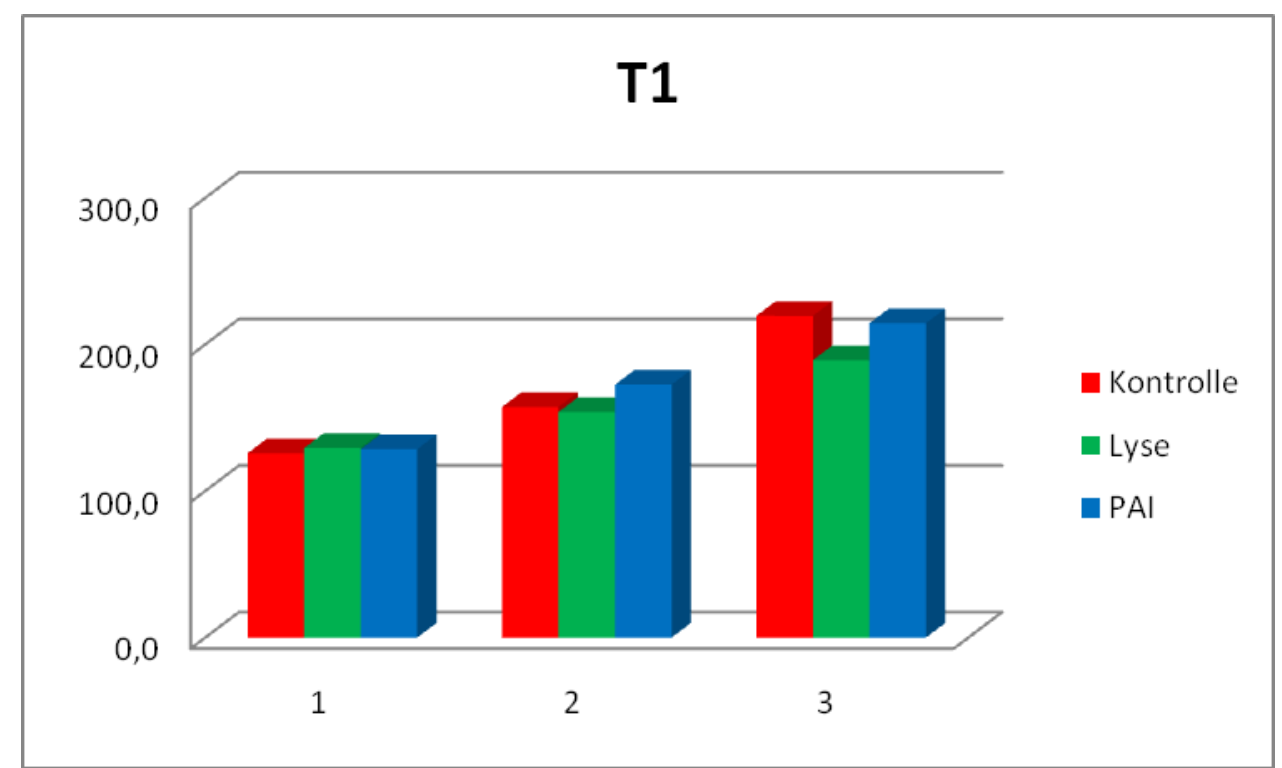

Tab. 2 Die Y-Achse zeigt die unterschiedlichen Messzeitpunkte, die X-Achse zeigt die Signalstärke.

T2:

In der Grafik der T2-Wichtung (Tab.3) erkennt man für die 1. Messung noch die nahezu gleichen Ausgangswerte aller Behandlungsgruppen. 
Kontrollgruppe: Zur 2. Messung zeigten die Hämatome die geringste Zunahme der Signalintensität. Und zur 3. Messung fielen die Werte noch weiter ab. Lysegruppe: Die Werte der Hämatome stiegen zur 2. Messung in ihrer Signalintensität am stärksten an und blieben auch zur 3. Messung insgesamt am stärksten. So kam es sowohl beim 2.- als auch beim 3. Messzeitpunkt zu einem signifikanten Signalunterschied zwischen Kontroll- und der Lysegruppe $(p<0,05)$. PAl-Gruppe: Hier war zur 2. Messung eine ähnliche Signalintensitätssteigerung wie bei der Lysegruppe zu verzeichnen. Zur 3. Messung lagen die Werte schließlich zwischen denen der Kontroll- und denen der Lyse-Gruppe.

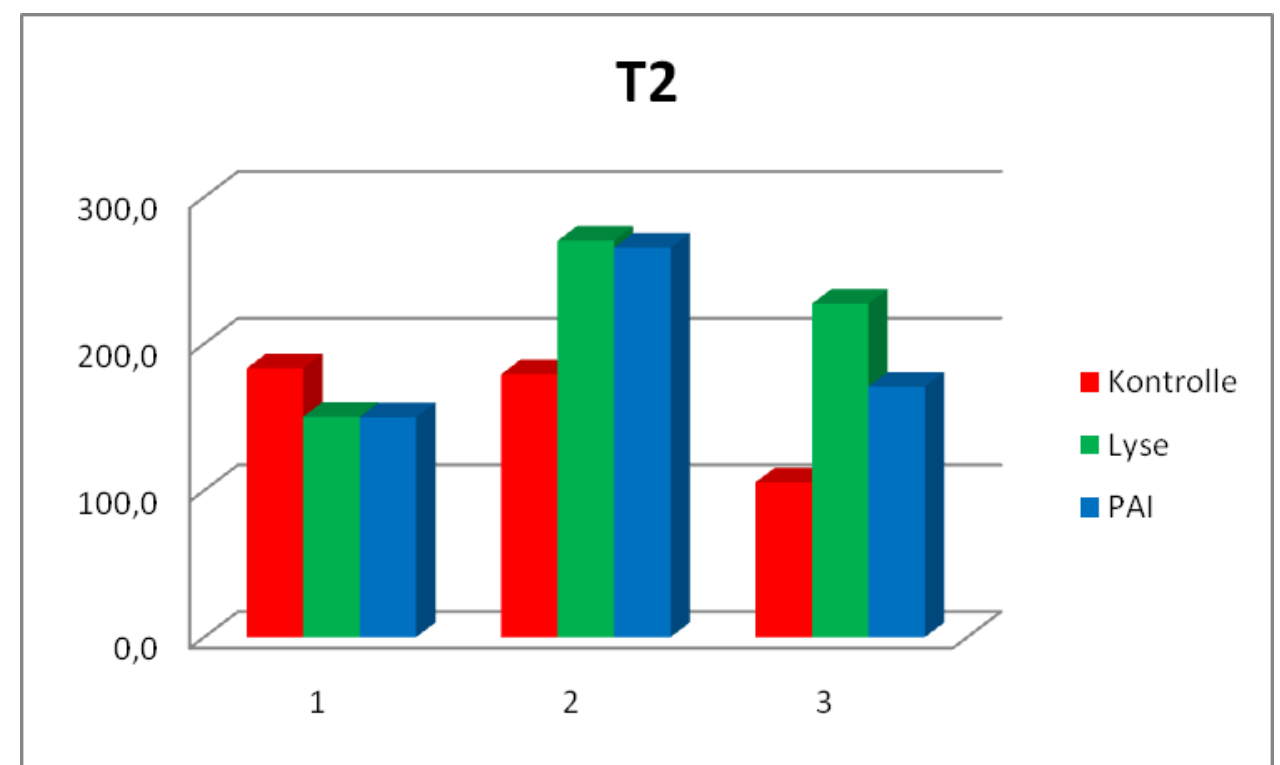

Tab. 3 Die Y-Achse zeigt die unterschiedlichen Messzeitpunkte, die X-Achse zeigt die Signalstärke.

\section{PDw:}

Auch in der Protonendichte-gewichteten Sequenz (Tab.4) sah man anfänglich ähnliche Ausgangswerte aller Behandlungsgruppen.

Kontrollgruppe: In der 2.- und 3. Messung, zeigten die Messergebnisse die niedrigsten Werte im Vergleich zu den anderen Gruppen.

Lysegruppe: Die Werte, die in der 2. Messung noch denen der PAI-Gruppe ähnelten, zeigten zur 3. Messung die höchsten Messergebnisse und zeigten signifikante Werte im Vergleich zur Kontrollgruppe.

PAl-Gruppe: Die Mittelwerte dieser Hämatome zeigten ihren Höchststand zur 2.

Messung. Zur 3. Messung befanden sich die Werte, zwischen den Ergebnissen der Kontroll- und denen der Lysegruppe. 


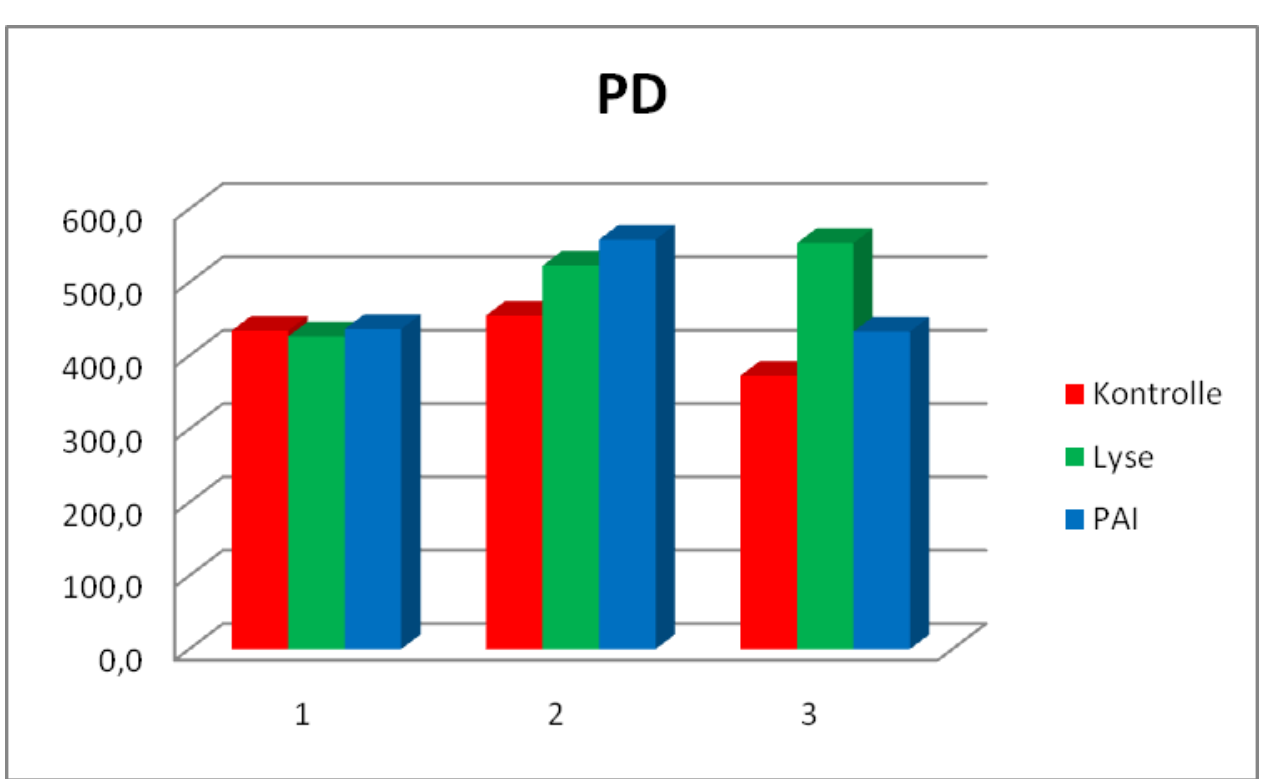

Tab. 4 Die Y-Achse zeigt die unterschiedlichen Messzeitpunkte, die X-Achse zeigt die Signalstärke.

$\underline{T^{*}:}$

In der T2*-Wichtung zeigte die PAI-Gruppe zur 1. Messung leicht höhere Mittelwerte als die beiden anderen Gruppen (Tab.5).

Kontrollgruppe: Ihre Messergebnisse waren zur 2. Messung am höchsten. Und zur 3. Messung war der Mittelwert im Vergleich zur Lysegruppe so niedrig, dass sich ein signifikanter Unterschied errechnete.

Lyse-Gruppe: Lyse- und PAI-Gruppe hatten in der 2. Messung gleiche Mittelwerte. Zur 3. Messung stieg der Mittelwert weiter an.

PAl-Gruppe: Nach dem höchsten Mittelwert zur 2. Messung, fiel er zur 3. Messung so stark ab, dass sich zwischen Lyse- und PAI-Gruppe ein signifikanter Unterschied errechnete. 


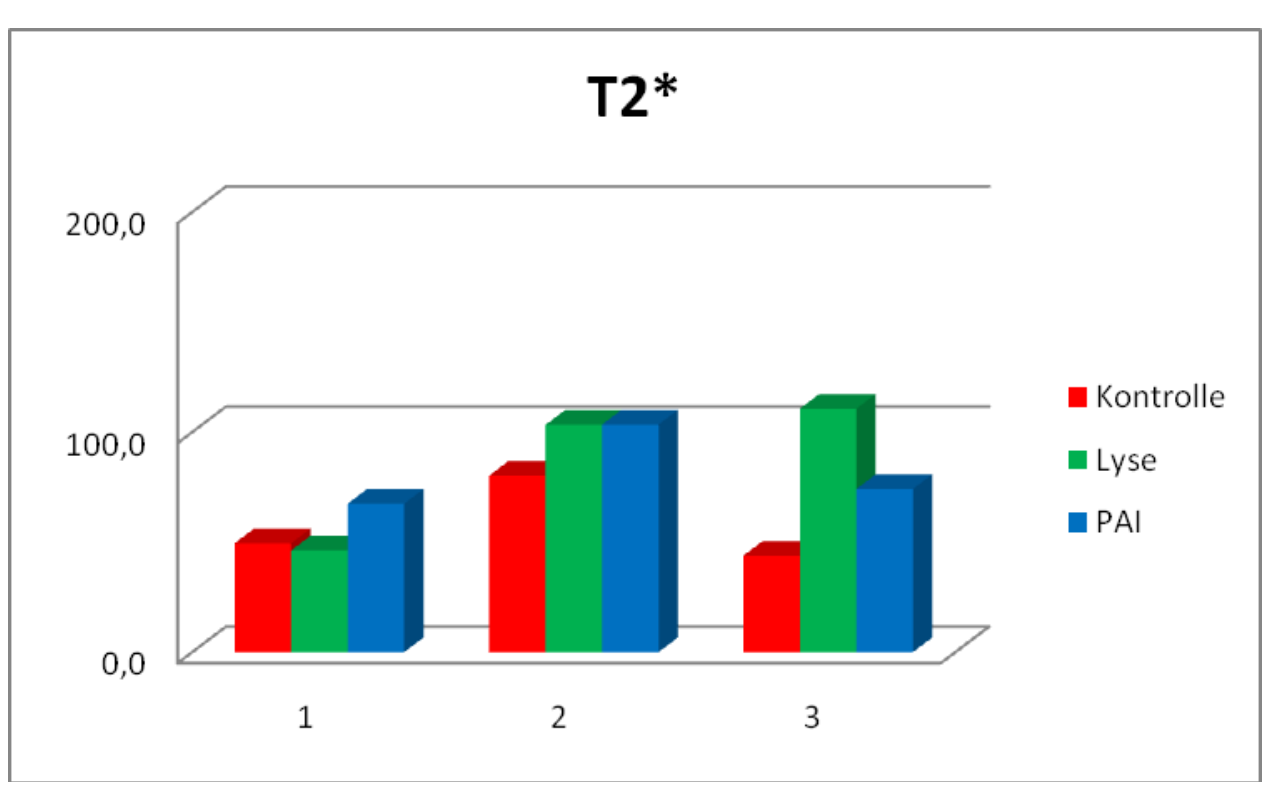

Tab. 5 Die Y-Achse zeigt die unterschiedlichen Messzeitpunkte, die X-Achse zeigt die Signalstärke

\section{FLAIR:}

Auch in der FLAIR-Sequenz kann man die ähnlichen Ausgangswerte aller Gruppen in der 1. Messung erkennen. Doch auch hier werden im weiteren Verlauf die unterschiedlichen Behandlungen sichtbar (Tab.6).

Kontrollgruppe: Die Signalintensität dieser Hämatome nahm in allen Messungen stetig an Hyperintensität ab.

Lyse-Gruppe: Die Mittelwerte stiegen vom niedrigsten Wert auf den jeweils höchsten Wert in der 2.- und 3. Messung an.

PAl-Gruppe: Der Mittelwert, der zur 2. Messung noch dem er Lysegruppe ähnelte, war zur 3. Messung etwa wie der Kontrollgruppenwert.

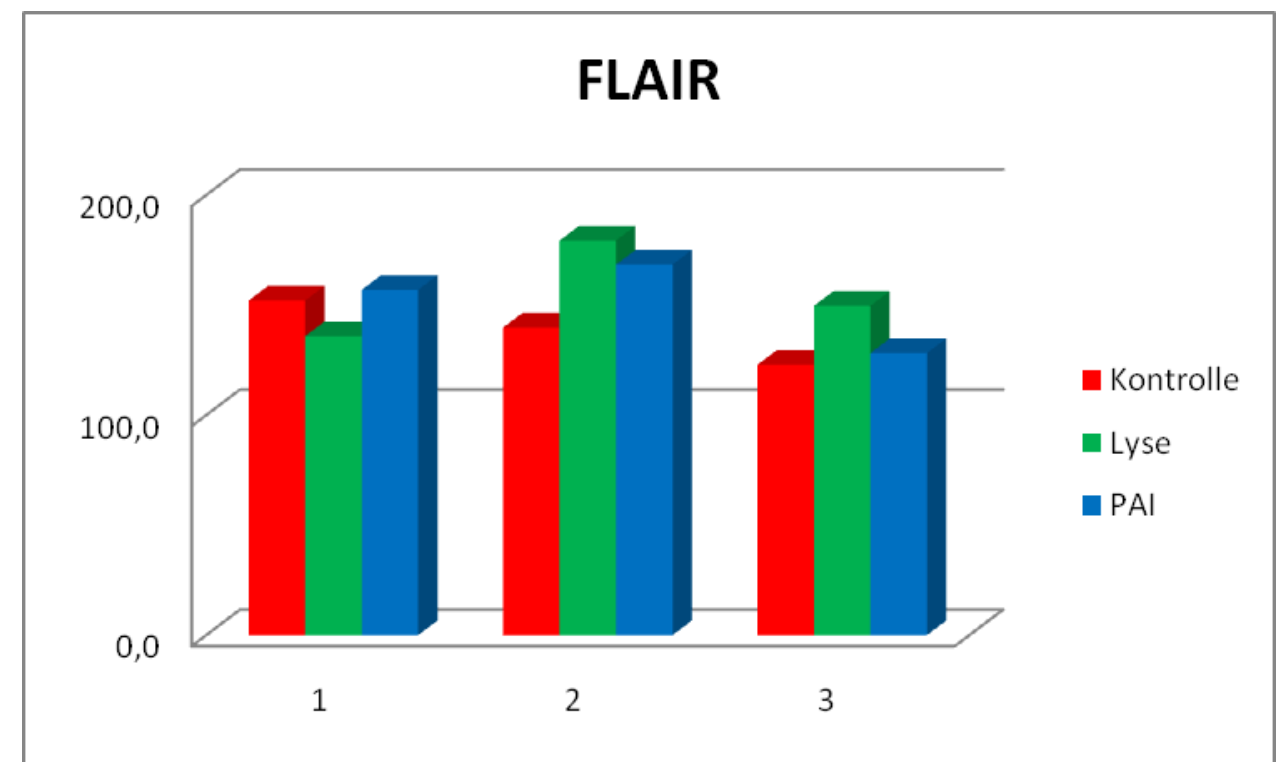

Tab. 6 Die Y-Achse zeigt die unterschiedlichen Messzeitpunkte, die X-Achse zeigt die Signalstärke. 


\section{DWl:}

Bei der DWI war die adäquate Lokalisierung der Blutungen am schwierigsten. Dies bestätigte sich auch durch die schon zu Anfang stark schwankenden Werte.

Kontrollgruppe: Die Mittelwerte fielen nach der 1. Messung ab und hielten sich dann auf einem konstanten Wert.

Lyse-Gruppe: Hier war ein von Messung zu Messung stetig steigender Mittelwert zu verzeichnen.

PAl-Gruppe: Man kann im Vergleich zwischen 2.- und 3. Messung erkennen, dass sich der Mittelwert zur letzten Messung wieder zwischen dem der beiden Gruppen befand.

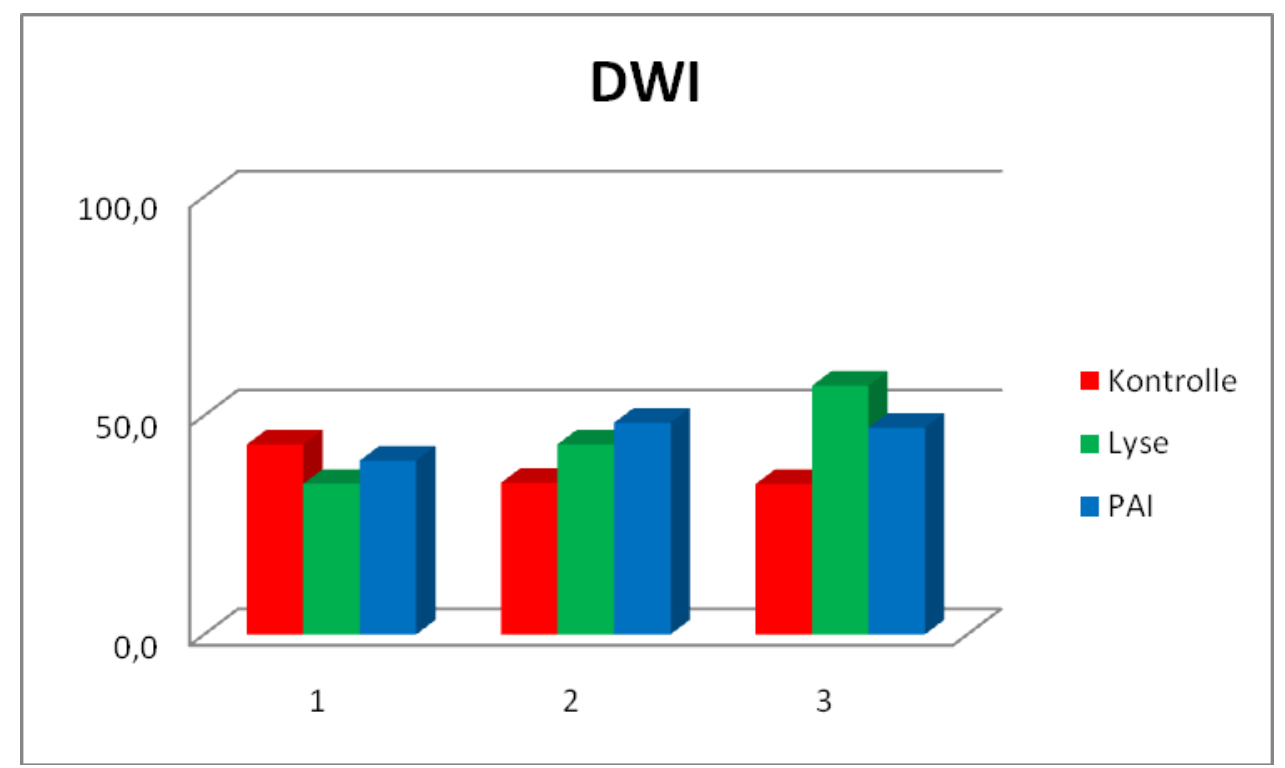

Tab. 7 Die Y-Achse zeigt die unterschiedlichen Messzeitpunkte, die X-Achse zeigt die Signalstärke

\section{ADC:}

Die ADC-Werte zeigten fast gleich hohe Ausgangswerte.

Kontrollgruppe: In der 2. Messung verdeutlichten die Messwerte eine erleichterte Diffusivität der Hämatome. Die zur 3. Messung im Vergleich zu den anderen Gruppen am meisten abfiel.

Lyse-Gruppe: Nach einem nur minimal erleichterten Anstieg der Diffusivität, bestätigten die Werte zur 3. Messung die höchste Diffusivität.

PAl-Gruppe: Durch einen enormen Sprung des Mittelwertes in der 2. Messung kam es zu einem signifikanten Wert zwischen der Lyse- und der PAI-Gruppe. 
Zur 3. Messung fiel der Wert, wie auch schon bei den vorherigen Sequenzen beobachtet, erneut ab, und spiegelte damit die Mittelstellung zwischen den beiden anderen Gruppen wider.

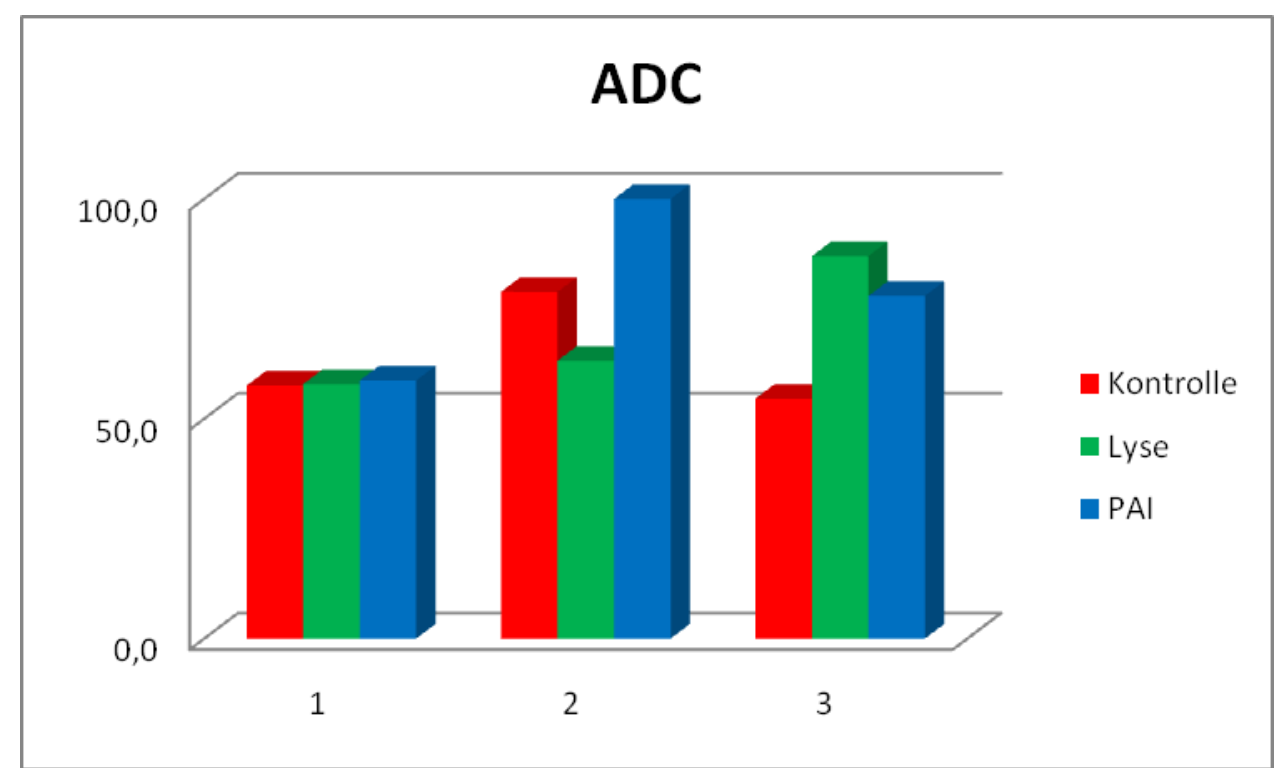

Tab. 8 Die Y-Achse zeigt die unterschiedlichen Messzeitpunkte, die X-Achse zeigt den apparenten Diffusionskoeffezienten $\left(\times 10^{-5} \mathrm{~mm}^{2} / \mathrm{s}\right)$.

Zum Vergleich sind im Folgenden die gemessenen ROI-Werte der, zur Blutung kontralateral gelegenen Seite $(=100 \%)$, graphisch dargestellt:

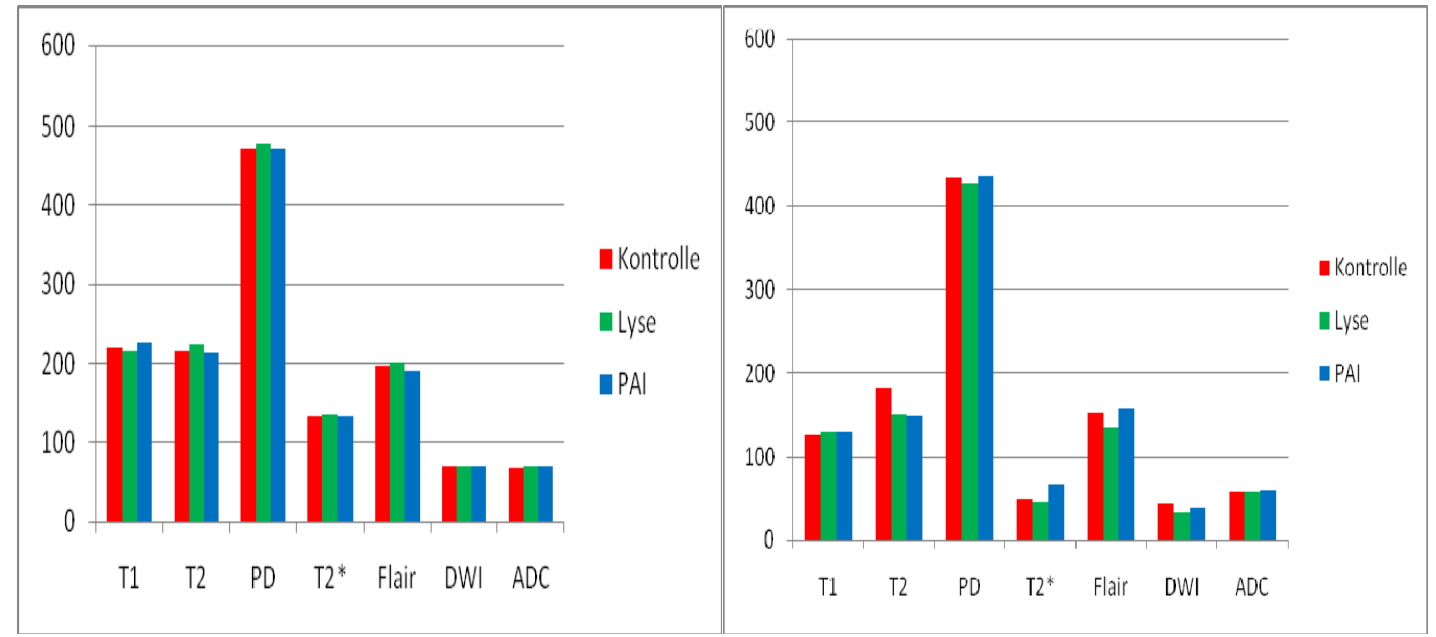

Tab. 9a) Sequenzen der kontralateralen Seite zur 1. Messung

9b) Sequenzen der Hämatome zur 1. Messung 


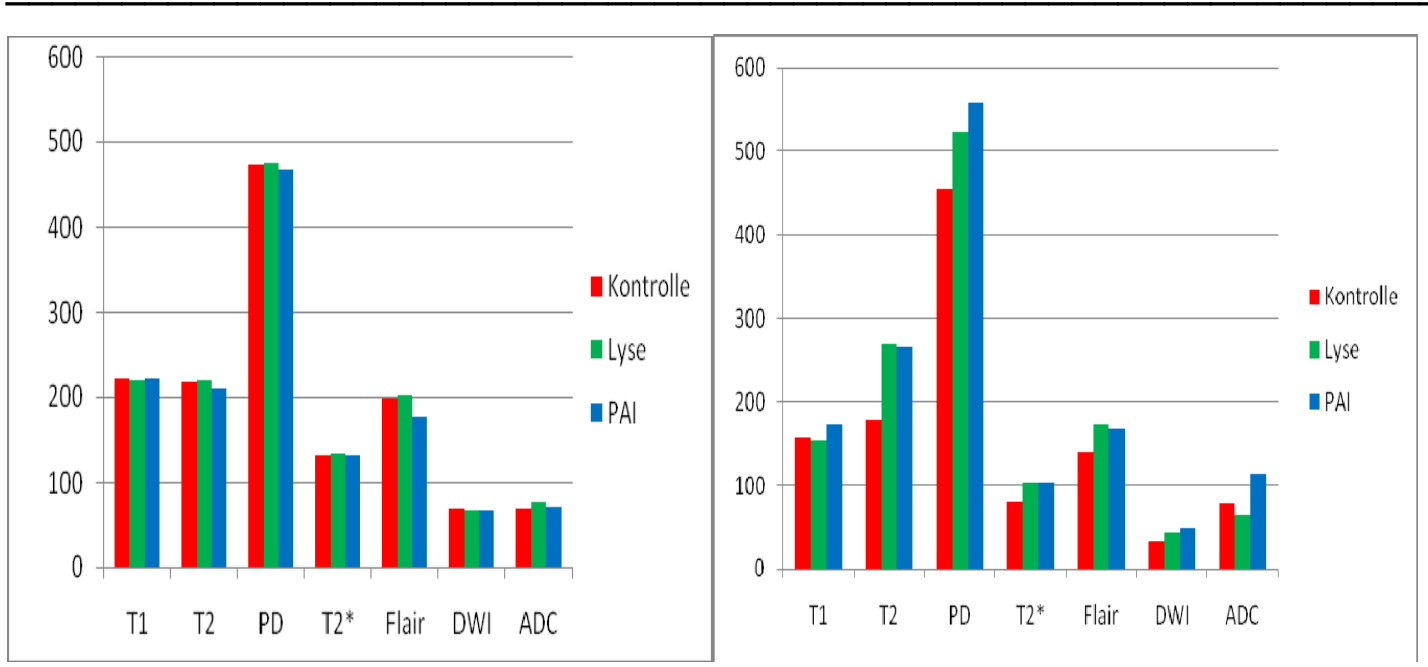

Tab. 10a)Sequenzen der kontralateralen Seite 10b) Sequenzen der Hämatome zur 2. Messung zur 2. Messung

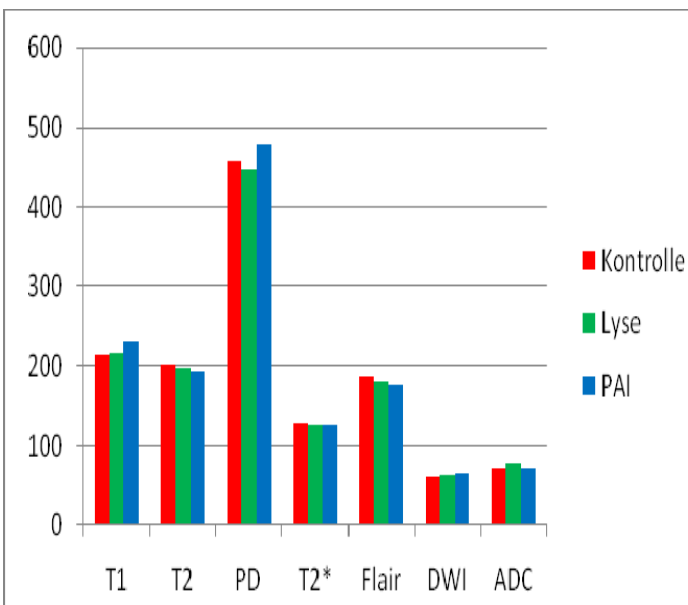

Tab. 11a) Sequenzen der kontralateralen Seite zur 3.Messung

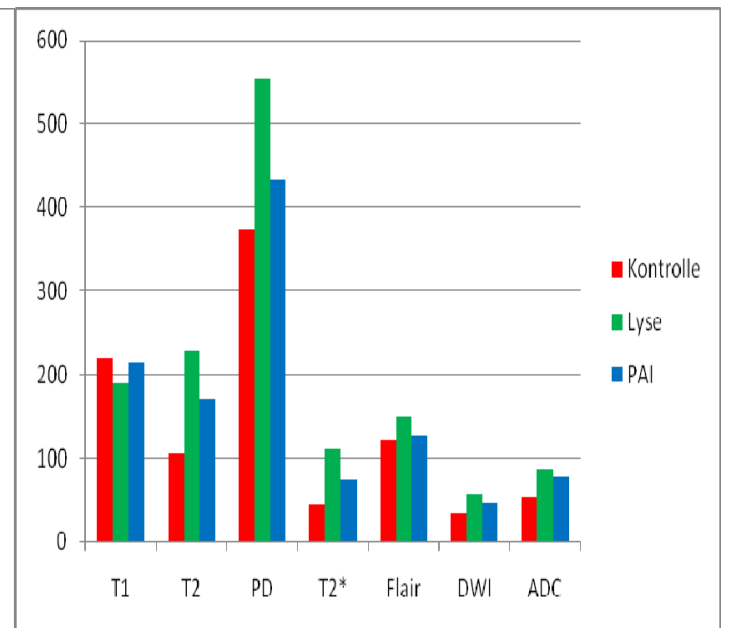

11b) Sequenzen der Hämatome zur 3. Messung 


\section{Diskussion}

Die vorliegende Dissertation beschreibt im Tiermodell das unterschiedliche magnetresonanztomographische Signalverhalten bei experimentellen ICBs im unbehandeltem Zustand im Vergleich zu Hämatomen, welche neurochirurgischinvasiv, mittels Lysekatheter, sowohl ohne, als auch mit zusätzlicher Gabe eines Lyseinhibitors therapiert wurden. Neben wichtiger Informationen für zukünftige experimentelle Studien soll hiermit die Grundlage für die MR-Diagnostik nach Durchführung der oben genannten Therapie geschaffen werden.

Das Kollektiv umfasste insgesamt 18 Schweine, welche in 3 Gruppen (Lyse, Lyse+Inhibitor, Kontrollgruppe mit unbehandeltem Hämatom) à 6 Tiere eingeteilt wurden. Anschließend wurden sie mit jeweils 7 verschiedenen MRT-Sequenzen zu 3 Zeitpunkten über einen Zeitraum von $10 \mathrm{bzw}$. 11 Tagen untersucht.

Signalveränderungen der Hämatome wurden gemessen und relativ zur kontralateralen, gesunden Seite beschrieben.

Die Auswertung erfolgte qualitativ, also visuell sowie quantitativ mittels ROI-Analyse. Die Auswirkung der beiden Therapieverfahren auf das Signalverhalten der Hämatome im zeitlichen Verlauf wurde beschrieben. Die Therapieeffekte wurden sowohl mit der Kontrollgruppe verglichen, als auch mit bislang publizierten Beschreibungen über das Signalverhalten spontaner ICBs.

Da sich in der vorliegenden Studie erwartungsgemäß die Hämatome initial, also unbehandelt , nicht signifikant unterschieden und auch weitgehend mit der Literatur übereinstimmen, wird im weiteren Text auf die Ergebnisse der 2.- und 3.-Messung näher eingegangen.

\subsection{Hämatomevolution in der T1-Wichtung}

Das Signal in der T1-Sequenz zeigte bei den experimentellen Hämatomen eine Entwicklung, wie es auch von spontanen Hämatomen zu erwarten war: Die Blutungen nahmen mit zunehmendem Hämoglobinabbau an Signalintensität zu (Seidenwurm et al. 1989; Bradley 1993).

Jeweils 5 Hämatome, der beiden behandelten Gruppen, verhielten sich in Bezug auf die Signalintensität der Hämatome der Kontrollgruppe konform. Dies könnte für einen 
nur geringen Effekt der Lyse in diesen Fällen sprechen. Da die rt-PA Dosis anhand der Hämatomgröße, gemessen durch T2* ${ }^{*}$, vor Applikation errechnet worden ist, so ist zu überlegen, ob die Abmessung durch diese Sequenz zu ungenau ist.

Alternativ kann diskutiert werden, ob bei diesen Fällen das Hämatom bereits zu fest für eine Lyse war.

Ein grundsätzliches Therapieversagen kann jedoch ausgeschlossen werden, da sich zum 3. Messzeitpunkt die lysierten Hämatome hypointens zeigten. Dies spiegelt den erwarteten Behandlungseffekt wider. Denn eine Organisation des Hämatoms und damit eine signifikante Umwandlung in Methämoglobin konnte MR-tomographisch nicht nachgewiesen werden. Diese Annahme könnte durch die Beobachtung gestützt werden, dass sich die PAI-Gruppe in der 3. Messung ähnlich der Kontrollgruppe verhielt und die Blutungen insgesamt hyperintenser als die rt-PA-Blutungen erschienen, der Lyseeffekt durch den Inhibitor also abgeschwächt wurde. Nach Applikation von rt-PA bzw. rt-PA+PAI, zeigte sich in den beiden Gruppen jeweils eine Signalintensitätssteigerung eines Hämatoms. Hierfür kann ein, durch Actilyse induziertes Artefakt, diskutiert werden. Denn neben Alteplase beinhaltet das Medikament die proteinogene Aminosäure Arginin sowie Phosphat und Polysorbat, wobei insbesondere Phosphat ähnlich der Gadoliniumchelate, zu einer T1Zeitverkürzung und damit zu einer Hyperintensität führt.

Da Polysorbat solubilisierend auf Proteine wirkt, kann durch diesen Zusatzstoff auch vermutet werden, dass, Protone, die aus Blutproteinen (hauptsächlich Hämoglobin) freigesetzt wurden mit der Lyseflüssigkeit interagieren und so zu einer T1Zeitverkürzung führen

\subsection{Hämatomevolution in der T2-Wichtung}

Die Kontrollgruppenhämatome nahmen in der T2-Wichtung stetig an Hypointensität zu. Geht man auf der einen Seite davon aus, dass Deoxygenierungs- und Gerinnungsvorgänge auf Grund von Luft- und Materialkontakt schneller als bei spontanen ICBs ablaufen, so kann man auf der anderen Seite argumentieren, dass die physiologischen Veränderungen einer experimentellen ICB langsamer ablaufen. Ein Grund dafür könnte sein, dass bei den Kontrollblutungen kein Gefäß tatsächlich rupturiert ist, die Blut-Hirn-Schranke somit intakt geblieben war und folglich der Hämatomabbau durch körpereigene Abwehrzellen langsamer verlief. 
Wie sich anhand des statistischen Vergleichs zeigen ließ, waren die Hämatome der beiden Therapiegruppen zur 2. Messung signifikant hyperintenser als die der Kontrollgruppe. Es zeigte sich kein unterschiedliches Signal zwischen Lyse- und PAIGruppe.

Als mögliche Ursache für eine T2-Zeitverlängerung kommt hier, analog zur T1Sequenz, ebenfalls das in Actilyse ${ }^{\circledR}$ verwendete Polysorbat in Betracht, welches zytolytisch und proteindenaturierend wirkt, somit konsektutiv eine Eisenfreisetzung mit entsprechenden Suszeptibilitätseffekten hervorrufen könnte.

Die bereits bekannte Neurotoxizität des rt-PAs, durch die es zu einem Vasospasmus und somit zu NMDA-Rezeptor (N-methyl-D-aspartat) vermittelten Neurodegeneration kommt, führt ebenfalls zu einer lokalen Protonensteigerung (Findlay et al. 1995). Des Weiteren zeigten Rohde und Thiex in ihren Studien, dass das neurotoxisch induzierte Ödem in den ersten 10 Tagen nach rt-PA-Therapie stetig an Größe zunahm (Rohde et al. 2002 b; Thiex et al. 2004 a).

Da die neurotoxische Wirkung des Lysemittels durch den PAI-Zusatz in der PAIGruppe antagonisiert werden sollte, kam es in der 3. Messung zu einem Signalabfall, und kann somit für einen erfolgreichen PAI-Effekt sprechen.

\subsection{Hämatomevolution in der PD-Wichtung}

Auch in dieser Wichtung nahmen die ICBs der Kontrollgruppe an Hypointensität zu. Diese Beobachtung deckt sich mit dem Argument der T2-Sequenz: Da keine intracranielle Arterie rupturiert war, die für einen stetigen Nachschub an oxygeniertem Hämoglobin sorgte, nahm die Signalintensität durch den Deoxyhämoglobingehalt schneller ab, als bei spontanen ICBs bisher beobachtet. Zur 2. Messung zeigten sich die lysierten Blutungen signalintensiver, also protonenreicher, im Vergleich zu den Kontrollblutungen. Dies kann wiederum an dem Phosphatzusatz im Lysemittel liegen. Dieser hat in der PDw einen größeren Einfluss auf die Signalgebung der Hämatome, als die T2w. Denn Phosphat ist hauptsächlich in kurzen TE relevant.

Die gesteigerte Signalintensität könnte aber ebenfalls durch die neurotoxische Wirkung des rt-PAs erklärt werden, wodurch es zu einer starken lokalen Erhöhung der Proteinkonzentration im Hämatomareal gekommen sein müsste. 
Der inhibitorische Effekt der Neurotoxizität des PAls begründet außerdem die Mittelstellung der PAI-Gruppe zur 3. Messung.

\subsection{Hämatomevolution in der T2*-Wichtung}

Dass die T2*-Wichtung selbst für kleinste Blutungen hoch sensitiv ist (Ripoll et al. 2004) zeigte sich auch in dieser Arbeit. Da sich schon kleinste Hämoglobinmassen stark hypointens darstellten, kann man diese Sequenz gut als Verlaufsparameter nach stereotaktischer Aspiration benutzen.

Die Kontrollgruppe zeigte zu jeder Messung hypointenser gewordene Hämatome. Diese Beobachtung deckt sich mit den zuvor beschriebenen Sequenzen: Durch den mutmaßlich fehlenden Nachschub oxygenierten Hämoglobins, schritt die Deoxygenierung bei den experimentellen ICBs schneller voran als bei spontanen ICBs.

In der 2. Messung war die Signalintensität der Hämatome beider Behandlungsgruppen im Vergleich zu den Kontrollgruppenhämatomen hyperintenser. Dies kann für einen gelungenen Lyseeffekt sprechen. Demnach konnten die Hämatome besser aspiriert werden.

\subsection{Hämatomevolution in der FLAIR-Wichtung}

Die unbehandelten Hämatome sollten sich in der FLAIR-Wichtung hypointenser darstellen als spontane Hämatome. Denn auch hier kann angenommen werden, dass sich spontane Blutungen auf Grund eines relativ höheren Oxyhämoglobinanteils signalintenser darstellen.Dies deckt sich mit den tatsächlichen Beobachtungen. Da Proteine in der FLAIR-Wichtung signalintens erscheinen, könnte sich damit die beobachtete Signalsteigerung beider Therapiegruppen erklären und die bereits beschriebene Neurotoxizität beweisen. Im Vergleich zwischen Messung 2 und 3 ist ein Signalabfall der Lysegruppe zu verzeichnen gewesen. Diese Beobachtung könnte für ein sich organisierendes Hämatom sprechen, und da der Mittelwert trotzdem noch über seinem Ausganswert lag, kann dies auch auf die Präsenz von Proteinen durch die Neurotoxizität schließen lassen.

Es wurde in Abschnitt 3.1.5 über eine eher inhomogene Bildgebung der lysierten Hämatome in der 3.Messung berichtet. Dieser Eindruck kann durch Zellbestandteile 
(wie sie auch bei der Tumornekrose vorkommen) zustande gekommen sein und somit ein weiteres Indiz für eine neurotoxische bewirkte Zytolyse darstellen. Die antagonistische Wirkung des PAls lässt sich auch in dieser Sequenz sowohl durch die Stellung des Mittelwerts zwischen Lyse- und Kontrollgruppe, als auch durch den, im Vergleich zur Lysegruppe, weniger inhomogenen Bildeindruck, untermauern.

\subsection{Hämatomevolution in der DWI und ADC-Karte}

Die, im Vergleich zur 1. Messung, hohen ADC-Werte der 2. Messung decken sich mit dem signalärmeren Bild.

Trotz gleicher Signalintensität in der 3. Messung zeigte die ADC-Kare eine relativ höhere Diffusivität besonders in den Therapiegruppen. Diese Unstimmigkeit, die auch in den anderen Therapiegruppen bestand, könnte mit den bereits erwähnten Artefakten durch die EPI zusammenhängen, die es schwer machten die Blutung adequat zu detektieren.

Erklärbar ist die verbesserte Diffusivität durch den durch Zytolyse induzierten hohen Proteingehalt in der Hämatomhöhle. Denn auch hier zeigte zur 3.Messung, also zu dem Zeitpunkt der ausgeprägtesten neurotoxischen Wirkung, die Lysegruppe die beste Diffusivität und die PAI-Gruppe nahm wieder die Mittelstellung ein. 


\section{Zusammenfassung}

Ausgehend von der Frage über die Signalgebung der mit rt-PA- und/oder PAI behandelten Hämatome im Vergleich zu unbehandelten Hämatomen, bestand die Zielsetzung der vorliegenden Arbeit darin, die Blutungen der unterschiedlichen Behandlungsgruppen zu detektieren um anschließend ihre Signalintensität an 3 unterschiedlichen Tagen in den Standard-Wichtungen (T1-, T2-, PD-, T2*-, FLAIR-, DWI -Wichtung, sowie ADC) darzustellen.

Die noch unbehandelten Hämatome der 3 Gruppen (1.unbehandelt 2. mit rt-PA 3. mit kombinierter Gabe von rt-PA und PAI) unterschieden sich erwartungsgemäß in der 1. Messung nicht.

Unter Therapie, am 3. Tag post operationem, konnten dann in der 2. MRTUntersuchung Signalunterschiede zwischen den Gruppen festgestellt werden:

Die unbehandelten Hämatome der Kontrollgruppe zeigten durch ihre Signalgebung einen im Vergleich zu spontanen ICBs, nur teilweise zeitgerechten Blutungsabbau. Das Signalverhalten experimenteller Blutungen ist demnach nicht 100\%-ig mit dem spontaner Blutungen gleichzusetzen. Denn da kein Zusammenbruch der Blut-HirnSchranke zu erwarten ist, kommt es folglich zu einer verspäteten Einwanderung körpereigener Mediatoren, die die Blutung organisieren.

Die therapierten Gruppen verhielten sich zur 2. Messung initial ähnlich. Denn der Haupteffekt scheint der Gleiche zu sein: Lysemittelbestandteile wie Phosphat und Polysorbat beeinflussen die Bildgebung beider Gruppen.

Zur 3. Messung zeigten alle Sequenzen, dass das Signal der PAI-Gruppe sich dem der Kontrollgruppe ähnlich verhält. Als Ursache hierfür ist ein spät einsetzender neurotoxischer Effekt durch rt-PA, mit Proteinfreisetzung und konsekutiver Flüssigkeitsakkumulation diskutiert worden. Dieser wurde durch PAI abgeschwächt. Schlussfolgernd sei zu erwähnen, dass es sich bei vorliegender Arbeit um die erste Studie handelt, die sich mit den Signalveränderungen unterschiedlich behandelter Hämatome befasst. Daher war dies nur mittels experimentell induzierten Hämatomen in Tierversuchen zu untersuchen. Auf Grund der Komplexität der Abläufe sowie der vielen, auf die Signalentstehung einflussnehmenden Faktoren sind experimentell induzierte ICBs nicht 1:1 auf spontane ICBs übertragbar. Für eine exaktere und damit für den klinischen Alltag noch nützlichere Beschreibung benötigt man ähnlich gewonnene Daten aus einer Therapiestudie. 


\section{Literaturverzeichnis}

Adams HP Jr, del Zoppo G, Alberts MJ, Bhatt DL, Brass L, Furlan A, Grubb RL, Higashida RT, Jauch EC, Kidwell C, Lyden PD, Morgenstern LB, Qureshi AI, Rosenwasser RH, Scott PA, Wijdicks EF (2007): Guidelines for the early management of adults with ischemic stroke: a guideline from the American Heart Association/American Stroke Association Stroke Council, Clinical Cardiology Council, Cardiovascular Radiology and Intervention Council, and the Atherosclerotic Peripheral Vascular Disease and Quality of Care Outcomes in Research Interdisciplinary Working Groups: the American Academy of Neurology affirms the value of this guideline as an educational tool for neurologists. Stroke $\underline{38}, 1655-711$.

Allkemper T, Tombach B, Schwindt W, Kugel H, Schilling M, Debus O, Möllmann F, Heindel W (2004): Acute and subacute intracerebral hemorrhages: comparison of MR Imaging at 1.5 and 3.0T-Initial Experience. Radiology 232, 874881.

Anderson CS, Chakera TM, Stewart-Wynne EG, Jamrozik KD (1994): Spectrum of primary intracerebral haemorrhage in Perth, Western Australia, 1989-90: incidence and outcome. J Neurol Neurosurg Psychiatry $\underline{8}, 936-40$.

Andrew ER (1985): The Wellcome Foundation lecture, 1981. Nuclear magnetic resonance imaging in medicine: physical principles. Proc R Soc Lond B Biol Sci 225 , $399-410$.

Ariesen MJ, Claus SP, Rinkel GJ, Algra A (2003): Risk factors for intracerebral hemorrhage in the general population: a systemic review. Stroke $\underline{34}, 2060-5$.

ASTM (American Society for Testing and Materials) International (2005): Standard Practice for Marking Medical Devices and Other Itmes for Safety in the Magnetic Resonance Environment. ASTM International ,West Conshohocken. ASTM F2503-05, Verfügbar unter: http://www.astm.org

Atlas SW, DuBois P, Singer MB, Lu D (2000): Diffusion measurements in intracranial hematomas: implications for MR imaging of acute stroke. Am J Neuroradiol 21, 1190-94.

Barnett HJ, Mohr JP, Stein BM: Stroke pathophysiology, diagnosis, and management. Churchill Livingstone, Philadelphia 1998.

Bergman SR, Fox KA, Ter-Pogossian MM, Sobel BE, Collen D (1983): clotselective coronary thrombolysis with tissue-type plasminogen activator. Science $\underline{220}$, 1181-3.

Bitar R, Leung G, Perng R, Tadros S, Moody A.R., Sarrazin J, McGregor C, Christakis M, Sean Symons S, Nelson A, Roberts T.P. (2006): MR pulse sequences: What every radiologist wants to know but is afraid to ask. Radiographics 26, 513-37. 
Bloch F, Hansen W.W., Packard M (1946): The nuclear induction experiment. Phys.Rev. $\underline{70}$, 474-85.

Bos MJ, Koudstaal PJ, Hofman A, Breteler MM (2007):Decreased glomerular filtration rate is a risk factor for hemorrhagic but not for ischemic stroke: the Rotterdam Study. Stroke $\underline{38}$, 3127-32.

Bradley WG: Hemorrhage and brain iron. In: Stark DD, Bradley WG, Magnetic resonance imaging. $2^{\text {nd }}$ ed, Mosby Year Books, St Louis 1992, S. 721-69.

Bradley WG (1993): MR appearance of hemorrhage in the brain. Radiology $189,15-$ 26.

Broderick J, Brott TG, Tomsick T, Barsan W, Spilker J (1990): Ultra-early evaluation of intracerebral hemorrhage. J Neurosurg 2, $195-9$.

Broderick J, Brott T, Duldner J (1993): Volume of intracerebral hemorrhage: A powerful and easy-to-use predictor of 30-day mortality. Stroke $\underline{24}, 987-93$

Broderick J, Connolly S, Feldmann E, Hanley D, Kase C, Krieger D, Mayberg M, Morgenstern L, Ogilvy CS, Vespa P, Zuccarello M (2007): Guidelines for the management of spontaneous intracerebral hemorrhage in adults: 2007 update: a guideline from the American Heart Association/American Stroke Association Stroke Council, High Blood Pressure Research Council, and the Quality of Care and Outcomes in Research Interdisciplinary Working Group. Stroke 38, 2001-23.

Brooks RA, Di Chiro G, Patronas N (1989): MR Imaging of Cerebral Hematomas at Different Field Strengths: Theory and Applications. J Comput Assist Tomogr $\underline{13}$, 194206.

Brott T, Broderick J, Kothari R, Barsan W, Tomsick T, Sauerbeck L, Spilker J, Duldner J, Khoury J (1997): Early hemorrhage growth in patients with intracerebral hemorrhage. Stroke $\underline{28}, 1-5$.

Brown M.A., Semelka R.C. (1999): MR imaging abbreviations, definitions, and descriptions: a review. Radiology 213, 647-62.

Caplan LR (1992): Intracerebral haemorrhage. Lancet $\underline{339}$, 656-8.

Carviy Nievas MN, Haas E, Hollerhage HG, Schneider H, Pollath A, Archavlis E (2004): Combined minimal invasive techniques in deep supratentorial intracerebral haematomas. Minim Invasive Neurosurg 47, 294-98.

Chapman N, Huxley R, Anderson C, Bousser MG, Chalmers J, Colman S, Davis S, Donnan G, MacMahon S, Neal B, Warlow C, Woodward M (2004): Effects of a perindopril-based blood pressure-lowering regimen on the risk of recurrent stroke according to stroke subtype and medical history: the PROGRESS Trial. Stroke $\underline{35}$, 116-21. 
Chiu D., Krieger D, Villar-Cordova C (1998): Intravenous tissue plasminogen activator for acute ischemic stroke: feasibility, safety, and efficacy in the first year of clinical practice. Stroke 29, 18-22.

Clark RA, Watanabe AT, Bradley WG Jr, Roberts JD (1990): Acute hematomas: effects of deoxygenation, hematocrit, and fibrin-clot formation and retraction on T2 shortening. Radiology $\underline{175}$, 201-206.

Cohen MS, Weisskoff RM (1991): Ultra-fast imaging. Magn Reson Imaging 1, 1-37.

Collen D (1980): On the regulation and control of fibrinolysis. Edward Kowaski Memorial Lecture, Thromb Haemost $\underline{43}$, 77-89.

Cordonnier C, Al-Shahi Salman R, Wardlaw J (2007): Spontaneous brain microbleeds: systematic review, subgroup analyses and standards for study design and reporting. Brain $\underline{8}, 1988-2003$.

Crabbe SJ , Cloninger CC (1987): Tissue plasminogen activator: a new thrombolytic agent. Clin Pharm $\underline{6}, 373-86$.

Damadian R (1971): Tumor Detection by Nuclear Magnetic Resonance. Science 171, 1151-53.

Daszkiewicz OK, Jedrychowski A, Kirchmayer S (1965): Studies on blood clotting by the spin echo technique. Acta Med Pol 1, 95-102.

Daverat P, Castel JP, Dartigues JF, Orgogozo JM (1991): Death and functional outcome after spontaneous intracerebral hemorrhage. A prospective study of 166 cases using multivariate analysis. Stroke $\underline{22}, 1-6$

Davis AM, Natelson BH (1993): Brain-heart interactions. The neurocardiology of arrhythmia and sudden cardiac death. Tex Heart Inst J $\underline{3}$, 158-69.

Davis SM, Broderick J, Hennerici M, Brun NC, Diringer MN, Mayer SA, Begtrup K, Steiner T (2006): Hematoma growth is a determinant of mortality and poor outcome after intracerebral hemorrhage. Neurology $\underline{8}, 1175-81$.

Dearden NM (1998): Mechanisms and prevention of secondary brain damage during intensive care. Clin Neuropathol $\underline{4}, 221-8$.

De Coene B, Hajnal JV, Gatehouse P, Longmore DB, White SJ, Oatridge A, Pennock JM, Young IR, Bydder GM (1992): MR oft he brain using fliud-attenuated inversion recovery pulse sequences. AJNR Am J Neuroradiol $\underline{13}$, 1555-1564.

Deinsberger W, Vogel J, Kuschinsky W, Auer LM Boker DK (1996): Experimental intracerebral hemorrhage: description of a double injection model in rats. Neurol Res $\underline{18}, 475-477$.

Dolderer S, Kallenberg K, Aschoff A, Schwab S, Schwarz S (2004): Long-term outcome after spontaneous cerebellar haemorrhage. Eur Neurol 52, 112-9. 
Ehrlich JH, Keijer J. Preissner KT, Lein Gebbink R, Pannekoek H (1991):

Functional interaction of plasminogen activator inhibitor type 1 and heparin.

Biochemistry $\underline{30}, 1021-1028$.

Erickson LA, Gisberg MH, Loskutoff DJ (1984): Detection and partial characterization of an inhibitor of plasminogen activator in human platelets. $\mathrm{J}$ Clin Invest $\underline{74}, 1465-72$.

Ergun I, Keven K, Uruc I, Ekmekci B, Canbakan B, Erden I, Karatan O (2006):

The safety of gadolinium in patients with stage 3 and 4 renal failure.

NDT $\underline{3}, 697$ - 700 .

Fiebach JB, Schellinger PD, Gass A, Kucinski T, Siebler M, Villringer A, Olkers P, Hirsch JG, Heiland S, Wilde P, Jansen O, Rother J, Hacke W, Sartor K (2004): Stroke magnetic resonance imaging is accurate in hyperacute intracerebral hemorrhage: a multicenter study on the validity of stroke imaging.

Stroke $\underline{35}, 502-6$.

Filippi M, Horsfield MA, Rovaris M, Yousry T, Rocca MA, Baratti C, Bressi S, Comi G (1998): Intraobserver and interobserver variability in schemes for estimating volume of brain lesions on MR images in multiple sclerosis. AJNR 2, 239-44.

Findlay JM, Kassell NF, Weir BK, Haley EC Jr, Kongable G, Germanson T, Truskowski L, Alves WM, Holness RO, Knuckey NW (1995): A randomized trial of intraoperative, intracisternal tissue plasminogen activator for the prevention of vasospasm . Neurosurgery $\underline{37}, 168-76$.

Flaherty ML, Haverbusch M, Sekar P (2006): Long-term mortality after intracerebral hemorrhage. Neurology $\underline{66}, 1182-6$.

Fogelholm R, Murros K, Rissanen A, Avikainen S (2005): Long term survival after primary intracerebral haemorrhage: a retrospective population based study. J Neurol Neurosurg Psychiatry $\underline{76}, 1534-8$.

Frahm J, Haase A, Matthaei D (1986): Rapid three-dimensional MR imaging using the FLASH technique. J Comput Assist Tomogr 10, 363-368

Franke CL, van Swieten JC, Algra A, van Gijn J (1992): Prognostic factors in patients with intracerebral haematoma. J Neurol Neurosurg Psychiatry $\underline{8}$, 653-7.

Friedman HS, Koroshetz WJ (1995): Tissue plasminogen activator for acute ischemic stroke. The national institute of neurological disorders and stroke r-tPA. Stroke Study Group, N Engl J Med 333, 1581-88.

Fullerton GD: Physiological basis of magnetic relaxation. In: Stark DD, Bradley WG Jr, Magnetic Resonance Imaging Mosby-Year Book, St.Louis 1992, S. 88-108.

Garcia JH, Ho KL (1992): Pathology of hypertensive arteriopathy. Neurosurg Clin N Am $\underline{3}, 497-507$. 
Garroway AN (1999): Solid state NMR, MRI and Sir Peter Mansfield: (1) from broad lines to narrow and back again; and (2) a highly tenuous link to landmine detection. MAGMA $\underline{3}$, 103-8.

Gomori JM, Grossman RI, Goldberg HI, Zimmerman RA, Bilaniuk LT (1983): Intracranial hematomas: imaging by high-field MR. Neuroradiology 157, 87-93.

Gorelick PB, Hier DB, Caplan LR, Langenberg P (1986): Headache in acute cerebrovascular disease. Neurology $\underline{11}, 1445-50$.

Gorelick PB, Weisman SM (2005): Risk of hemorrhagic stroke with aspirin use: an update. Stroke $\underline{36}, 1801-7$.

Grossman (1988): MR imaging of hemorrhagic conditions of the head and neck. Radiographics $\underline{8}, 441-455$.

Hacke W, Schwab S, Horn M, Spranger M, De Georgia M, von Kummer R (1996): 'Malignant' middle cerebral artery territory infarction: clinical course and prognostic signs. Arch Neurol $\underline{4}$, 309-15.

Hackney DB, Atlas SW, Grossman RI (1987): Subacute intracranial hemorrhage: contribution of spin density to appearance on spin-echo MR images. Radiology $\underline{165}$, 199-202.

Hahn E.L. (1950): Spin Echoes. Phys Rev $\underline{80}$, 580-94.

Hallevi H, Albright KC, Aronowski J, Barreto AD, Martin-Schild S, Khaja AM, Gonzales NR, Illoh K, Noser EA, Grotta JC (2008): Intraventricular hemorrhage: Anatomic relationships and clinical implications. Neurology 11, 848-52.

Hankey GJ (2003): Evacuation of intracerebral hematoma is likely to be beneficial-against. Stroke $\underline{34}, 1568-9$.

Hayman LA, Pagan JJ, KirkpatrickJB, Hinck VC (1989): Pathophysiology of acute intracerebral and subarachnoid hemorrhage: applications to MR imaging. AJNR $\underline{10}$, 457-81.

Hoylaerts M, Rijken DC, Lijnen HR, Collen D (1982): Kinetics oft he activation of plasminogen by human tissue plasminogen activator. Role of fibrin. J Biol Chem 257 , 2912-9.

Kanal E; Borgstede JP; Barkovich AJ; Bell C; Bradley WG; Etheridge S; Felmlee JP; Froelich JW; Hayden J; Kaminski EM; Lester JW Jr; Scoumis EA (2004): American College of Radiology White Paper on MR Safety: 2004 update and revisions. AJR 182, 1111-4.

Kang DW, Chalela JA, Dunn W, Warach S (2005): MRI screening before standard tissue plasminogen activator therapy is feasible and safe.

Stroke 36, 1939-43. 
Kang KB, Na DG, Ryoo JW, Byun HS, Roh HG, Pyeun SY (2001): Diffusionweighted MR imaging of intracerebral hemorrhage. Korean J Radiol 2, 183-91.

Keeton M, Eguchi Y, Sawdey M, Ahn C, Loskutoff DJ (1993): Cellular localization of type 1 plasminogen activator inhibitor messenger RNA and protein in murine renal tissue. Am J Pathol 142, 59-70.

Kidwell CS, Wintermark M (2008): Imaging of intracranial haemorrhage. Lancet Neurol $\underline{3}, 256-67$.

Kidwell CS, Chalela JA, Saver JL, Starkman S, Hill MD; Demchuk AM, Butman JA, Patronas N, Alger JR, Latour LL, Luby ML, Baird AE, Leary MC, Tremwel M, Ovbiagele B, Fredieu A, Suzuki S; Villablanca JP, Davis S, Dunn B, Todd JW, Ezzeddine MA; Haymore J, Lynch JK, Davis L, Warach S (2004): Comparison of MRI and CT for detection of acute intracerebral hemorrhage. JAMA $\underline{15}$, 1823-30.

Kruithof EK, Trank-Thang C, Ransijn A, Bachmann F.(1984): Demonstration of a fast-acting inhibitor of plasminogen activators in human plasma. Blood 64, 907-913.

Kumar A, Welti D, Ernst RR (1975): NMR Fourier zeugmatography. J Magn Reson $18,69-83$.

Kuo PH, Kanal E, Abu-Alfa AK, Cowper SE (2007): Gadolinium-based MR contrast agents and nephrogenic systemic fibrosis. Radiology $\underline{242}$, 647-9.

Lijnen HR, Collen D (1995): Mechanisms of physiological fibrinolysis. Baillieres Clin Haematol $\underline{8}$, 277-90.

Linfante I, Llinas RH, Caplan LR, Warach S (1999): MRI features of intracerebral hemorrhage within 2 hours of sympotm onset. Stroke $\underline{30}$, 2263-76.

Lo EH, Wang X, Cuzner ML (2002): Extracellular proteolysis in brain injury and inflammation: role for plasminogen activators and matrix metalloproteinases. $J$ Neurosci Res $\underline{69}, 1-9$.

Mansfield J, Phays C. (1977): Multiplanar image formation using NMR spin echoes, Solid State Phys $\underline{10}$, L55-L58.

Marcu CB; Beek AM; van Rossum AC (2006): Clinical applications of cardiovascular magnetic resonance imaging. CMAJ $\underline{8}, 911-7$.

Matsu O, Riken DC, Collen D (1981): Comparison oft he relative fibrinogenolytic, fibrinolytic and thrombolytic properties of tissue plasminogen activator and urokinase in vitro. Throb Haemost $\underline{45}$, 225-9.

Matys T, Strickland S (2003): Tissue plasminogen activator and NMDA receptor cleavage. Nature Med $\underline{9}, 371-373$.

Mayer SA, Brun NC, Begtrup K, Broderick J, Davis S, Diringer MN, Skolnick BE, Steiner T (2008): Efficacy and Safety of Recombinant Activated Factor VII for Acute Intracerebral Hemorrhage. N Engl J Med 20, 2127-2137. 
Mendelow AD, Gregson BA, Fernandes HM, Murray GD, Teasdale GM, Hope DT, Karimi A, Shaw MD; Barer DH (2005): Early surgery versus initial conservative treatment in patients with spontaneous supratentorial intracerebral haematomas in the International Surgical Trial in Intracerebral Haemorrhage (STICH): a randomised trial. Lancet $\underline{365}, 387-97$.

Minematsu K (2003): Evacuation of intracerebral hematoma is likely to be beneficial. Stroke $\underline{34}, 1567-8$.

Nicole O, Docagne F, Ali C, Margaill I, Carmeliet P (2001): The proteolytic activity of tissue-plasminogen activator enhances NMDA receptor-mediated signaling. Nat Med $\underline{7}, 59-64$.

Nighoghossian N, Hermier M, Adeleine P, Blanc-Lasserre K, Derex L, J. Honnorat J, Philippeau F, Dugor JF, Froment JC, Trouillas P (2002): Old Microbleeds Are a Potential Risk Factor for Cerebral Bleeding After Ischemic Stroke. Stroke $\underline{33}, 735-42$.

Offenbacher H, Fazekas F, Schmidt R, Koch M, Fazekas G, Kapeller P (1996): MR of cerebral abnormalities concomitant with primary intracerebral hematomas. AJNR Am J Neuroradiol $\underline{3}, 573-8$.

Okuda S, Kikinis R, Geva T, Chung T, Dumanli H, Powell A.J. (2000): 3D-shaded surface rendering of gadolinium-enhanced MR angiography in congenital heart disease. Pediatr Radiol $\underline{8}, 540-545$.

Parizel PM, Makkat S, Van Miert E (2001): Intracranial hemorrhage: principles of CT and MRI interpretation. Eur Radiol 11, 1770-1783

Pauling L, Coryell C (1936): The magnetic properties and structure of hemoglobin, oxyhemoglobin, and carbonmonoxyhemoglobin. Proc Natl Acad Sci 22, 210-216.

Perutz, MF: Molecular anatomy, physiology, and pathology of hemoglobin. In: Stamatoyannopoulos G, Nienhuis AW : The Molecular Basis of Blood Disorders. WB Saunders, Philadelphia 1987 S.127.

Purcell E.M., Torrey H.C., Pound R.V. (1946): Resonance absorption by nuclear magnetic moments in a solid. Phys Rev $\underline{69}, 37-38$.

Ripoll A , Gustafsson O , Siösteen B , Olsson Y. Raininko R (2002): MR follow-up of small experimental intracranial haemorrhages from hyperacute to subacute phase. Acta Radiol $\underline{43}$, 2-9.

Ripoll A, Stenbor A, Sonninen P, Terent A, Raininko R (2004): Detection and appearance of intraparenchymal haematomas of the brain at 1.5T with spinc-echo, FLAIR and GE sequences: poor relationship to the age of the haematoma.

Neuroradiology $\underline{46}, 435-43$. 
Rohde V, Schaller C, Hassler WE (1995): Intraventricular recombinant tissue plasminogen activator for lysis of intraventricular haemorrhage. J Neurol Neurosurg Psychiatry $\underline{58}, 447-51$.

Rohde V, Graf G, Hassler W (2002 a): Complications of burr-hole craniostomy and closed-system drainage for chronic subdural hematomas: a retrospective analysis of 376 patients. Neurosurg Rev $\underline{25}$, 89-94.

Rohde V, Rohde I, Thiex R (2002 b): Fibrinolysis therapy achieved with tissue plasminogen activator and aspiration of the liquefied clot after experimental intracerebral hemorrhage:rapid reduction in hematoma volume but intensification of delayed edema formation. J Neurosurg $\underline{97}$, 954-62.

Schaefer PW, Grand PE, Gonzalez RG (2000): Diffusion-weigted MR imaging of the brain. Radiology 217, 331-45.

Seidenwurm D, Meng TK, Kowalski HK, WeinrebJC, Kricheff II (1989):

Intracranial hemorrhagic lesions: evaluation with spin-echo and gradient-refocused MR imaging at 0.5 and $1.5 \mathrm{~T}$. Radiology $\underline{172}, 189-194$.

Seynaeve PC, Broos JI (1995): The history of tomography. J Belge Radiol $\underline{5}$, 284-8.

Silva Y, Leira R, Tejada J, Lainez JM, Castillo J, Davalos A (2005): Molecular signatures of vascular injury are associated with early growth of intracerebral hemorrhage. Stroke $\underline{36}, 86-91$.

SingerJR, Crooks LE (1978): Some magnetic studies of normal and leukemic blood. Clin Eng $\underline{3}, 357-363$.

Stejskal EO, Tanner JE (1965): Spin diffusion measurements:spin-echoes in the presence of a time-dependent field gradient . J Chem Phys $\underline{42}, 288-292$.

Sturgeon JD, Folsom AR, Longstreth WT Jr, Shahar E, Rosamond WD, Cushman M (2007): Risk factors for intracerebral hemorrhage in a pooled prospective study. Stroke $\underline{10}, 2718-25$.

Thiex R, Kuker W, Muller HD, Rohde I, Schroder JM, Gilsbach JM, Rohde V (2003): The long-term effect of recombinant tissue-plasminogen-activator (r-tPA) on edema formation in a large-animal model of intracerebral hemorrhage. Neurol Res $\underline{25}, 254-62$.

Thiex R, Mayfrank L, Rohde V, Gilsbach JM, Tsirka SA (2004 a): The role of endogenous versus exogenous tPA on edema formation in murine ICH. Exp Neurol $189,25-32$.

Thiex R, Rohde V, Rohde I (2004 b): Frame-based and frameless stereotactic hematoma puncture and subsequent fibrinolytic therapy fort he treatment of spontaneous intracerebral hemorrhage, J Neurol 251, 1443-1450. 
Thrift AG, McNeil, JJ, Forbes, A (1996): Risk factors for cerebral hemorrhage in the era of well controlled hypertension. Melbourne Risk Factor Study (MERFS) Group. Stroke 27, 2020.

Thrift AG, McNeil JJ, Forbes A, Donnan GA (1998): Three important subgroups of hypertensive persons at greater risk of intracerebral hemorrhage. Melbrourne Risk Factor Study Group. Hypertension $\underline{6}$, 1223-9.

Thulborn KR, Sorensen AG, Kowall NW, McKee A, Lai A, RC McKinstry RC, Moore J, Rosen BR, Brady TJ (1990): The role of ferritin and hemosiderin in the MR appearance of cerebral hemorrhage: a histopathologic biochemical study in rats. AJR 154, 1053-1059.

Twieg D.B.(1983): k-trajectory formulation oft he NMR imaging process with applications in analysis and synthesis of imaging methods. Med Phys $\underline{10}, 610-621$.

U-King-Im JM, Trivedi RA, Graves MJ, Harkness K, Eales H, Joubert I, Koo B, Antoun N, Warburton EA, Gillard JH, Baron JC (2005): Utility of an ultrafast magnetic resonance imaging protocol in recent and semi-recent strokes. J Neurol Neurosurg Psychiatry $7,1002-5$.

Vespa PM, O'Phelan K, Shah M (2003): Acute seizures after intracerebral hemorrhage:a factor in progressive midline shift and outcome. Neurology $\underline{60}, 1441-$ 1446.

Vogt FM, Goyen M, Debatin JF (2003): MR angiography of the chest.

Radiol Clin North Am 1, 29-41.

Wardlaw JM, Seymour J, Cairns J, Keir S, Lewis S, Sandercock P (2004): Immediate computed tomography scanning of acute stroke is cost-effective and improves quality of life. Stroke $\underline{35}, 2477-83$.

Warren DT, Klein G, Eliasziw M, Buchan AM (2003): Neurotoxic effects of t-PA in a rat model of permanent focal ischemia. Neurology 60, 1 Suppl, A65.

Weitz JI, Leslie B, Gisnberg J (1991): Soluble fibrin degradation products potentiate tissue plasminogen activator-induced fibrinogen proteolysis. J Clin Invest, $\underline{87}, 1082-$ 90.

White CS (2000): MR imaging of thoracic veins. Magn Reson Imaging Clin N Am 1,17-32.

Wiesman M, Mayer TE, Medele R, Brückmann H (1999): Nachweis der akuten Subarachnoidalblutung. Radiologe $\underline{39}$, 860-65.

Wintrobe MM, Lee GR, Boggs DR: Clinical hematology Philadelphia. Lea and Febiger, Philadelphia, 1981 88-102.

Wun TC (1988): Plasminogen activation: biochemistry, physiology, and therapeutics. Crit Rev Biotechnol 2, 131-48. 
Xu BN, Yabuki A, Mishina H, Miyazaki M, Maeda M, Ishii S (1993):

Pathophysiology of brain swelling after acute experimental brain compression and decompression. Neurosurgery 2 , 289-96.

Yoon HC, Lufkin RB, Vinuela F, Bentson J, Martin N, Wilson G (1988): MR of acute subarachnoid hemorrhage. AJNR Am J Neuroradiol 2, 405-8.

Zamarron, C, Lijnen HR, Collen D (1984): Kinetics oft he activation of plasminogen by natural and recombinant tissue-type plasminogen activator J Biol Chem 259 , 2080-3. 
7. Anhang: Abbildungen

\section{T1 Kontrolle}

(2)

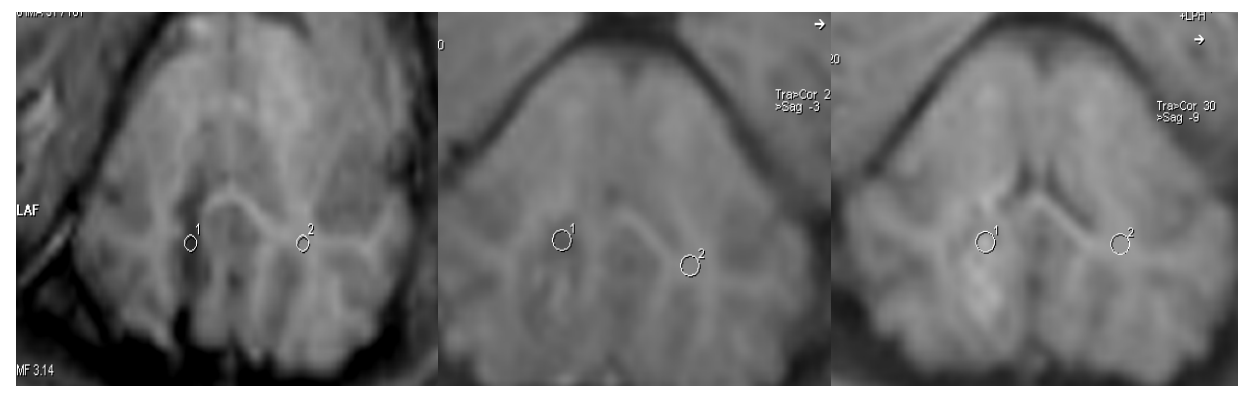

(3)

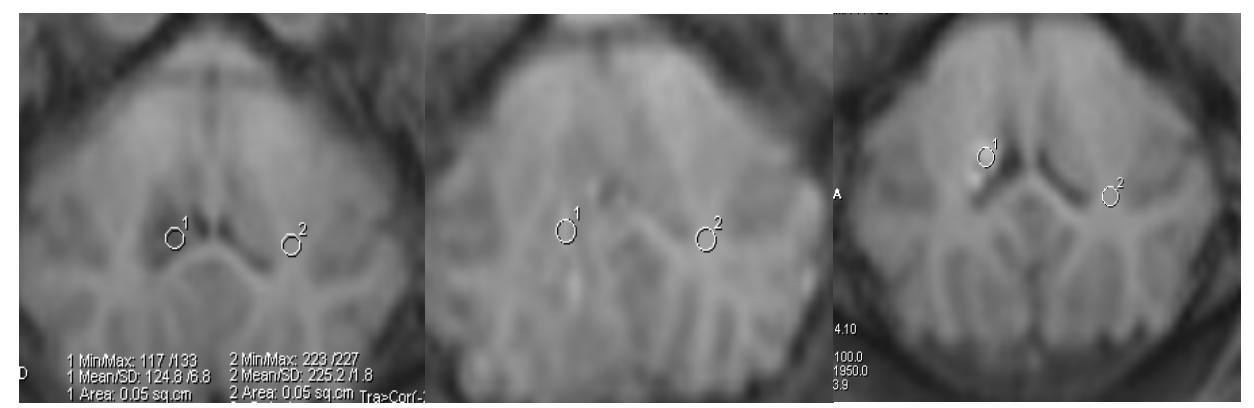

(6)

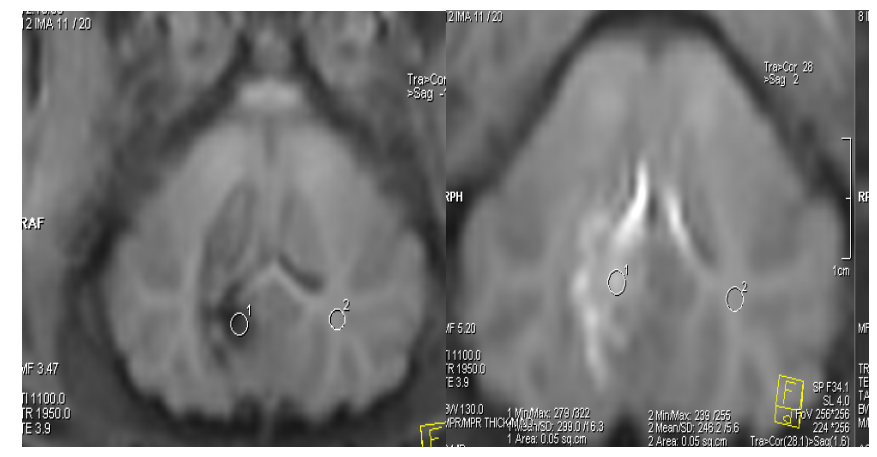

(10)

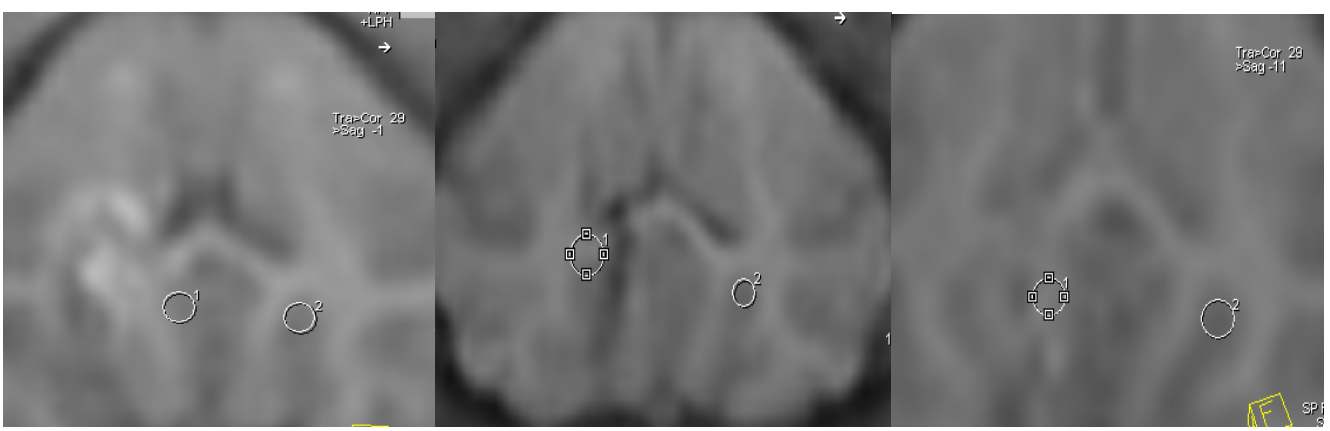


(20)

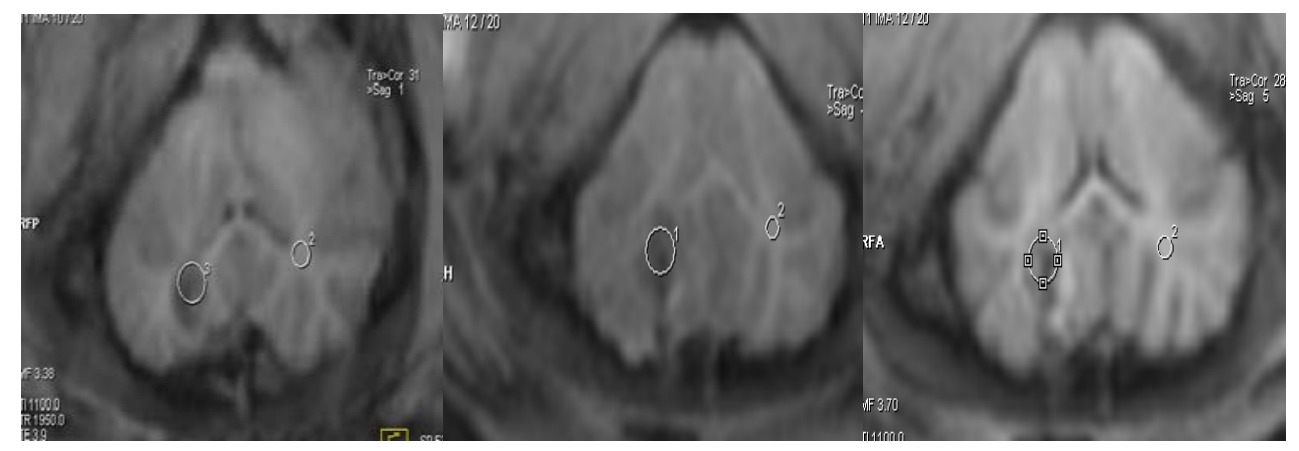

Lyse T1

(4)

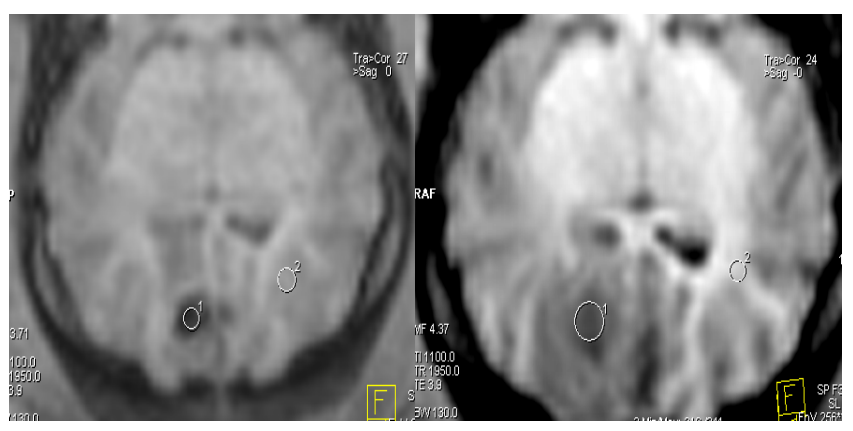

(7)

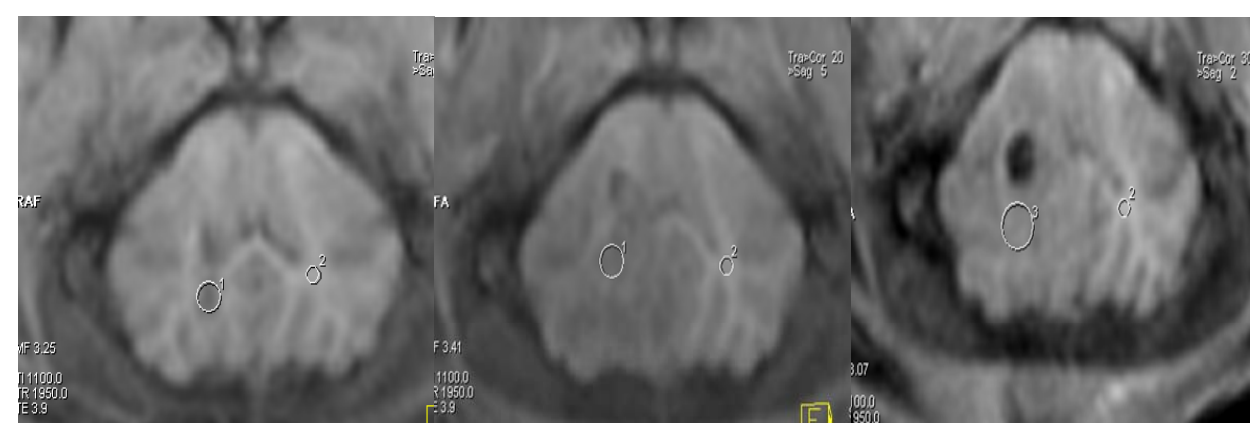

(12)

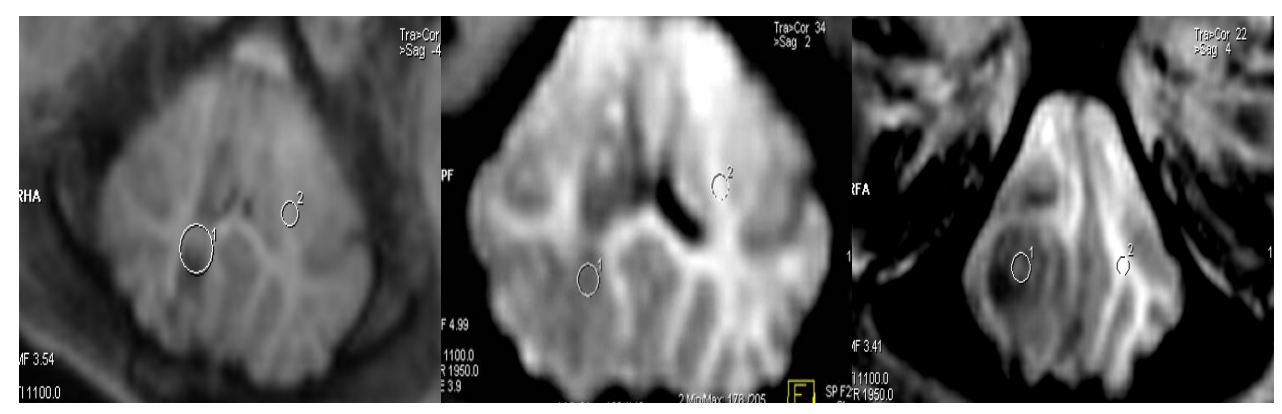


(13)

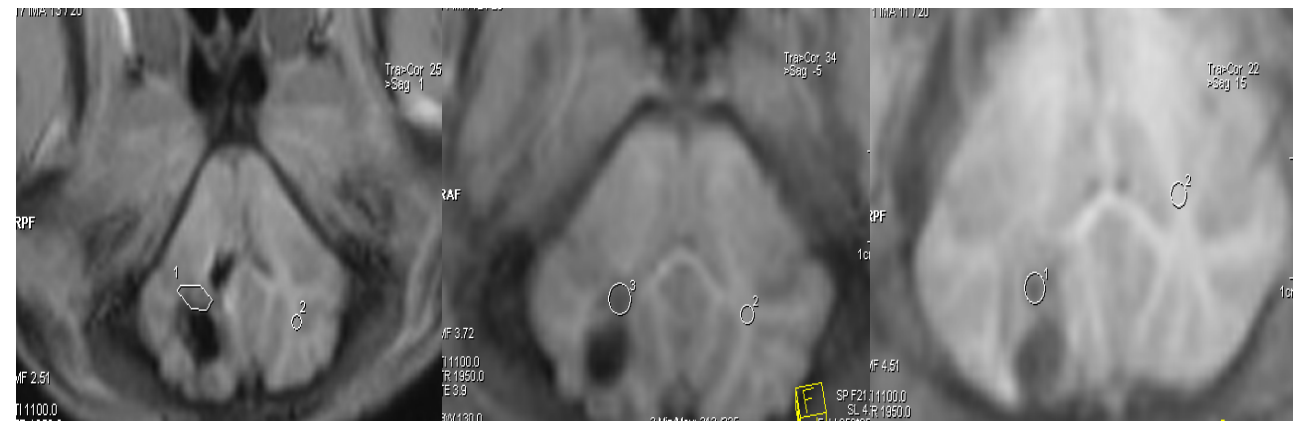

(14)

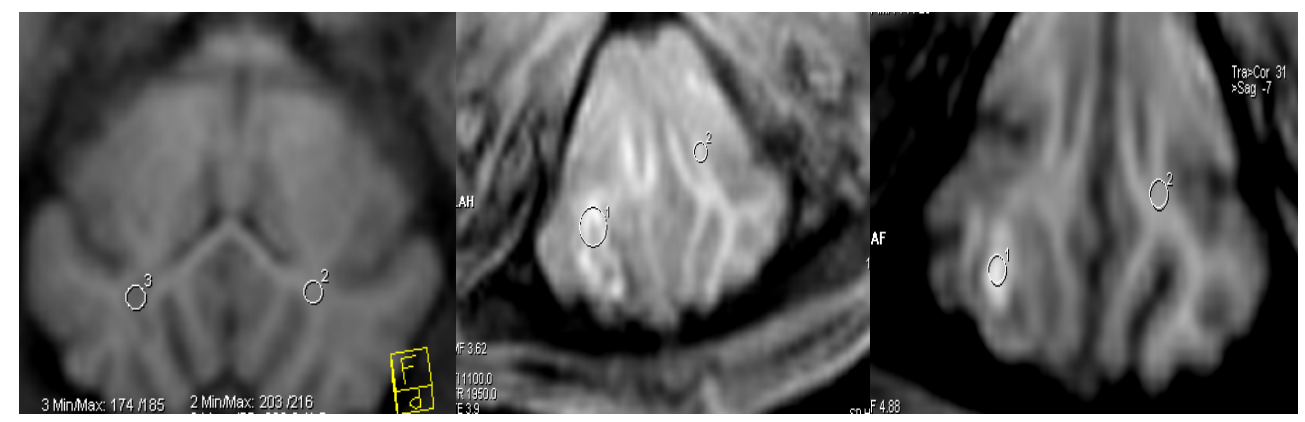

(18)a

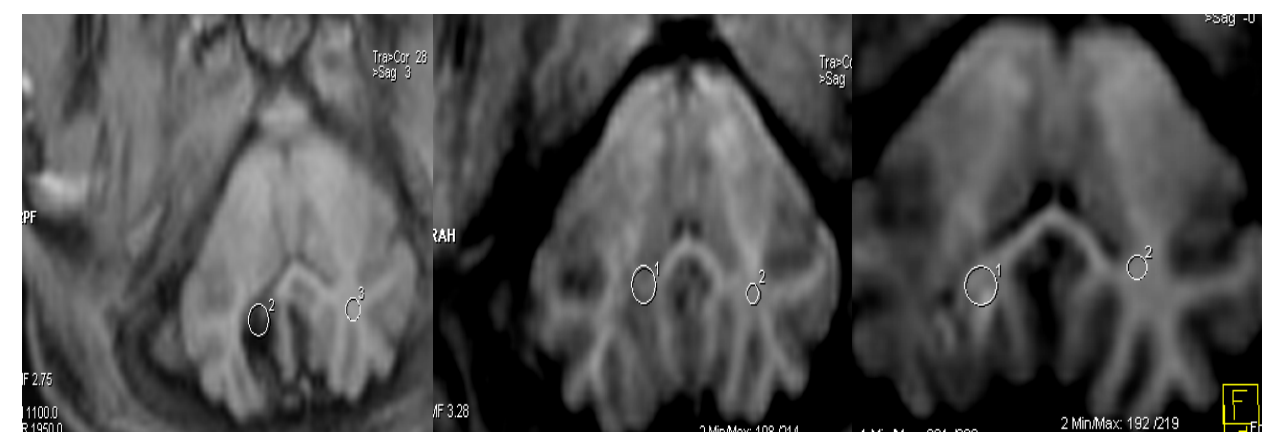

PAI T1

(9)

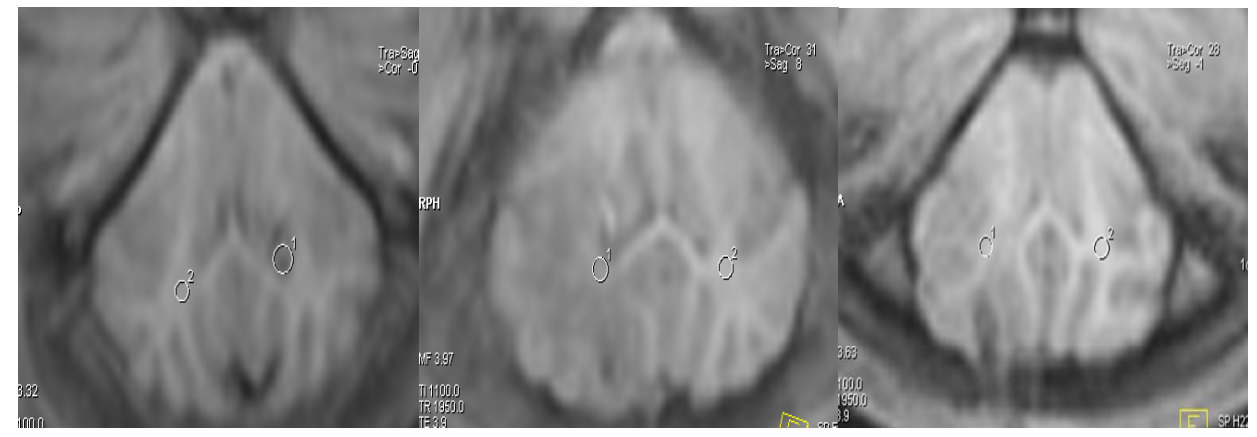


(11)

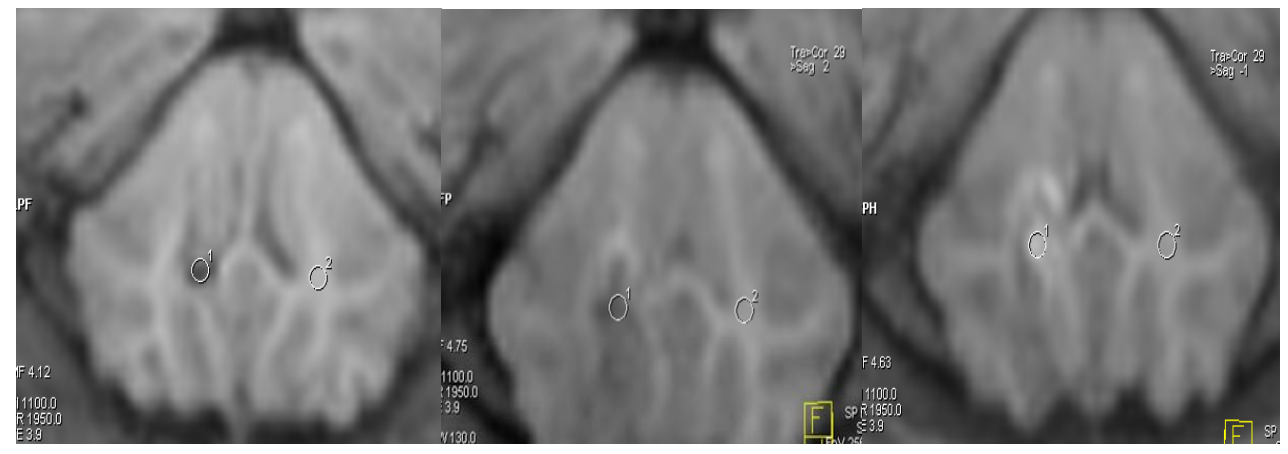

(15)

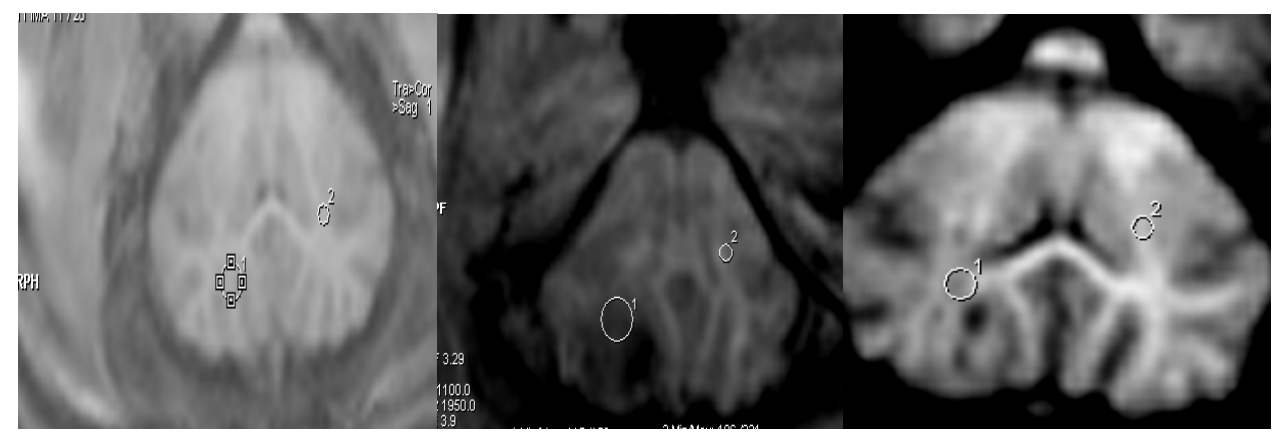

(16)

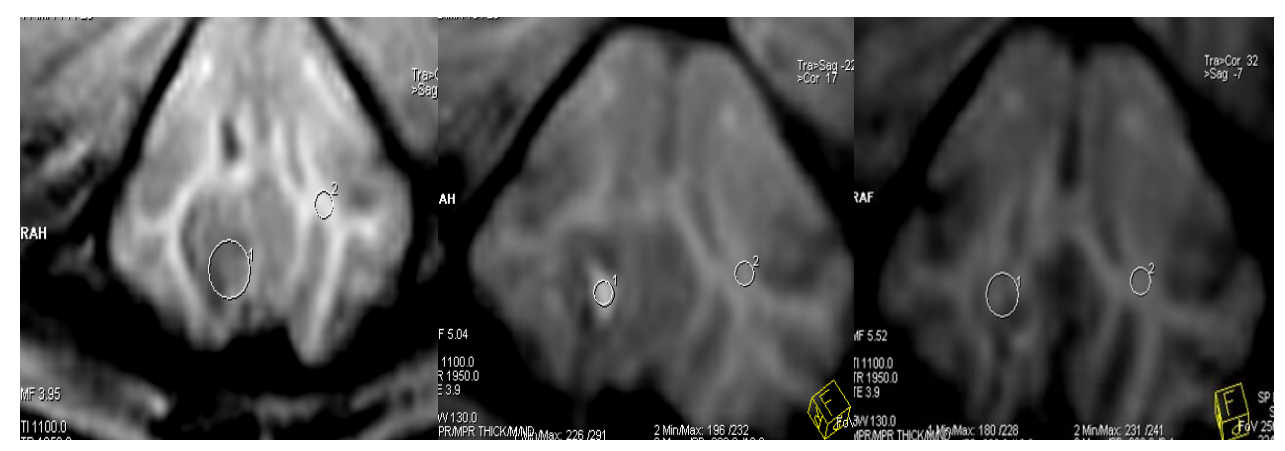

(17)

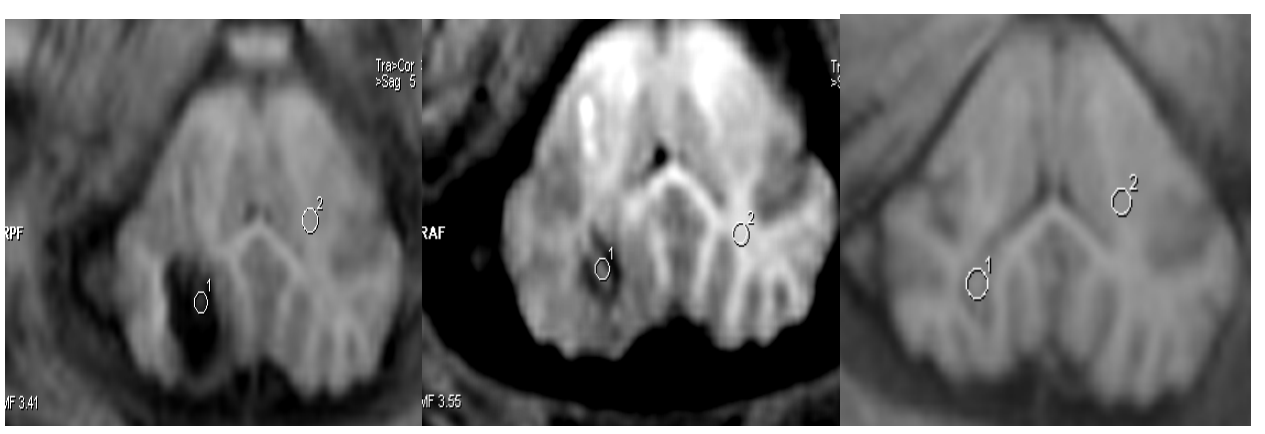


(21)

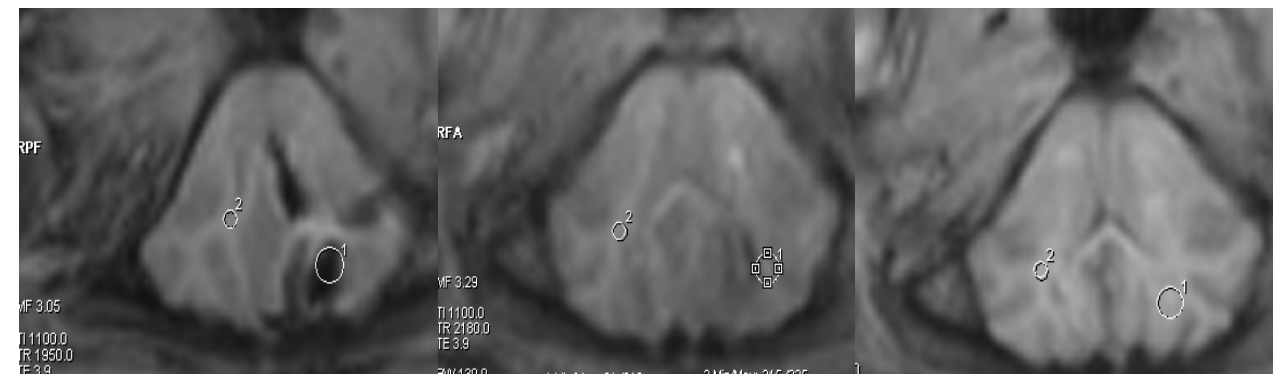

\section{Kontrolle T2}

(2)

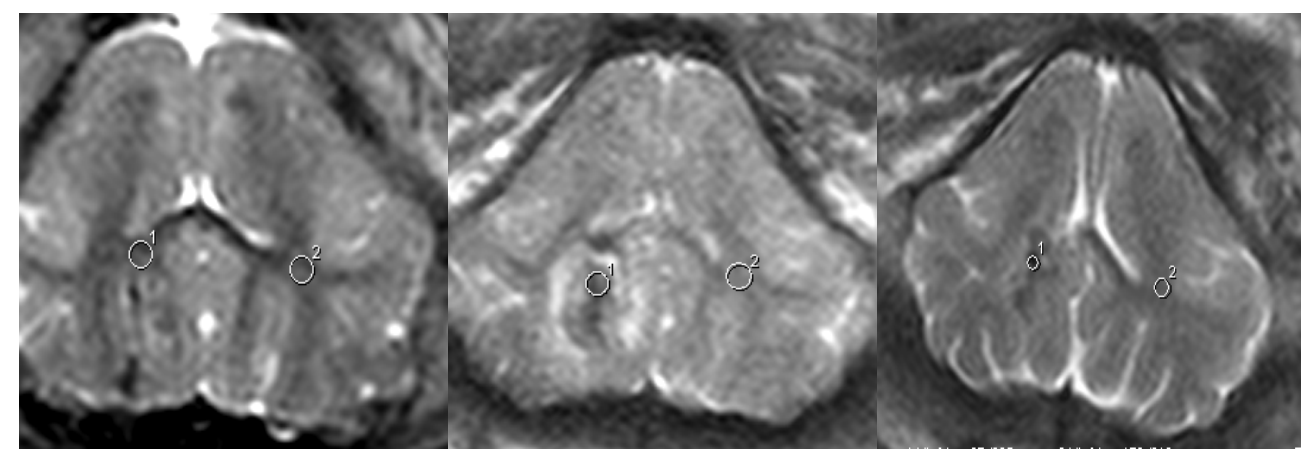

(3)

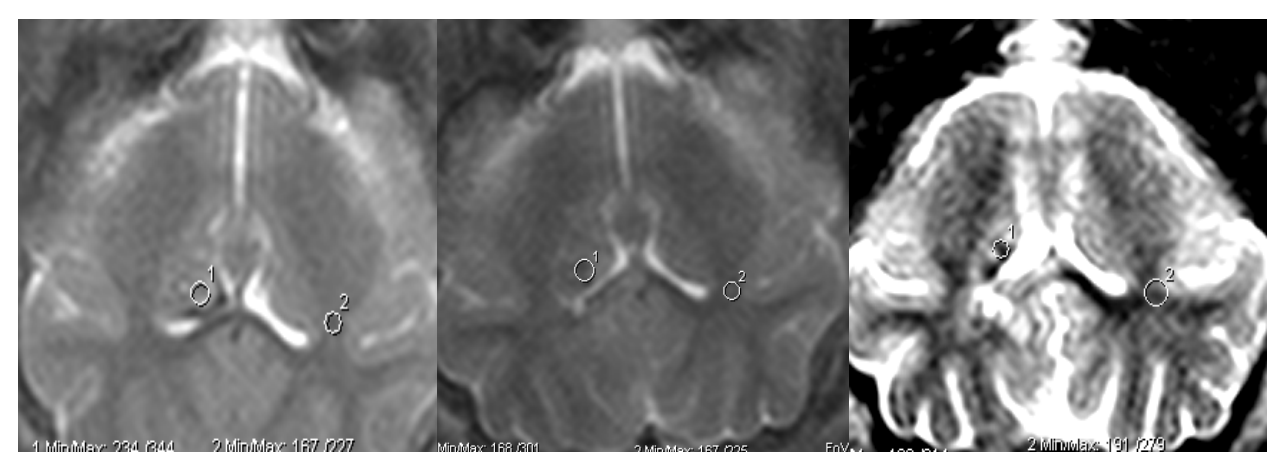

(6)

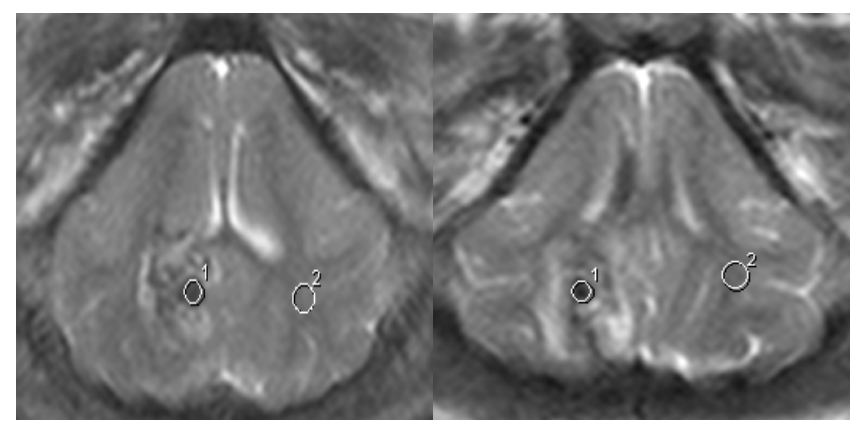


(10)

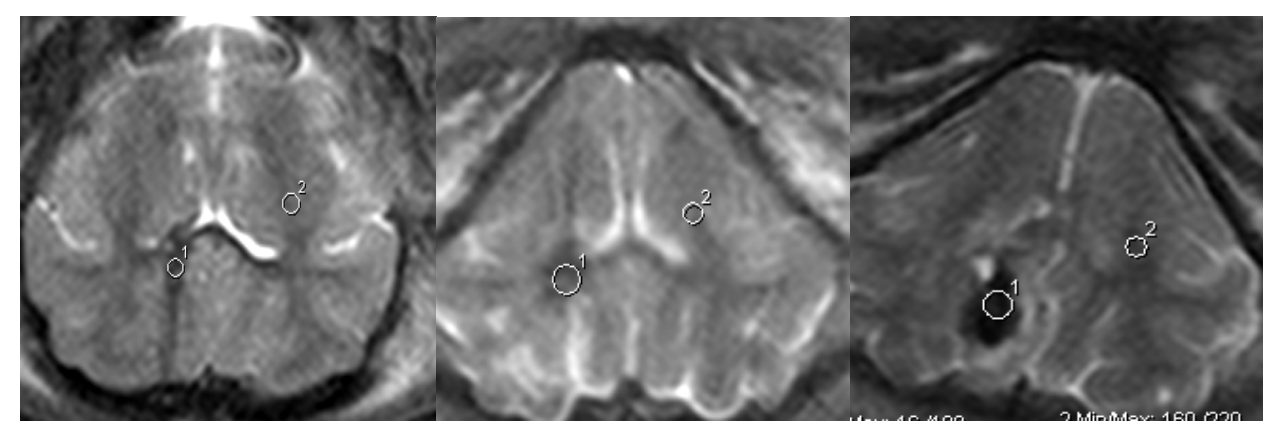

(20)

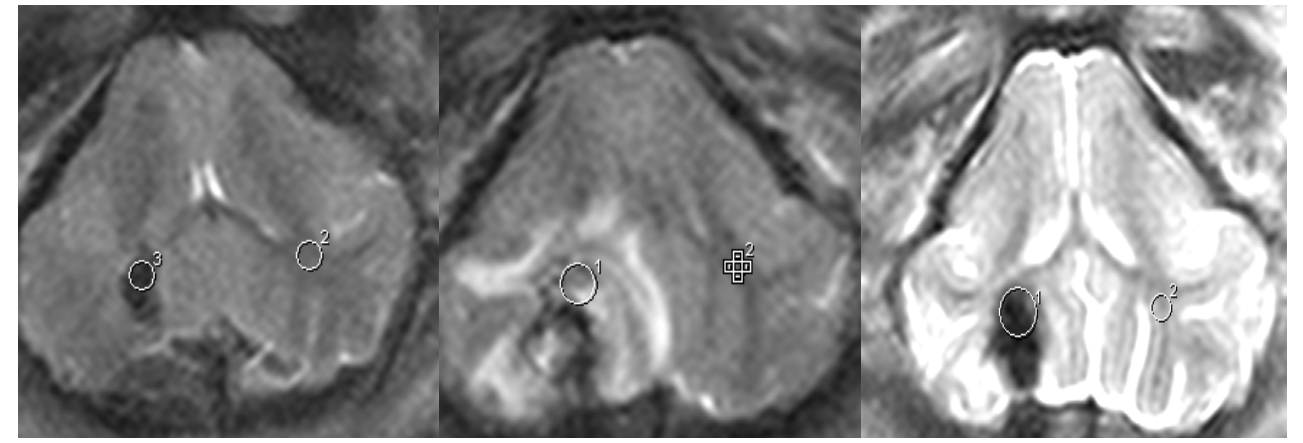

\section{Lyse T2}

(4)

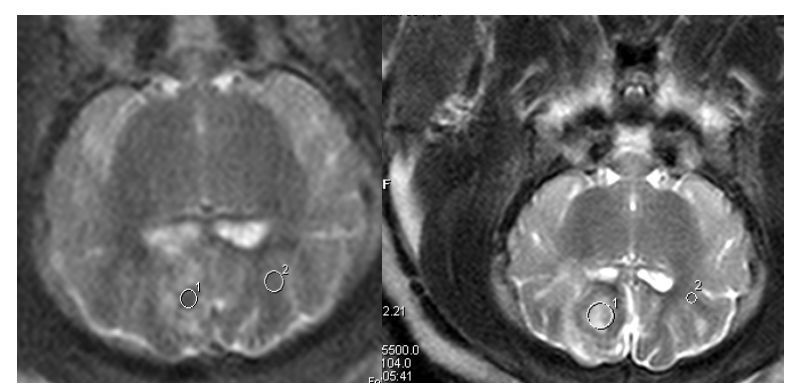

(7)

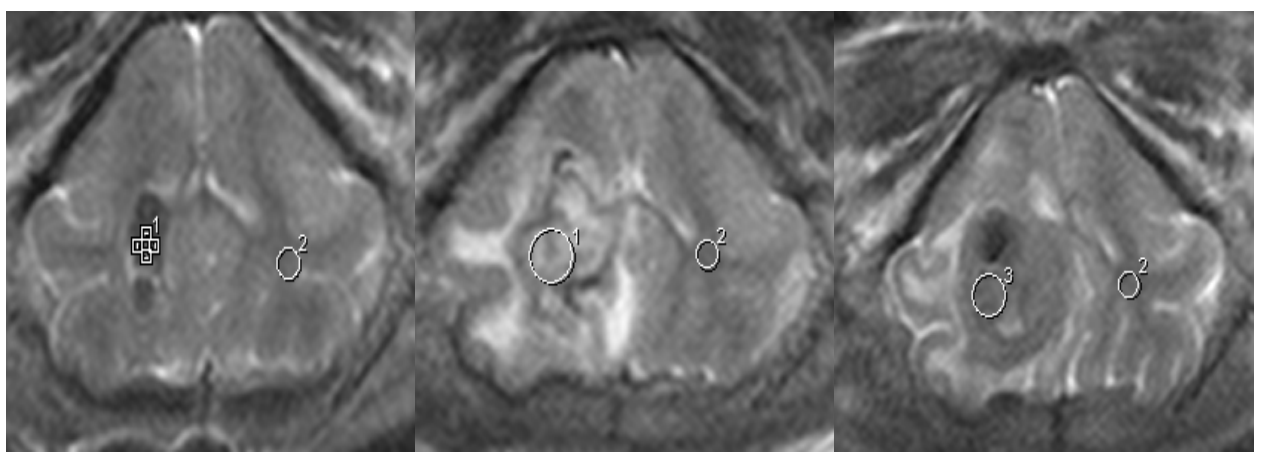


(12)

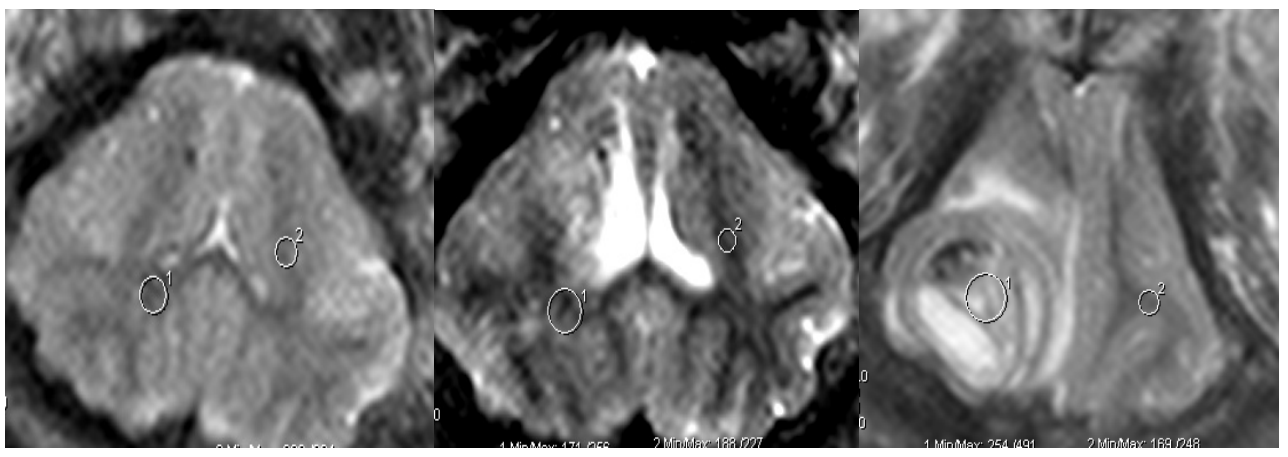

(13)

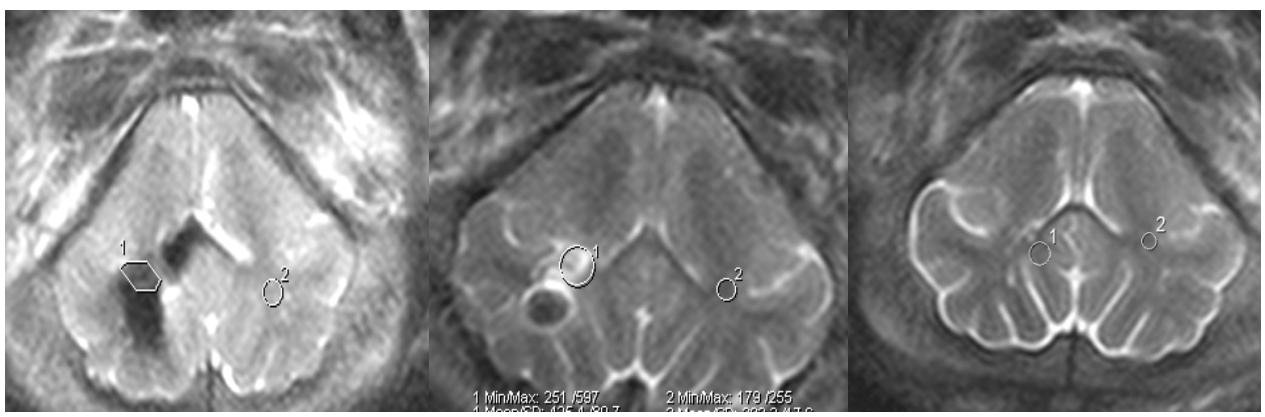

(14)

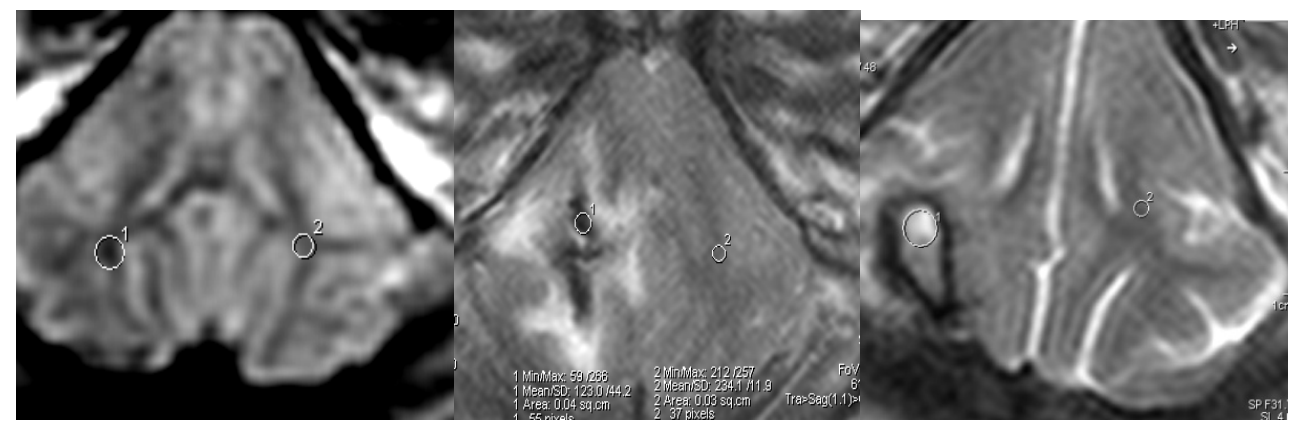

(18)

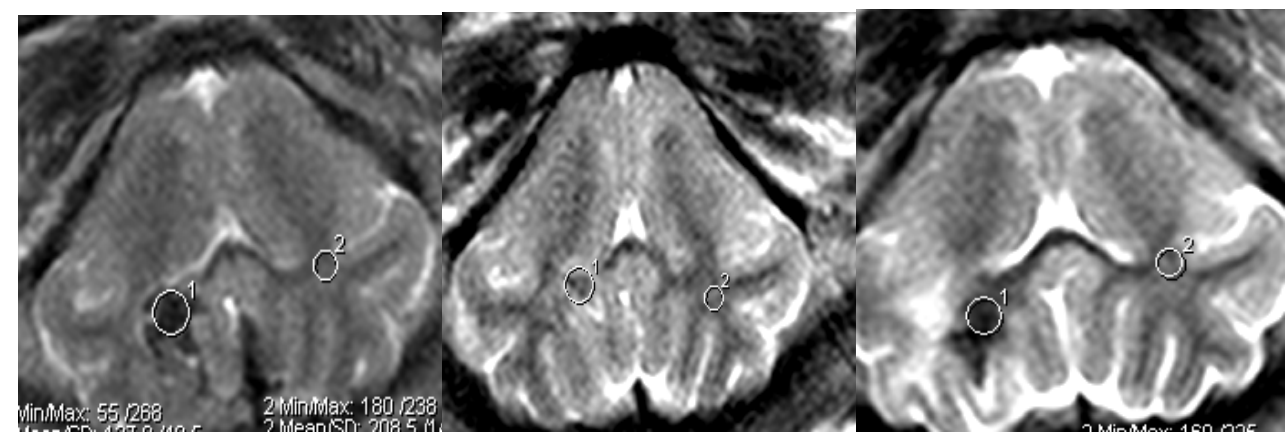




\section{PAI T2}

(9)

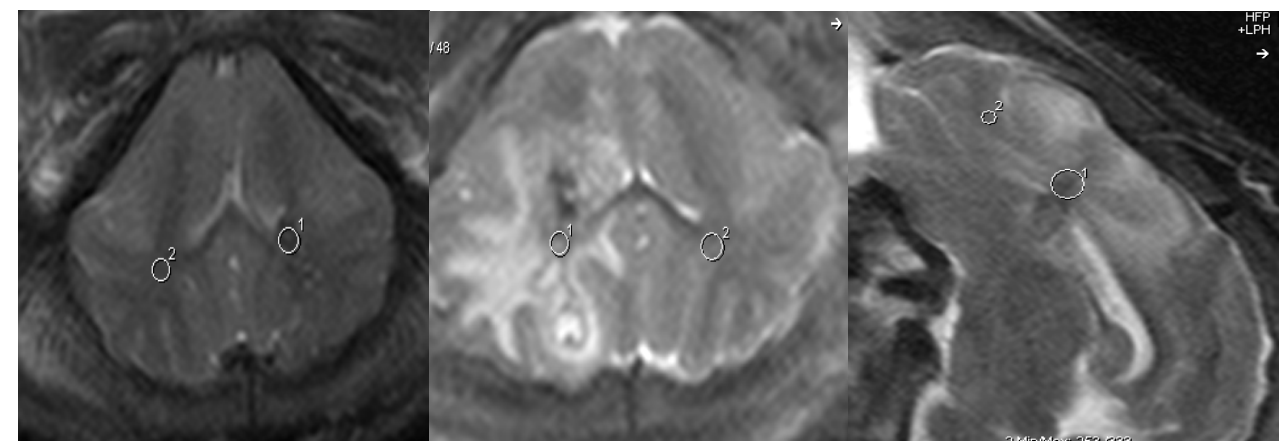

(11)

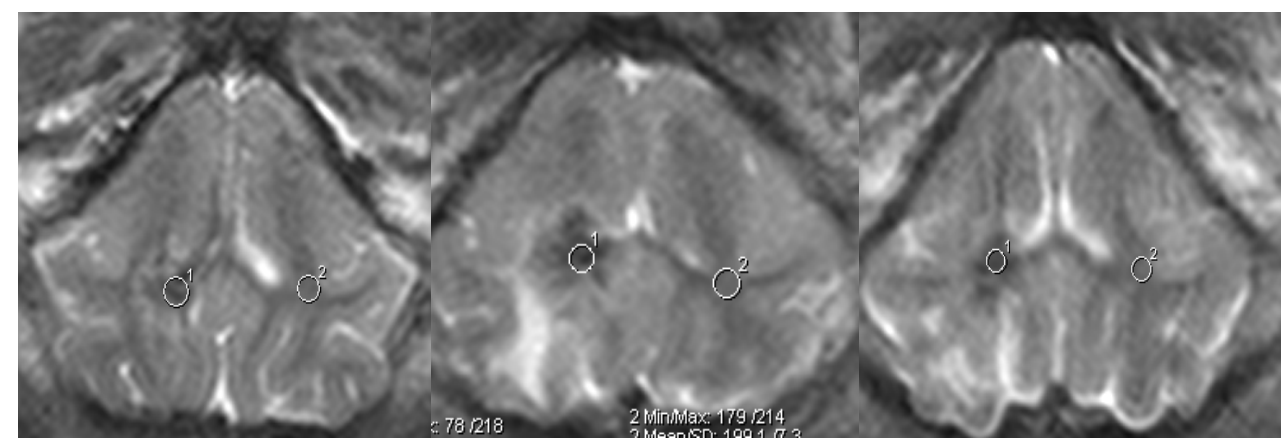

(15)

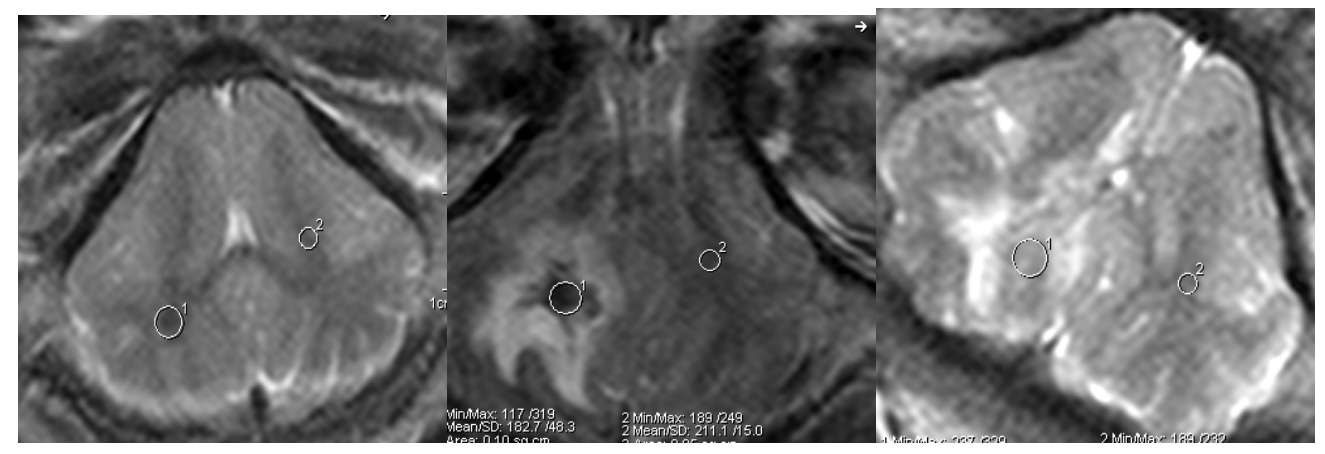

(16)

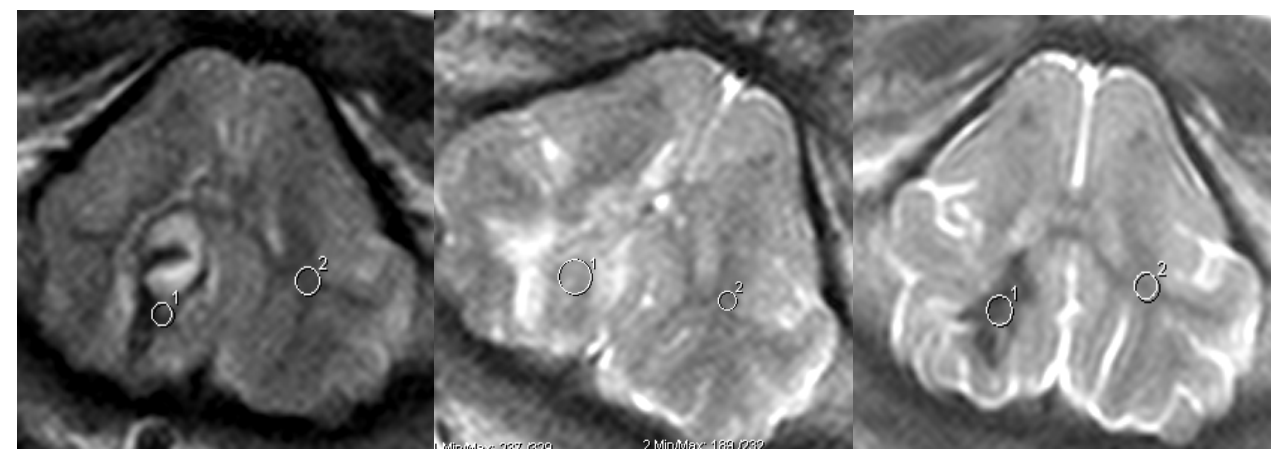


(17)

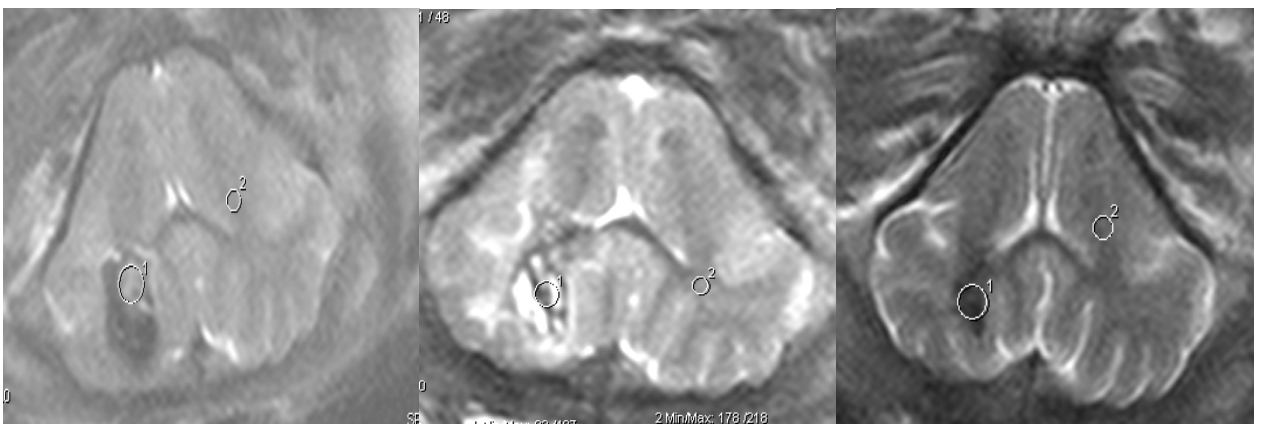

(21)

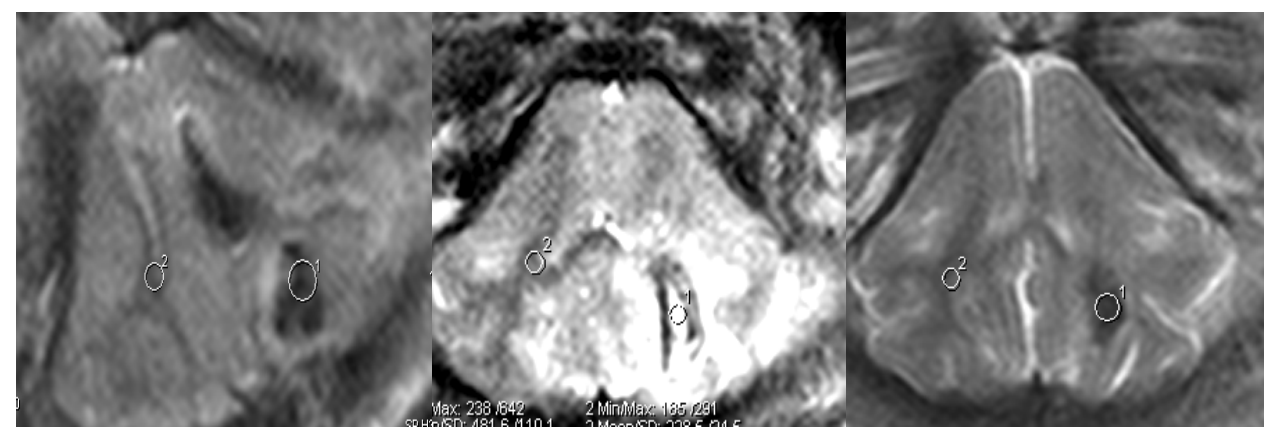

\section{Kontrolle PD}

(2)
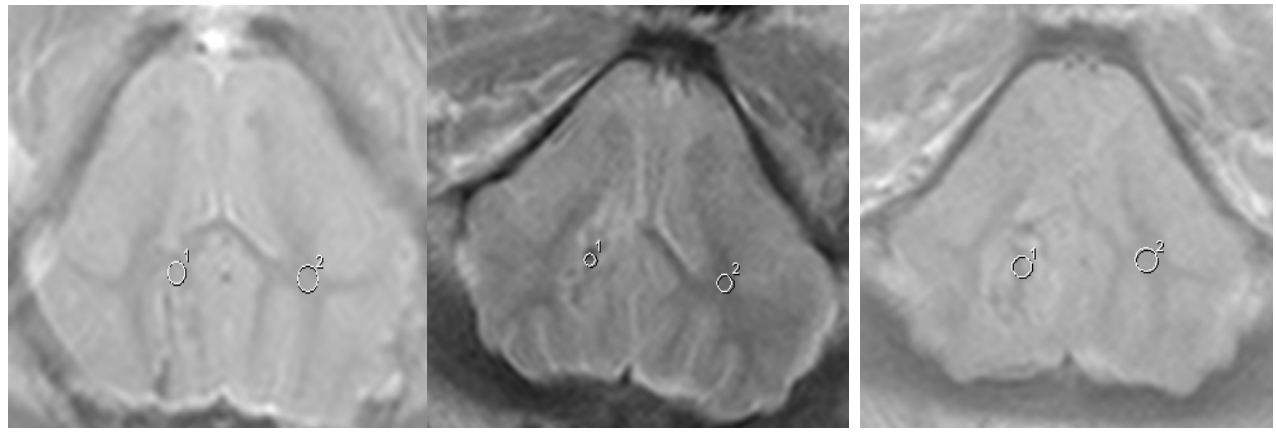

(3)

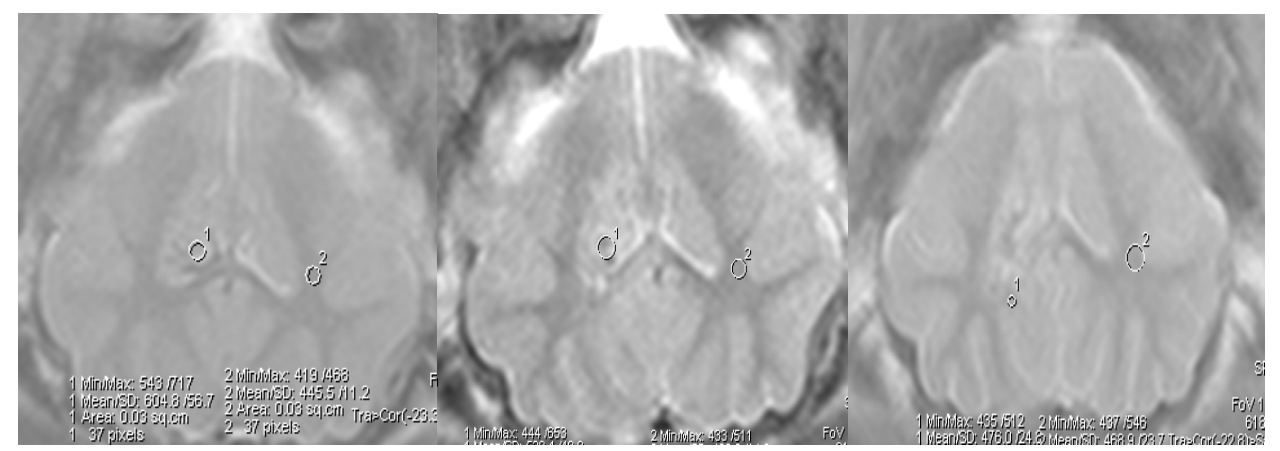


(6)

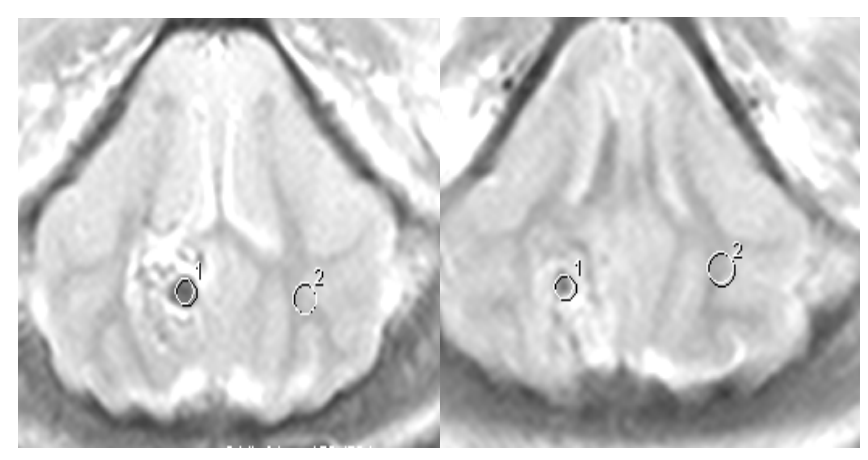

(10)

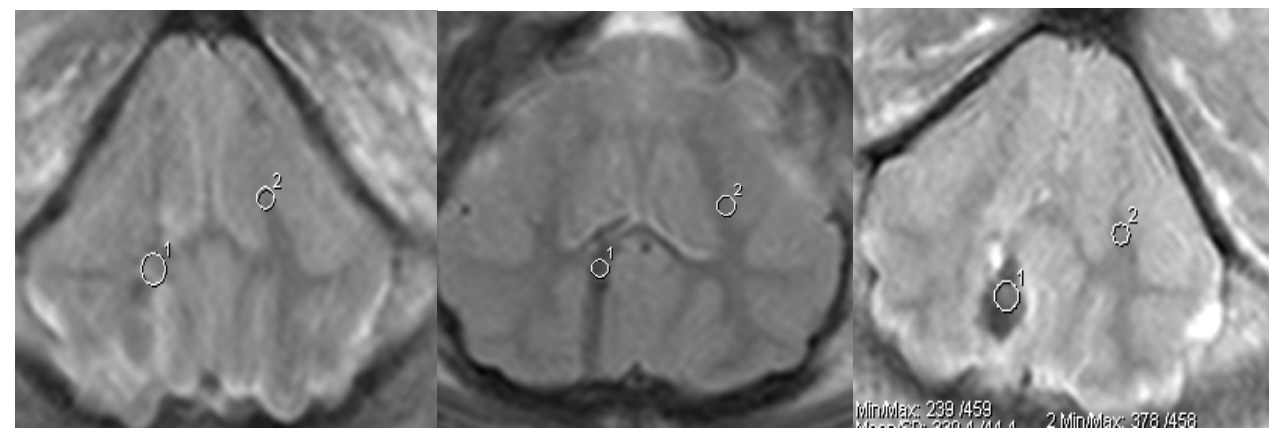

(20)
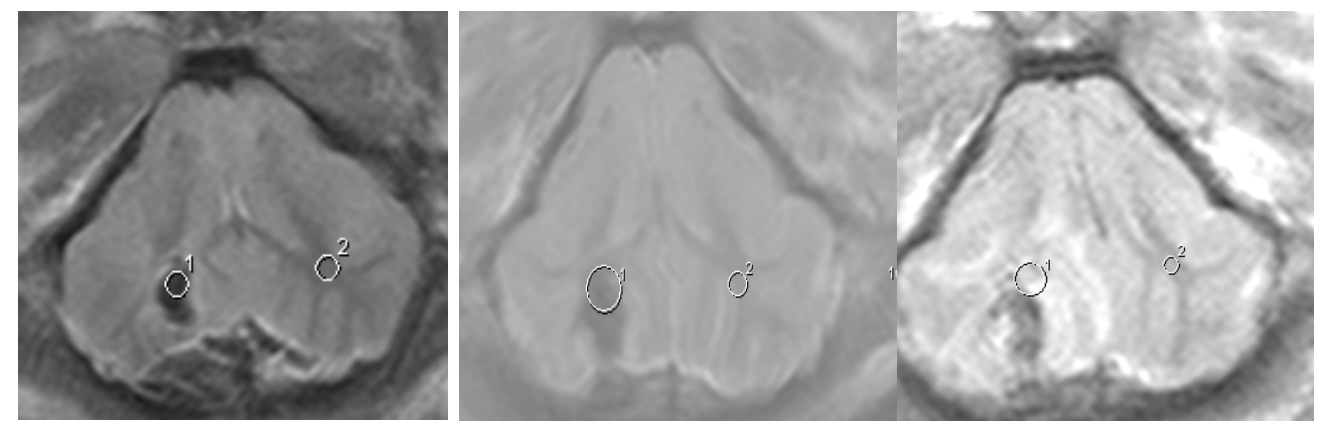

\section{Lyse PD}

(4)

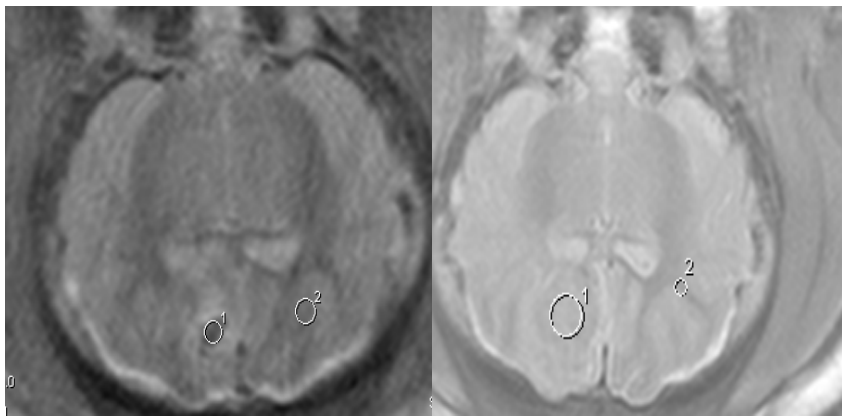


(5)

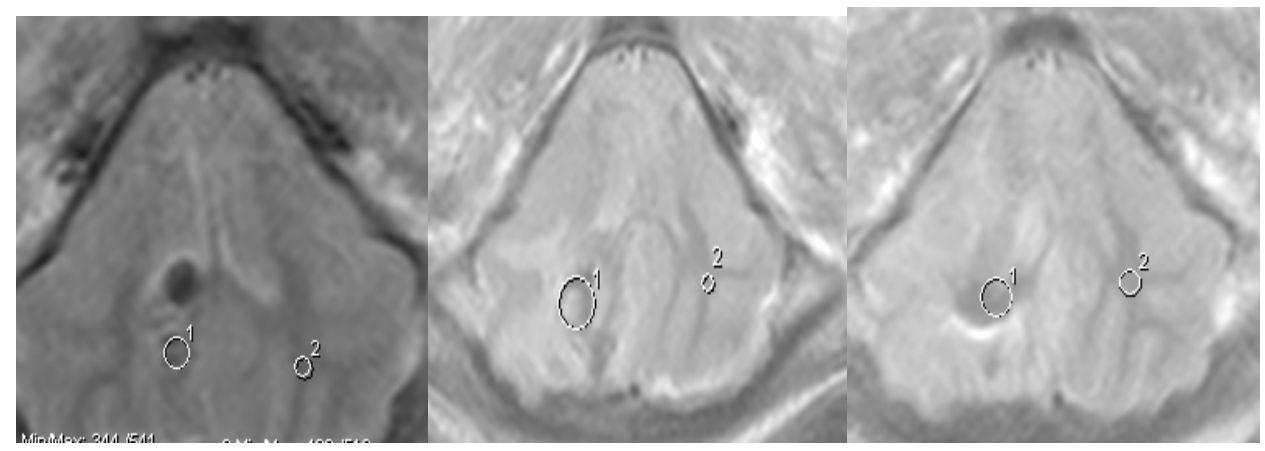

(7)

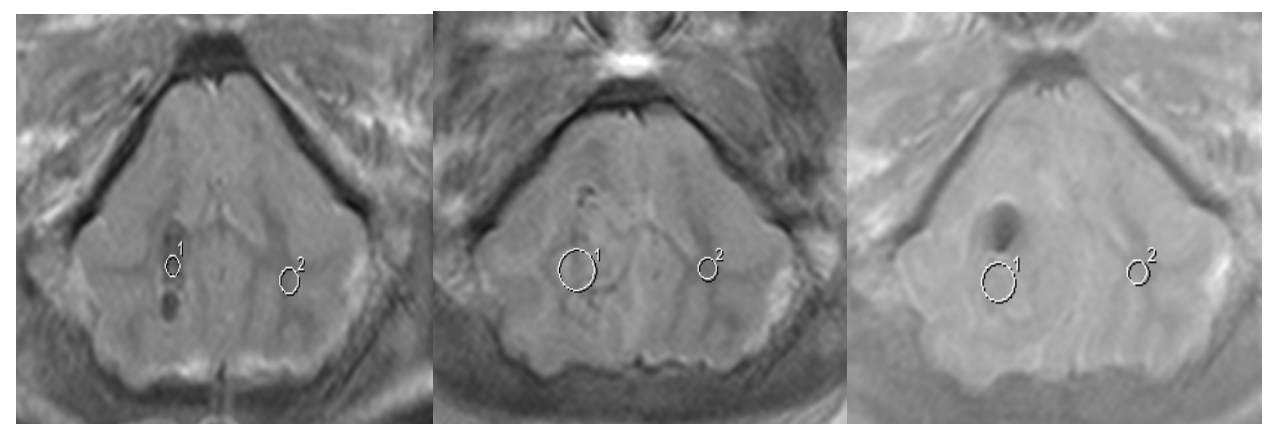

(12)

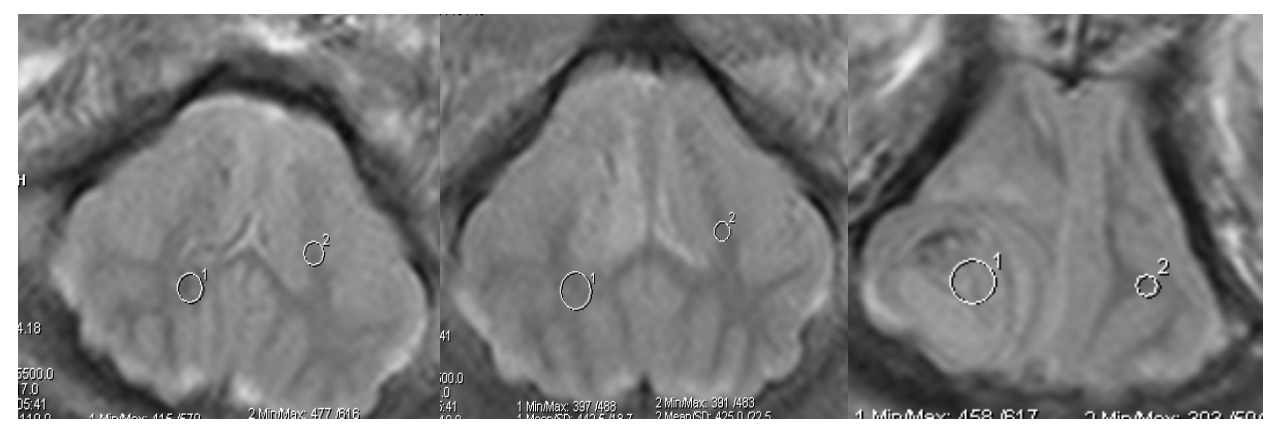

(13)

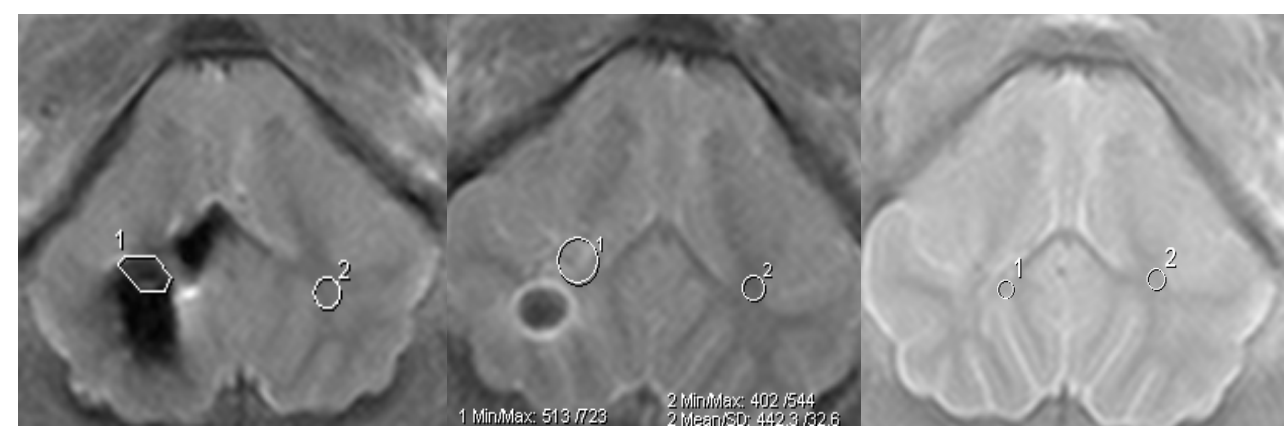


(14)

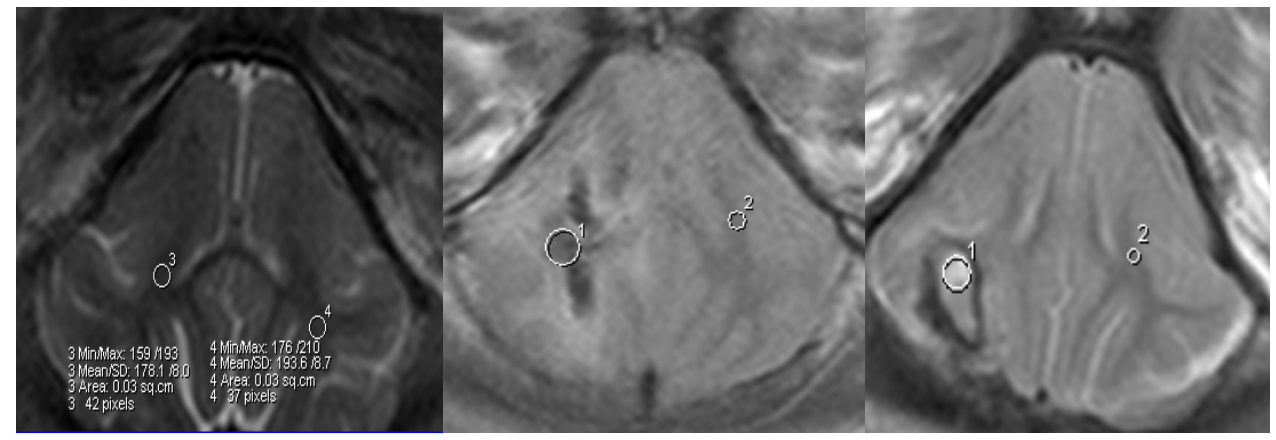

(18)

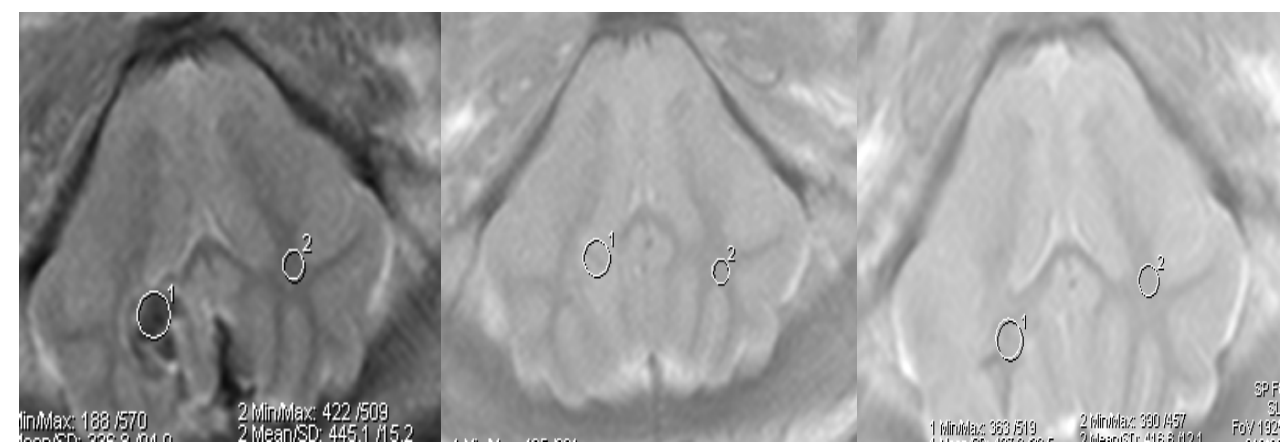

\section{PAI PD}

(9)

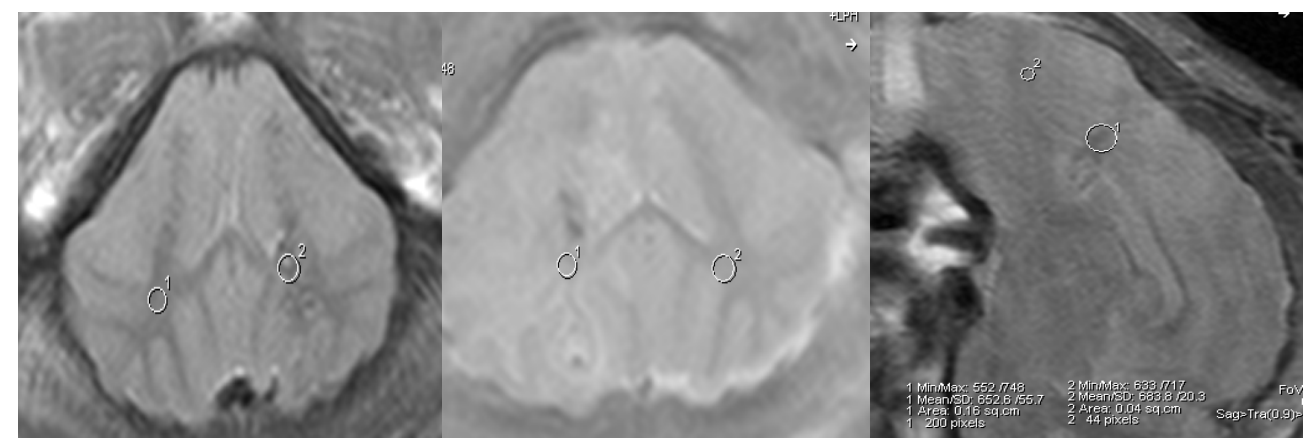

(11)

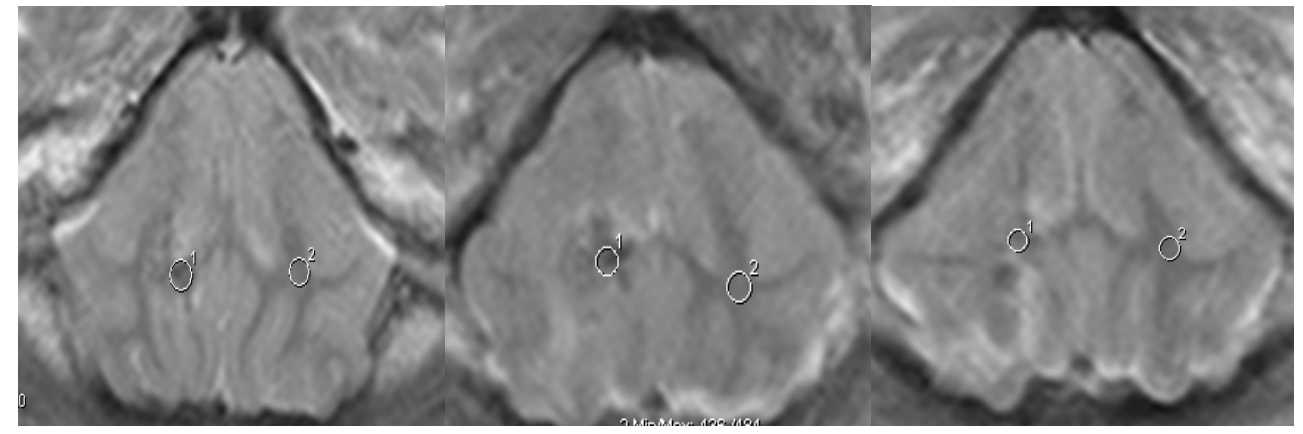


(15)

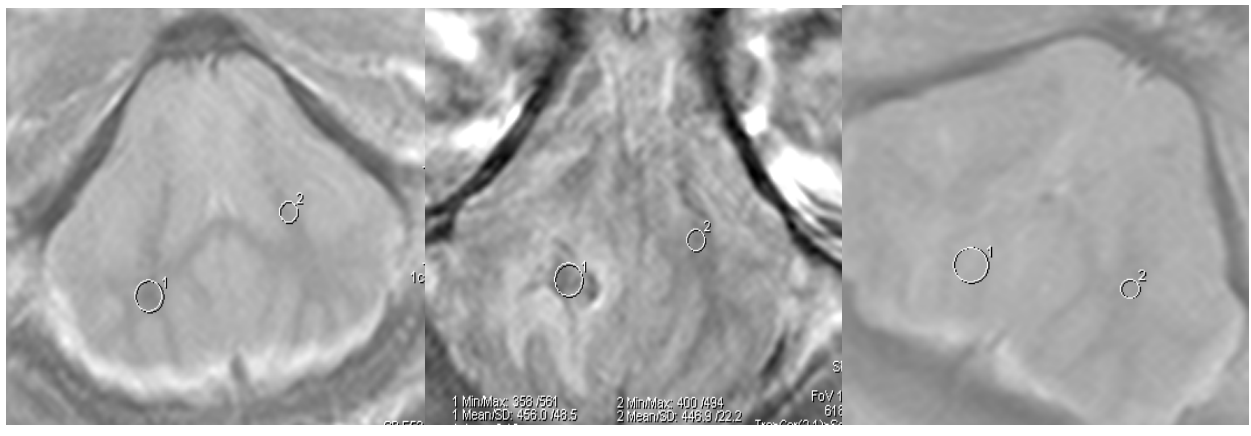

(16)

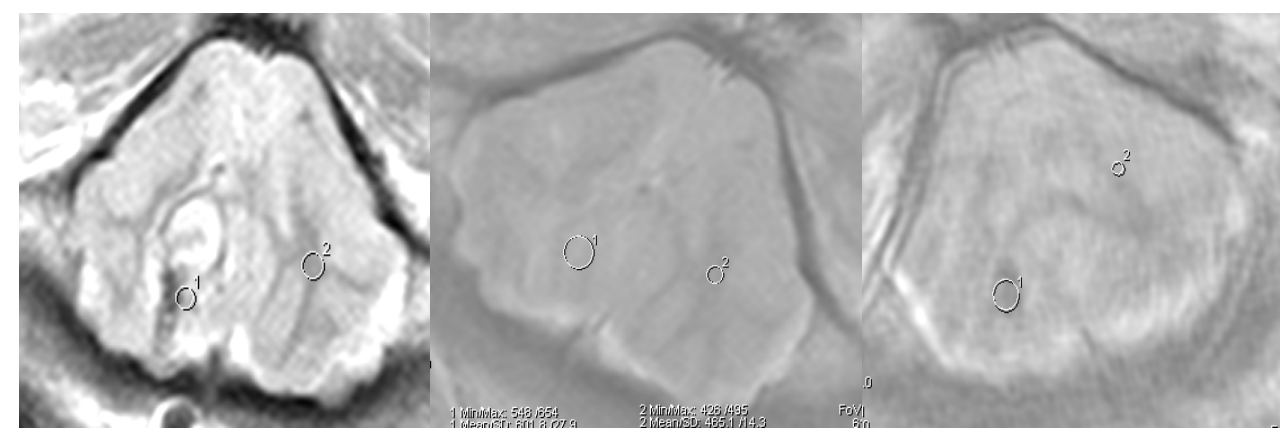

(17)

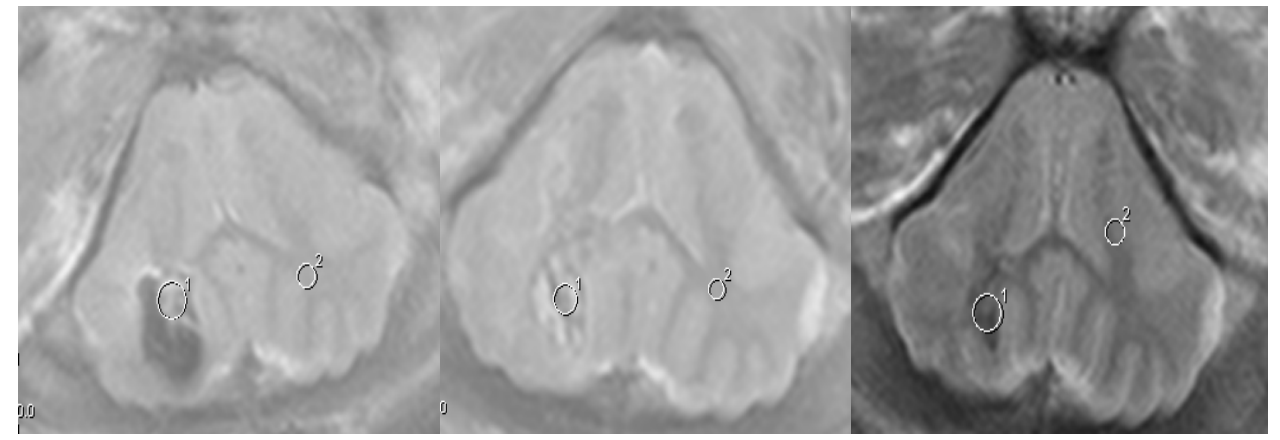

(21)

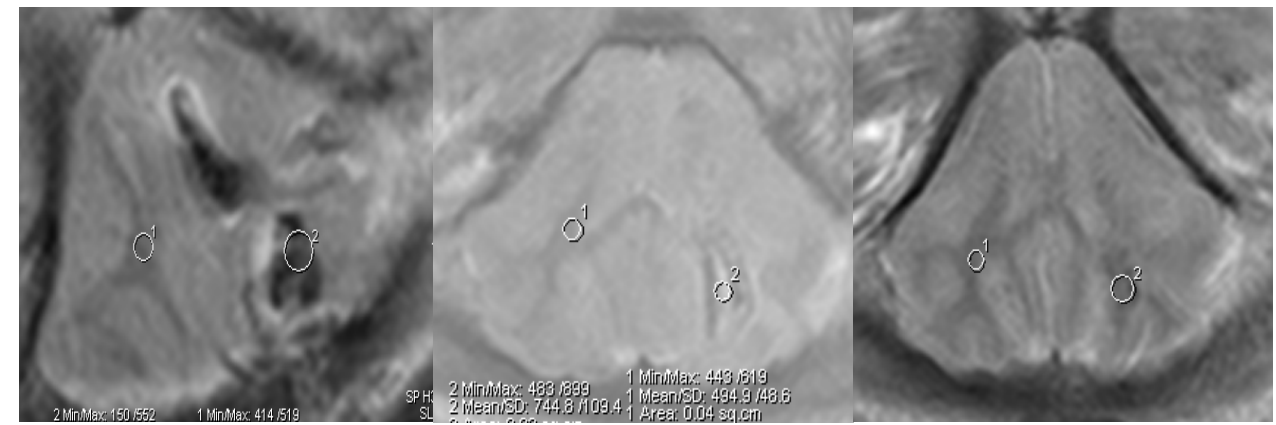


Kontrolle T2*

(2)

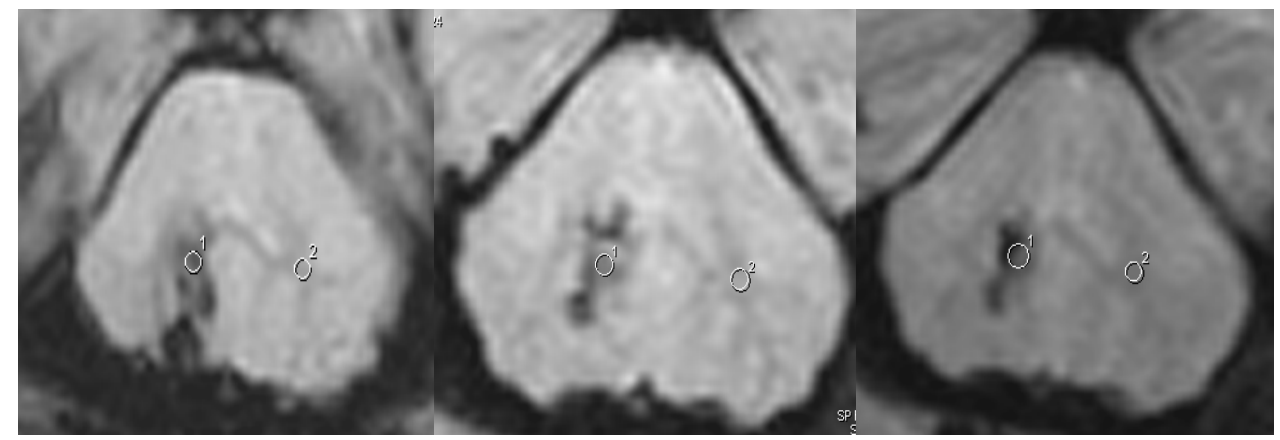

(3)

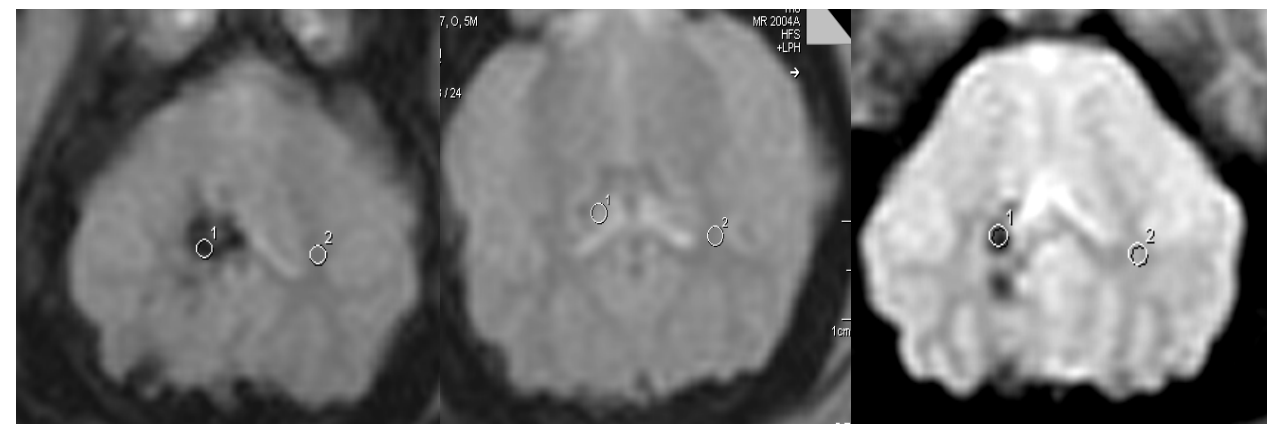

(6)

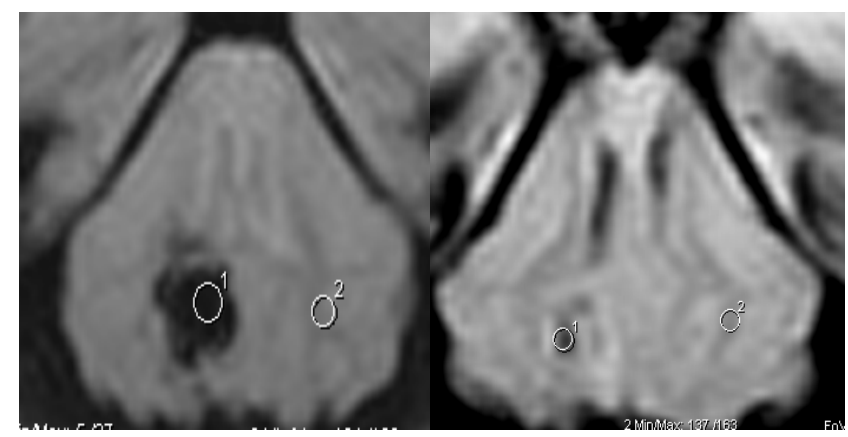

(10)

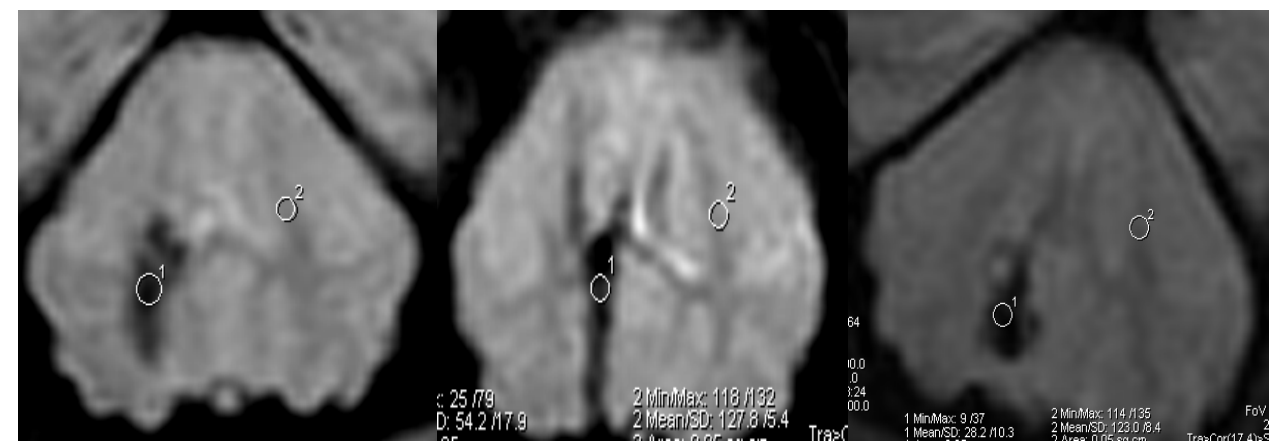


(20)

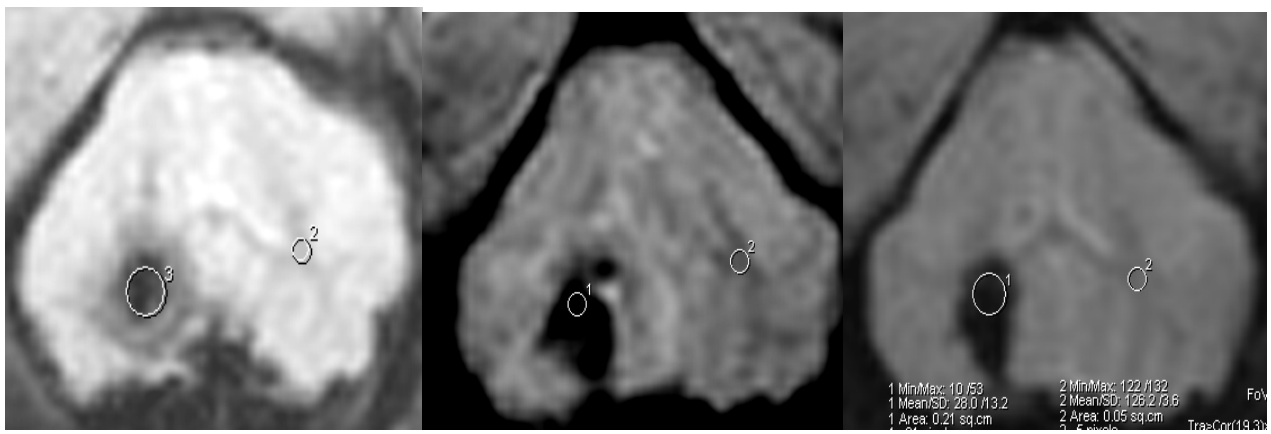

\section{Lyse T2*}

(4)

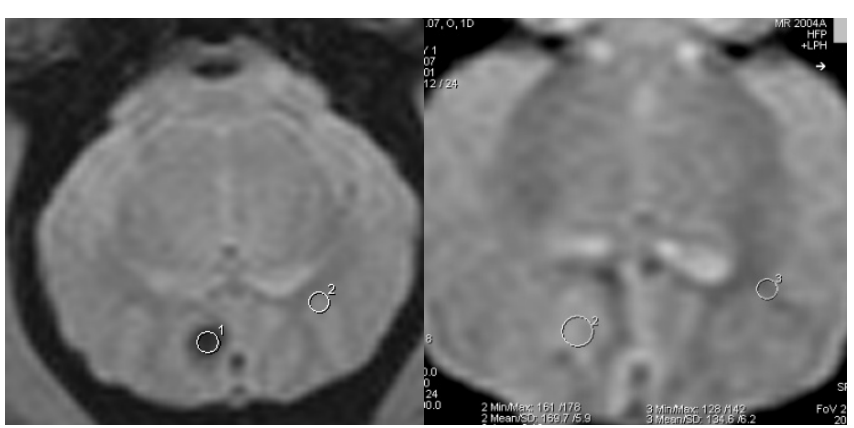

(7)

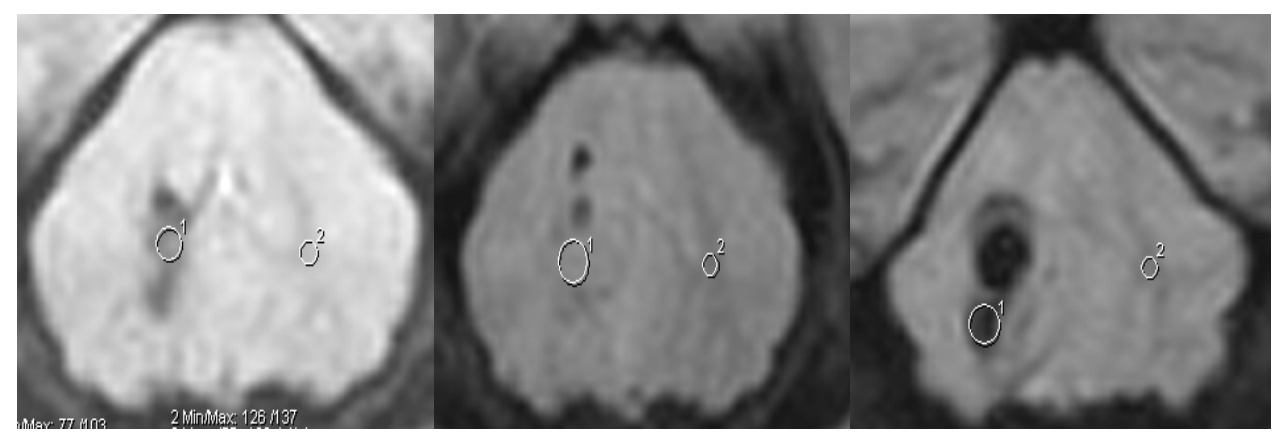

(12)

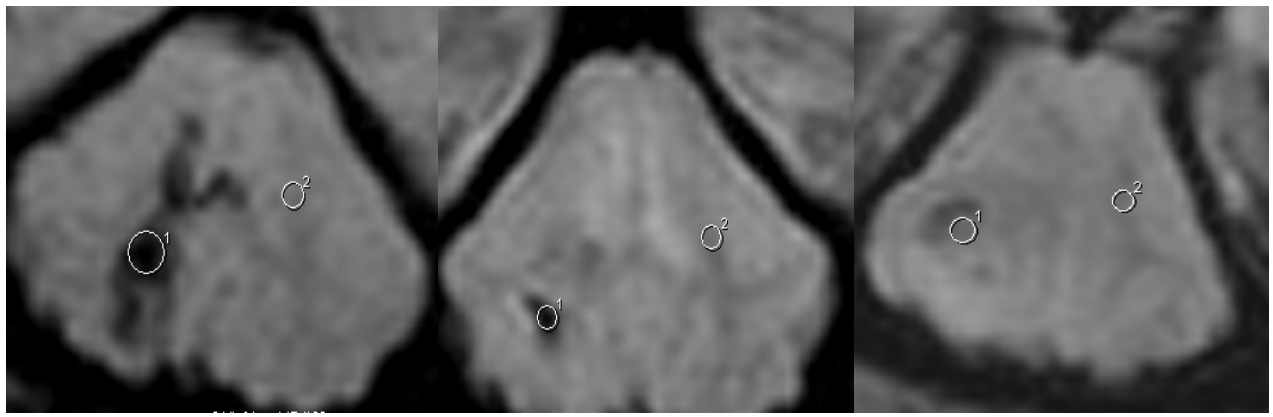


(13)

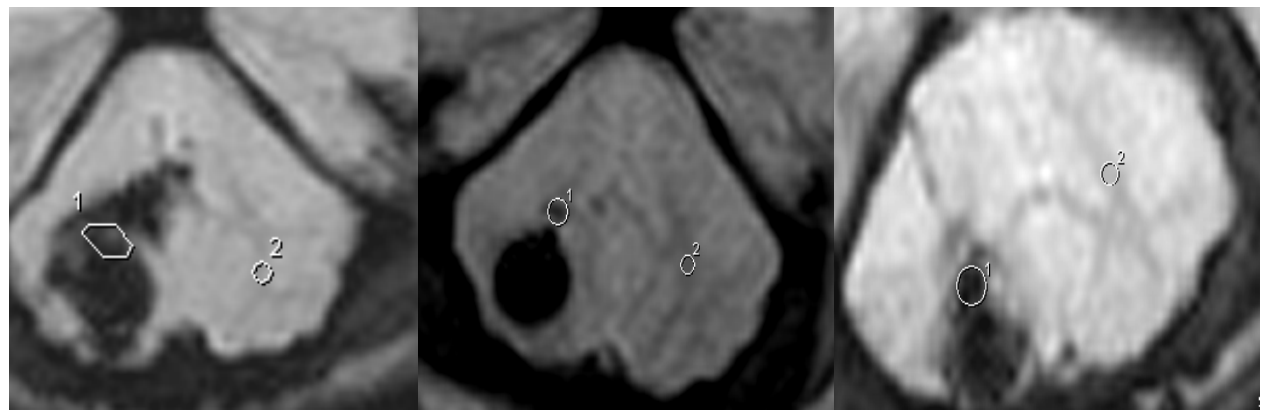

(14)
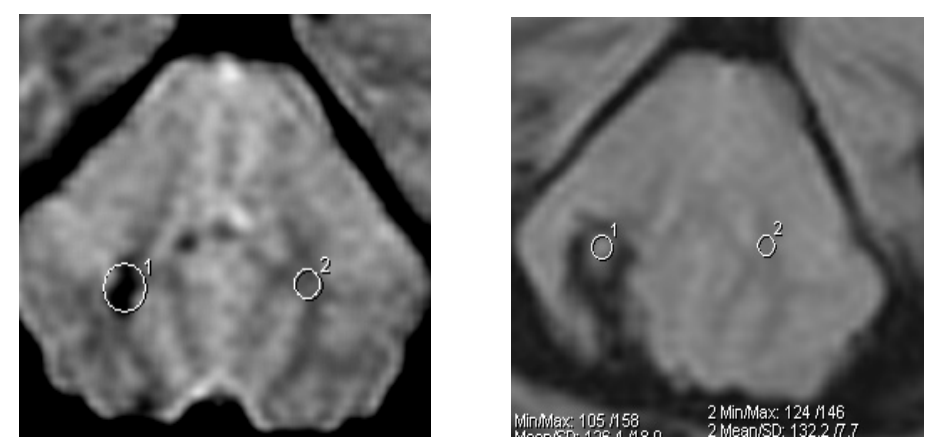

(18)

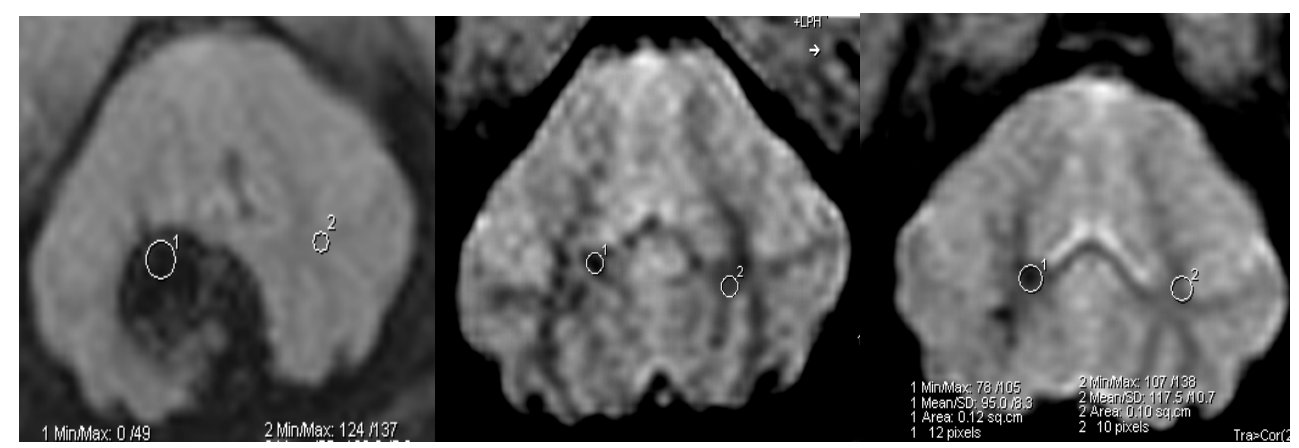

\section{PAI T2*}

(9)

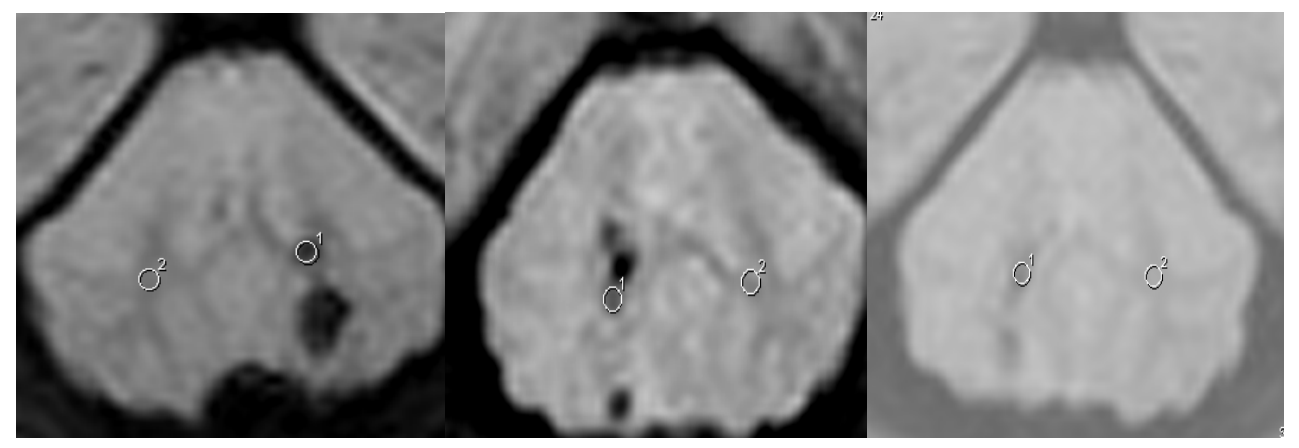


(11)

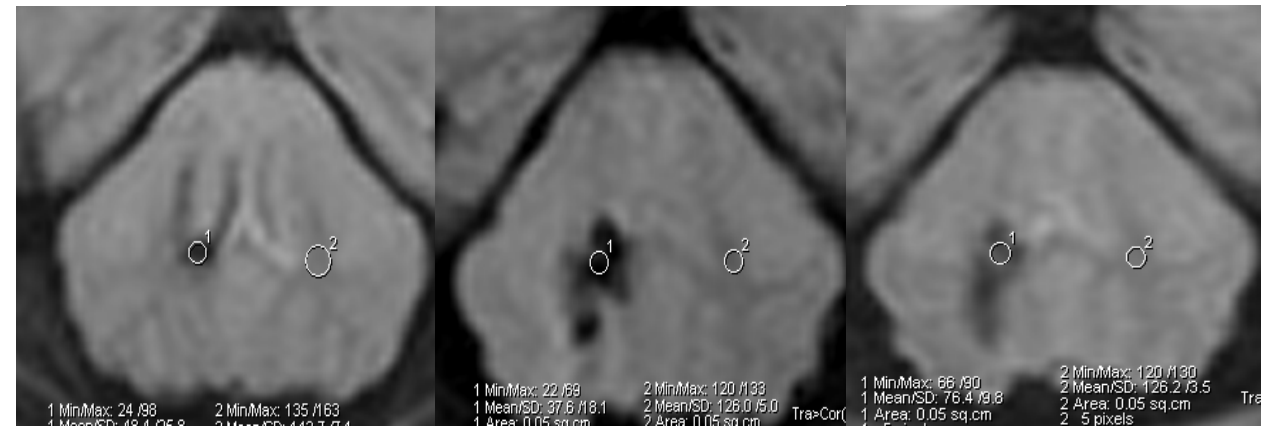

(15)

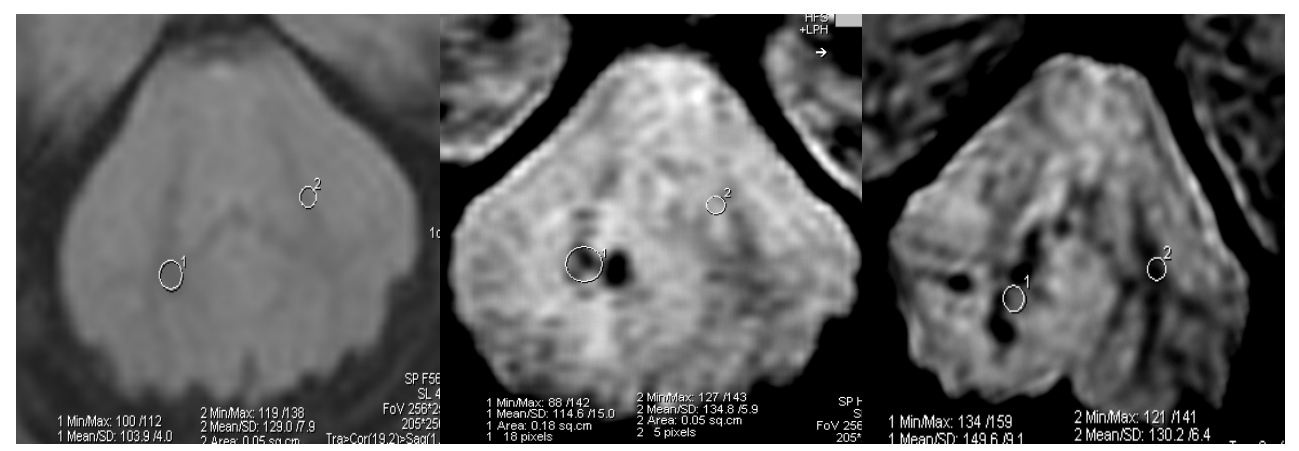

(16)

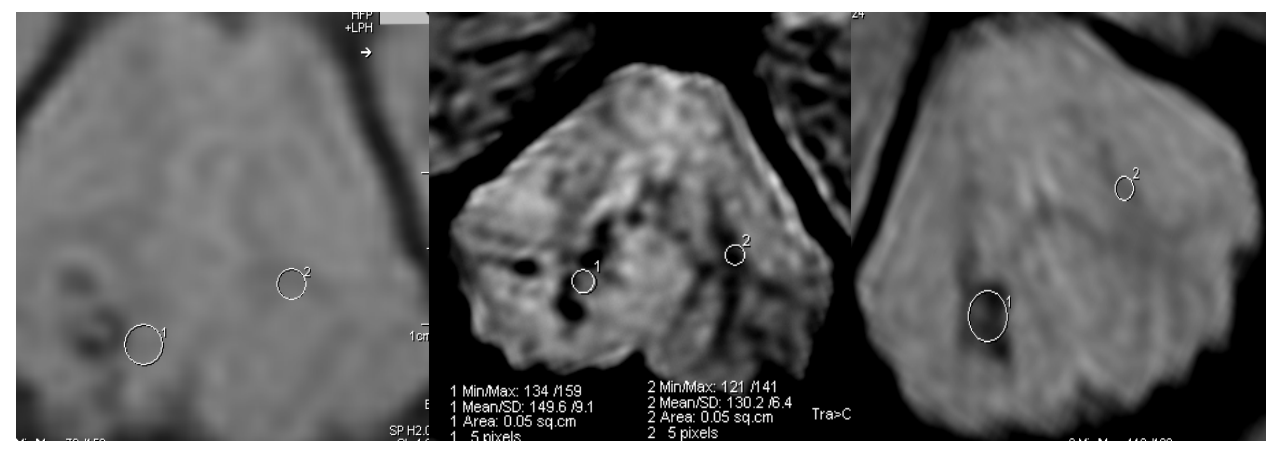

(17)

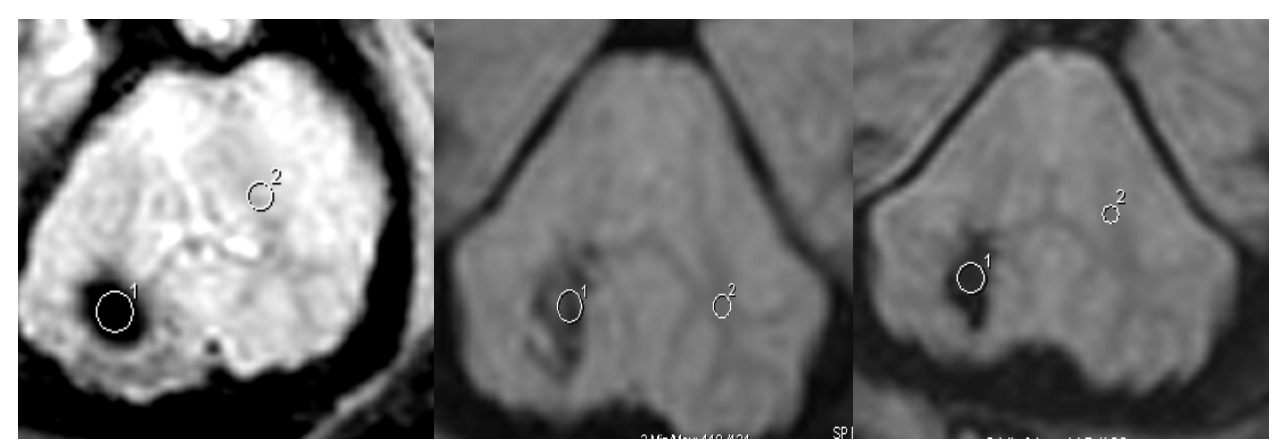




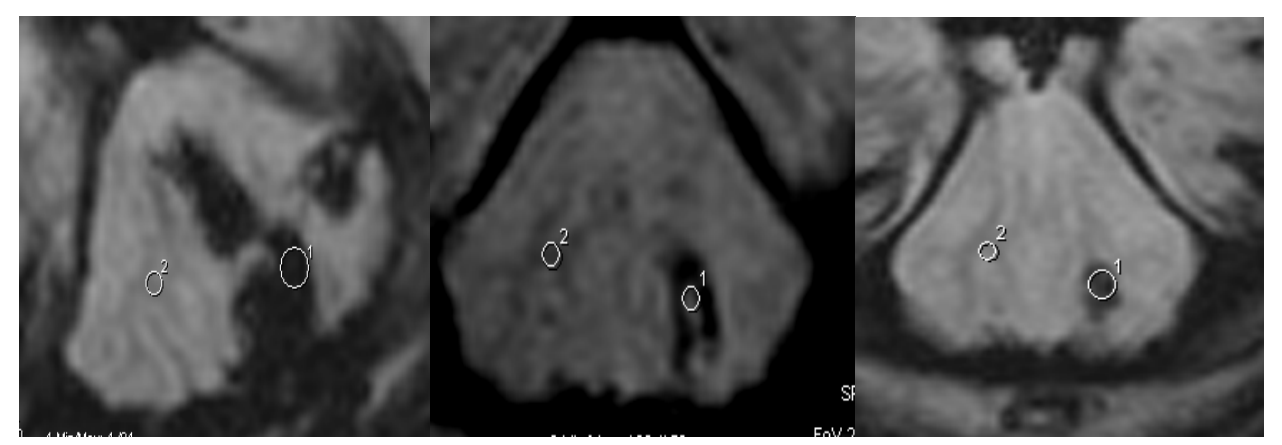

\section{Kontrolle Flair}

(2)

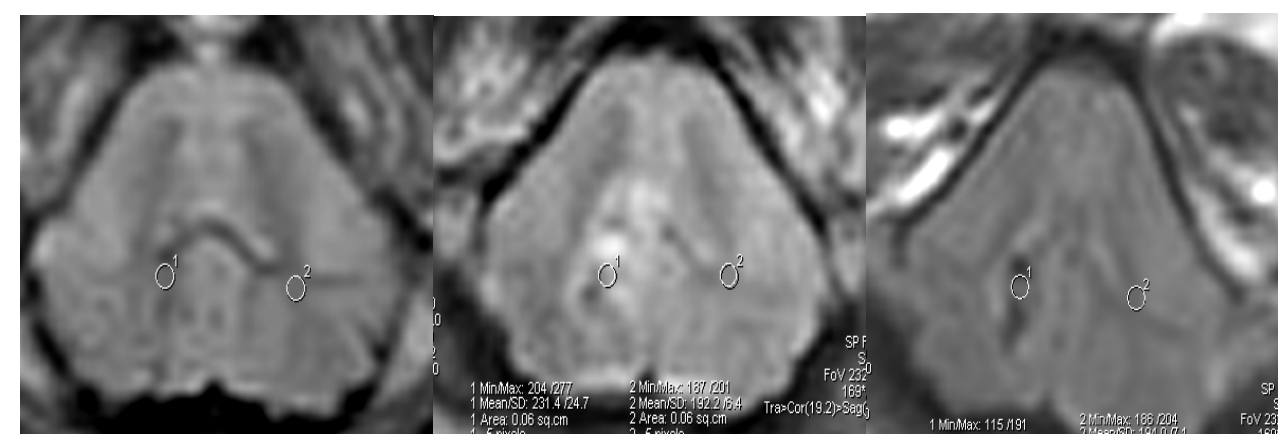

(3)

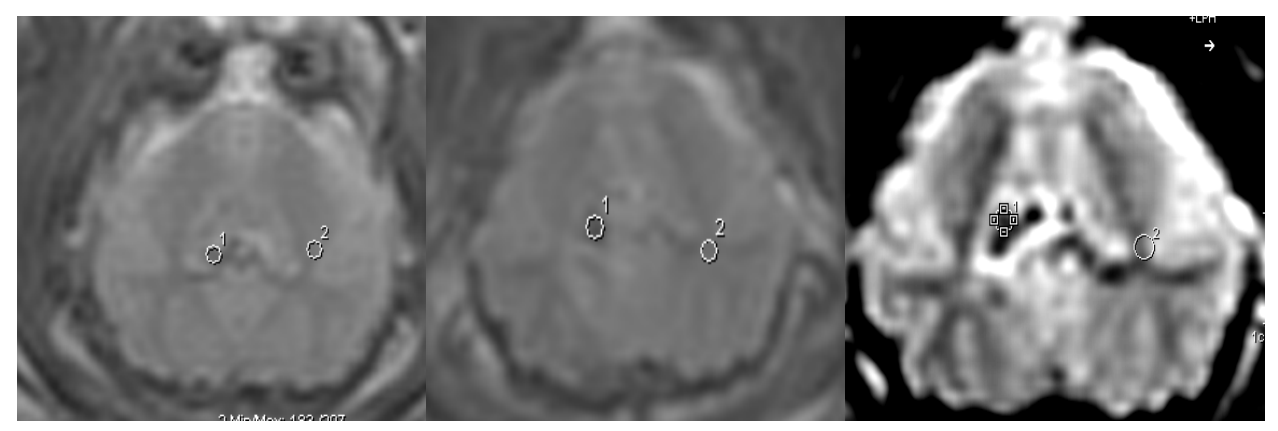

(6)

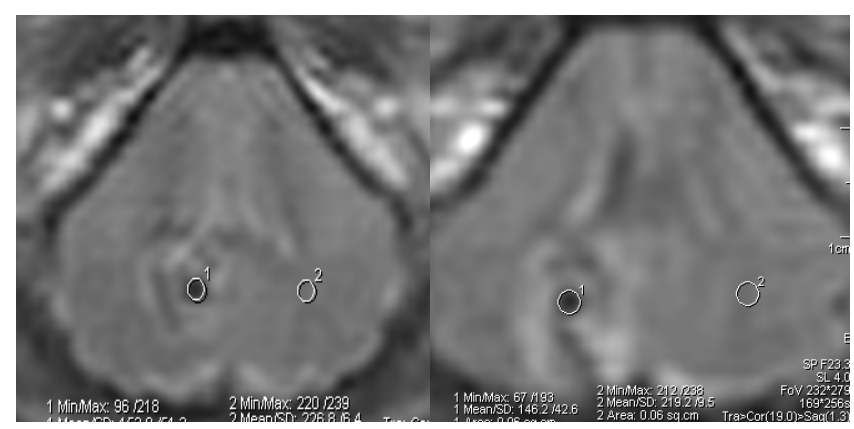

(10) 


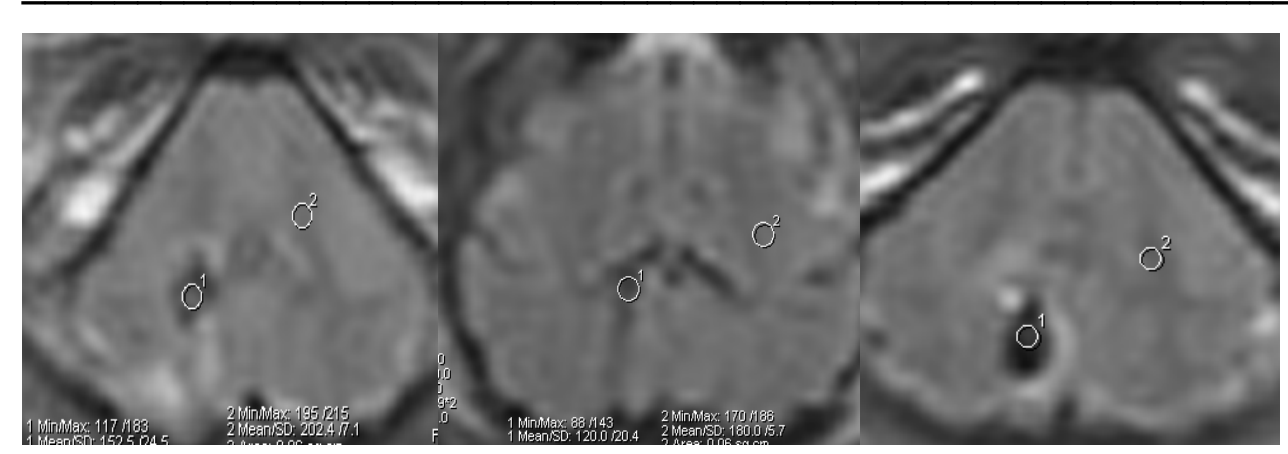

(20)

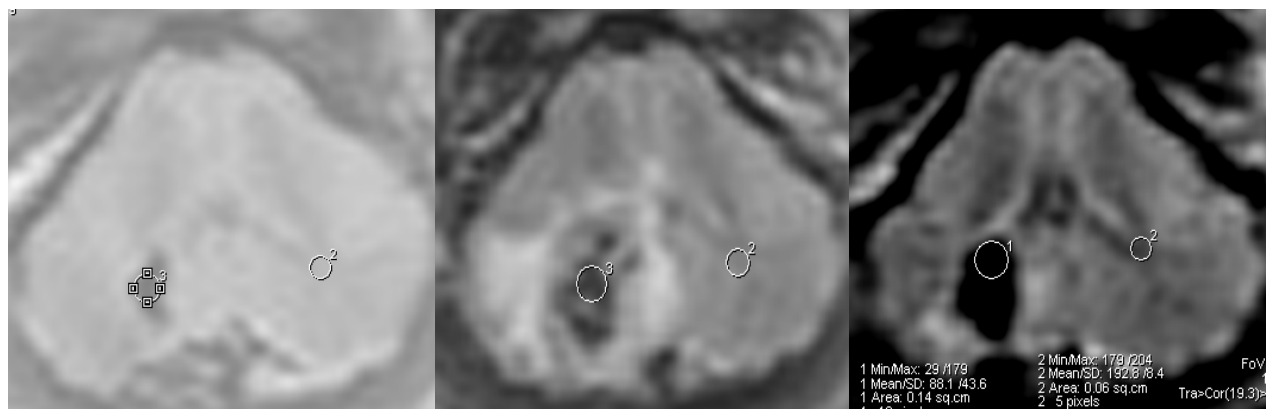

\section{Lyse Flair}

(4)

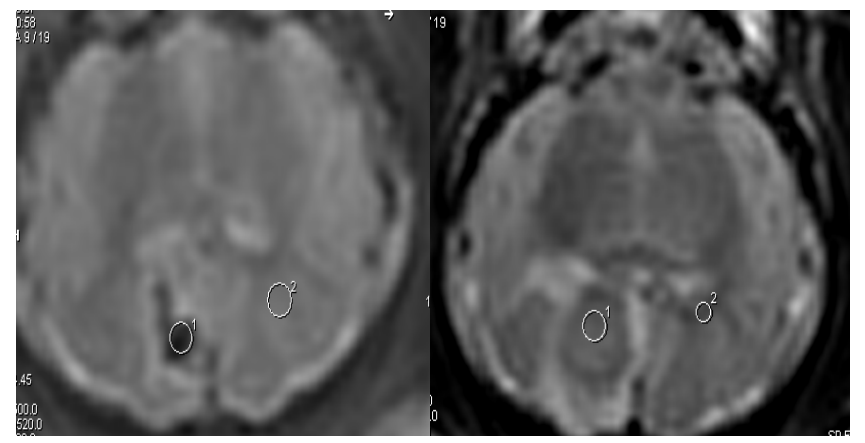

(5)

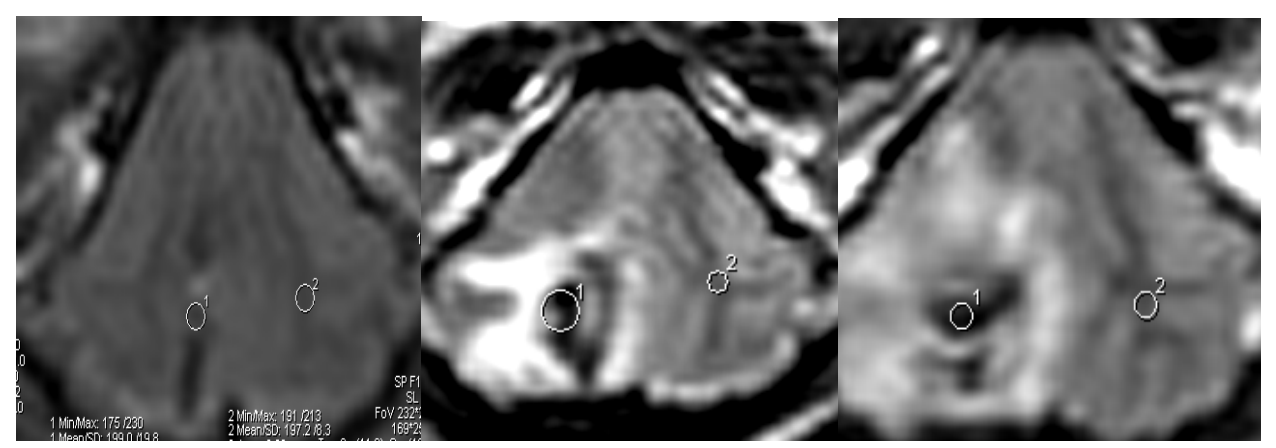

(7) 


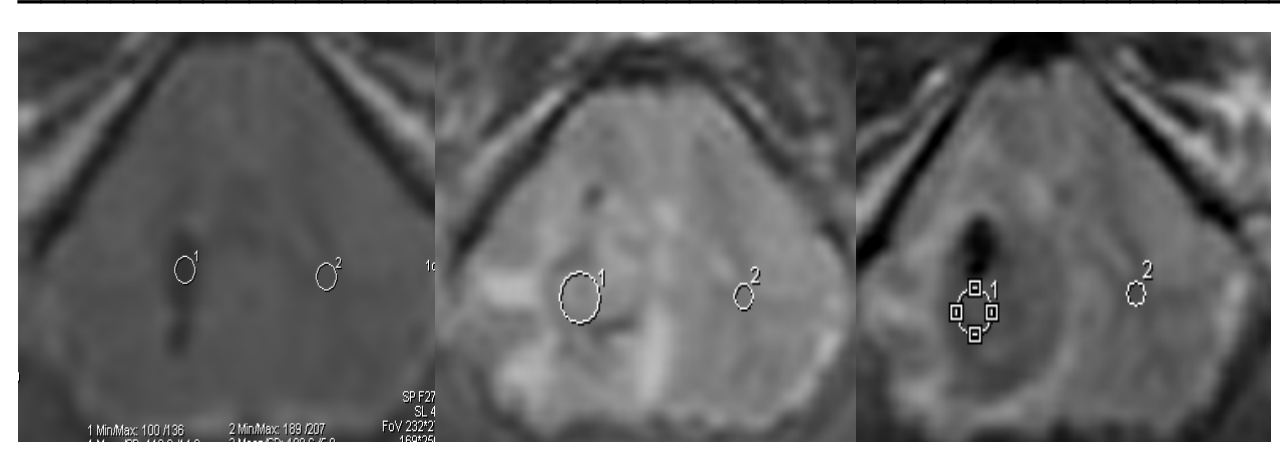

(12)

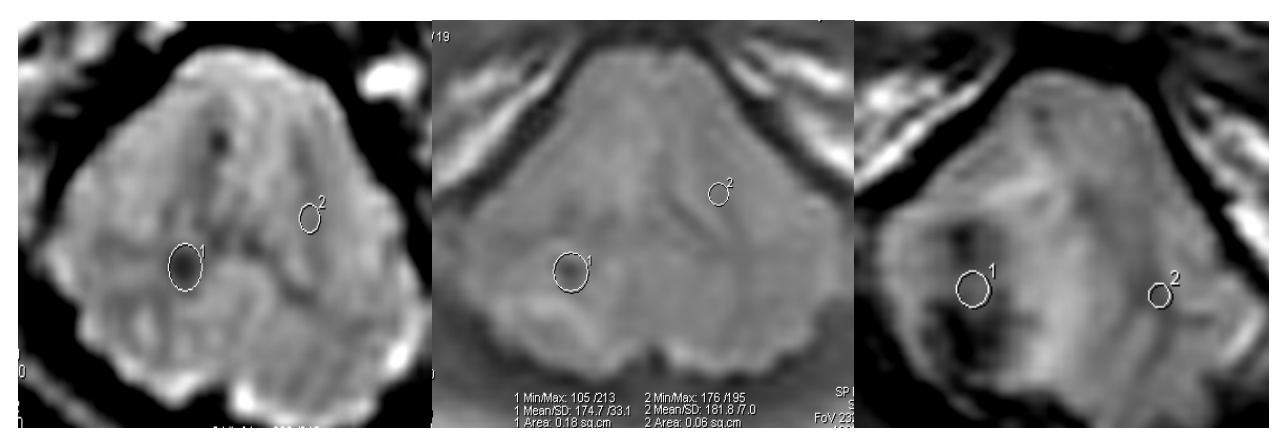

(13)

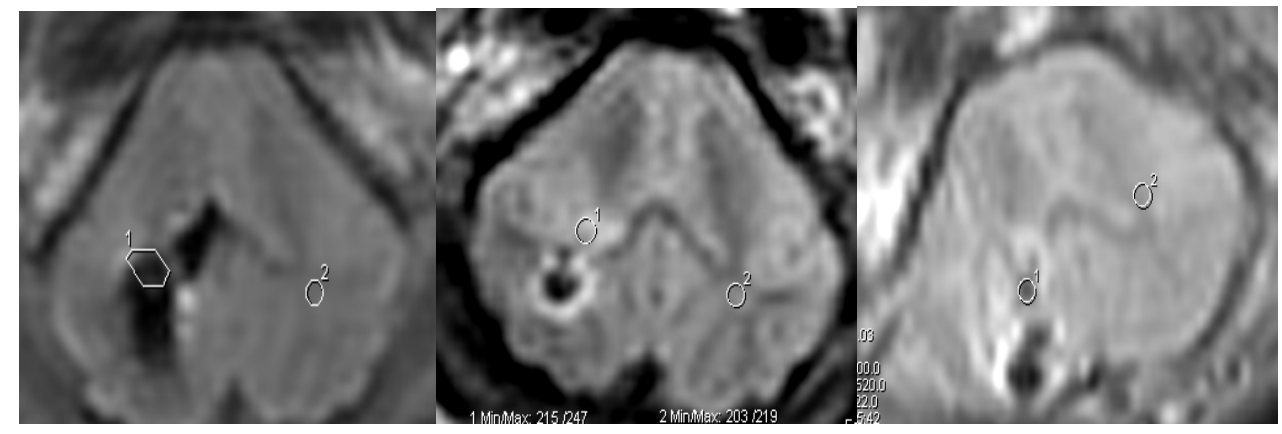

(14)

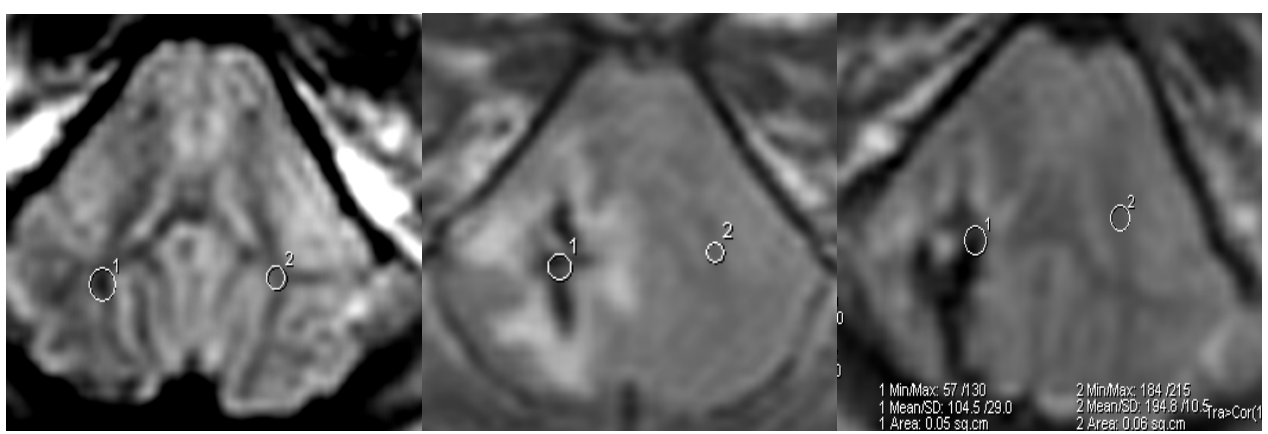


(18)

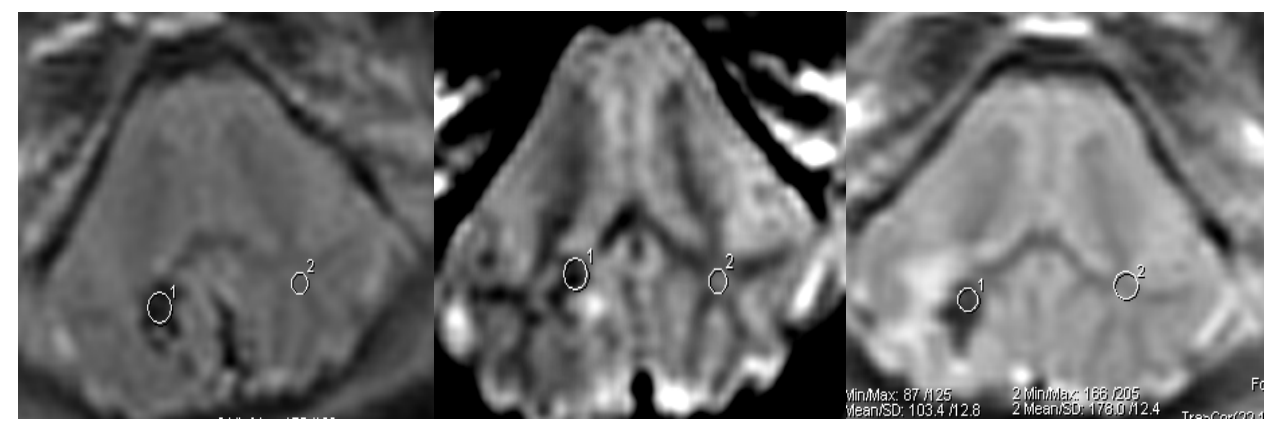

\section{PAI Flair}

(9)

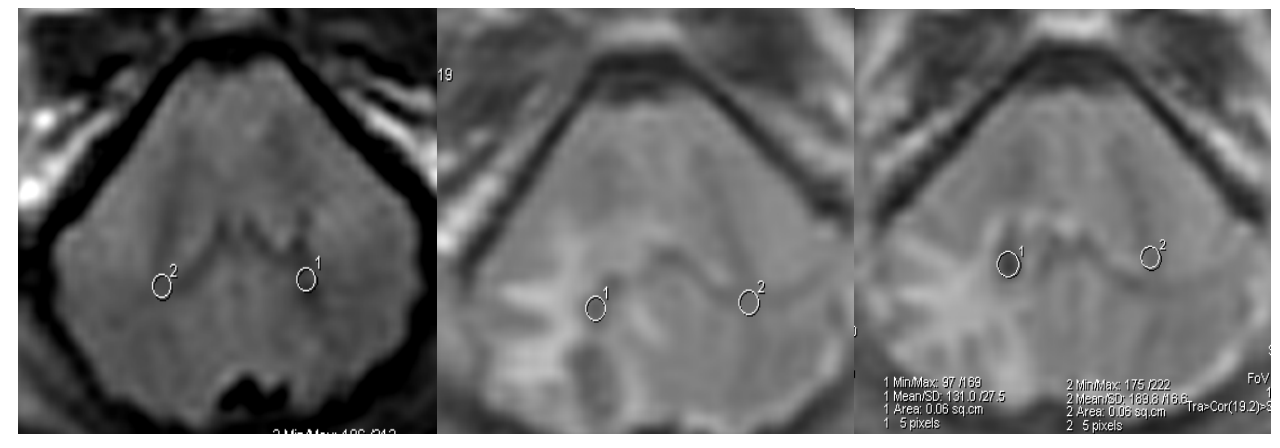

(11)

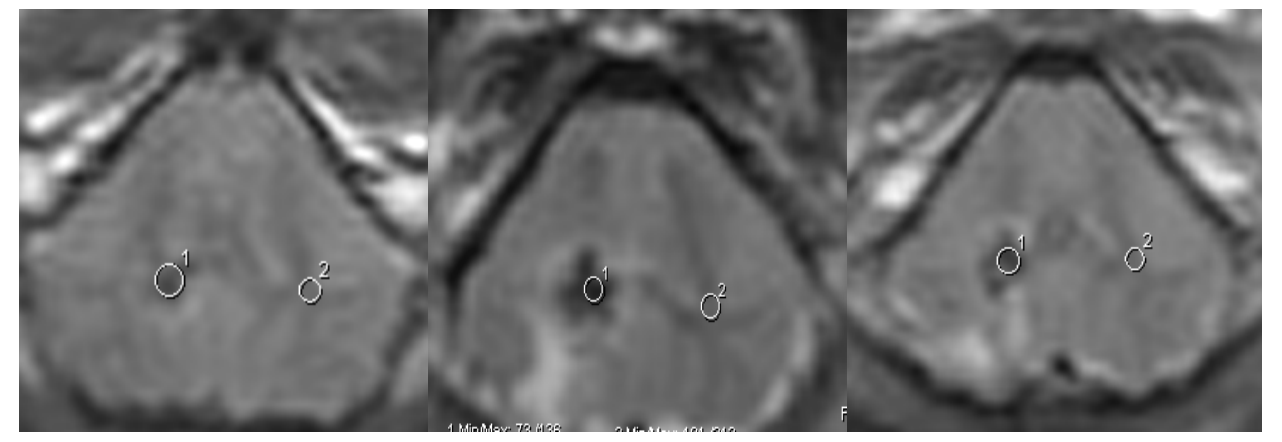

(15)

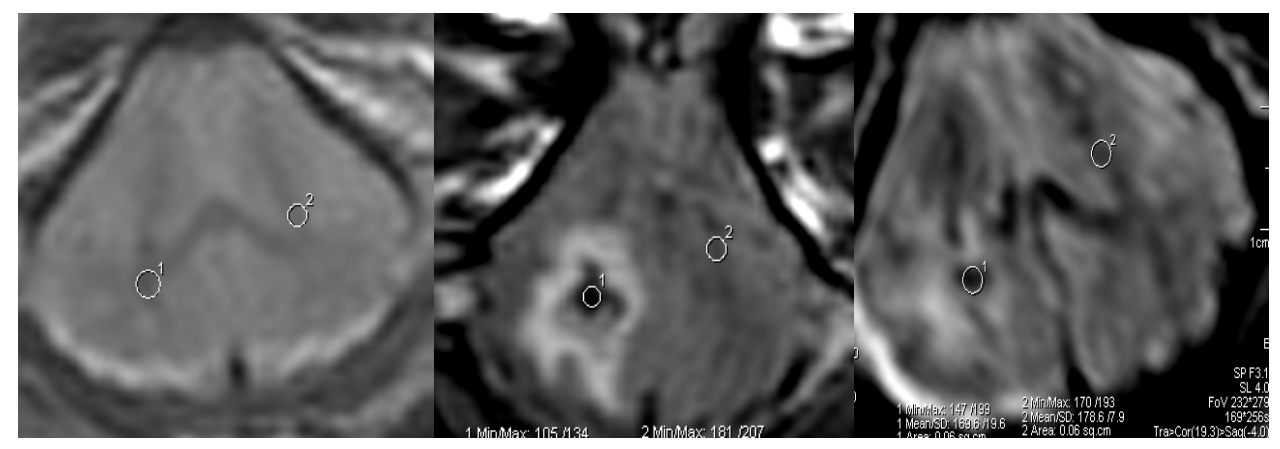


(16)

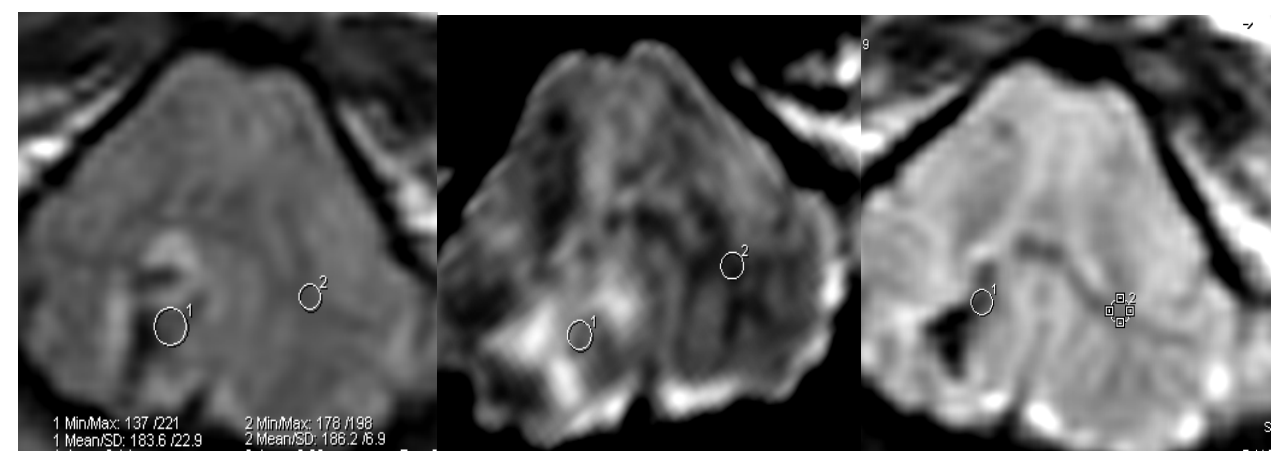

(17)

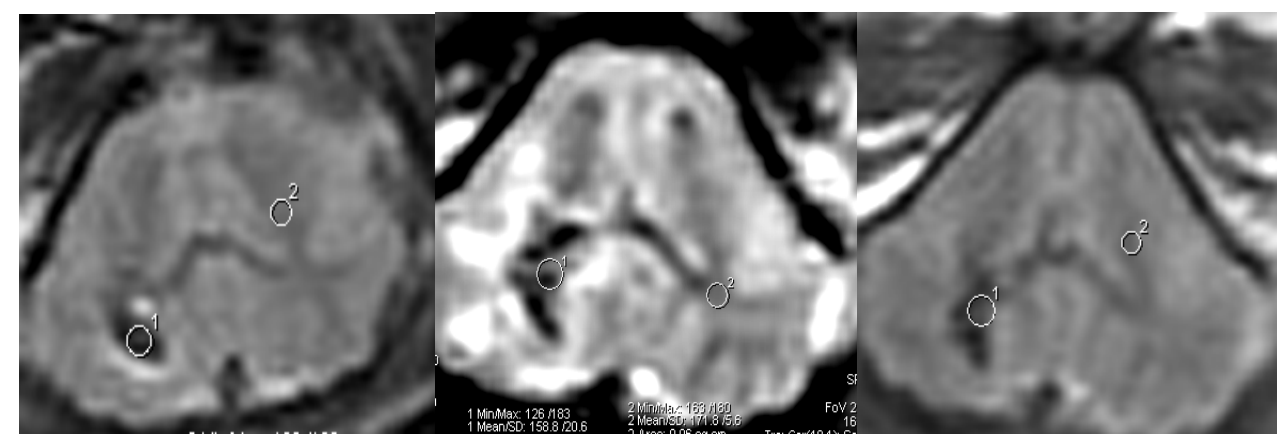

(21)

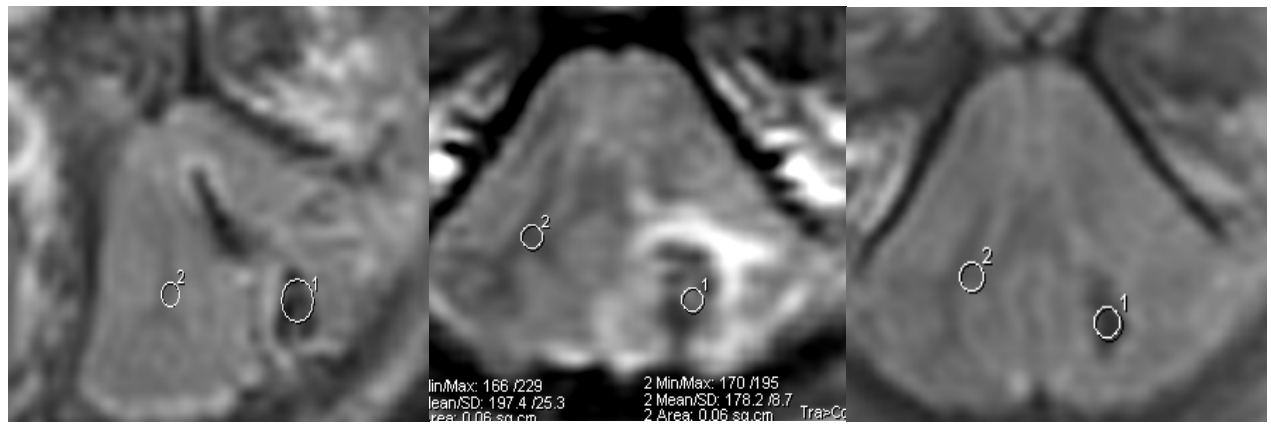

\section{Kontrolle Diff 1000}

(2)

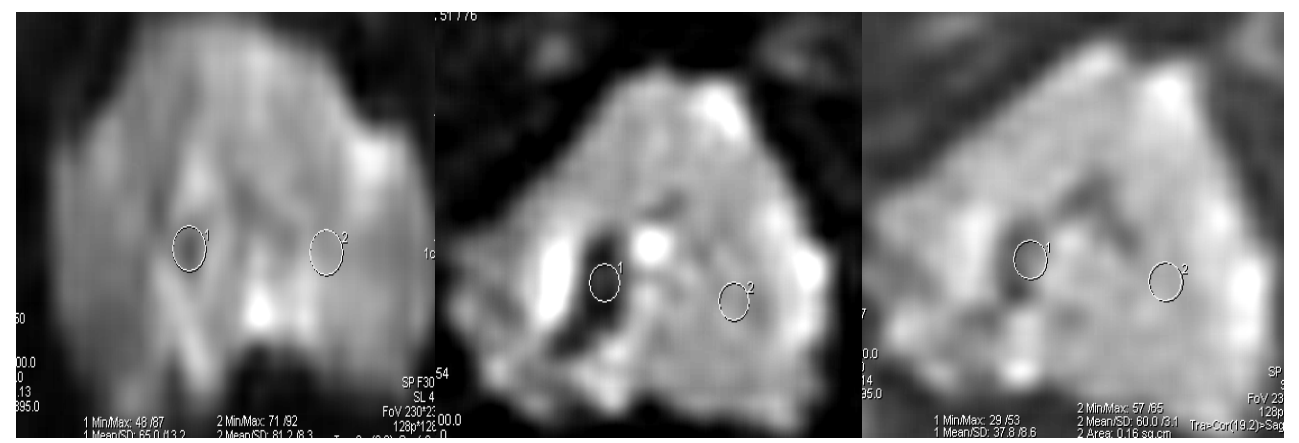

(3) 


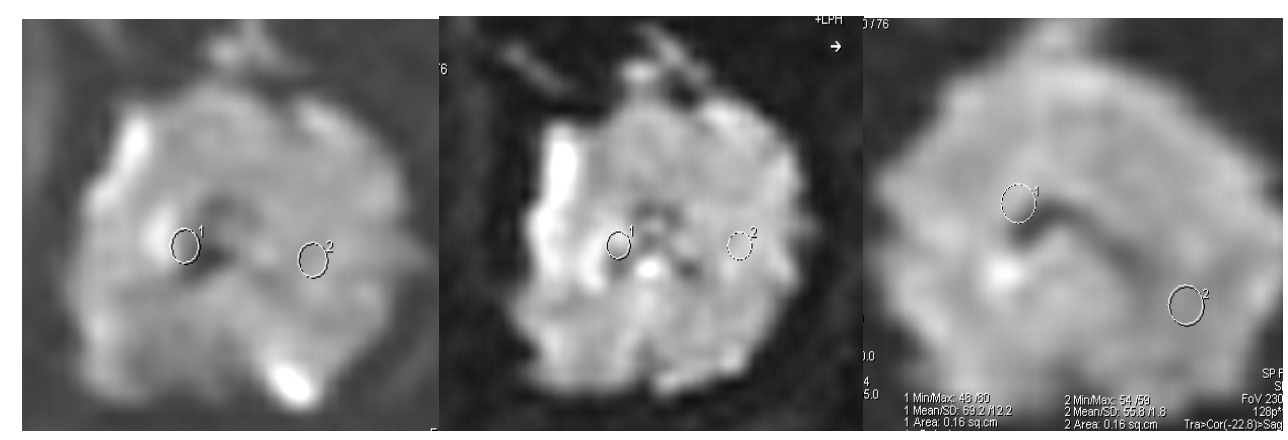

(6)

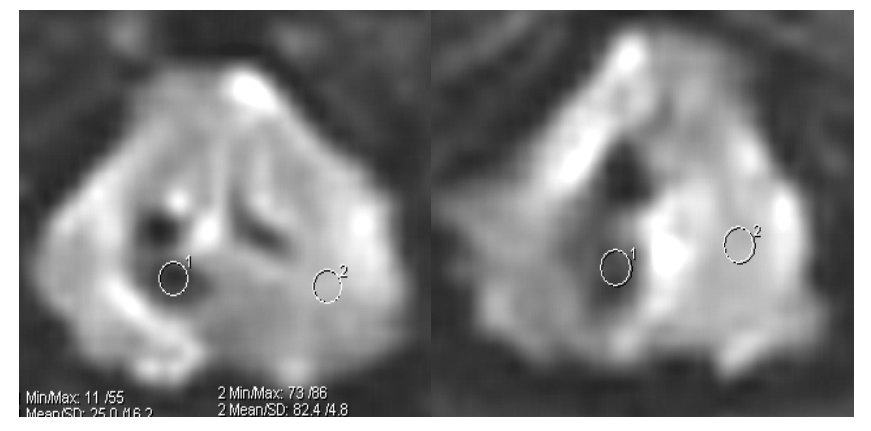

(10)

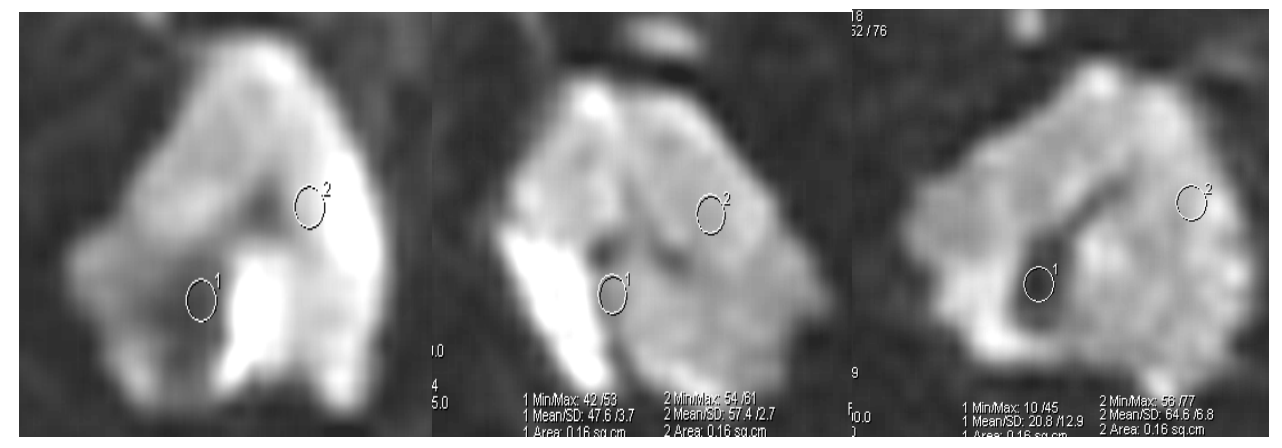

(20)

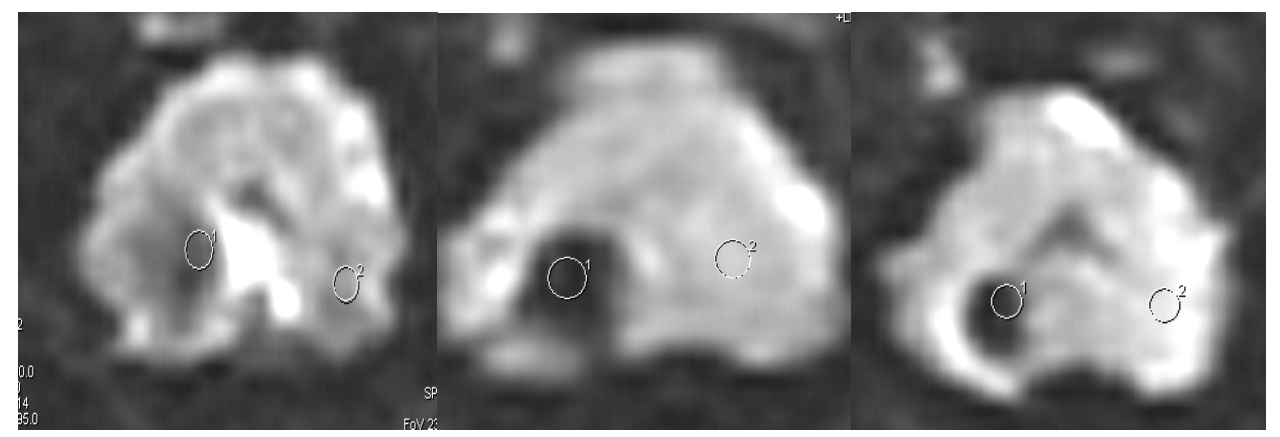




\section{Lyse Diff 1000}

(4)

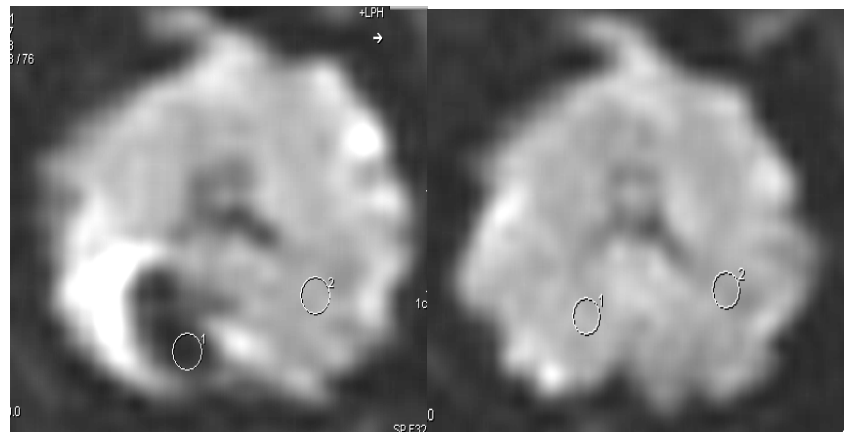

(5)

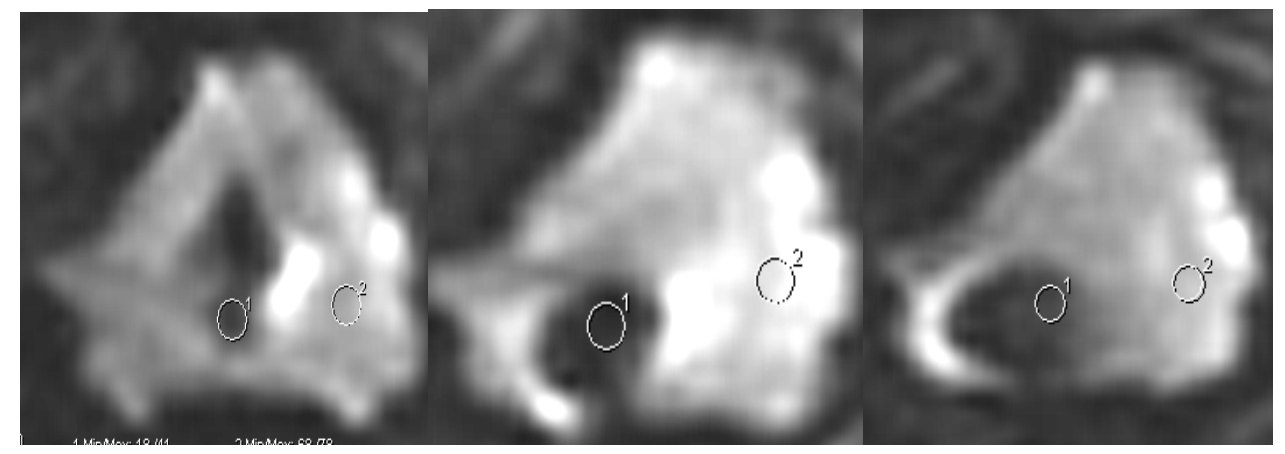

(7)

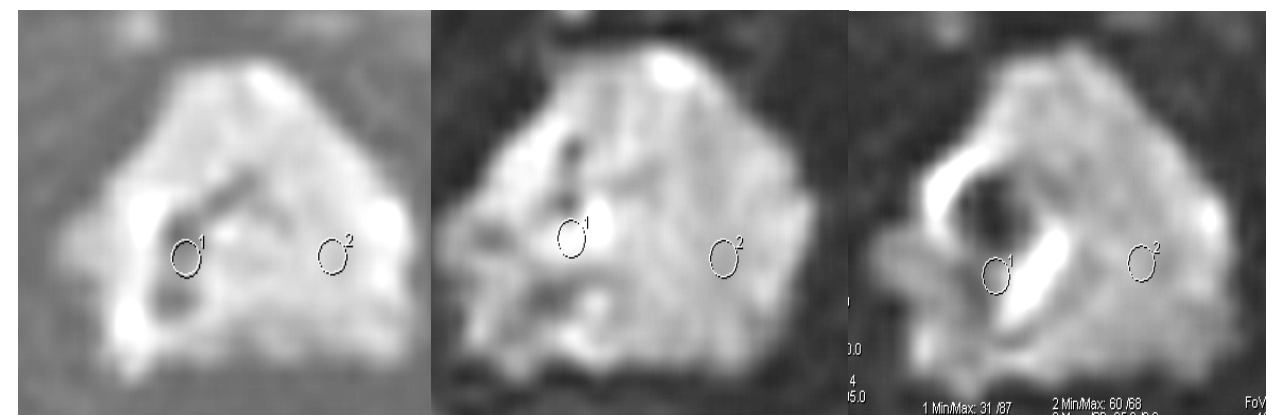

(12)

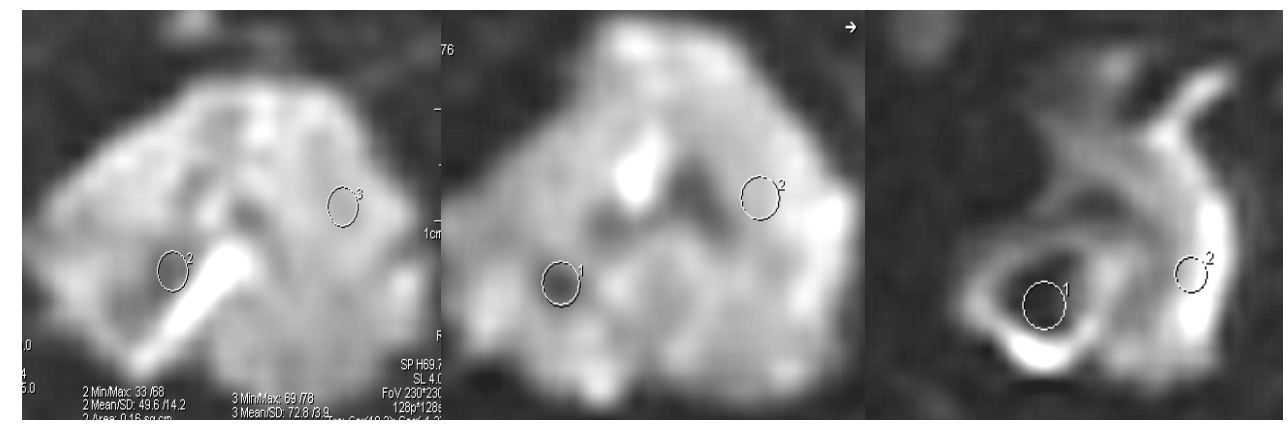


(13)

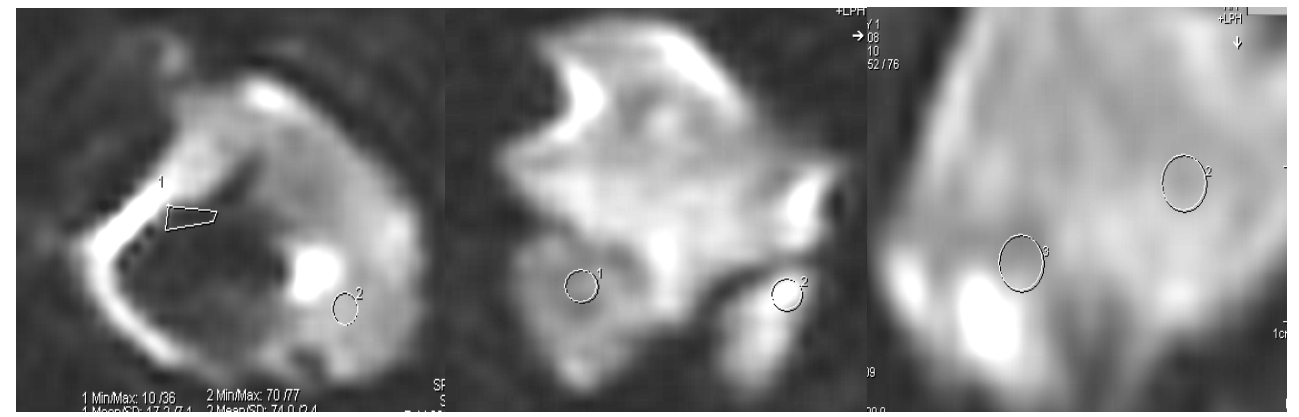

(14)

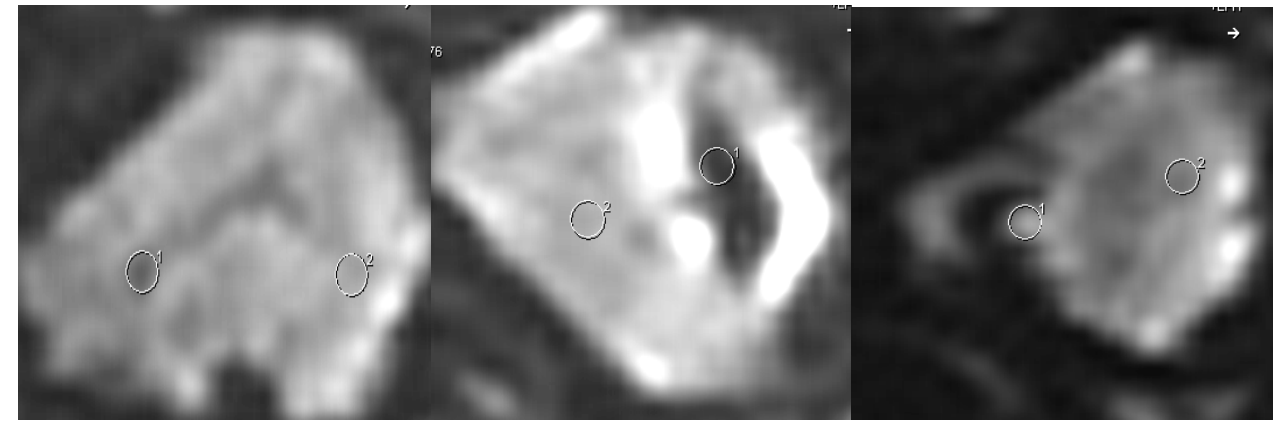

(18)

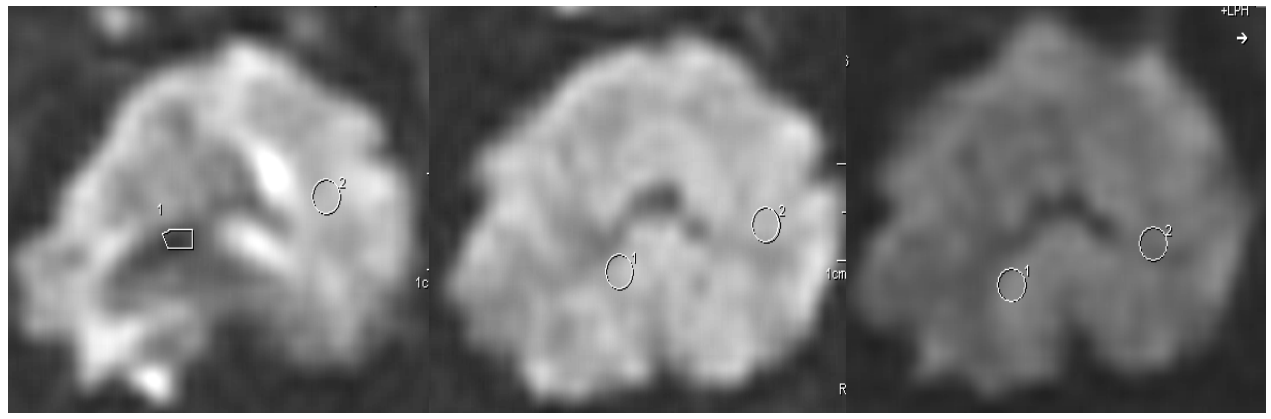

PAI Diff 1000

(9)
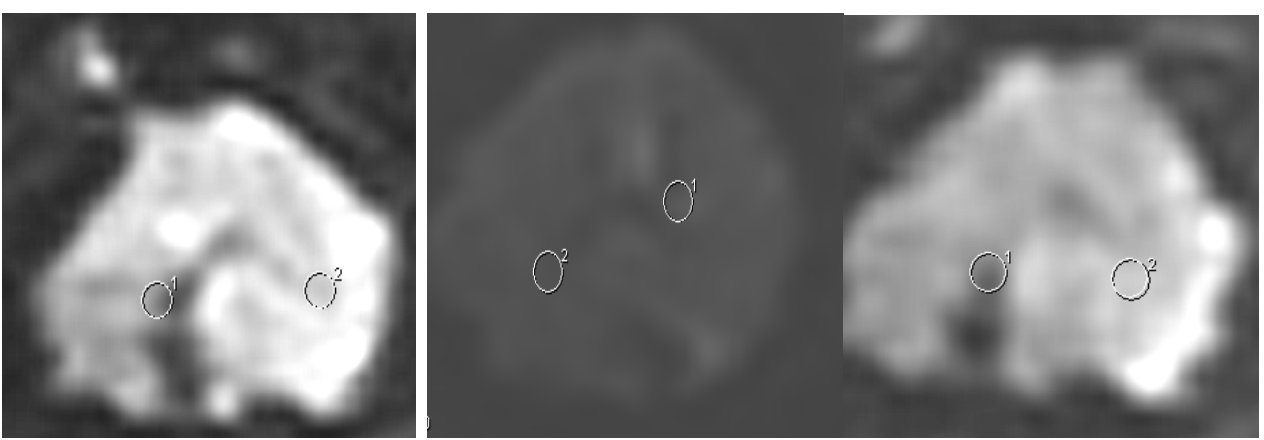
(11)

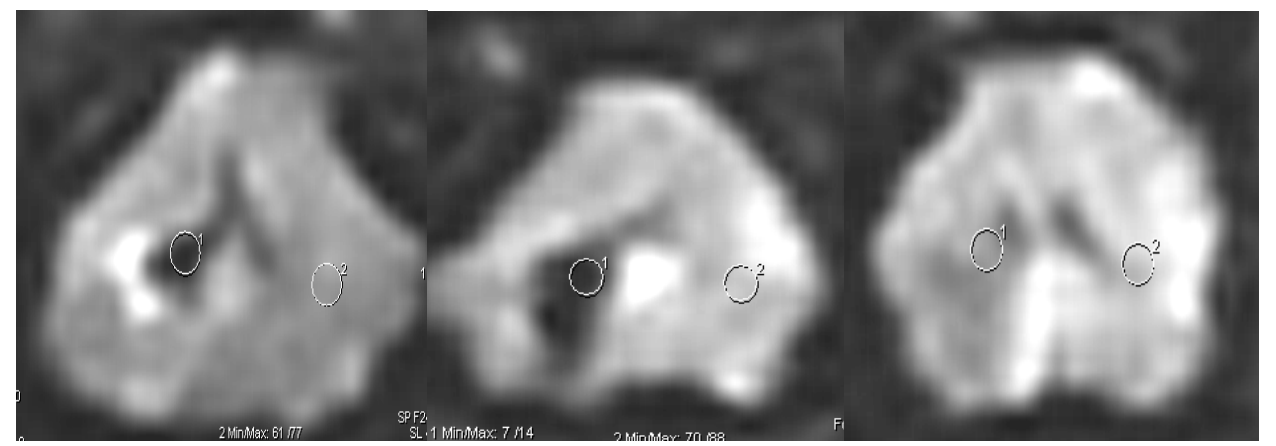

(15)

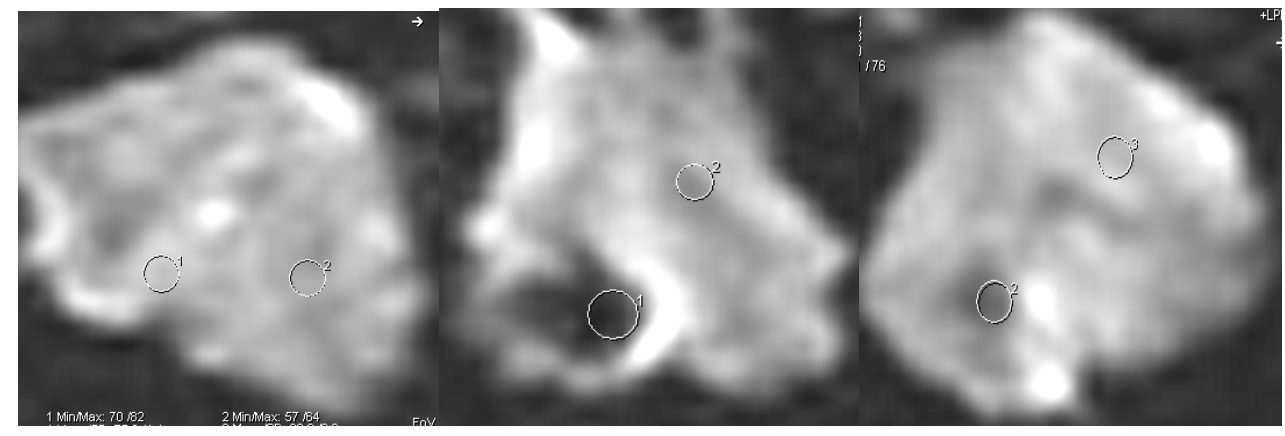

(16)

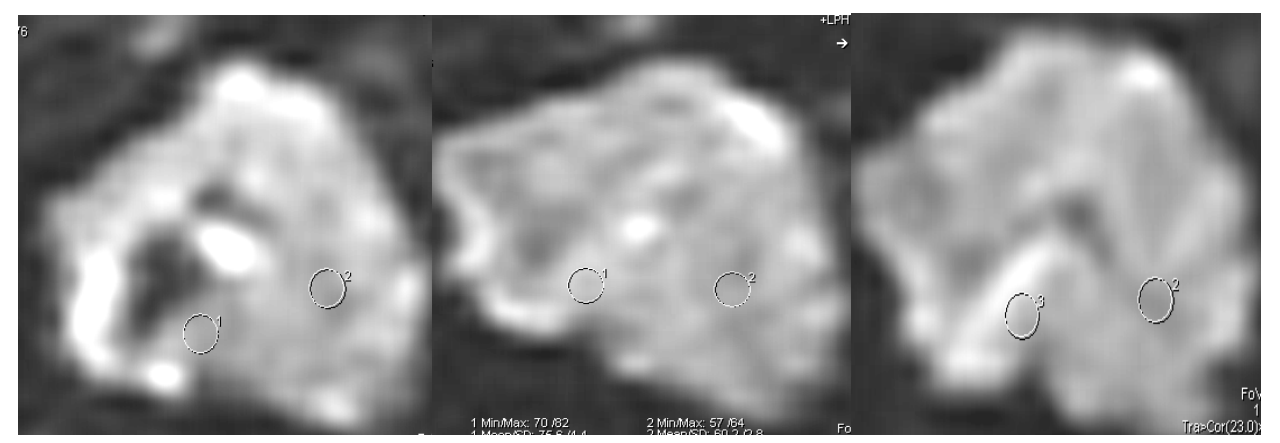

(17)

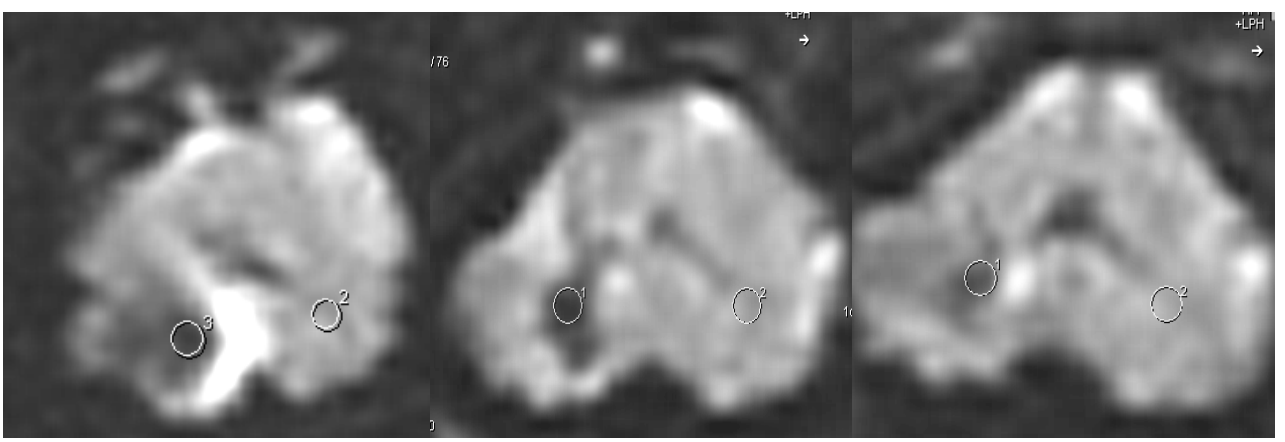


(21)

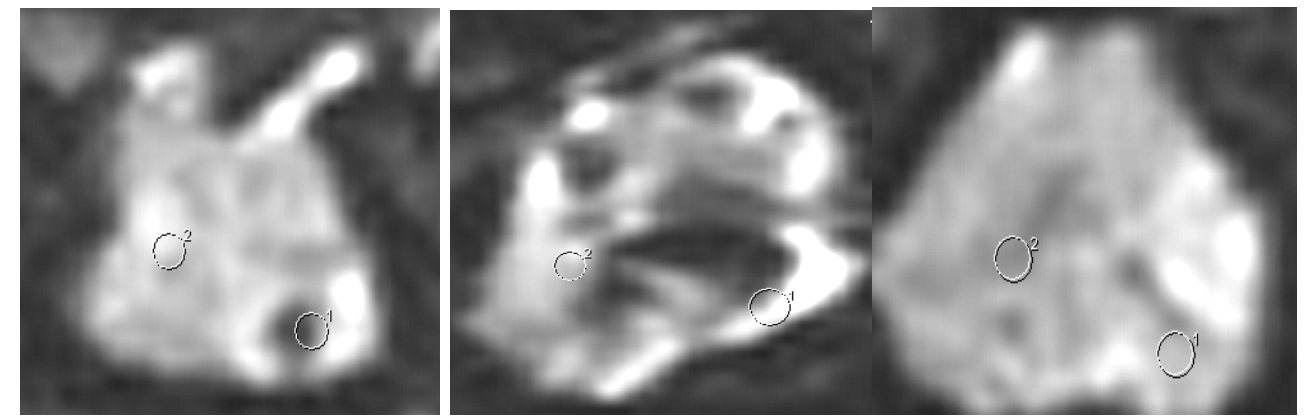

Kontrolle ADC

(2)

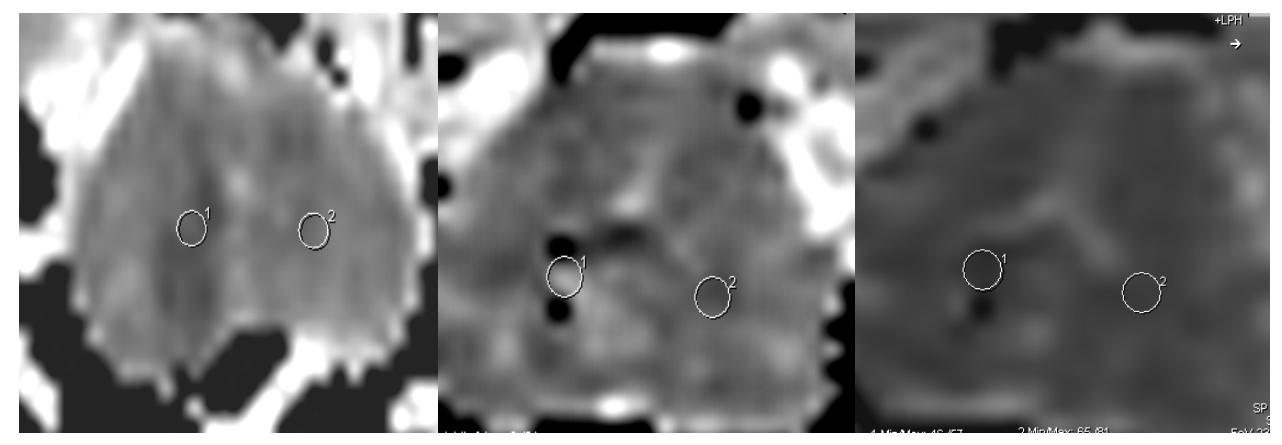

(3)

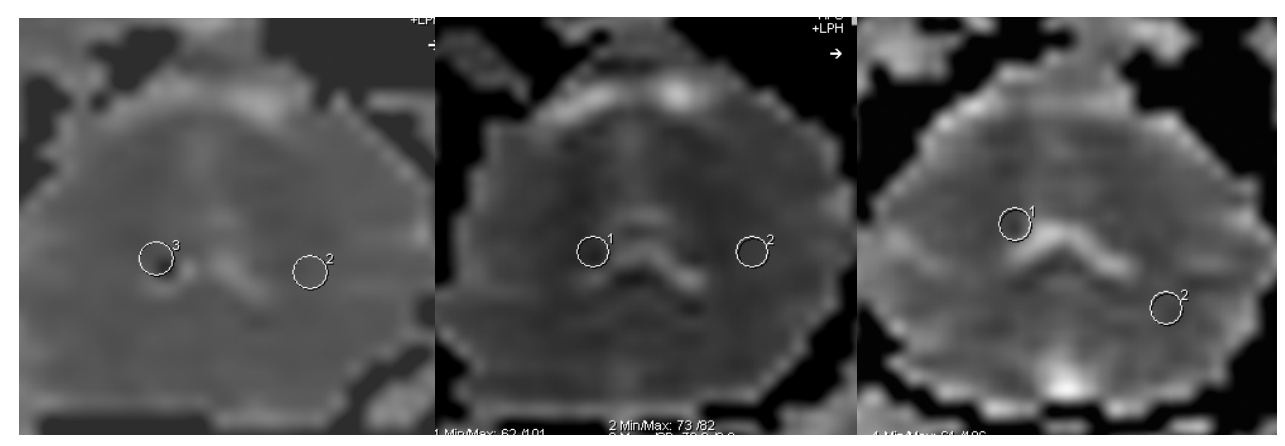

(6)

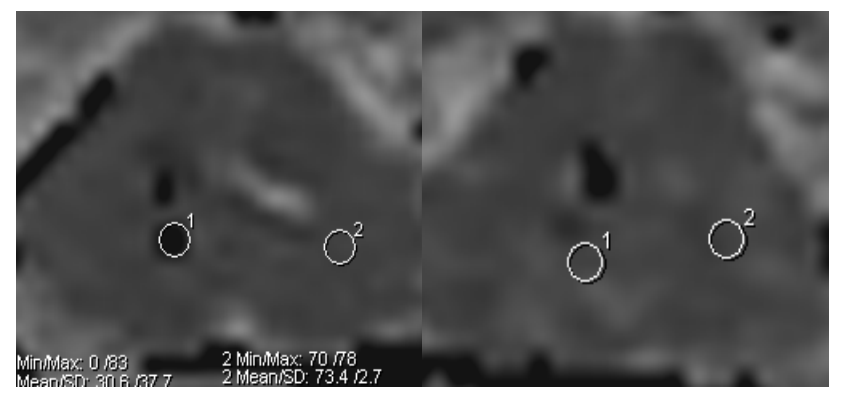

(10) 


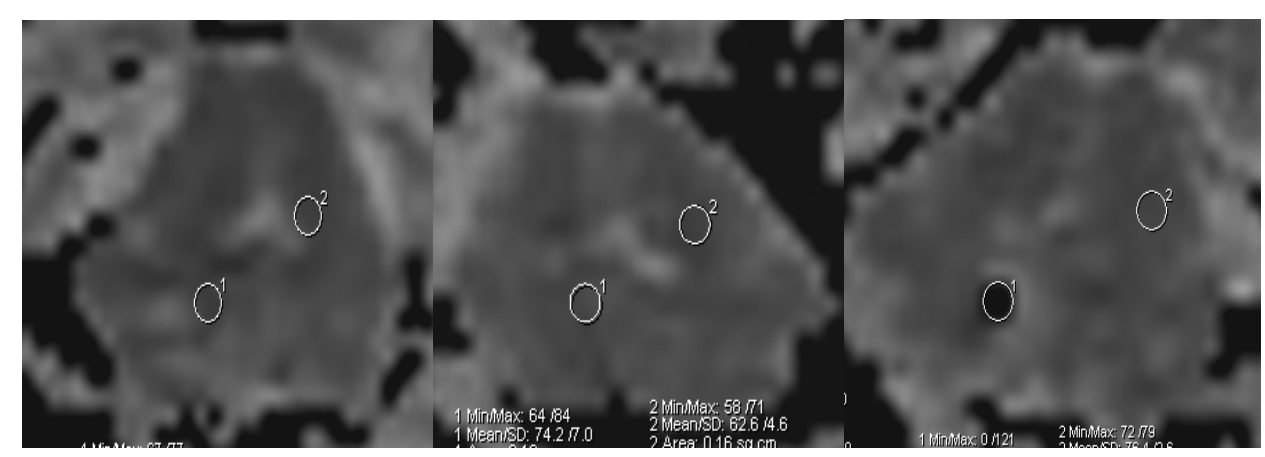

(20)

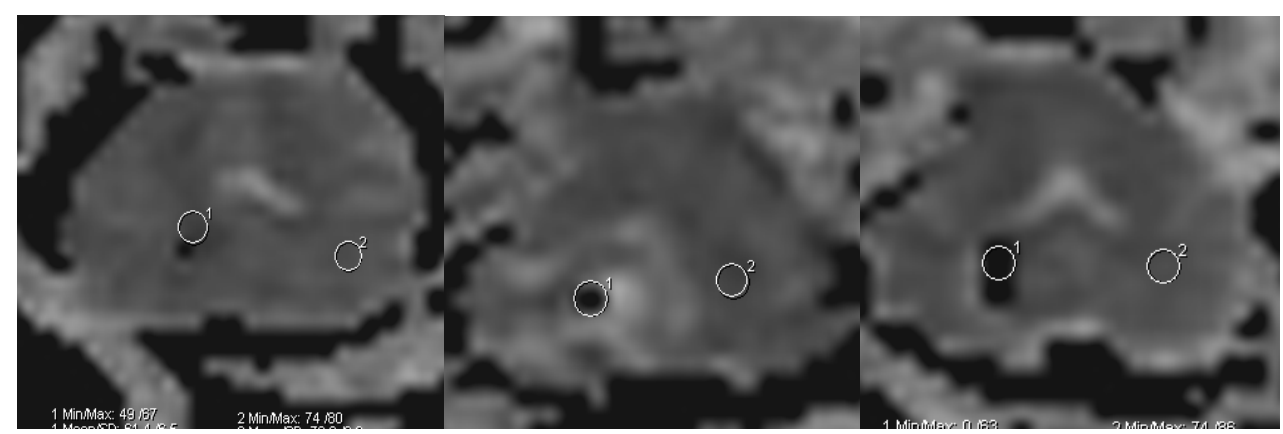

\section{Lyse ADC}

(4)

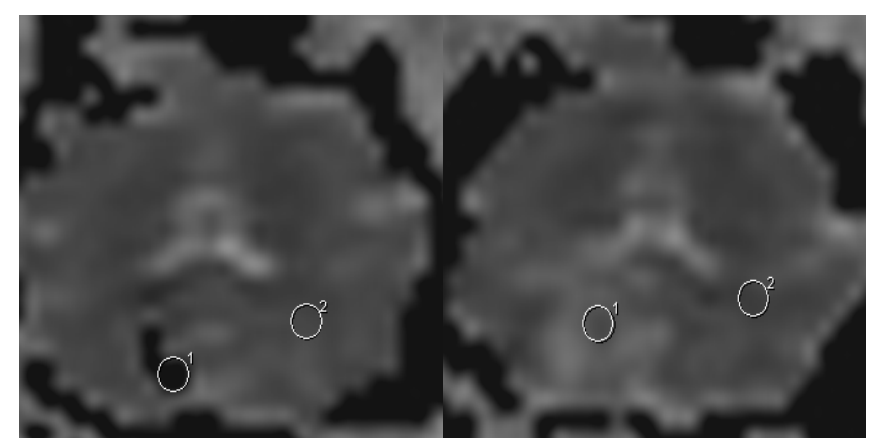

(5)

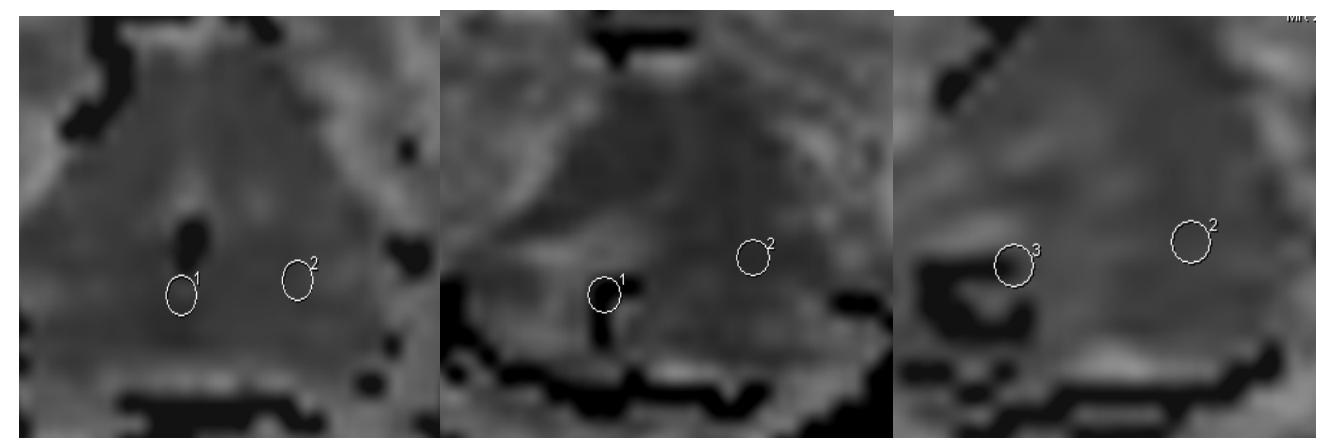


(7)

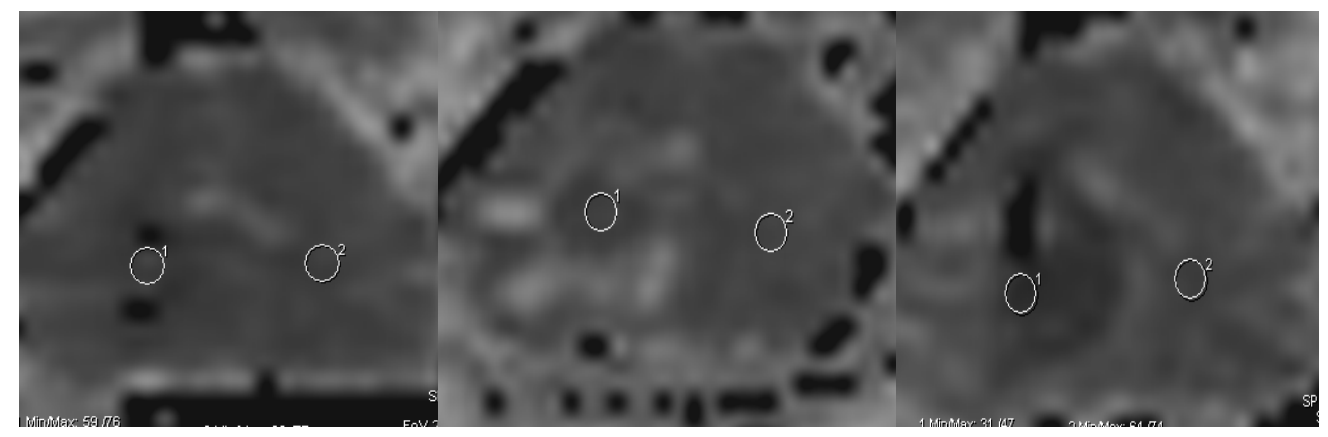

(12)

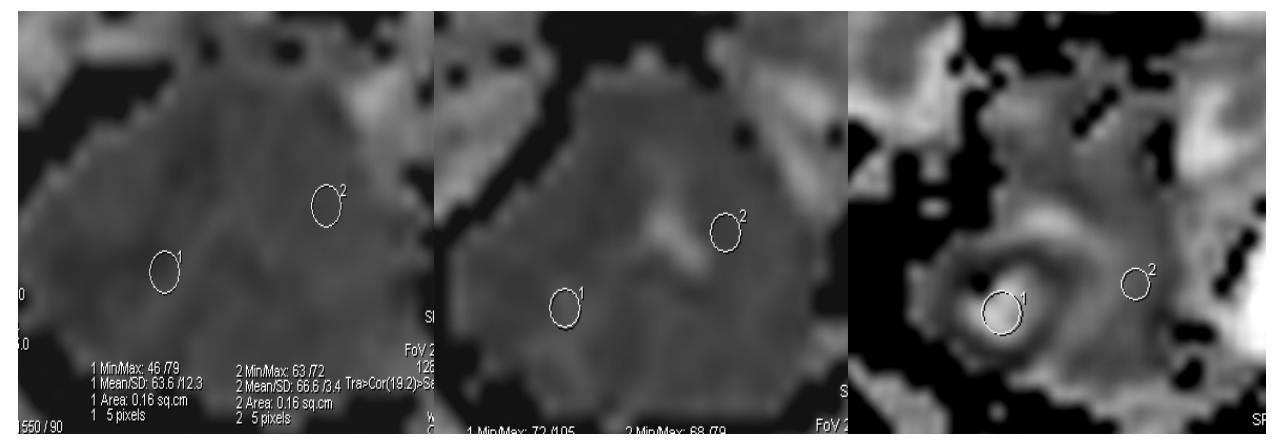

(13)

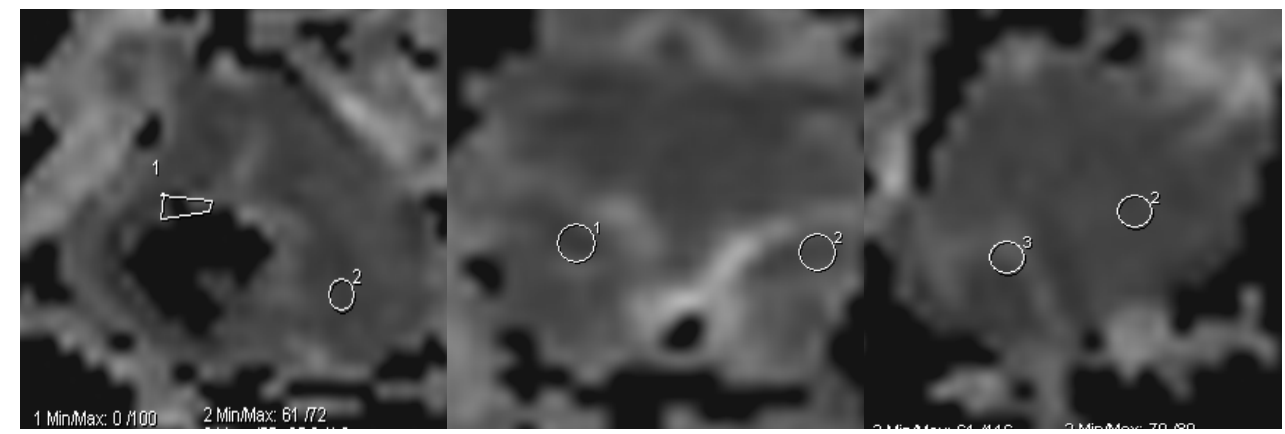

(14)

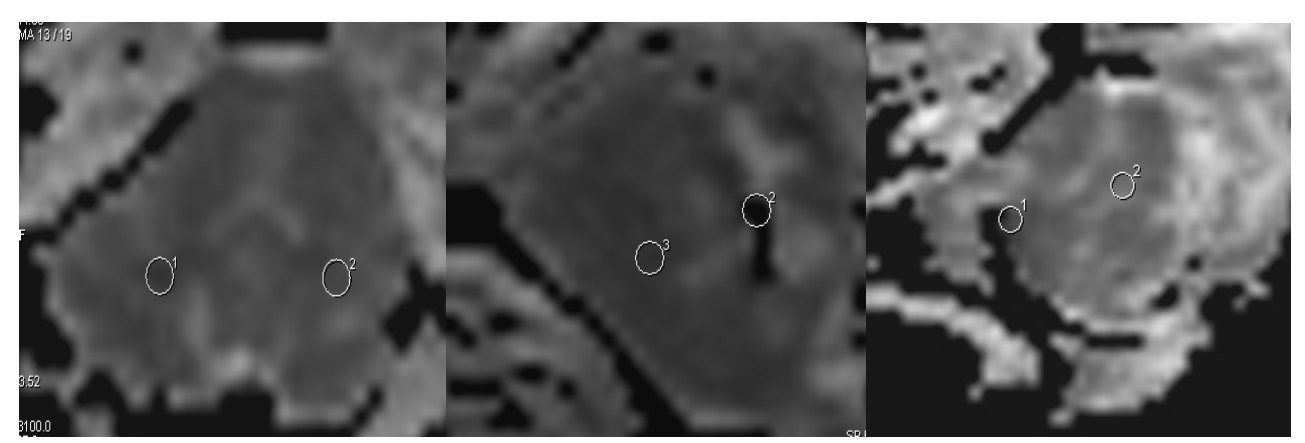


(18)

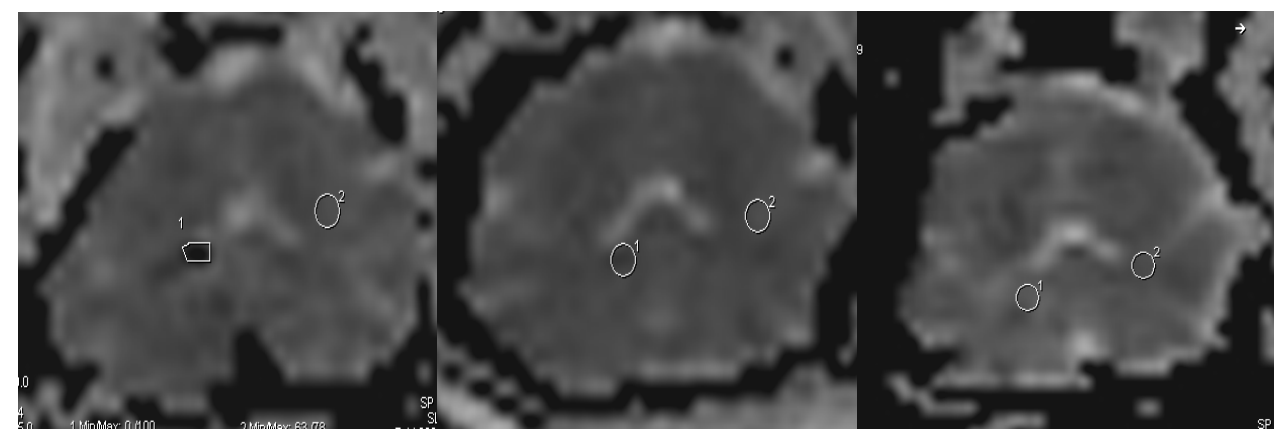

\section{PAI ADC}

(9)

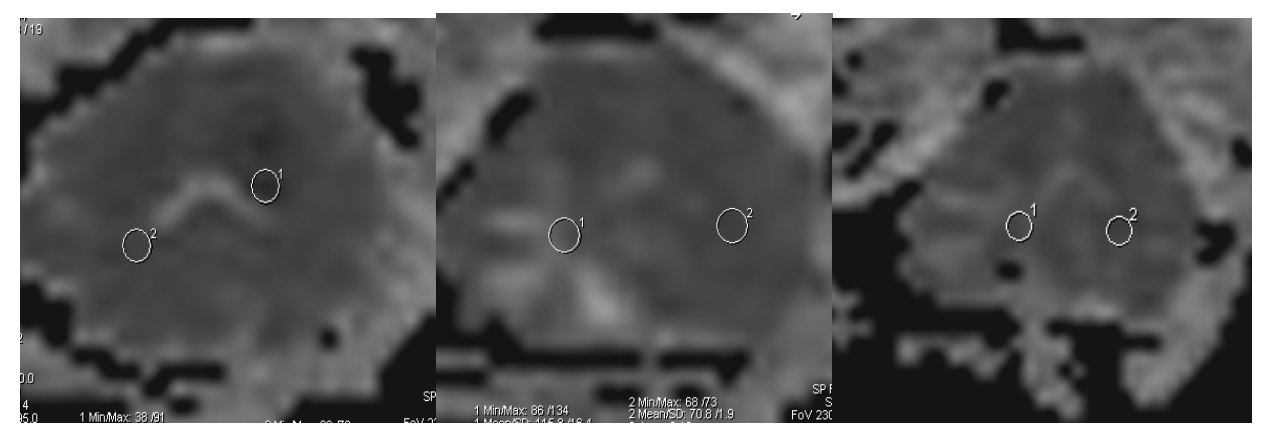

(11)

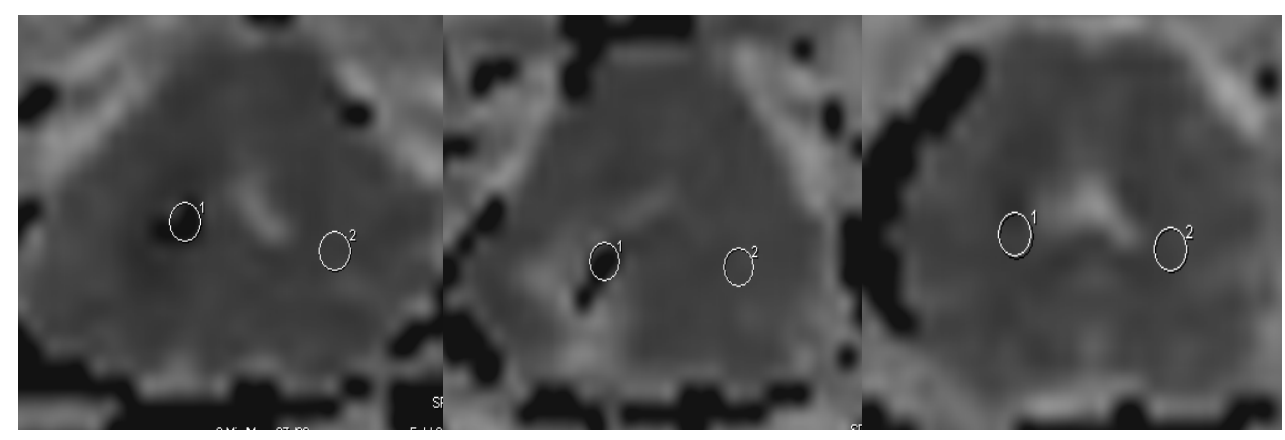

(15)

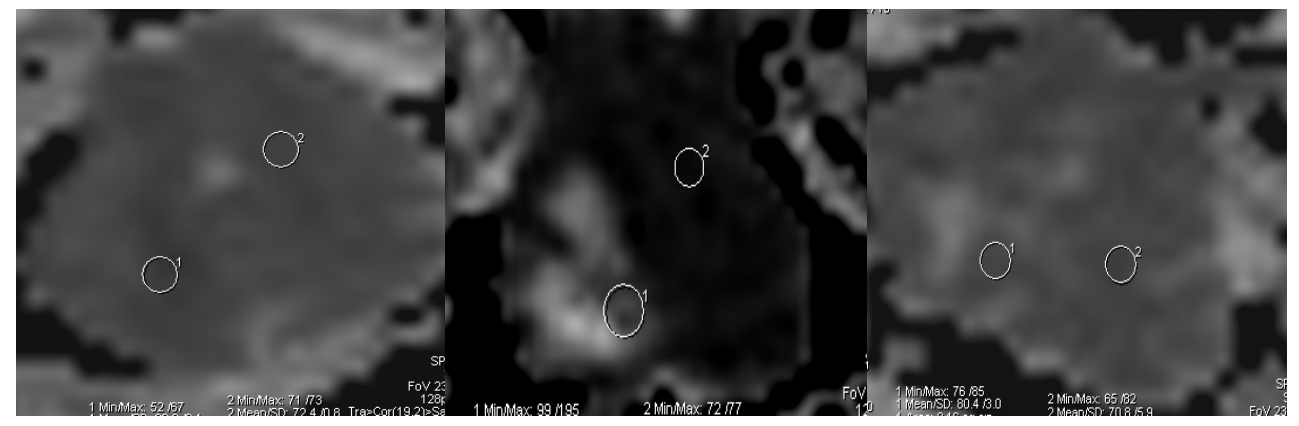


(16)

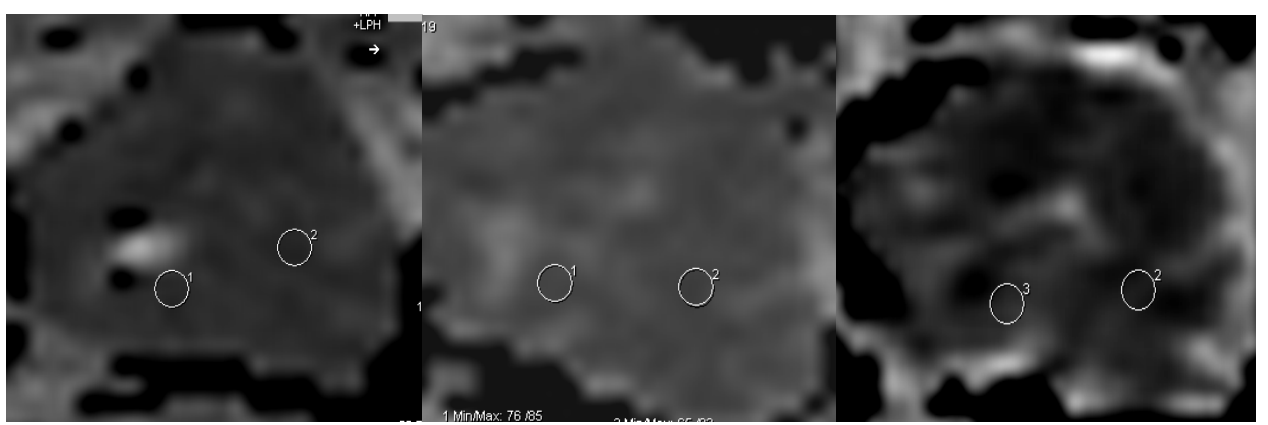

(17)

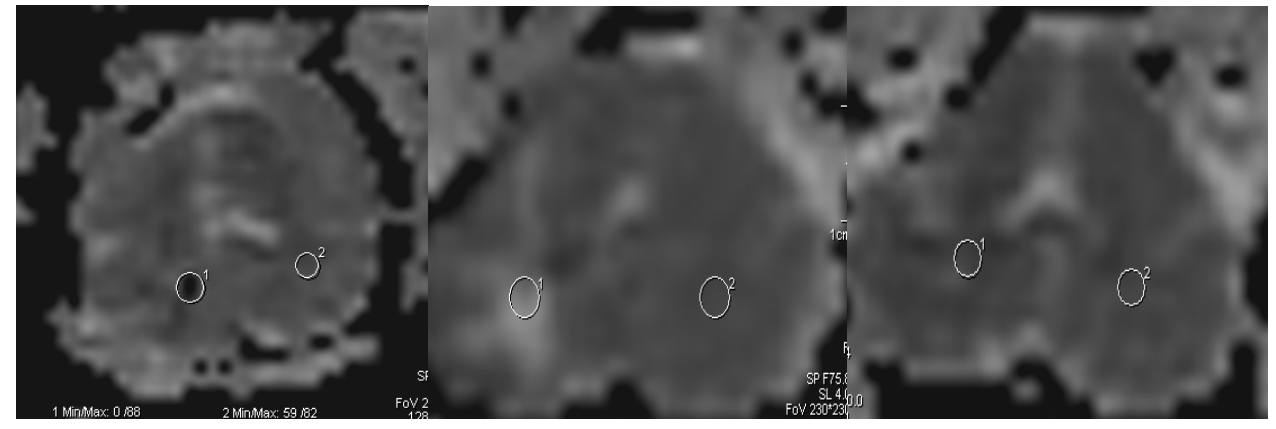

(21)

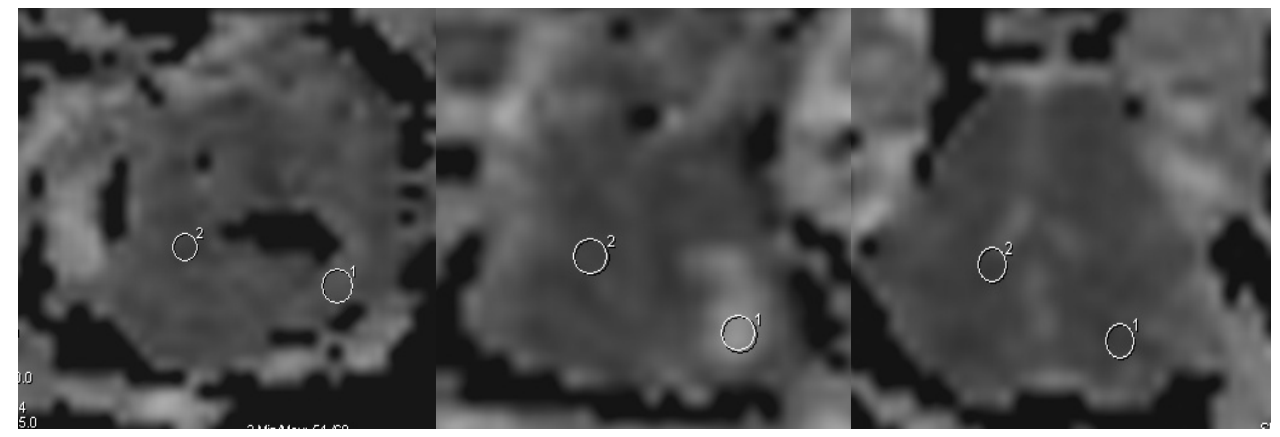




\section{Danksagung}

Für die Unterstützung beim Erstellen der Doktorarbeit möchte ich mich bei folgenden Personen recht herzlich bedanken:

Zunächst ganz herzlichen Dank an Prof. Dr. M. Knauth für die Möglichkeit, die Arbeiten an seiner Abteilung durchzuführen. Die Arbeit in seiner Abteilung hat mir stets große Freude bereitet.

Mein besonderer Dank gilt Herrn Dr. K. Kallenberg, der mir die Dissertation überließ und sich ungeachtet der eigenen Arbeitsbelastung immer uneingeschränkt Zeit genommen hat, um Fragen und Ergebnisse mit mir zu diskutieren. Durch seine exzellente Anleitung und Betreuung hatte ich die Möglichkeit, mich mit dem Fach Neuroradiologie auf vielfältige Art und Weise auseinanderzusetzen. Die Zusammenarbeit mit inm hat viel Spaß gemacht. Eine bessere Betreuung ist kaum vorstellbar.

Herzlichen Dank für die konstruktive Zusammenarbeit an die Mitarbeiter des neurochirurgischen Forschungsteams um Prof. Dr. med. V. Rohde.

Den medizinisch-technischen Assistenten, insbesondere Frau I.Pfahlert, danke ich herzlich für die nette Aufnahme, die professionelle technische Unterstützung und ihr Engagement in zahlreichen Situationen. 


\section{Lebenslauf}

Am 4. April 1982 wurde ich als Kind von Claudia Meddour, geb. Boethin, und Dr. Abdelraouf Meddour in Wolfen geboren.

Von August 1988 bis Juli 1992 besuchte ich die Grundschule auf der Wanne in Tübingen und anschließend bis 2001 das Keplergymnasium Tübingen, wobei ich von August 1997 bis Juli 1998 ein Jahr an der Northome High School, Minnesota, USA absolvierte. Im Juni 2001 erlangte ich die Allgemeine Hochschulreife.

Zum Sommersemster 2003 nahm ich das Studium der Humanmedizin an der Georg-August-Universität zu Göttingen auf. Die ärztliche Vorprüfung bestand ich im Wintersemester 2004.

Von September 2006 bis April 2007 studierte ich an der Université Claude Bernard, Faculté de Médecine, Lyon, Frankreich.

Meine Famulaturen absolvierte ich am Universitätsklinikum Tübingen, an der Ammerlandklinik Westerstede, am Hopital Debrousse in Lyon, am Mnazi Moja Hospital in Stone Town, am Pius Hospital Oldenburg, bei einem niedergelassenen Kardiologen in Algerien sowie im Moorfields Eye Hospital, London.

Das erste Tertial des Praktischen Jahrs leistete ich an der Scripps Green Clinic in San Diego, USA ab. Danach absolvierte ich ein Tertial am Pius Hospital Oldenburg. Das letzte Tertial verbrachte ich im Moorfields Eye Hospital in London und in der Augenklinik der Georg-August-Universität zu Göttingen.

Das Staatsexamen legte ich in Göttingen erfolgreich im Dezember 2009 ab. Vom Februar bis April 2010 war ich Assistenzärztin in der Augenklinik der Schlossparkklinik in Berlin.

Seit April 2010 arbeite ich als Assistenzärztin in der Augenklinik der Universität Heidelberg.

Seit April 2008 arbeite ich unter Anleitung von Dr. K. Kallenberg an der vorliegenden Dissertation.

Göttingen, 24.5.2010 